Report Title:

\title{
LOW-TEMPERATURE, ANODE-SUPPORTED HIGH POWER DENSITY SOLID OXIDE FUEL CELLS WITH NANOSTRUCTURED ELECTRODES
}

Type of Report: Final Technical Report

$\begin{array}{ll}\text { Reporting Period Start Date: } & \text { October 1, } 1999 \\ \text { Reporting Period End Date: } & \text { March 31, 2003 } \\ \text { Principal Author: } & \text { Professor Anil V. Virkar } \\ \text { Date Report Was Issued: } & \text { May 23, 2003 } \\ \text { DOE Award Number: } & \text { DE-FC26-99FT40713 }\end{array}$

Name and Address of Submitting Organization:

Department of Materials Science \& Engineering

122 S. Central Campus Drive

University of Utah

Salt Lake City, UT 84112 


\section{DISCLAIMER:}

This report was prepared as an account of work sponsored by an agency of the United States Government. Neither the United States Government nor any agency thereof, nor any of their employees, makes any warranty, express or implied, or assumes any legal liability or responsibility for the accuracy, completeness, or usefulness of any information, apparatus, product or process disclosed, or represents that its use would not infringe privately owned rights. Reference herein to any specific commercial product, process, or service by trade name, trademark, manufacturer, or otherwise does not necessarily constitute of imply its endorsement, recommendation, or favoring by the United State Government or any agency thereof. The views and opinions of authors expressed herein do not necessarily state or reflect those of the United States Government or any agency thereof. 


\section{ABSTRACT}

This report summarizes the work done during the entire project period, between October 1, 1999 and March 31, 2003, which includes a six-month no-cost extension. During the project, eight research papers have, either been, published, accepted for publication, or submitted for publication. In addition, several presentations have been made in technical meetings and workshops. The titles of the papers that have been published based on this project are listed below.

1) "Synthesis of Nanosize Yttria-Stabilized Zirconia by a Molecular Decomposition Process", Y. Jiang, S. V. Bhide and A. V. Virkar, J. of Solid State Chem., 157 149-159 (2001).

2) "The Effect of Testing Geometry on the Measurement of Cell Performance in AnodeSupported Solid Oxide Fuel Cells", Y. Jiang, A. V. Virkar, and F. Zhao, J. Electrochem. Soc., 148 [10] A1091-A1099 (2001).

3) "The Effect of Electrode Microstructure on Cathodic Polarization", F. Zhao, Y. Jiang, GY. Lin, and A. V. Virkar, in SOFC-VII, edited by S. C. Singhal and H. Yokokawa, The Electrochemical Society, Pennington, NJ (2001).

4) "A High Performance, Anode-Supported Solid Oxide Fuel Cell Operating on Direct Alcohol", Y. Jiang and A. V. Virkar, J. Electrochem. Soc., 148 [7] A701-A709 (2001).

5) "Performance of Solid Oxide Fuel Cells with LSGM-LSM Composite Cathodes", T. J. Armstrong and A. V. Virkar, J. Electrochem. Soc., 149 [12] A1565-A1571 (2002).

6) "Reduction and Re-Oxidation Kinetics of Nickel-Based Solid Oxide Fuel Cell (SOFC) Anodes", N. M. Tikekar, T. J. Armstrong, and A. V. Virkar, in SOFC-VIII, edited by S. C. Singhal and M. Dokiya, The Electrochemical Society, Pennington, NJ (2003).

7) "Measurement of $\mathrm{O}_{2}-\mathrm{N}_{2}$ Effective Diffusivity in Porous Media at High Temperatures using an Electrochemical Cell", F. Zhao, T. J. Armstrong, and A. V. Virkar, J. Electrochem. Soc., 150 [3] A249-A256 (2003).

8) "Fuel Composition and Diluent Effect on Gas Transport and Performance of AnodeSupported SOFCs", Y. Jiang and A. V. Virkar, J. Electrochem. Soc., 150 [7] (2003).

The project also has provided support for four graduate students working towards advanced degrees. The principal technical objective of the project was to analyze the role of electrode microstructure on solid oxide fuel cell performance. Prior theoretical work conducted in our laboratory demonstrated that the particle size of composite electrodes has a profound effect on cell performance; the finer the particle size, the lower the activation polarization, the better the performance. The composite cathodes examined consisted of electronically conducting perovskites such as Sr-doped $\mathrm{LaMnO}_{3}$ (LSM) or Sr-doped $\mathrm{LaCoO}_{3}$ (LSC), which is also a mixed conductor, as the electrocatalyst, and yttria-stabilized zirconia (YSZ) or rare earth oxide doped $\mathrm{CeO}_{2}$ as the ionic conductor. The composite anodes examined were mixtures of $\mathrm{Ni}$ and YSZ. A procedure was developed for the synthesis of nanosize YSZ by molecular decomposition, in which unwanted species were removed by leaching, leaving behind nanosize YSZ. Anode-supported cells were made using the as-synthesized powders, or using commercially acquired powders. The electrolyte was usually a thin ( $\sim 10$ microns), dense layer of YSZ, supported on a thick $(\sim 1 \mathrm{~mm})$, porous $\mathrm{Ni}+\mathrm{YSZ}$ anode. The cathode was a porous mixture of electrocatalyst and an ionic conductor. Most of the cell testing was done at $800^{\circ} \mathrm{C}$ with hydrogen as fuel and air as the oxidant. Maximum power densities as high as $1.8 \mathrm{~W} / \mathrm{cm}^{2}$ 
were demonstrated. Polarization behavior of the cells was theoretically analyzed. A limited amount of cell testing was done using liquid hydrocarbon fuels where reforming was achieved internally.

Significant polarization losses also occur at the anode, especially at high fuel utilizations. An analysis of polarization losses requires that various contributions are isolated, and their dependence on pertinent parameters is quantitatively described. An investigation of fuel composition on gas transport through porous anodes was investigated and the role of fuel diluents was explored. This work showed that the molecular weight of the diluent has a significant effect on anode concentration polarization. This further showed that the presence of some molecular hydrogen is necessary to minimize polarization losses.

Theoretical analysis has shown that the electrode microstructure has a profound effect on cell performance. In a series of experiments, cathode microstructural parameters were varied, without altering other parameters. Cathode microstructural parameters, especially three phase boundary (TPB) length, were estimated using techniques in quantitative stereology. Cell performance was quantitatively correlated with the relevant microstructural parameters, and charge transfer resistivity was explicitly evaluated. This is the first time that a fundamental parameter, which governs the activation polarization, has been quantitatively determined.

An important parameter, which governs the cathodic activation polarization, and thus cell performance, is the ionic conductivity of the composite cathode. The traditional composite cathode is a mixture of LSM and YSZ. It is well known that $\mathrm{Sr}$ and $\mathrm{Mg}$-doped $\mathrm{LaGaO}_{3}$ (LSGM), exhibits higher oxygen ion conductivity compared to YSZ. Cells were fabricated with composite cathodes comprising a mixture of LSM and LSGM. Studies demonstrated that LSGM-based composite cathodes exhibit excellent behavior.

Studies have shown that Ni + YSZ is an excellent anode. In fact, in most cells, the principal polarization losses, at least at low fuel utilizations, are associated with the cathode. Theoretical analysis conducted in our group has also shown that anode-supported cells exhibit lower polarization losses compared to cathode-supported or electrolyte-supported cells. It is essential, however, that Ni + YSZ anode be not subjected to a re-oxidation step, such as may occur accidentally, as this can cause anode disintegration. A theoretical model was developed for reduction and re-oxidation kinetics of Ni-based anodes. The model was experimentally verified. In addition, criteria for the development of redox tolerant, yet Ni-based, anodes were established. 


\section{TABLE OF CONTENTS}

Page

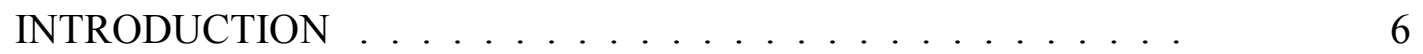

EXECUTIVE SUMMARY $\ldots \ldots \ldots \ldots \ldots$

EXPERIMENTAL $\ldots \ldots \ldots \ldots \ldots \ldots \ldots$

RESULTS AND DISCUSSION $\ldots \ldots \ldots \ldots \ldots \ldots$

CONCLUSIONS $\quad \ldots \ldots \ldots \ldots \ldots \ldots \ldots \ldots$

REFERENCES $\ldots \ldots \ldots \ldots \ldots \ldots \ldots \ldots$

TABLES $\ldots \ldots \ldots \ldots \ldots \ldots \ldots \ldots \ldots \ldots \ldots$

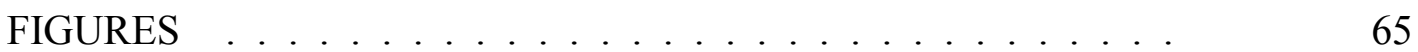

LIST OF ACRONYMS AND ABBREVIATIONS _ . . . . . 131 


\section{INTRODUCTION}

Research over the past few years has shown that in thin-film, electrode-supported solid oxide fuel cells (SOFC), significant part of the polarization losses are associated with the cathode, where the reaction of oxygen reduction to oxygen ions occurs. Substantial losses can also occur at the anode. Theoretical work has shown that electrode polarization can be minimized provided the electrodes have adequate porosity to allow rapid transport of gaseous species, and the electrodes exhibit mixed ionic electronic conducting (MIEC) characteristics. In a typical SOFC, the anode is a porous cermet of Ni and yttria-stabilized zirconia (YSZ). In such an anode, MIEC characteristics arise due to electronic conduction through $\mathrm{Ni}$ and ionic conduction through YSZ. For several years, the material of choice for the cathode has been Srdoped $\mathrm{LaMnO}_{3}$ (LSM). While LSM is good electronic conductor, its ionic conductivity is poor. In order to improve its performance, it is necessary to impart MIEC characteristics. This can be achieved by mixing LSM with YSZ. There are other perovskites, which can exhibit MIEC characteristics in a single-phase material. An example is $\mathrm{Sr}$-doped $\mathrm{LaCoO}_{3}$ (LSC). Experience shows, however, that the addition of an ionic conductor, such as ceria, to LSC improves the performance further.

Theoretical work conducted in our laboratory has shown that electrode microstructure has a profound effect on polarization. Specifically, the finer the microstructure, the lower the polarization resistance. A natural extension of the concept leads to the conclusion that ideally the electrode microstructure should be on a nanometer scale. Thus, the first step is the synthesis of nanosize powders of the prospective electrode materials. During the course of this work, a method for the synthesis of nanosize powders of zirconia and ceria was developed. The approach led to the synthesis of powders of size between 5 and $10 \mathrm{~nm}$. However, making welldispersed, agglomerate-free composite electrodes is a major challenge. In addition, the nanosize powders invariably coarsen at the cell operating temperature. Despite this, significant benefit can still be gained as long as the electrode microstructure is on a submicron scale - if not at the nanometer scale. Experimental work conducted during the course of this project confirmed the validity of this hypothesis.

Characterization of the polarization behavior in thin-film, electrode-supported fuel cells is difficult for two reasons. (1) In small cells, one of the electrodes (the thinner one) is usually of an area smaller than that of the thicker, supporting electrode, necessitated by difficulties in testing procedures. Research done, both theoretical and experimental, showed that as long as the diameter of the smaller electrode is much greater than the electrolyte thickness, the error introduced is relatively modest - and can be easily corrected for. (2) The second factor concerns the placement of reference electrodes in thin film, electrode-supported cells. Some numerical work on the mapping of equipotential lines and flux lines through thin film cells has shown that substantial errors can be introduced in the measurement of overpotentials. These studies recommend that reference electrodes, as such, should not be used. Despite this recommendation, reference electrodes were used in the present work in selected cases, especially when only one of the parameters was varied. Work is currently underway to conduct additional numerical analysis for the geometries used in the present work. 
Most of the work reported on cathode polarization measurements has been on porous cathode materials screen-printed on the surface of an electrolyte disc, and then using techniques such as complex impedance spectroscopy, or techniques involving the application of a DC bias. The measurements are rarely related to the microstructural parameters in order to isolate the fundamental, microstructure-independent parameter. Experimental approach was used to explicitly determine the charge transfer resistivity, assuming that the electrochemical reaction occurs at three-phase boundaries (TPB) between the electrocatalyst, electrolyte and the gas phase.

An important contribution to the total polarization arises due to the resistance associated with the transport of gases through porous electrodes, oxidant through the cathode and fuel through the anode. Often, impedance spectroscopy has been used. The approach involves the use of an equivalent circuit approach - such as the Warburg impedance. However, such an approach does not lend itself to relating polarization losses to fundamental transport parameters, such as binary and Knudsen diffusivities, and to microstructural parameters - such as porosity and tortuosity. An approach chosen here involves solving the relevant transport equations, and conducting out of cell (and in-cell) measurements to explicitly determine concentration polarization. Using such an approach, concentration polarization behavior was investigated at both the cathode and the anode. 


\section{EXECUTIVE SUMMARY}

Nanosize yttria-stabilized zirconia (YSZ) was synthesized by a novel approach based on molecular decomposition. Precursors, yttria-doped $\mathrm{BaZrO}_{3}\left(\mathrm{Y}-\mathrm{BaZrO}_{3}\right)$ and yttria-doped $\mathrm{Na}_{2} \mathrm{ZrO}_{3}\left(\mathrm{Y}-\mathrm{Na}_{2} \mathrm{ZrO}_{3}\right)$, were boiled in dilute $\mathrm{HNO}_{3}$ or water, respectively, to leach away the unwanted species, $\mathrm{BaO}$ or $\mathrm{Na}_{2} \mathrm{O}$, resulting in the formation of nanosize YSZ, of a particle size on the order of $5 \mathrm{~nm}$. Even when the powder was heated to as high as $1000^{\circ} \mathrm{C}$, the particle size was well in the nanosize range, indicating suitability for application as an electrolyte or electrodes.

A simple, approximate analysis of the effect of differing cathode and anode areas on the measurement of cell performance on anode-supported solid oxide fuel cells, wherein the cathode area is smaller than the anode area, was developed. It was shown that the effect of cathode area on cathode polarization, on electrolyte contribution, and on anode resistance, as normalized on the basis of the cathode area, is negligible. There is a small but measurable effect on anode polarization, which results from concentration polarization. Effectively, it is the result of a greater amount of fuel transported to the anode/electrolyte interface in cases wherein the anode area is larger than the cathode area. Experiments were performed on cells made with differing cathode areas and geometries. Cathodic and anodic overpotentials measured using reference electrodes, and the measured ohmic area specific resistances by current interruption, were in good agreement with expectations based on the analysis presented. At $800^{\circ} \mathrm{C}$, the maximum power density measured with a cathode area of $\sim 1.1 \mathrm{~cm}^{2}$ was $\sim 1.65 \mathrm{~W} / \mathrm{cm}^{2}$ compared to $\sim 1.45 \mathrm{~W} / \mathrm{cm}^{2}$ for cathode area of $\sim 2 \mathrm{~cm}^{2}$, for anode thickness of $\sim 1.3 \mathrm{~mm}$, with hydrogen as the fuel and air as the oxidant. At $750^{\circ} \mathrm{C}$, the measured maximum power densities were $\sim 1.3 \mathrm{~W} / \mathrm{cm}^{2}$ for the cell with a cathode area $\sim 1.1 \mathrm{~cm}^{2}$, and $\sim 1.25 \mathrm{~W} / \mathrm{cm}^{2}$ for the cell with a cathode area $\sim 2 \mathrm{~cm}^{2}$.

$\mathrm{Ni}+$ yttria-stabilized zirconia (YSZ)-anode-supported cells with a thin YSZ electrolyte and Srdoped $\mathrm{LaMnO}_{3}(\mathrm{LSM})+\mathrm{YSZ}$ composite cathode were fabricated. Volume fractions of LSM and YSZ in the composite cathode were varied over a wide range. Cell performance was measured at $800^{\circ} \mathrm{C}$ with hydrogen as fuel and air as oxidant. Cathode microstructures were characterized by quantitative stereology to estimate the three-phase boundary (TPB) length, porosity and the aggregate grain size of YSZ in the cathode. Measured polarization was correlated with microstructure. Experimental results are in good agreement with the previously published theoretical model. The intrinsic charge transfer resistivity, $\rho_{c t}$, at LSM/YSZ/air TPB was determined as $\sim 1.0 \times 10^{5} \Omega \mathrm{cm}$ at $800^{\circ} \mathrm{C}$.

Since LSGM is known to exhibit higher ionic conductivity compared to YSZ, it was chosen as a prospective material for composite cathodes. The relative proportions of LSGM and LSM were varied between $30 \mathrm{wt} \%$ LSGM $+70 \mathrm{wt} . \% \mathrm{LSM}$ and $70 \mathrm{wt} . \% \mathrm{LSGM}+30 \mathrm{wt} . \% \mathrm{LSM}$, while the firing temperature was varied between 1000 and $1200^{\circ} \mathrm{C}$. The cathode interlayer composition had a profound effect on cathode performance at $800^{\circ} \mathrm{C}$ with overpotentials ranging between 60 and $425 \mathrm{mV}$ at $1.0 \mathrm{~A} / \mathrm{cm}^{2}$ and exhibiting a minimum for $50 \mathrm{wt} . \% \mathrm{LSGM}+$ $50 \mathrm{wt} . \%$ LSM. The cathodic overpotential decreased with increasing firing temperature of the composite interlayer in the range $1000 \leq \mathrm{T} \leq 1150^{\circ} \mathrm{C}$, and then increased dramatically for the interlayer fired at $1200^{\circ} \mathrm{C}$. The cell with the optimized cathode interlayer of $50 \mathrm{wt} . \% \mathrm{LSM}+50$ 
wt.\% LSGM fired at $1150^{\circ} \mathrm{C}$ exhibited an area specific cell resistance of $0.18 \Omega \mathrm{cm}^{2}$ and a maximum power density of $1.4 \mathrm{~W} / \mathrm{cm}^{2}$ at $800^{\circ} \mathrm{C}$. Chemical analysis revealed that LSGM reacts with YSZ above $1000^{\circ} \mathrm{C}$ to form the pyrochlore phase, $\mathrm{La}_{2} \mathrm{Zr}_{2} \mathrm{O}_{7}$. The formation of the pyrochlore phase at the interface between the LSGM/LSM composite cathode and the YSZ electrolyte limits the firing time and temperature of the cathode interlayer.

Anode-supported cells were operated directly on pure methanol and on an equi-volume mixture of ethanol and water over a range of temperatures. Power density achieved with methanol was between $0.6 \mathrm{~W} / \mathrm{cm}^{2}$ at $650^{\circ} \mathrm{C}$ and $1.3 \mathrm{~W} / \mathrm{cm}^{2}$ at $800^{\circ} \mathrm{C}$, and with ethanol + water between $0.3 \mathrm{~W} / \mathrm{cm}^{2}$ at $650^{\circ} \mathrm{C}$ and $0.8 \mathrm{~W} / \mathrm{cm}^{2}$ at $800^{\circ} \mathrm{C}$. Results were compared with tests on humidified hydrogen as a fuel. No carbon deposition on Ni-YSZ anode was observed with either methanol or an equi-volume solution of ethanol and water as fuels. Differences in performance with different fuels were attributed to differences in anode polarization.

Reduction and re-oxidation kinetics of Ni-based anodes were investigated over a range of temperatures between 650 and $800^{\circ} \mathrm{C}$. The experimental part of the investigation consisted of first fabricating $\mathrm{NiO}+$ YSZ two-phase composites of essentially full density. The fully dense samples were subsequently reduced in a hydrogen-containing environment. The reduced layer thickness was measured as a function of time at temperature. Some of the samples were reduced for a time long enough to ensure that they were fully reduced. Subsequently, the reduced samples were re-oxidized in air at various temperatures, ranging between 650 and $800^{\circ} \mathrm{C}$. In this set of experiments, the re-oxidized layer thickness was measured as a function of time at temperature. These two types of experiments were used for determining the kinetics of reduction as well as that of re-oxidation. It was observed that the reduction kinetics was linear (interface-controlled), while the re-oxidation kinetics was parabolic (diffusion-controlled). A simple theoretical analysis was conducted to describe the two processes. The interface control of the reduction process was attributed to the rapid gaseous transport through the pores formed upon reduction of $\mathrm{NiO}$ to $\mathrm{Ni}$. By contrast, diffusion control for the re-oxidation process was attributed to the existence of a very small amount of porosity that forms when Ni re-oxidizes to $\mathrm{NiO}$, which occurs due presumably to a slight shape change of Ni particles.

Anode-supported solid oxide fuel cells with $\mathrm{Ni}+$ yttria-stabilized zirconia (YSZ) anode, YSZsamaria-doped ceria (SDC) bi-layer electrolyte and Sr-doped $\mathrm{LaCoO}_{3}(\mathrm{LSC})+\mathrm{SDC}$ cathode were fabricated. Fuel used consisted of $\mathrm{H}_{2}$ diluted with $\mathrm{He}, \mathrm{N}_{2}, \mathrm{H}_{2} \mathrm{O}$ or $\mathrm{CO}_{2}$, mixtures of $\mathrm{H}_{2}$ and $\mathrm{CO}$, and mixtures of $\mathrm{CO}$ and $\mathrm{CO}_{2}$. Cell performance was measured at $800^{\circ} \mathrm{C}$ with abovementioned fuel gas mixtures and air as oxidant. For a given concentration of the diluent, the cell performance was higher with $\mathrm{He}$ as the diluent than with $\mathrm{N}_{2}$ as the diluent. Mass transport through porous Ni-YSZ anode for $\mathrm{H}_{2}-\mathrm{H}_{2} \mathrm{O}, \mathrm{CO}-\mathrm{CO}_{2}$ binary systems and $\mathrm{H}_{2}-\mathrm{H}_{2} \mathrm{O}$-diluent gas ternary systems was analyzed using multi-component gas diffusion theory. At high concentrations of the diluent, the maximum achievable current density was limited by the anodic concentration polarization. From this measured limiting current density, the corresponding effective gas diffusivity was estimated. Highest effective diffusivity was estimated for fuel gas mixtures containing $\mathrm{H}_{2}-\mathrm{H}_{2} \mathrm{O}-\mathrm{He}$ mixtures $\left(\sim 0.55 \mathrm{~cm}^{2} / \mathrm{s}\right)$, and the lowest for $\mathrm{CO}-\mathrm{CO}_{2}$ mixtures $\left(\sim 0.07 \mathrm{~cm}^{2} / \mathrm{s}\right)$. The lowest performance was observed with $\mathrm{CO}-\mathrm{CO}_{2}$ mixture as a fuel, which in part was attributed to the lowest effective diffusivity of the fuels tested, and higher activation polarization. 


\section{EXPERIMENTAL}

\section{Nanosize YSZ Powder Synthesis:}

For the synthesis of nanosize yttria-stabilized zirconia by the present method, the precursor can be a suitable alkali or an alkaline earth zirconate. Two types of precursors, namely, yttriadoped barium zirconate, $\left(\mathrm{Y}-\mathrm{BaZrO}_{3}\right)$, and yttria-doped sodium zirconate, $\left(\mathrm{Y}-\mathrm{Na}_{2} \mathrm{ZrO}_{3}\right)$, were synthesized by a conventional solid state reaction method. For preparing $\mathrm{Y}-\mathrm{BaZrO}_{3}$, the starting materials, namely, $\mathrm{BaCO}_{3}, \mathrm{ZrO}_{2}$ and $\mathrm{Y}_{2} \mathrm{O}_{3}$, or $\mathrm{BaCO}_{3}$ and a commercial yttriastabilized zirconia (YSZ) powder, were mixed in requisite proportions, wet ball-milled in alcohol for $24 \mathrm{~h}$ and then dried. For the synthesis of $\mathrm{Y}-\mathrm{Na}_{2} \mathrm{ZrO}_{3}, \mathrm{Na}_{2} \mathrm{CO}_{3}$ and commercial YSZ powder were mixed in requisite proportion, wet ball-milled and then dried. The ball-milled and dried powder mixtures were calcined at various temperatures and the resulting powders were examined by $\mathrm{x}$-ray diffraction (XRD) with $\mathrm{CuK} \alpha$ radiation to identify calcination conditions which ensured the formation of completely converted, single phase, precursor powders; i.e., Y$\mathrm{BaZrO}_{3}$ or $\mathrm{Y}-\mathrm{Na}_{2} \mathrm{ZrO}_{3}$.

Doped sodium zirconate was then boiled and washed in de-ionized water since the reaction between $\mathrm{Na}_{2} \mathrm{ZrO}_{3}$ and water is thermodynamically favored. In this way, $\mathrm{Na}_{2} \mathrm{O}$ can be easily leached out. To ensure the complete removal of $\mathrm{Na}_{2} \mathrm{O}$, the powder was continuously washed until the $\mathrm{pH}$ of the solution was near neutral $(\sim 7)$. Then, the resulting powder was dried and later characterized. The Gibbs free energy change for the reaction of barium zirconate with water at or near room temperature is close to zero [1] indicating that $\mathrm{BaZrO}_{3}$ is thermodynamically stable in the presence of water. Thus, water is not a suitable leaching agent for $\mathrm{BaZrO}_{3}$. A dilute acid solution is necessary to facilitate the removal of $\mathrm{BaO}$ from barium zirconate. Y-doped barium zirconate was boiled in dilute $\mathrm{HNO}_{3}$ acid $(0.07 \mathrm{M})$ repeatedly until no further change in $\mathrm{pH}$ of the solution occurred. Then, the powder was thoroughly washed with de-ionized water and dried. In both cases, the leaching solution as well as the assynthesized powder, were chemically analyzed using Inductively Coupled Plasma (ICP) technique. For the analysis of the as-synthesized YSZ powder by ICP, samples were dissolved in concentrated $\mathrm{HCl}$. The as-synthesized powders were also examined by XRD with $\mathrm{CuK} \alpha$ radiation. The objective was to determine the crystal structure and to estimate the particle size by line broadening. Specific surface area was measured by Brunauer-Emmett-Teller (BET) adsorption isotherm using nitrogen gas.

Raman spectra were obtained to determine the crystallographic polymorph of the YSZ formed with an Ar plasma laser (Spectra-Physics, Model 2580) and a $0.6 \mathrm{~m}$ triple spectrometer (Spex. Industries, Inc., Model 1877). The spectrometer was calibrated using Ar laser plasma lines. A $488 \mathrm{~nm}$ laser was focused on the sample with a beam diameter of $1 \mathrm{~mm}$. The plasma lines were removed from the laser beam using a $10 \mathrm{~nm}$ bandpass filter. The spectrometer slit width was adjusted to $20 \mathrm{~nm}$.

One of the samples was also examined under a transmission electron microscope (TEM) to

estimate the crystallite size of as-synthesized YSZ using JEOL 4000FX transmission electron microscope. 
Differential Thermal Analysis (DTA) was conducted on the as-synthesized YSZ powders. In the DTA experiments, the samples were purged with purified air and heated up to $1200^{\circ} \mathrm{C}$ at a heating rate of $10^{\circ} \mathrm{C} / \mathrm{min}$. Based on the DTA information, several temperatures were identified for the calcination of the powders after the leaching treatments. The as-synthesized YSZ powders were subsequently calcined at various temperatures up to a maximum of $1000^{\circ} \mathrm{C}$. The calcined powders were further examined by XRD.

\section{Cathode Area Effect:}

The following is a simple theoretical analysis of the testing of SOFC of different electrode areas. It is to be emphasized that the exact solution will require numerical analysis, as the actual problem is a three dimensional, mixed boundary value problem with rather complex boundary conditions, which result from the various processes that occur. Specifically, a rigorous solution will need to address: (a) A mixed boundary value problem of electrostatic potential distribution, with cathode/electrolyte interface as well as anode/electrolyte interface exhibiting interface resistances, thus precluding them from being equipotential surfaces. (b) A mixed boundary value problem of gaseous transport through porous electrodes, with similar issues concerning the boundary conditions at the electrode/electrolyte interfaces. (c) A coupling between these two. A rigorous analysis of this problem is a formidable task, even numerically. What is desirable is a simple analytical approach, albeit approximate, which will yield simple analytical expressions that can be succinctly used to describe cell behavior. The analytical results then can be readily verified experimentally to determine the accuracy and the applicability of analytical results. This is the approach followed in the present work.

Figure \#1(a) shows a schematic of a cell wherein the cathode diameter is the same as the anode diameter, the preferred testing geometry, but difficult to achieve experimentally. Figure \#1(b) is the one often used, and the one in question. Insofar as the anode is concerned, transport of two species through the anode must be examined; transport of electrons (electronic current) through the contiguous $\mathrm{Ni}$, and the transport of gaseous species (e.g. $\mathrm{H}_{2}$ and $\mathrm{H}_{2} \mathrm{O}$ ) through the porosity. Transport of electrons, or the electronic current, is determined by solving the Laplace equation in the anode subject to appropriate boundary conditions.

There appear to be three possible ways in which the asymmetry of the cathode and the anode (cathode/electrolyte interface area $<$ anode/electrolyte interface area) may influence the measured cell performance characteristics: (a) Extended region of the electrolyte beyond the periphery of the cathode. (b) Lower electronic resistance of the anode due to the larger anode/fuel gas interface compared to the active anode/electrolyte interface. (c) Lower resistance to gas transport through the anode due to the larger anode/fuel gas interface compared to the active anode/electrolyte interface. These three aspects are discussed in what follows, and approximate analytical relations are developed.

The Effective Electrolyte Extension beyond the Cathode Periphery: One possible consequence of the asymmetry between the cathode and the anode is an extended region in the electrolyte through which ionic current may flow. This is shown schematically in Figure \#2 wherein the diameter of the conical region at the electrolyte/anode interface is shown to be somewhat larger than the cathode radius, $r_{c}$. Let the radius of the active part of the electrolyte be given by $r_{o}$ 
where $r_{o}>r_{c}$. Figure \#3 shows an exploded schematic in which the approximate nature of ionic flux distribution through the extended region is shown. Again, an order of magnitude calculation of the ionic resistance of this region (which is an in-plane contribution) can be given by

$$
R_{e x} \approx \int_{r_{c}}^{r_{o}} \frac{\rho_{e} d r}{2 \pi r l_{e}}=\frac{\rho_{e}}{2 \pi l_{e}} \ln \left(\frac{r_{o}}{r_{c}}\right)
$$

The above is only an order of magnitude estimate since it ignores the fact that the in-plane current through the electrolyte between $r_{o}$ and $r_{c}$ is distributed. The distributed nature of the current can be estimated, for example, by, a ladder network approach, which consists of constructing an equivalent circuit of resistive and other circuit elements to represent distributed current. Thus, the above equation overestimates the in-plane resistance. This resistance is for the current between the cathode and the anode, through the extended region of the electrolyte. Note that this resistance is in parallel with the usual electrolyte resistance for the current flowing between the cathode and the anode, through the flat and parallel surfaces. This is simply the electrolyte resistance given by

$$
R_{e l}=\frac{\rho_{e} l_{e}}{\pi r_{c}^{2}}
$$

Since these resistances are in parallel, the currents flowing through these two are inversely proportional to the respective resistances. Let us estimate the magnitude of the extension assuming for $R_{e x}$ to be about 100 times $R_{e l}$, that is, $R_{e x} \approx 100 R_{e l}$ and estimate the radius $r_{o}$ of the extended region; that is, for a correction of $\sim 1 \%$. Thus,

$$
\ln \left(\frac{r_{o}}{r_{c}}\right) \approx 200\left(\frac{l_{e}}{r_{c}}\right)^{2}
$$

where $l_{e}$ is the electrolyte thickness. Now $l_{e}<<r_{c}$ for an anode-supported cell with a thin YSZ film as an electrolyte. Thus, the above reduces to

$$
r_{o}-r_{c} \approx 200 \frac{l_{e}^{2}}{r_{c}}
$$

For $r_{c}=1 \mathrm{~cm}$ and $l_{e}=10 \mu \mathrm{m}$, it is seen that $\left(r_{o}-r_{c}\right) \sim 2 \mu \mathrm{m}$. That is, there is negligible extension of the region in the electrolyte through which an in-plane current can flow. Thus, this effect can be neglected.

Electronic Resistance of the Asymmetric Anode: Figure \#4(a) shows a schematic of equipotential lines and flux (electrical) lines. The flux lines are orthogonal to the equipotential lines, within the anode, away from the anode/electrolyte interface. At the anode/electrolyte interface, the flux lines need not meet the interface orthogonally, if a significant interfacial resistance exists (as discussed by Tanner et al. [2]). It is clear, however, that the net current across the anode/external contact is the same as that across active anode/electrolyte interface. Solution to Laplace equation for this geometry will have to be obtained numerically, and is not available analytically. However, as a simplification, we will assume that the net current flows through the conical region shown in Figure \#4(b). The net anode electronic resistance then can be determined as follows: 
The radius $r(y)$ through which electronic current transports at a cross section at $y$ is given by

$$
r(y)=r_{a}+\left(r_{c}-r_{a}\right) \frac{y}{l_{a}}
$$

where $r_{a}, r_{c}$ and $l_{a}$ denote the anode radius (in contact with the fuel), the cathode radius, and the anode thickness, respectively. If the anode electronic resistivity is $\rho_{a}$, the net anode electronic resistance is given by

$$
R_{a}=\frac{\rho_{a}}{\pi} \int_{0}^{l_{a}} \frac{d y}{r^{2}(y)}=\frac{\rho_{a} l_{a}}{\pi r_{a} r_{c}}
$$

The electronic resistivity of $\mathrm{Ni}$ at $800^{\circ} \mathrm{C}$ is about $\sim 15 \times 10^{-6} \Omega \mathrm{cm}$ [3]. Assuming the volume fraction of Ni to be about $55 \%, \rho_{a}$ is about $\sim 27 \times 10^{-6} \Omega \mathrm{cm}$. For an anode thickness of $1 \mathrm{~mm}$, a cathode radius of $1 \mathrm{~cm}$, and an anode radius of $2 \mathrm{~cm}$, the anode resistance is estimated to be $\sim 4.3 \times 10^{-7} \Omega$. As the cathode area is $\pi$, the area specific resistance of the anode (normalized to the cathode area) is $\sim 1.35 \times 10^{-5} \Omega \mathrm{cm}^{2}$. This is negligible in comparison to the electrolyte area specific resistance given by $\rho_{e} l_{e} \approx 4 \times 10^{-2} \Omega \mathrm{cm}^{2}$, assuming $\rho_{e} \approx 40 \Omega \mathrm{cm}$. That is, the overall contribution to the anode resistance due to the asymmetry of the cathode and anode (different diameters) is negligible. It would matter little whether the anode radius is the same as the cathode, or is different. This assumes that the anode radius is not too different from the cathode radius (a difference of within a factor of few, not orders of magnitude different), and the anode is relatively thick.

The preceding estimate assumes that the anode is relatively thick. If the anode is relatively thin, as shown in Figure \#4(c), such that $\left(r_{a}-r_{c}\right)>>l_{a}$, then not all of the anode/fuel gas area will be active. Thus, in this case, the active anode radius will not be the actual anode radius, but some effective anode radius, $r_{a(e f f)}$, which will be a function of the cathode radius, and the anode thickness, $l_{a}$, but not a function of anode radius, $r_{a}$. It is expected, based on the dimensional grounds, that

$$
r_{a(e f f)} \approx r_{c}+\lambda l_{a}
$$

where $\lambda$ is a geometric factor. Then, the corresponding anode resistance is given by

$$
R_{a}=\frac{\rho_{a}}{\pi} \int_{0}^{l_{a}} \frac{d y}{r^{2}(y)}=\frac{\rho_{a} l_{a}}{\pi r_{a(e f f)} r_{c}}
$$

We will assume $\lambda$ to be approximately unity in what follows. Experimentally, however, one should be able to estimate $\lambda$ by fitting to experimental data.

Resistance to Gas Flow through an Asymmetric Anode: Concentration Polarization: Our recent work $[4,5]$ has analyzed the role of both anodic and cathodic concentration polarizations on fuel cell performance. The analysis was based on the use of effective diffusivities and the assumption of negligible viscous flow [6,7]. Under these conditions, it can be shown that the fluxes of $\mathrm{H}_{2}$ and $\mathrm{H}_{2} \mathrm{O}$ through the anode are given by

$$
J_{H_{2}}=-D_{e f f(a)} \nabla n_{H_{2}}=-\frac{D_{e f f(a)}}{k_{B} T} \nabla p_{H_{2}}
$$


and

$$
J_{\mathrm{H}_{2} \mathrm{O}}=-D_{\text {eff }(a)} \nabla n_{\mathrm{H}_{2} \mathrm{O}}=-\frac{D_{e f f(a)}}{k_{B} T} \nabla p_{\mathrm{H}_{2} \mathrm{O}}
$$

where $n_{\mathrm{H}_{2}}$ and $n_{\mathrm{H}_{2} \mathrm{O}}$ denote the number of $\mathrm{H}_{2}$ and $\mathrm{H}_{2} \mathrm{O}$ molecules per unit volume, respectively, $p_{\mathrm{H}_{2}}$ and $p_{\mathrm{H}_{2} \mathrm{O}}$ denote the partial pressures of $\mathrm{H}_{2}$ and $\mathrm{H}_{2} \mathrm{O}$, respectively, $k_{B}$ is the Boltzmann's constant, $T$ is the temperature, and $D_{e f f(a)}$ is the effective anode diffusivity, which, for hydrogen as a fuel, is given by [6]

$$
D_{e f f(a)}=\frac{V_{v}}{\tau} D_{H_{2}-H_{2} O}
$$

in which $V_{v}$ is the anode porosity, $\tau$ is the tortuosity factor, and $D_{\mathrm{H}_{2}-\mathrm{H}_{2} \mathrm{O}}$ is the binary diffusivity.

Now, under steady state conditions,

$$
\left|J_{H_{2}}\right|=\left|J_{H_{2} O}\right|=\frac{i N_{A}}{2 F}
$$

wherein the fluxes are measured at the anode/electrolyte interface, and so is the current density, which will be on the basis of $r_{o}$, which is $\approx r_{c}$. For the geometry shown in Figure \#4(b), the local fluxes of $\mathrm{H}_{2}$ or $\mathrm{H}_{2} \mathrm{O}$ vary from position to position along the y-axis by virtue of the varying cross sectional area. Referring to Figure \#4(b), it is readily seen that

$$
J_{H_{2}}(y) \pi r^{2}(y)=J_{H_{2}}(0) \pi r_{a}^{2}=J_{H_{2}}\left(l_{a}\right) \pi r_{c}^{2}
$$

where $J_{H_{2}}(y), J_{H_{2}}(0)$, and $J_{H_{2}}\left(l_{a}\right)$ are local flux densities at $y=y, y=0$, and $y=l_{a}$, respectively.

A simplified, pseudo one-dimensional flux equation leads to

$$
\int_{p_{H_{2}(0)}}^{p_{H_{2}\left(l_{a}\right)}} d p_{H_{2}(y)}=-\frac{i N_{A} k_{B} T}{2 D_{e f f(a)} F} \int_{0}^{l_{a}} \frac{d y}{\left\{\frac{r_{a}}{r_{c}}+\left(\frac{r_{c}-r_{a}}{r_{c}}\right) \frac{y}{l_{a}}\right\}^{2}}
$$

which gives

$$
p_{H_{2}\left(l_{a}\right)}=p_{H_{2}(0)}-\frac{R T l_{a}}{2 F D_{\text {eff }(a)}}\left(\frac{r_{c}}{r_{a}}\right) i
$$

and the anode limiting short circuit current density, $i_{a s}$, is given by

$$
i_{a s}=\frac{2 F D_{e f f(a)} p_{H_{2}(0)}}{R T l_{a}}\left(\frac{r_{a}}{r_{c}}\right)
$$

which is the current density at which $p_{H_{2}\left(l_{a}\right)} \approx 0$. This equation for $i_{a s}$ differs from the one given in our earlier work $[4,5]$, which is for symmetric electrodes, by the factor $\left(\frac{r_{a}}{r_{c}}\right)$. That is, the anode limiting short circuit current density, as calculated on the basis of the cathode area, is 
larger by the above factor. If the anode radius, $r_{a}$, is much greater than the cathode radius, $r_{c}$, in relation to thickness (Figure \#4(c)), then $r_{a}$ from equation (16) is to be replaced by $r_{a(e f f}$ ) from equation (7). In such a case, the $i_{a s}$ is given by

$$
i_{a s}=\frac{2 F D_{e f f(a)} p_{H_{2}(0)}}{R T l_{a}}\left(\frac{r_{a(e f f)}}{r_{c}}\right)
$$

Our prior work has shown that the anodic concentration polarization is given by $[4,5]$

$$
\eta_{\text {conc }(a)}=-\frac{R T}{2 F} \ln \left(1-\frac{i}{i_{a s}}\right)+\frac{R T}{2 F} \ln \left(1+\frac{p_{H_{2}(0)}}{p_{H_{2} O(0)}} \frac{i}{i_{a s}}\right)
$$

or, substituting for the $i_{a s}$

$$
\eta_{\operatorname{conc}(a)}=-\frac{R T}{2 F} \ln \left(1-\frac{i}{i_{a s}}\right)+\frac{R T}{2 F} \ln \left(1+\frac{R T l_{a}}{2 F D_{\text {eff }(a)}}\left(\frac{r_{c}}{r_{a(e f f)}}\right) \frac{i}{p_{H_{2} O(0)}}\right)
$$

The preceding analysis shows that the source of potential differences in the reported power densities due to asymmetric electrodes (cathode area smaller than the anode area) lies principally in differences in the anodic concentration polarization. The magnitude of the difference will depend upon a number of factors such as the anode thickness, $l_{a}$, the effective diffusivity of the anode, $D_{\text {eff }(a)}$, and the factor $\left(\frac{r_{a}}{r_{c}}\right)$ or $\left(\frac{r_{a(e f f)}}{r_{c}}\right)$.

Using the preceding analysis, and measurements reported in [4], an estimate of the difference in anodic overpotentials for two different cell geometries is given in what follows. The following values based on our prior work were used for the calculations:

$$
\begin{aligned}
D_{e f f(a)} & \approx 0.2 \mathrm{~cm}^{2} / \mathrm{sec} \text { at } 800^{\circ} \mathrm{C} . \\
l_{a} & \approx 1 \mathrm{~mm} \\
p_{H_{2}(0)} & \approx 0.97 \mathrm{~atm} \\
p_{H_{2} O(0)} & \approx 0.03 \mathrm{~atm} . \\
r_{a} & \approx 1.3 \mathrm{~cm}
\end{aligned}
$$

We will choose two values of $r_{c}$; namely $0.5 \mathrm{~cm}$ and $1.0 \mathrm{~cm}$. The corresponding anodelimiting short circuit current densities are $\sim 5.53 \mathrm{~A} / \mathrm{cm}^{2}$ for the larger cathode radius, and $\sim 11.06 \mathrm{~A} / \mathrm{cm}^{2}$ for the smaller cathode radius using equation (16). The estimated anodic concentration polarizations, $\eta_{\text {conc(a) }}$, for the two cases, are plotted vs. current density, $i$, in Figure \#5(a). The figure shows that, for the numbers chosen, the difference in the overpotentials is modest. In the example chosen above, note that for $r_{c} \approx 0.5 \mathrm{~cm}$, $\left(r_{a}-r_{c}\right)>>l_{a}$, and for $r_{c} \approx 1 \mathrm{~cm},\left(r_{a}-r_{c}\right)>l_{a}$. Thus, one should use equation (17) instead of equation (16). Choosing $r_{a(\text { eff })} \approx r_{c}+l_{a}$, the corresponding anode-limiting short circuit current densities, $i_{\text {as }}$, become $4.68 \mathrm{~A} / \mathrm{cm}^{2}$ for the larger cathode, and $5.1 \mathrm{~A} / \mathrm{cm}^{2}$ for the smaller cathode. Figure \#5(b) shows the estimated anodic concentration polarizations, $\eta_{\text {conc }(a)}$, for the 
two cases plotted vs. current density, $i$. Experiments were conducted to test the above analysis. This is described in what follows.

Cell Fabrication: Anode-supported cells with $\mathrm{Ni}+\mathrm{YSZ}$ as the anode, YSZ electrolyte, a thin, dense layer of $\mathrm{Sm}_{2} \mathrm{O}_{3}$-doped $\mathrm{CeO}_{2}$ (SDC) barrier layer which serves as a part of the electrolyte, Sr-doped $\mathrm{LaCoO}_{3}$ (LSC) + SDC porous cathode, and a porous LSC layer as a current collector, were fabricated using the following procedure. Discs of NiO + YSZ powder mixture were diepressed. A thin layer of YSZ was applied on one surface, and edges, by drop coating a YSZ slurry. After drying, a thin layer of SDC was also applied by drop coating. The disc was subsequently sintered in air at a temperature between 1400 and $1500^{\circ} \mathrm{C}$.

Two types of cells were made. In one case, the cathode was applied in a circular area. A paste of LSC + SDC made in an organic liquid was applied on the electrolyte (dense SDC layer) in a circular area. Two discs were prepared; in one case the area covered was $\sim 1.1 \mathrm{~cm}^{2}$, while in the other case, the area covered was $\sim 2 \mathrm{~cm}^{2}$. After drying, a layer of LSC was applied over it. Reference electrodes on the cathode side, prepared similarly, were deposited in a similar manner. The cell was heated to a temperature between 1000 and $1200^{\circ} \mathrm{C}$ to ensure a good bond between the cathode and the electrolyte. In the second case, the two cathodes were applied on one cell, both semicircular in geometry, as shown in Figure \#6. Care was to taken to ensure that spacing between the two semicircular areas was made as small as possible. In this case also, reference electrodes were deposited on the cathode side. The rationale for placing two cathodes on the same cell was that this should eliminate any possible differences in the electrolyte thickness, or possible differences in cathode activity that may result in any inadvertent differences in cathode preparations between cells, or possible differences in the fuel composition; e.g. the amount of water content.

Cell Testing: Cells were mounted in a fixture using alumina tubes and flexible, glass-free, compression seals. Figure \#7 shows a schematic of the cell testing setup. Silver wire meshes, in the same geometry as the electrode areas, were placed on the cathode. Silver wire leads were connected to the wire meshes. The cells were heated in a furnace. Hydrogen gas, bubbled through water, was circulated past the anode, and air was circulated past the cathode. The NiO from the anode was reduced to $\mathrm{Ni}$, in-situ. Voltage vs. current traces, were measured using an external electronic load. Anode and cathode potentials were measured with respect to the reference electrodes. The ohmic contribution was measured by current interruption. The cathode and anode overpotentials were determined by subtracting the ohmic contribution. For cells with circular cathodes, cell performance measurements were made at two different temperatures; $750^{\circ} \mathrm{C}$ and $800^{\circ} \mathrm{C}$. In all experiments, the temperature was measured very close to the cell.

For the cell with semicircular cathodes, three separate measurements were made; the two semicircular cathodes separately, and a third measurement wherein the two cathodes were shorted (externally) using a heavy gage silver wire.

Microstructural Characterization: The cells after testing were fractured and examined in a scanning electron microscope (SEM) to measure the electrolyte, the anode interlayer and the 
cathode interlayer thicknesses; and to examine the microstructures of the cathode and anode interlayers.

\section{Effect of Cathode Microstructure:}

$\mathrm{NiO}+$ YSZ powders were mixed in requisite proportions. Discs of the powder were diepressed. A thin interlayer of $\mathrm{NiO}+\mathrm{YSZ}$ was applied on one surface by spray coating. Subsequently, a thin layer of YSZ was applied by spray coating on the NiO + YSZ interlayer. The disc was then sintered in air at $1400^{\circ} \mathrm{C}$ for 2 hours. The cathode interlayer was made of LSM + YSZ wherein the composition of LSM was $\mathrm{La}_{0.8} \mathrm{Sr}_{0.2} \mathrm{MnO}_{(3-\delta)}$. The interlayer composition, that is the relative proportion of LSM and YSZ, was varied between 25 wt.\% $\mathrm{LSM}+75 \mathrm{wt} . \% \mathrm{YSZ}$ and $60 \mathrm{wt} . \% \mathrm{LSM}+40 \mathrm{wt} . \% \mathrm{YSZ}$. An organic liquid was added to the interlayer powder mixture to form a paste. The YSZ electrolyte layer on the surface of the sintered disc was coated with the cathode interlayer paste. Subsequently, a layer of LSM was applied over the cathode interlayer, again by mixing it in an organic liquid to form a paste. The cell was then heated in air to $1150^{\circ} \mathrm{C}$ to remove the organic liquid, and form a good bond between the cell and the cathode interlayer, and between the cathode interlayer and the LSM cathode current collector, while maintaining sufficient porosity. At all stages, care was to taken to ensure that, within the accuracy and repeatability of the experimental procedure, the thickness of any given layer was essentially the same in all cells. The only differences from cell to cell were differences in cathode interlayer compositions, and any associated microstructural differences.

Each cell was mounted in a test fixture, which consists of an alumina tube and an alumina ring. Each cell was secured between the alumina tube and the alumina ring. Flexible gaskets were used to ensure good sealing. No glass was used. Silver wire gauzes were pressed against the two electrodes, to which silver wires were connected. Air was circulated past the cathode, and humidified hydrogen was circulated past the anode. The cell was then heated to $800^{\circ} \mathrm{C}$. Reduction of $\mathrm{NiO}$ to $\mathrm{Ni}$ was achieved in-situ. Voltage vs. current polarization curves were recorded using an electronic load.

After testing, cells were removed from the fixture and fractured. One of the fractured pieces of each cell was impregnated with an epoxy. The epoxy used completely filled up the porosity of the cathode current collector, the cathode interlayer, the anode interlayer, and the anode support. Upon curing and hardening the epoxy, the sample was mounted in a plastic mount, and subsequently polished to a 1 micron finish. A thin layer of carbon was deposited on the sample, which was then examined under an electron microprobe (Cameca SX 50). Several color-coded micrographs of cathode interlayers were obtained.

Color-coded micrographs of the cathode interlayers were used for quantitative stereological measurements. The parameters of specific interest are: (a) Grain (actually grain aggregate) size of YSZ in the cathode interlayer, $d$, (b) Porosity of the cathode interlayer, $V_{v}$, and (c) Three phase boundary (TPB) line length in the cathode interlayer, $l_{T P B}$. The grain aggregate size, $d$, of the YSZ in the cathode interlayer can be related to the average intercept length determined by repeatedly applying a test line on the micrographs [8]. For the determination of the average intercept length, a test line of equivalent length $\sim 8 \mu \mathrm{m}$ was applied on micrographs of each 
cathode interlayer up to 50 times [8]. The $V_{v}$ was measured by a systematic point count procedure wherein a 25 point grid was applied on each micrograph up to 50 times. Similarly, volume fractions of LSM and YSZ in the cathode interlayer were also estimated. The average TPB line length, $l_{T P B}$, was estimated by measuring number of three phase boundary (TPB) points per unit area of each micrograph, $P_{A}$ [8]. The experimentally measured parameters are as follows.

$P_{p(V)}=$ Fraction of points falling on the porous regions of the cathode interlayer $=V_{v}$ (volume fraction of porosity). $P_{p(L S M)}=$ Fraction of points falling on LSM in the cathode interlayer $=V_{L S M}\left(\right.$ volume fraction of LSM). $P_{p(Y S Z)}=$ Fraction of points falling on YSZ in the cathode interlayer $=V_{Y S Z}($ volume fraction of YSZ).

A test line was applied and the number of intersections with boundaries of YSZ grain aggregates were measured. This measurement is $P_{L}$ in units of 1/length. The surface area of YSZ grains per unit volume is given by $S_{V}=2 P_{L}$ [8]. Finally, the grain aggregate diameter is given by $d=3 V_{Y S Z} / P_{L}$.

For the measurement of three phase boundary (TPB) length, number of TPB points per unit area, $P_{A}$, was measured. The three phase boundary (TPB) length per unit area of the YSZ grains in the cathode interlayer is given by $l_{T P B}=L_{V} / S_{V}=P_{A} / P_{L}$.

\section{Alcohol as a Fuel:}

Cell Fabrication: A typical single cell consists of five layers; anode support, anode interlayer, thin YSZ electrolyte, cathode interlayer and cathode layer. $\mathrm{NiO}$ and YSZ powders from commercial sources were mixed in requisite proportion and ball-milled in alcohol, dried and screened through a 150-mesh sieve. A circular disc of $\sim 1.25 \mathrm{~mm}$ thickness and of $\sim 3 \mathrm{~cm}$ diameter was uniaxially die-pressed. The disk was pre-sintered at $1000^{\circ} \mathrm{C}$ for one hour. The disc was then coated with a slurry of an anode interlayer of NiO + YSZ. Subsequently, a thin layer of YSZ was applied using its slurry in a suitable liquid. The disk was then sintered at $1400^{\circ} \mathrm{C}$ for a couple of hours. The thickness of the disc after sintering was $\sim 1 \mathrm{~mm}$. The typical thicknesses of the anode interlayer and the YSZ film were, respectively, $\sim 10-30 \mu \mathrm{m}$ and $\sim 10$ $\mu \mathrm{m}$. The cathode interlayer was a porous composite of Sr-doped $\mathrm{LaMnO}_{3}$ (LSM) and YSZ, wherein the composition of LSM was $\mathrm{La}_{0.8} \mathrm{Sr}_{0.2} \mathrm{MnO}_{3-\delta}$. A paste of LSM + YSZ powder mixture in an organic liquid was applied on the YSZ surface of the disc, followed by a layer of a pure LSM paste prepared similarly. The disc was then heated to a temperature typically between $\sim 1000$ and $\sim 1200^{\circ} \mathrm{C}$ for $1 \mathrm{~h}$. The thicknesses of the cathode interlayer and the LSM layer were, respectively, $\sim 10-30 \mu \mathrm{m}$, and $\sim 100 \mu \mathrm{m}$. The effective electrode area was $1.1 \mathrm{~cm}^{2}$. The single cell was mounted in a test fixture, which consists of an alumina tube and an alumina ring. A flexible gasket was used for sealing. Figure 1 shows a schematic of the cell-testing fixture. Silver and nickel meshes were used as current collectors on the cathode and the anode, respectively. A reference electrode of platinum was applied on the cathode side, a few millimeters away from the cathode, and heated in air to $800^{\circ} \mathrm{C}$ for $1 \mathrm{~h}$ to ensure a good bond. 
Cell Testing: Prior to testing with alcohols as fuels, the anode was reduced, in-situ, by flowing hydrogen gas at $800^{\circ} \mathrm{C}$ over the anode for a few hours. Then, further cell testing was conducted using $\mathrm{CH}_{3} \mathrm{OH}$ and $\mathrm{C}_{2} \mathrm{H}_{5} \mathrm{OH}+\mathrm{H}_{2} \mathrm{O}$ (equi-volume mixture) as fuels. The liquid fuel was injected by a microinjection device at a controlled flow rate of $0.2 \mathrm{ml} / \mathrm{min}$, and vaporized before introducing into the anode compartment. On the cathode side, air was circulated over the cathode surface at a flow rate of $600 \mathrm{ml} / \mathrm{min}$. Voltage between the anode and the cathode, as well as between the anode and the reference electrode, was measured as a function of current. The ohmic resistances of: (1) the cell, (2) that between the anode and the reference electrode, and (3) between the cathode and the reference electrode, were determined using a current interruption technique with a potentiostat/galvanostat (EG\&G 263), in conjunction with an oscilloscope (HP54622A). Voltage drops were measured at several current densities. Voltage drops were linearly related to the current density. Electrode overpotentials were obtained by subtracting ohmic contributions. Cell performance was measured over a range of temperatures between 550 and $800^{\circ} \mathrm{C}$ using $\mathrm{H}_{2}, \mathrm{CH}_{3} \mathrm{OH}$ and $\mathrm{C}_{2} \mathrm{H}_{5} \mathrm{OH}+\mathrm{H}_{2} \mathrm{O}$ as fuels.

\section{$\underline{\text { LSM-LSGM Cathodes: }}$}

The anode-supported solid oxide fuel cells of the present study are comprised of five component layers: a Ni/YSZ composite anode support, a Ni/YSZ anode interlayer, a thin film YSZ electrolyte, an LSGM/LSM composite cathode interlayer, and an LSM current collecting cathode layer. The Ni/YSZ anode is thick relative to the other four layers and provides the support and mechanical integrity to the fuel cell. The anode substrates were prepared by, tape casting a solvent-based slip consisting of $80 \mathrm{wt} \% \mathrm{NiO}$ and $20 \mathrm{wt} . \% \mathrm{YSZ}$, and an organic pore former. Multiple tapes were laminated together in order to achieve an anode thickness of approximately $1.0 \mathrm{~mm}$. The anodes used in this work were taken from the same batch of tape in order to minimize possible differences in the anode from cell to cell. Circular cells with a diameter of approximately $3 \mathrm{~cm}$ were cut from the tape and were subsequently bisqued at $1000^{\circ} \mathrm{C}$ in air for one hour in order to remove the binders and pore formers and to partially sinter the green part. An anode interlayer of $60 \mathrm{wt} \% \% \mathrm{NiO}$ and $40 \mathrm{wt}$ \% YSZ was deposited on the anode by suspending the powders in a solvent and spraying the mixture on the anode support. The anodes with the anode interlayers were fired a second time at $1000^{\circ} \mathrm{C}$ for one hour resulting in an anode interlayer of approximately $20 \mu \mathrm{m}$ in thickness. Similarly, the YSZ electrolyte was deposited by spraying YSZ (TZ-8Y) powder suspended in a solvent onto the bisqued part. The cell was fired at $1400^{\circ} \mathrm{C}$ for 2 hours resulting in a dense YSZ film with a thickness of $\sim 10 \mu \mathrm{m}$.

The composite cathode interlayer was prepared from $\mathrm{La}_{0.9} \mathrm{Sr}_{0.1} \mathrm{Ga}_{0.8} \mathrm{Mg}_{0.2} \mathrm{O}_{(3-\lambda)}$ (LSGM) and $\mathrm{La}_{0.8} \mathrm{Sr}_{0.2} \mathrm{MnO}_{(3-\delta)}$ (LSM) (Praxair) powders. The relative amounts of LSGM and LSM were varied between 30 and $70 \mathrm{wt} . \%$ LSGM and 70 and $30 \mathrm{wt} \%$ LSM. The two powders were mixed with a solvent-binder system in order to form a paste that was subsequently applied to the YSZ electrolyte by a modified screen-printing method. The cells were masked before printing to produce a uniform area of cathode coverage of $1 \mathrm{~cm}^{2}$ that was fixed for all cells. The composite cathode interlayer was fired at a temperature between 1000 and $1200^{\circ} \mathrm{C}$ for 2 hours in air. The composite cathode interlayers were between 20 and $25 \mu \mathrm{m}$ thick after firing. The final LSM cathode current collecting layer was applied in a paste form by a similar 
method. In addition, a platinum reference electrode was applied on the electrolyte in close proximity to the cathode. The LSM cathode current collector layer was fired at $1000^{\circ} \mathrm{C}$ for 2 hours and had a thickness of approximately $50 \mu \mathrm{m}$ after firing.

The performance and electrochemical properties of the fuel cells were measured in a spring loaded testing fixture shown in Figure \#7. The spring-loaded fixture ensures good electrical contact and good sealing, thus preventing leakages. Nickel mesh and silver mesh were used for current collection on the anode and cathode sides, respectively. A high temperature gasket was used for sealing. The cathode side of the cell was exposed to flowing air at a rate of $0.91 / \mathrm{min}$. The anode side was exposed to a flowing stream of hydrogen gas saturated with water vapor at $25^{\circ} \mathrm{C}\left(\mathrm{pH}_{2} \mathrm{O} \sim 0.032 \mathrm{~atm}\right)$ at a rate of $0.1 \mathrm{l} / \mathrm{min}$. The $\mathrm{NiO} / \mathrm{YSZ}$ composite anodes were reduced, in situ, at $800^{\circ} \mathrm{C}$ for $24 \mathrm{~h}$ before electrochemical measurements were conducted at $800^{\circ} \mathrm{C}$. During testing, the voltage differences between the anode and the reference electrode, and the cathode and the reference electrode were measured. The ohmic resistance of the cells was measured by current interruption. The DC current was cycled with a potentiostat/galvanostat (EG\&G 263A) and the voltages between the cathode, the anode, and the reference electrode were recorded by a digital oscilloscope (Agilent 54662A). The overpotentials were determined by correcting for the requisite ohmic contributions.

In order to investigate the possibility of chemical interactions between LSGM and YSZ, powders of LSGM and YSZ were mixed, milled, and fired at a temperature between 1000 and $1200^{\circ} \mathrm{C}$ for 2 hours. In addition, to study the possible reaction at the interface between LSGM and YSZ, a thin layer of LSGM was applied on sintered YSZ pellets by a modified screenprinting method and fired at a temperature between 1000 and $1200^{\circ} \mathrm{C}$ for 2 hours. The samples were then characterized using X-ray powder diffraction (XRD) to identify any secondary phases that may form at the interface. In order to determine the chemical composition of the resulting phases, sintered samples of LSGM and YSZ were prepared. LSGM and YSZ powders were mixed, milled, pelletized, and sintered at temperatures between 1000 and $1200^{\circ} \mathrm{C}$. The pellets were polished and evaluated with electron dispersive spectroscopy (EDAX).

\section{Anode Reduction-Re-Oxidation Kinetics:}

In what follows, a brief description of the kinetic model is given along with relevant equations, for both reduction and reoxidation. Figure \#8 shows a schematic of the reduction process for a dense $\mathrm{NiO}+$ YSZ two-phase composite into a porous $\mathrm{Ni}+$ YSZ cermet. The reduced layer thickness is $X$. A simple model, which takes into account gas transport through the porous cermet, and the occurrence of reduction at the interface, shows that the kinetics can be described by an equation of the form

$$
X^{2}+\frac{D_{e f f}^{r}}{R T k_{r}} X=\frac{2 D_{e f f}^{r}}{R T} \frac{V_{\mathrm{NiO}}^{M}}{V_{\mathrm{NiO}}^{f}}\left(p_{\mathrm{H}_{2} \mathrm{O}}^{e q}-p_{\mathrm{H}_{2} \mathrm{O}}^{o}\right) t
$$

where

$X=$ Thickness of the reduced layer.

$V_{N i O}^{M}=$ Molar volume of $\mathrm{NiO}, V_{N i O}^{f}=$ Volume fraction of $\mathrm{NiO}$. 
$p_{\mathrm{H}_{2} \mathrm{O}}^{o}=$ Partial pressure of water vapor in the $\mathrm{H}_{2}-\mathrm{H}_{2} \mathrm{O}$ mixture, used as the reducing environment.

$p_{\mathrm{H}_{2} \mathrm{O}}^{e q}=$ Equilibrium partial pressure of water vapor corresponding to the reaction.

$\mathrm{NiO}(\mathrm{s})+\mathrm{H}_{2}(\mathrm{~g}) \rightarrow \mathrm{Ni}(\mathrm{s})+\mathrm{H}_{2} \mathrm{O}(\mathrm{g})$, under the condition that

$$
p_{\mathrm{H}_{2}}^{o}+p_{\mathrm{H}_{2} \mathrm{O}}^{o}=p_{\mathrm{H}_{2}}^{e q}+p_{\mathrm{H}_{2} \mathrm{O}}^{e q}
$$

$D_{\text {eff }}^{r}=$ Effective binary gaseous diffusivity (of $\mathrm{H}_{2}-\mathrm{H}_{2} \mathrm{O}$ ) through the porous Ni-YSZ. cermet formed. (If an inert gas is also present, e.g. nitrogen, its effect may also have to be taken into account).

$k_{r}=$ Rate constant which defines the kinetics of reduction of $\mathrm{NiO}$ to $\mathrm{Ni}$.

$t=$ Time of reduction, $R=$ Ideal gas constant, and $T=$ Temperature.

The two limiting forms of equation (20) are:

\section{a. $k_{r}$ very large relative to $D_{\text {eff }}^{r}$ :}

In this case, the rate of reduction at the reaction interface is sufficiently fast such that equation (20) reduces to

$$
X^{2} \approx \frac{2 D_{e f f}^{r}}{R T} \frac{V_{\mathrm{NiO}}^{M}}{V_{\mathrm{NiO}}^{f}}\left(p_{\mathrm{H}_{2} \mathrm{O}}^{e q}-p_{\mathrm{H}_{2} \mathrm{O}}^{o}\right) t
$$

That is, the reduction reaction is diffusion-controlled and a plot of the square of the reduced layer thickness as a function of time should be linear, consistent with the parabolic law of reduction kinetics. The above equation may also be written as

$$
X^{2} \approx D_{\text {red }} t
$$

where a phenomenological diffusion coefficient is defined by

$$
D_{\text {red }} \approx \frac{2 D_{e f f}^{r}}{R T} \frac{V_{\mathrm{NiO}}^{\mathrm{M}}}{V_{\mathrm{NiO}}^{f}}\left(p_{\mathrm{H}_{2} \mathrm{O}}^{e q}-p_{\mathrm{H}_{2} \mathrm{O}}^{o}\right)
$$

\section{b. $k_{r}$ very small relative to $D_{e f f}^{r}$ :}

In this case, equation (20) becomes

$$
X \approx 2 k_{r} \frac{V_{\mathrm{NiO}}^{\mathrm{M}}}{V_{\mathrm{NiO}}^{f}}\left(p_{\mathrm{H}_{2} \mathrm{O}}^{e q}-p_{\mathrm{H}_{2} \mathrm{O}}^{o}\right) t
$$

In such a case, the reduction reaction is interface-controlled and a plot of reduced layer thickness, as a function of time should be linear. The above equation may be written as

$$
X \approx k_{\text {red }} t
$$

where a phenomenological interface parameter is defined as

$$
k_{r e d} \approx 2 k_{r} \frac{V_{\mathrm{NiO}}^{\mathrm{M}}}{V_{\mathrm{NiO}}^{f}}\left(p_{\mathrm{H}_{2} \mathrm{O}}^{e q}-p_{\mathrm{H}_{2} \mathrm{O}}^{o}\right)
$$


Thus, based on this model, the dependence of reduced layer thickness on reduction time at a given temperature should give insight into the nature of the reduction process.

Figure \#9 shows a schematic of the re-oxidation process. If the original $\mathrm{NiO}+\mathrm{YSZ}$ is fully dense, it is expected that after re-oxidation, $\mathrm{Ni}+$ YSZ should re-oxidize to a fully dense body. However, in the reduced state, if particle shape change of Ni occurs, which is likely due to faster diffusional creep in $\mathrm{Ni}$ as compared to $\mathrm{NiO}$, upon re-oxidation the newly formed $\mathrm{NiO}$ may have a different shape than the available cavity corresponding to the original $\mathrm{NiO}$ particle (in the as-sintered state). In such a case, the re-oxidized composite will not be fully dense, and there will be some porosity. Assuming molecular (or atomic) oxygen transport through the solid part (either $\mathrm{NiO}$ or YSZ or both) is negligible, during the re-oxidation stage, the required oxygen must be transported to the reaction front by gaseous diffusion through the porous interstices. Under this assumption, the kinetics of re-oxidation may be given by an equation of the form

$$
X^{2}+\frac{D_{e f f}^{o}}{R T k_{o}} X=\frac{4 D_{e f f}^{o}}{R T} \frac{V_{N i}^{M}}{V_{N i}^{f}}\left(p_{O_{2}}^{o}-p_{O_{2}}^{e q}\right) t
$$

where

$X=$ Thickness of the re-oxidized layer.

$V_{N i}^{M}=$ Molar volume of $\mathrm{Ni}, V_{N i}^{f}=$ Volume fraction of $\mathrm{Ni}$.

$p_{\mathrm{O}_{2}}^{o}=$ Partial pressure of oxygen in the oxidant (air).

$p_{\mathrm{O}_{2}}^{e q}=$ Equilibrium partial pressure of oxygen corresponding to the reaction

$$
\mathrm{Ni}(\mathrm{s})+{ }^{1} /{ }_{2} \mathrm{O}_{2}(\mathrm{~g}) \rightarrow \mathrm{NiO}(\mathrm{s})
$$

$D_{\text {eff }}^{o}=$ Effective binary diffusivity $\left(\mathrm{O}_{2}-\mathrm{N}_{2}\right)$ through pores of the re-oxidized $\mathrm{NiO}+\mathrm{YSZ}$ layer. and

$k_{o}=$ Rate constant which governs the oxidation of $\mathrm{Ni}$ to $\mathrm{NiO}$.

The remaining terms have the same meanings as before. Two limiting cases of this equation are as follows:

\section{a. $\boldsymbol{k}_{o}$ very large relative to $D_{\text {eff }}^{o}$ :}

In this case, the rate of re-oxidation at the reaction interface is sufficiently fast such that equation (27) reduces to

$$
X^{2} \approx \frac{4 D_{e f f}^{o}}{R T} \frac{V_{N i}^{M}}{V_{N i}^{f}}\left(p_{O_{2}}^{o}-p_{O_{2}}^{e q}\right) t
$$

That is, the re-oxidation reaction is diffusion-controlled and a plot of the square of the reoxidized layer thickness as a function of time should be linear, consistent with the parabolic law of re-oxidation kinetics. The above equation may be written as

$$
X^{2} \approx D_{o x} t
$$

where a phenomenological diffusion coefficient is defined by 


$$
D_{o x} \approx \frac{4 D_{e f f}^{o}}{R T} \frac{V_{N i O}^{M}}{V_{N i O}^{f}}\left(p_{O_{2}}^{o}-p_{O_{2}}^{e q}\right)
$$

\section{b. $k_{o}$ very small relative to $D_{\text {eff }}^{o}$ :}

In this case, equation (27) becomes

$$
X \approx 4 k_{o} \frac{V_{N i}^{M}}{V_{N i}^{f}}\left(p_{O_{2}}^{o}-p_{O_{2}}^{e q}\right) t
$$

In such a case, the re-oxidation reaction is interface-controlled and a plot of re-oxidized layer thickness as a function of time should be linear. The above equation may be written as

$$
X \approx k_{\text {ox }} t
$$

where a phenomenological interface parameter is defined by

$$
k_{o x} \approx 4 k_{o} \frac{V_{N i}^{M}}{V_{N i}^{f}}\left(p_{O_{2}}^{o}-p_{O_{2}}^{e q}\right)
$$

Thus, based on this model, the dependence of re-oxidized layer thickness on re-oxidation time at a given temperature should give insight into the nature of the re-oxidation process.

Powder mixtures consisting of 60 vol. $\% \mathrm{NiO}$ and 40 vol.\% YSZ were made and attrition milled for $24 \mathrm{~h}$. The powders were dried, screened and uniaxially pressed into rectangular bars. The samples were sintered at $1400^{\circ} \mathrm{C}$ for $2 \mathrm{~h}$. The sintered samples were then cut to a final dimension of approximately $15 \mathrm{~mm} \times 4 \mathrm{~mm} \times 4 \mathrm{~mm}$. The bulk density of the samples was determined by the Archimedes technique in accordance with ASTM C20-00. The samples were then reduced in a tube furnace under a flowing gas mixture of $10 \%$ hydrogen and $90 \%$ nitrogen in the temperature range 600 to $800^{\circ} \mathrm{C}$. Reduction experiments were conducted in 50-degree intervals in the range 600 to $800^{\circ} \mathrm{C}$ for various periods of time. Some of the samples were reduced for a time long enough to ensure that they were fully reduced. These samples were subsequently re-oxidized in air over a range of temperatures between 600 and $800^{\circ} \mathrm{C}$, and the re-oxidized layer thickness was measured as a function of time at temperature. Reduced and reoxidized layer thicknesses were measured using optical and scanning electron microscopy (SEM).

\section{Fuel Composition Effects on Anode Polarization:}

Cell Fabrication: While only measurements on one cell are reported, a number of cells were fabricated. Single cells consisted of a Ni + YSZ anode substrate, a Ni + YSZ anode interlayer, a YSZ-SDC bi-layer thin film electrolyte, a LSC + SDC cathode interlayer, and a LSC cathode current collector layer. The procedure for preparing an anode substrate and an anode interlayer was described elsewhere in detail [9], and is briefly described here. NiO and YSZ powders from commercial sources were mixed in requisite proportions and ball-milled in alcohol, dried and screened through a 150-mesh sieve. A circular disc of $\sim 1.2 \mathrm{~mm}$ thickness and $\sim 3 \mathrm{~cm}$ diameter was uniaxially die-pressed, and pre-sintered at $1000^{\circ} \mathrm{C}$ for one hour. The disc was then coated with a slurry of $\mathrm{NiO}+\mathrm{YSZ}$ anode interlayer and fired again at the same temperature for one hour to form a NiO + YSZ interlayer of $\sim 20 \mu \mathrm{m}$ thickness. YSZ and SDC 
layers were applied on the anode interlayer surface sequentially using YSZ and SDC suspensions made from YSZ and 20 mol.\% samarium-doped $\mathrm{CeO}_{2}$ powders, dispersed ultrasonically in appropriate amounts of suitable liquids. Then, the bi-layer electrolyte - anode substrate assembly was sintered in air at a temperature between 1400 and $1500^{\circ} \mathrm{C}$ to form a dense, well-bonded YSZ-SDC bi-layer electrolyte - anode structure. The thickness of the SDC layer was around $3 \mu \mathrm{m}$ and the total thickness of the YSZ-SDC bi-layer electrolyte thin film was $\sim 10 \mu \mathrm{m}$. The thin SDC layer, as part of the electrolyte, served as a barrier, which prevented a direct contact between YSZ and LSC. In this manner, the possible chemical reaction between YSZ and LSC, which can form insulating $\mathrm{La}_{2} \mathrm{Zr}_{2} \mathrm{O}_{7}$ during a hightemperature firing step, could be prevented.

The porous cathode interlayer was a composite of $50 \mathrm{wt} \%$ strontium-doped lanthanum cobaltite $\left(\mathrm{La}_{1-\mathrm{x}} \mathrm{Sr}_{\mathrm{x}} \mathrm{CoO}_{3-\delta}\right.$ (LSC), $\left.\mathrm{x}=0.3 \sim 0.7\right)$ and $50 \mathrm{wt} \%$ SDC. The cathode interlayer was applied by screen-printing, followed by firing at a temperature between 1050 and $1300^{\circ} \mathrm{C}$ for 2 hours to form a good bond between the SDC layer and the cathode interlayer. The thickness of the interlayer after firing was $\sim 20 \mu \mathrm{m}$. On top of the interlayer, a porous layer of LSC was applied, followed by firing at a temperature between 1050 and $1300^{\circ} \mathrm{C}$ for 1 hour in air. The final anode thickness and the disk diameter were respectively $1.1 \mathrm{~mm}$ and $27.7 \mathrm{~mm}$. The cathode area was $1.1 \mathrm{~cm}^{2}$.

The Measurement of Cell Performance: The cell was mounted in a test fixture, which consisted of an alumina tube and an alumina ring. The cell was secured between the alumina tube and the alumina ring and spring-loaded to ensure good sealing between the cell and the alumina tube using a flexible gasket. A silver mesh and a Ni mesh, used as current collectors at the cathode and the anode, respectively, were spring-loaded against, respectively, the cathode and the anode. Measurements were carried out at $800^{\circ} \mathrm{C}$, at one atmosphere total pressure (both fuel and air), and at predetermined, constant total flow rates of fuel or fuel mixture, and of air. The cell was reduced in situ at $800^{\circ} \mathrm{C}$ in a $10 \% \mathrm{H}_{2}+90 \% \mathrm{~N}_{2}$ mixture for several hours prior to measurements. The fuel flow-rate was maintained at $140 \mathrm{ml} / \mathrm{min}$, and the air flow-rate was maintained at $550 \mathrm{ml} / \mathrm{min}$, in all experiments. Open circuit potentials were measured under constant fuel flow over the anode and the airflow over the cathode.

Cell performance was measured using various fuel gas mixtures, which included as-received $\mathrm{H}_{2}$ (straight from the as-received cylinders $-99.99 \%$ pure $\mathrm{H}_{2}$ ), as-received $\mathrm{CO}$ (straight from the as-received cylinders $-99.99 \%$ pure $\mathrm{CO}$ ), $\mathrm{H}_{2}+\mathrm{CO}$ mixtures, $\mathrm{H}_{2}$ diluted with $\mathrm{He}, \mathrm{N}_{2}, \mathrm{CO}_{2}$, $\mathrm{H}_{2} \mathrm{O}$ and $\mathrm{CO}$ diluted with $\mathrm{CO}_{2}$. I-V curves were measured at various diluent concentrations, i.e. at various partial pressures of the diluent while the total flow rate of fuel mixture was kept constant. Current densities were calculated based on the cathode area. The fact that cathode area is different from the anode surface exposed to fuel introduces a small error (typically $<10 \%$ ) in the power density. This issue has been addressed in detail elsewhere [9]. Cell tests with as-received hydrogen were conducted without bubbling through a water bubbler.

Cell Characterization: Porosity of the Ni-YSZ anode was measured using the Archimedes method. The tested cell was broken into several small pieces. Dry weight, $W_{d r y}$, wet weight, $W_{\text {wet }}$, and weight in water, $W_{\text {water }}$, were measured using a high accuracy balance. Wet weight 
was measured (in air) soon after the surface of the sample was wiped dry, after boiling in water for two hours. Porosity was calculated according to the equation:

$$
\text { Porosity }=\frac{W_{\text {wet }}-W_{d r y}}{W_{\text {wet }}-W_{\text {water }}}
$$

One of the fractured pieces was evacuated (to remove air from the pores) and impregnated with an epoxy. After hardening the epoxy, the sample was polished down to $1 \mu \mathrm{m}$ finish. The microstructure of the cell was examined using scanning electron microscopy (SEM) and the mean pore radius was determined by quantitative stereology [8].

\section{RESULTS AND DISCUSSION}

\section{Nanosize YSZ Powder Synthesis:}

Figures \#10(a) and \#10(b) show XRD patterns of $\mathrm{Y}-\mathrm{BaZrO}_{3}$ powders made by calcining mixtures of $\mathrm{BaCO}_{3}, \mathrm{ZrO}_{2}$ and $\mathrm{Y}_{2} \mathrm{O}_{3}$, and mixtures of $\mathrm{BaCO}_{3}$ and $\mathrm{YSZ}$, respectively, at $1250^{\circ} \mathrm{C}$ for $2 \mathrm{~h}$. The patterns are almost identical and match the standard pattern for the cubic structure of perovskite, $\mathrm{BaZrO}_{3}$. Figure \#10(b) shows the presence of a single phase, perovskite structure. In Figure \#10(a), small peaks, indicating the existence of a small amount of a second phase, can be seen. Overlap of peaks prevents an unequivocal determination of the second phase. However, the peak positions of the second phase are consistent with cubic or tetragonal zirconia. Presumably, the precursor was not fully homogenized under the chosen calcination conditions. The results nevertheless show that yttria-doped $\mathrm{BaZrO}_{3}$ can be synthesized with either of the starting materials at a temperature of $1250^{\circ} \mathrm{C}$ or above. Figure $\# 11$ is an XRD pattern of a mixture of $\mathrm{Na}_{2} \mathrm{CO}_{3}$ and $\mathrm{YSZ}$ after calcining at $1250^{\circ} \mathrm{C}$ for $2 \mathrm{~h}$, which corresponds to monoclinic sodium zirconate, $\mathrm{Na}_{2} \mathrm{ZrO}_{3}$. Since $\mathrm{YSZ}$ was used instead of $\mathrm{ZrO}_{2}$, it is expected that $\mathrm{Na}_{2} \mathrm{ZrO}_{3}$ formed should be yttria-doped, i.e., Y-Na $\mathrm{ZrO}_{3}$. Again, XRD revealed that the reaction was complete and resulted in the formation of a single phase, within the accuracy of the XRD technique. A calcination temperature lower than $1050^{\circ} \mathrm{C}$ was not high enough to ensure the completion of the reaction, as evidenced by the lack of formation of a single phase material.

Chemical leaching of $\mathrm{BaO}$ from yttria-doped $\mathrm{BaZrO}_{3}\left(\mathrm{Y}-\mathrm{BaZrO}_{3}\right)$ precursor was achieved in a dilute $\mathrm{HNO}_{3}$ solution in water. The precursor was boiled in a dilute $\mathrm{HNO}_{3}$ acid solution, filtered and washed repeatedly until the solution $\mathrm{pH}$ was unchanged. Then, it was thoroughly washed using de-ionized water to completely remove $\mathrm{Ba}$ as $\mathrm{Ba}\left(\mathrm{NO}_{3}\right)_{2}$. The solution containing leachable ions was chemically analyzed to determine the concentrations of $\mathrm{Ba}, \mathrm{Y}$, and $\mathrm{Zr}$. The results showed (Table 1) a significant concentration of $\mathrm{Ba}^{2+}$ but only trace concentrations of $\mathrm{Zr}^{4+}$ and $\mathrm{Y}^{3+}$, confirming that $\mathrm{Ba}^{2+}$ was selectively dissolved and led to the formation $\mathrm{Y}_{2} \mathrm{O}_{3}-$ $\mathrm{ZrO}_{2}$, which is essentially insoluble in dilute $\mathrm{HNO}_{3}$, by a reaction such as

$$
\mathrm{Y}-\mathrm{BaZrO}_{3}+2 \mathrm{HNO}_{3} \rightarrow \mathrm{Ba}\left(\mathrm{NO}_{3}\right)_{2}+\mathrm{Y}_{2} \mathrm{O}_{3}-\mathrm{ZrO}_{2}+\mathrm{H}_{2} \mathrm{O}
$$

For the yttria-doped doped $\mathrm{Na}_{2} \mathrm{ZrO}_{3}\left(\mathrm{Y}-\mathrm{Na}_{2} \mathrm{ZrO}_{3}\right)$ precursor, since $\mathrm{Na}_{2} \mathrm{ZrO}_{3}$ readily reacts with water by a reaction such as

$$
\mathrm{Y}-\mathrm{Na}_{2} \mathrm{ZrO}_{3}+2 \mathrm{H}_{2} \mathrm{O} \rightarrow 2 \mathrm{NaOH}+\mathrm{Y}_{2} \mathrm{O}_{3}-\mathrm{ZrO}_{2}
$$

repeated boiling in de-ionized water, filtering and washing was adequate to completely remove $\mathrm{Na}_{2} \mathrm{O}$ as $\mathrm{NaOH}$. In this case also, the chemical analysis showed that the solution contained 
predominantly $\mathrm{Na}$, but only trace amounts of $\mathrm{Y}$ and $\mathrm{Zr}$ (Table 2). In order to determine the purity of the as-washed powders, chemical analysis was performed using Inductively Coupled Plasma (ICP) technique by dissolving YSZ powders synthesized using both precursors in concentrated $\mathrm{HCl}$. Table 3 gives the results of this analysis. It is seen that for the case of YSZ made with $\mathrm{Y}-\mathrm{Na}_{2} \mathrm{ZrO}_{3}$, the concentrations of $\mathrm{Zr}^{+4}$ and $\mathrm{Y}^{+3}$ in the solution are in accord with expected concentrations of $\mathrm{Zr}$ and $\mathrm{Y}$ in YSZ. However, in the case of YSZ made using $\mathrm{Y}$ $\mathrm{BaZrO}_{3}$, the concentration of $\mathrm{Y}^{+3}$ is lower than expected on the basis of the starting powder. This suggests that some of the yttrium was leached out in dilute $\mathrm{HNO}_{3}$. In both cases, the concentrations of $\mathrm{Na}^{+}$and $\mathrm{Ba}^{+2}$ are in the ppm level, indicating that the concentrations of these impurities in the powders are small (on the order of $\sim 0.5 \mathrm{wt} . \%$ or less in the respective YSZ powders). Some of this may, in part, be related to the possible incomplete washing of the powders, and not necessarily an indication of impurities dissolved in the YSZ powders.

XRD patterns of leached and washed powders synthesized from the two precursors are given in Figure \#12(a). In both cases, the XRD patterns of leached and washed powders were quite different from those of the corresponding precursors $\left(\mathrm{Y}-\mathrm{Na}_{2} \mathrm{ZrO}_{3}\right.$ and $\left.\mathrm{Y}-\mathrm{BaZrO}{ }_{3}\right)$. At the same time, the XRD patterns of the leached and washed powders were nearly identical, regardless of the precursor used, $\mathrm{Y}-\mathrm{Na}_{2} \mathrm{ZrO}_{3}$ or $\mathrm{Y}-\mathrm{BaZrO}_{3}$. Figure \#12(b) shows an XRD pattern of commercial YSZ. It is readily seen that the XRD patterns of leached and washed powders are similar to the commercial YSZ, insofar as peak positions are concerned. This shows that during leaching of the respective precursors, only $\mathrm{BaO}$ or $\mathrm{Na}_{2} \mathrm{O}$ are leached away resulting in a residue containing $\mathrm{Y}, \mathrm{Zr}$, and $\mathrm{O}$ such that the $\mathrm{Zr}-\mathrm{Y}-\mathrm{O}$ skeleton has either a cubic or a tetragonal symmetry. Large peak broadening observed in XRD patterns makes it impossible to determine whether the phase formed is cubic or tetragonal, since there is only a small difference in XRD patterns of the two phases. The XRD peaks in the patterns of leached powders are very broad indicative of a very fine particle size. This shows that very fine (nanosize) particles of YSZ can be formed starting with precursors $\left(\mathrm{Y}-\mathrm{BaZrO}_{3}\right.$ or $\left.\mathrm{Y}-\mathrm{Na}_{2} \mathrm{ZrO}_{3}\right)$, whose particle size is several microns.

The formation of nanosize powders, starting with coarse precursor powders, can be illustrated via the following example. Let us consider the reaction of $\mathrm{Y}-\mathrm{BaZrO}_{3}$ with dilute $\mathrm{HNO}_{3}$. The precursor, $\mathrm{Y}-\mathrm{BaZrO}_{3}$, is essentially insoluble in dilute $\mathrm{HNO}_{3}$. However, it can react with $\mathrm{HNO}_{3}$, as given by equation (36). Although the following illustration assumes that the formed structure of YSZ is cubic, the general conclusions concerning the accompanying volume change, leading to the formation of nanosize powders, are independent of the structure formed. The volume of a $\mathrm{Y}-\mathrm{BaZrO}_{3}$ unit cell is about $73.72 \mathrm{~A}^{3}$. One unit cell of cubic zirconia contains four formula units, i.e. 4 ' $\mathrm{ZrO}_{2}$ ' or 4 ' $\mathrm{Y}-\mathrm{ZrO}_{2}$ ', with a volume of $\sim 135.72 \mathrm{~A}^{3}$. Thus, per one formula unit, such as is created per one $\mathrm{Y}-\mathrm{BaZrO}_{3}$ unit cell, the volume is $135.72 / 4$ or 33.93 $\mathrm{A}^{3}$. That is, as $\mathrm{Y}-\mathrm{BaZrO}_{3}$ reacts with $\mathrm{HNO}_{3}$ to form $\mathrm{Y}-\mathrm{ZrO}_{2}$, there is a net change in volume from $73.72 \mathrm{~A}^{3}$ to $33.93 \mathrm{~A}^{3}$. This is equivalent to $\frac{(73.72-33.93)}{73.72} \times 100 \approx 54 \%$ decrease in volume. In terms of a linear change, this corresponds to $\frac{\sqrt[3]{73.72}-\sqrt[3]{33.93}}{\sqrt[3]{73.72}} \times 100 \approx 25 \%$ decrease in a linear dimension. As the surface of the precursor particle reacts with $\mathrm{HNO}_{3}$ to form soluble $\mathrm{Ba}\left(\mathrm{NO}_{3}\right)_{2}$, there is a substantial volume change and a linear change (a decrease), which should lead to cracks and fissures at the unit cell (A) level. 
This should thus lead to the formation of tiny fragments at the angstrom or nanometer level. As the product, $\mathrm{Y}-\mathrm{ZrO}_{2}$, is insoluble (or has a very low solubility) in the liquid used, Ostwald ripening, which requires dissolution, transport and reprecipitation, should not occur. Figure \#13 shows a schematic of the leaching process of $\mathrm{Y}-\mathrm{BaZrO}_{3}$ in dilute $\mathrm{HNO}_{3}$. The outer layer of the particle becomes porous since $\mathrm{BaO}\left(\right.$ as $\left.\mathrm{Ba}\left(\mathrm{NO}_{3}\right)_{2}\right)$ is leached out of $\mathrm{Y}-\mathrm{BaZrO}_{3}$. Further reaction occurs by the transport of $\mathrm{HNO}_{3}$ to the porous YSZ/dense $\mathrm{Y}-\mathrm{BaZrO}_{3}$ interface, reaction to form $\mathrm{Ba}\left(\mathrm{NO}_{3}\right)_{2}$ and $\mathrm{YSZ}$, and the transport of dissolved $\mathrm{Ba}\left(\mathrm{NO}_{3}\right)_{2}$ away from the interface, through the porous YSZ, into the acid bath. The porous YSZ is easily fragmented into a very fine powder. Thus, even though the original $\mathrm{Y}-\mathrm{BaZrO}_{3}$ powder is coarse, the resulting YSZ powder should be nanosize. A similar mechanism is expected to be operative during the synthesis of nanosize YSZ starting with $\mathrm{Y}-\mathrm{Na}_{2} \mathrm{ZrO}_{3}$. This is the origin of the molecular decomposition process for the synthesis of nanosize powders. The preceding also suggests that the initial precursor particle size should have no bearing on the final size of nanoparticles. Indeed, nanosize powder can be synthesized using precursors that are considerably coarse; for example several microns in size.

The Scherrer formula relates the average particle size, $d$, to X-ray peak broadening, $B$, by

$$
d=\frac{0.9 \lambda}{B \cos \theta}
$$

In order to determine the peak broadening attributable only to the particle size effect, a commercial YSZ powder was sintered at $1500^{\circ} \mathrm{C}$ for a few hours to obtain a strain-free, coarsegrained (grain size on the order of a few microns) sample. An XRD pattern of the sample was obtained. Peak width (at half the peak height) from this sample for a given $(h k l)$, in the present case (111), was subtracted from the corresponding peak width of the leached and washed powders. In this manner, line broadening attributable to the instrument as well as the presence of both $K \alpha_{1}$ and $K \alpha_{2}$, could be corrected for. The corrected peak width was measured to be approximately $4^{\circ}(\sim 0.07$ radians) for the case of the as-washed powders, which is equivalent to an average crystallite size of about a few nanometers ( $\sim 2$ to $\sim 3 \mathrm{~nm})$ for both of the as-washed powders (Table 4).

As an independent confirmation of the nanosize of the powders formed, specific surface area measurements were conducted using the BET adsorption isotherm method. The surface area measurements were made on both of the precursors $\left(\mathrm{Y}-\mathrm{Na}_{2} \mathrm{ZrO}_{3}\right.$ and $\left.\mathrm{Y}-\mathrm{BaZrO}{ }_{3}\right)$ and the synthesized powders. The specific surface area of the precursors was typically only $\sim 3 \mathrm{~m}^{2} / \mathrm{g}$ (Table 5), consistent with the large particle size of the precursors. The specific surface area of the naonosize powder made from the $\mathrm{Na}_{2} \mathrm{ZrO}_{3}$ precursor, however, was measured to be around $67 \mathrm{~m}^{2} / \mathrm{g}$. Assuming particles to be spherical for simplcity, the diameter of the particle can be estimated from the relation

$$
d=\frac{6}{S \rho}
$$

where $\rho$ is the density of YSZ and $S$ is the specific surface area. Assuming $\rho=5.9 \mathrm{~g} / \mathrm{cm}^{3}$ for YSZ and $67 \mathrm{~m}^{2} / \mathrm{g}$ for $S$ (measured by BET), the diameter is estimated to be $\sim 15 \mathrm{~nm}$. Thus, specific surface area measurement also shows that the synthesized powder is indeed nanosize. However, the estimated particle size from surface area measurements is about 5 to 6 times greater than that estimated from XRD peak broadening. A possible reason for this may be the formation of agglomerates. In order to explore this possibility, samples were examined by 
transmission electron microscopy (TEM) on JEOL 4000FX TEM. For TEM examination, a sample of YSZ powder synthesized using $\mathrm{Y}-\mathrm{BaZrO}_{3}$ was suspended in alcohol, and vibrated ultrasonically. Figure \#14(a) shows a bright field image of the sample at 25,000 X. It is seen that the observed particles, which are agglomerates, are in the range of 50 to $200 \mathrm{~nm}$ in size. A higher magnification image $(1,000,000 \mathrm{X})$ in Figure \#14(b) shows lattice fringes of individual particles in the agglomerates. As evident from this micrograph, the individual crystallite size is about $5 \mathrm{~nm}$, in reasonably good agreement with an estimate based on XRD peak broadening. The lattice image also shows that the as-synthesized powder is crystalline and not amorphous.

The above results conclusively demonstrate that nanosize YSZ powder can be effectively prepared by the molecular decomposition approach using alkali or alkaline earth metal oxide precursors. XRD patterns of the YSZ obtained from the two precursors are consistent with the formation of cubic zirconia. However, it is known that XRD peaks of cubic and tetragonal zirconia are very similar and thus difficult to delineate, especially when the peaks are rather broad. Thus, XRD is not a very good technique for distinguishing between cubic and tetragonal zirconia, especially if the crystallite size is in the nanometer range. However, Raman spectra of cubic, tetragonal and monoclinic zirconia are quite different. For this reason, selected samples were examined by Raman spectroscopy, the results of which are discussed below.

Figures \#15(a) and \#15(b) are Raman spectra of monoclinic $\mathrm{ZrO}_{2}$ and cubic $\left(8 \mathrm{~mol} \% \mathrm{Y}_{2} \mathrm{O}_{3}\right.$ doped) zirconia obtained commercial vendors, respectively. It is seen that the spectra of these two materials are quite different. The cubic structure of zirconia is characterized by, a broad peak between 600 and $650 \mathrm{~cm}^{-1}$, while the monoclinic spectrum contains several sharp lines. These results are similar to the ones reported in the literature. A spectrum of the tetragonal phase is known to exhibit characteristic lines at $260 \mathrm{~cm}^{-1}, 500 \mathrm{~cm}^{-1}$, and $640 \mathrm{~cm}^{-1}$. Figure $\# 15$ (c) shows a spectrum of the as-synthesized nanosize powder made using $\mathrm{Y}-\mathrm{BaZ}_{\mathrm{rO}}$. Note that, this pattern is also characterized by the existence of rather broad peaks. The pattern shows no evidence of either the monoclinic or the tetragonal phases, and is similar to the cubic spectrum. Figure \#15(d) is a spectrum of the synthesized powder after a thermal treatment at $1000^{\circ} \mathrm{C}$ for $5 \mathrm{~h}$. This spectrum is also characterized by the presence of broad peaks. Peaks representative of monoclinic phase are absent. However, the presence of humps at $\sim 260 \mathrm{~cm}^{-1}$ and $\sim 640 \mathrm{~cm}^{-1}$ may indicate the possible existence of a mixture of cubic and tetragonal phases. Note, however, that the same peaks are present in commercial YSZ as well.

In order to examine possible changes in the crystal structure of the synthesized nanosize YSZ powders, Differential Thermal Analysis (DTA) on the as-washed powders was conducted. In addition, XRD patterns were obtained on powders after heat-treating the as-washed powders at various temperatures. Figure \#15 shows the DTA traces of YSZ nanopowders synthesized from both precursors. The peaks centered at $\sim 235^{\circ} \mathrm{C}$ in the two traces are attributed to endothermic desorption of adsorbed water. The traces also show broad exothermic peaks in the temperature range from $\sim 300$ to $\sim 600^{\circ} \mathrm{C}$. An exothermic peak is usually attributed to the crystallization process, provided the as-formed powders are amorphous. In the present case, the assynthesized powder is crystalline and not amorphous, as seen in the TEM micrograph given in Figure \#15(b), unlike some other YSZ powders prepared by sol-gel or chemical coprecipitation. In such cases, the exothermic peak due to the crystallization, is generally well defined and sharp. In the present work, by contrast, the exothermic peak is very broad for 
powders made using either of the precursors, but more so in the case of nanosize YSZ powder made from $\mathrm{Y}-\mathrm{BaZrO}_{3}$ precursor, indicating that there is neither the occurrence of a distinct crystallization, nor the occurrence of a phase transition over the temperature range investigated. The broad exothermic peak may be attributed to the possible removal of point defects, and/or the occurrence of particle growth during the thermal treatment. The occurrence of particle growth during thermal treatment can be readily verified by XRD examination of nano YSZ powders heat-treated at various temperatures.

Figure \#17 shows the XRD spectra of nanosize YSZ powders, synthesized from $\mathrm{Y}-\mathrm{BaZrO}_{3}$, thermally treated at various temperatures. It is seen that the crystal structure of the YSZ powder is essentially unaffected by the thermal treatment, all the way up to $1000^{\circ} \mathrm{C}$, the maximum temperature to which the synthesized powders were heated. The structure of YSZ appears to be cubic, although the presence of a small amount of tetragonal phase cannot be ruled out. The possible presence of tetragonal phase will cause splitting of (200) and (220) peaks from the original peaks into $(200) /(002)$ and $(220) /(202)$ doublets. The approximate peak positions for these two sets of peaks (with $\mathrm{CuK} \alpha$ radiation) are $\sim 30.95^{\circ}$ and $\sim 50.27^{\circ}$, respectively. XRD pattern of the powder after $5 \mathrm{~h}$ at $1000^{\circ} \mathrm{C}$ given in Figure 8 shows that there is no evidence of peak splitting indicating that even after $5 \mathrm{~h}$ at $1000^{\circ} \mathrm{C}$, the powder remains cubic. Very small peaks observed in these patterns at $\sim 43.3^{\circ}$ and $\sim 54.05^{\circ}$ are due to the incomplete removal of the original precursor, $\mathrm{Y}-\mathrm{BaZrO}_{3}$. As the temperature of heat treatment is increased, the peak height increases at the expense of peak width, consistent with the occurrence of particle growth. The estimated particle size of the powders after heat treatment at $1000^{\circ} \mathrm{C}$ is about $37 \mathrm{~nm}$, showing that the nanosize particles are relatively stable against significant growth at temperatures as high as $1000^{\circ} \mathrm{C}$.

Nanosize YSZ obtained from $\mathrm{Y}-\mathrm{Na}_{2} \mathrm{ZrO}_{3}$ precursor was similarly subjected to various thermal treatments. The corresponding XRD patterns are given in Figure \#18, and the dependence of the particle size on the temperature of heat treatment is given in Table 4. It is seen that in this case also, even after heat treating at $1000^{\circ} \mathrm{C}$ for $5 \mathrm{~h}$, the average particle size is only about 31 $\mathrm{nm}$. This shows that nanosize powder derived from $\mathrm{Y}-\mathrm{Na}_{2} \mathrm{ZrO}_{3}$ is also stable against significant particle growth, up to $1000^{\circ} \mathrm{C}$ for $5 \mathrm{~h}$. However, the XRD pattern of the powder heat treated at $1000^{\circ} \mathrm{C}$ shows the presence of a small amount of monoclinic phase (characterized by two small peaks on either side of the (111) peak at $\sim 30.05^{\circ}$ ). It is not clear if this is the result of possible low-level sodium as an impurity. The other possibility is that in the original precursor formulation, not all of the $\mathrm{Na}_{2} \mathrm{ZrO}_{3}$ was doped with $\mathrm{Y}_{2} \mathrm{O}_{3}$. That is, there may be have been some $\mathrm{Na}_{2} \mathrm{ZrO}_{3}$ present with little or no $\mathrm{Y}_{2} \mathrm{O}_{3}$ dissolved in it. The presence of some undoped $\mathrm{Na}_{2} \mathrm{ZrO}_{3}$ cannot be ruled out on the basis of $\mathrm{XRD}$ results. If some undoped $\mathrm{Na}_{2} \mathrm{ZrO}_{3}$ is present, it is expected to form nanosize, undoped $\mathrm{ZrO}_{2}$ upon boiling in water. The as-synthesized, undoped zirconia is expected to be cubic rather than monoclinic by virtue of the lower surface energy of the cubic phase compared to the monoclinic phase. When heated to a high temperature where growth of particles occurs, the monoclinic phase will become the stable phase. The formation of some monoclinic phase when heated to $1000^{\circ} \mathrm{C}$, as evidenced in Figure \#18, may be related to the possible existence of some undoped $\mathrm{Na}_{2} \mathrm{ZrO}_{3}$ in the precursors. Table 4 gives the average particle size of YSZ powders, treated at various temperatures after synthesis, calculated from the Scherrer formula using the half peak widths from the XRD patterns given in Figures $\# 17$ and \#18. The particle sizes of YSZ from both 
precursors are similar, which are in the range from a few nanometers to tens of nanometers after thermal treatment at a temperature as high as $1000^{\circ} \mathrm{C}$. An investigation of the sinterability of YSZ powders made by the present process, and the measurement of ionic conductivity of sintered samples is underway. The results of these studies will be reported in a separate communication.

\section{Cathode Area Effect:}

Cell Microstructure and Dimensions: Figures \#19(a) and \#19(b) show scanning electron micrographs of the two cells with different cathode areas; $\sim 1.1 \mathrm{~cm}^{2}$ and $\sim 2 \mathrm{~cm}^{2}$. Note that the electrolyte thicknesses are essentially identical, and so are the thicknesses of cathodic and anodic interlayers. It is also seen that electrode microstructures are similar.

Cell Performance with Circular Cathodes: Figures \#20 and \#21 show voltage, $V$, vs. current density, $i$, (as-determined on the basis of cathode area) traces, as well as power density (as determined on the basis of the cathode area) vs. $i$, for cells with cathode areas of $\sim 1.1 \mathrm{~cm}^{2}$ and $\sim 2 \mathrm{~cm}^{2}$, tested at 800 and $750^{\circ} \mathrm{C}$, respectively. Note that the maximum power density measured for the cell with the smaller cathode is $\sim 1.65 \mathrm{~W} / \mathrm{cm}^{2}$, while that for the larger cathode is $\sim 1.45 \mathrm{~W} / \mathrm{cm}^{2}$ at $800^{\circ} \mathrm{C}$. At $750^{\circ} \mathrm{C}$, the maximum power density for the cell with the smaller cathode is $\sim 1.3 \mathrm{~W} / \mathrm{cm}^{2}$, while that for the cell with the larger cathode is $\sim 1.25 \mathrm{~W} / \mathrm{cm}^{2}$. The preceding shows that the difference at $800^{\circ} \mathrm{C}$ is about $\sim 0.2 \mathrm{~W} / \mathrm{cm}^{2}$ and at $750^{\circ} \mathrm{C}$, it is about $\sim 0.05 \mathrm{~W} / \mathrm{cm}^{2}$. That is, the difference in power densities is rather modest, even when the cathode area in the cell with the larger cathode is almost twice as large as the cell with the smaller cathode area. A preliminary conclusion is that there is a small difference, which decreases with decreasing temperature.

Figure \#22 shows the plots of ohmic contribution (IR drop) as a function of current density, $i$, (on the basis of the cathode area) at $800^{\circ} \mathrm{C}$ for the two cells with cathodes of circular areas. As can be seen, the two plots overlap showing that there is virtually no discernible difference. This is consistent with the analysis presented here. The results of tests at $750^{\circ} \mathrm{C}$ were similar.

Figure \#23 shows the plots of measured cathodic overpotential as a function of current density, $i$, at $800^{\circ} \mathrm{C}$ for the two cells with circular cathodes of different areas. In this case also, it is readily seen that the two plots are virtually identical, which essentially overlap. The results of the tests at $750^{\circ} \mathrm{C}$ were similar.

Figure \#24 shows the plots of measured anodic overpotential vs. current density at $800^{\circ} \mathrm{C}$, for cells with circular cathodes of two different areas, namely, $\sim 1.1 \mathrm{~cm}^{2}$ and $\sim 2 \mathrm{~cm}^{2}$. The figure shows that the anodic overpotential is larger for the cell with the larger cathode area, in qualitative agreement with the analysis presented here, and the plots given in Figure \#5. The results of the tests at $750^{\circ} \mathrm{C}$ were similar, with the exception that the difference in overpotentials was even smaller.

Figure \#25 shows plots of voltage, $V$, vs. current density, $i$, and power density vs. $i$, for cell with semicircular cathodes individually, and shorted with an external wire. Note that the $V$ vs. $i$ as well as power density vs. $i$ traces with the two semicircular cathodes are identical, while for 
the one shorted are slightly lower. Figure \#26 shows the measured anodic overpotentials vs. $i$. Note that the plots for the two semicircular cathodes are identical, with the one for the two cathodes shorted being slightly higher, again consistent with the analysis. A quantitative comparison with the analytical results is difficult, however, due to the complicated nature of the cathode geometries. Nevertheless, the effect of asymmetric cathode on anodic polarization, principally anodic concentration polarization, is quite clear. By contrast, the ohmic contribution (Figure \#27) and cathodic overpotentials (Figure \#28) were virtually identical for the individual semicircular cathodes, as well as for shorted cathodes.

Figures \#22 and \#23 show that the cathodic overpotentials as well as the ohmic drops are virtually the same for two circular cathodes of differing areas. Similar conclusions are arrived at for cells with semicircular cathodes (Figures \#27, and \#28). This is in accord with expectations.

Figure \#5 shows the plots of calculated anodic concentration polarization, $\eta_{\text {conc(a) }}$, vs. current density, $i$, calculated for two values of cathode radii; $0.5 \mathrm{~cm}$ and $1 \mathrm{~cm}$, with an anode radius of $1.3 \mathrm{~cm}$. It is readily seen that the dependence of the calculated $\eta_{\text {conc(a) }}$ on. $i$ plots is qualitatively similar to that observed experimentally. For the experimental data shown in Figure \#24, not all of the relevant parameters were known; for example, $i_{a s}, p_{H_{2}(0)}$ and $p_{\mathrm{H}_{2} \mathrm{O}(0)}$, were not known. As is evident from equation (18), an accurate knowledge of $p_{\mathrm{H}_{2}(0)} / p_{\mathrm{H}_{2} \mathrm{O}(0)}$ is especially important since this ratio can vary over a wide range; from say $\sim 33$, for $3 \%$ water vapor in the fuel to say $\sim 9$, for $10 \%$ water in the fuel. Alternatively, from equation (19), it is clear that the partial pressure of $\mathrm{H}_{2} \mathrm{O}$ in the fuel has a significant effect on concentration polarization. In the absence of this information, $\eta_{\operatorname{conc}(a)}$ vs. $i$ curve cannot calculated for comparison with the experimental results. However, a comparison between the two plots in Figure \#24 for different cathode areas (radii) may be made as follows.

For the cell with cathode area of $\sim 2 \mathrm{~cm}^{2}\left(r_{c} \approx 0.8 \mathrm{~cm}\right)$, the open circuit voltage (OCV) was $1.018 \mathrm{~V}$. At $800^{\circ} \mathrm{C}$, this corresponds to a $p_{H_{2}(0)} / p_{H_{2} O(0)} \approx 5.91$. A lower value of $p_{\mathrm{H}_{2}(0)} / p_{\mathrm{H}_{2} \mathrm{O}(0)}$ than a typical practical fuel cell may be the result of some air leakage into the fuel stream. A value of $i_{a s}$ estimated for the best fit to the experimental data given in Figure $\# 24$ is $\sim 5.6 \mathrm{~A} / \mathrm{cm}^{2}$. The OCV for the cell with a cathode area of $\sim 1.1 \mathrm{~cm}^{2}\left(r_{c} \approx 0.6 \mathrm{~cm}\right)$ was $\sim 1.021 \mathrm{~V}$. The corresponding value of $p_{H_{2}(0)} / p_{H_{2} O(0)}$ is 6.296. From these results, and equation (18), the estimated value of $i_{a s}$ is $7.62 \mathrm{~A} / \mathrm{cm}^{2}$. Using this value of $i_{a s}$, and $p_{\mathrm{H}_{2}(0)} / p_{\mathrm{H}_{2} \mathrm{O}(0)} \approx 6.296, \eta_{\text {conc(a) }}$ was calculated at various values of current density. The calculated values of $\eta_{\text {conc }(a)}$ are compared with the experimental results in Figure \#29. Note that there is qualitative agreement between the experimental results and prediction, insofar as the general trends are concerned. An exact agreement is not to be expected as the calculations only give $\eta_{\text {conc (a) }}$, while the experimental measurements also include anodic activation polarization. Also, the assumptions made in developing simple analytical relations are not 
sufficiently rigorous to expect an exact agreement. In addition, the neglect of viscous flow in the derivation of anodic concentration polarization, and the assumption of fixed $D_{\text {eff }(a)}$, probably are other sources of uncertainty. Finally, there are critical issues concerning the placement of reference electrodes, which imply that there also are uncertainties in the exact measurement of anodic and cathodic overpotentials.

The value of $i_{a s}$ corresponding to the best fit in Figure \#24 is about $5.6 \mathrm{~A} / \mathrm{cm}^{2}$. From this value and equation (16), the effective anode diffusivity, $D_{\text {eff }(a)}$, can be estimated. This value turns out to be $\sim 0.31 \mathrm{~cm}^{2} / \mathrm{sec}$. Indeed, this value is close to that deduced by curve fitting a previously developed theoretical model to voltage, $V$, vs. current density, $i$, traces $[4,5]$. An important point to note is that the estimated $i_{a s}$ is not necessarily the short-circuit current density measured experimentally. An examination of Figures \#22, \#23, and \#24 shows that at any current density, anodic overpotential is lower than either the ohmic overpotential or the cathodic overpotential. That is, the experimental short circuit current density is largely due to these two overpotentials instead of the anode-limiting short circuit current density, $i_{a s}$.

The preceding discussion suggests that in the case of cathode-supported cells with a smaller anode compared to the cathode, qualitatively similar effects would be observed; i.e., in this case the cathodic concentration polarization will be smaller, the smaller is the anode area relative to the cathode area. In general, however, cathodic concentration polarization is expected to be greater due to the lower binary diffusivity of $\mathrm{O}_{2}-\mathrm{N}_{2}$ compared to that of $\mathrm{H}_{2}-\mathrm{H}_{2} \mathrm{O}$. As a consequence, it is expected that the effect of asymmetric electrodes would be more pronounced in the case of cathode-supported cells than in the case of anode-supported cells.

\section{Effect of Cathode Microstructure:}

Figure $\# 30$ shows typical voltage vs. current density traces for two cells tested at $800^{\circ} \mathrm{C}$ with humidified hydrogen and air. Note that cell performance is dependent on cathode interlayer composition, with the maximum power density ranging between $\sim 0.35 \mathrm{~W} / \mathrm{cm}^{2}$ and $\sim 1.1$ $\mathrm{W} / \mathrm{cm}^{2}$, depending upon the cathode interlayer composition. Figure \#31 shows a plot of the maximum power density measured as a function of wt.\% LSM in the cathode interlayer.

Figure \#32 is a photomicrograph of the cathode interlayer of composition $35 \mathrm{wt} . \%$ LSM and 65 wt.\% YSZ, obtained on Cameca SX 50 electron microprobe. The length and width of the micrograph are $\sim 18.3 \mu \mathrm{m}$ and $\sim 13.6 \mu \mathrm{m}$, respectively. White areas are YSZ, gray areas are LSM, and black regions represent porosity. Table 6 lists results of the microstructural measurements made on the cells tested.

Figure \#31 shows that the maximum power density depends on the composition of the cathode interlayer, all other factors remaining the same. Table 6 shows that there is a significant variation in the microstructural parameters as a function of cathode interlayer composition, the most notable being the three phase boundary length, $l_{T P B}$, which varies between $\sim 1780$ and $\sim 6550 \mathrm{~cm}^{-1}$. Also of interest to note is that the YSZ aggregate grain size, $d$, of the sample with the least amount of LSM was one and a half to three times that of the other samples. The 
cathode interlayer compositions were chosen such that all three phases are contiguous. The contiguity of LSM was confirmed by measuring the in-plane resistance of the cathode interlayer. Specifically, it was ensured that the layer was not insulating at room temperature, which would have been the case had LSM not been contiguous. The $V_{Y S Z}$ was above 0.34 in all samples, and thus is expected to be contiguous. The $V_{v}$ was between $\sim 0.14$ and $\sim 0.19$. For a random distribution of near spherical particles, the usual guideline for contiguity is that the volume fraction of a given phase be in excess of $\sim 0.3$ (the percolation threshold). This condition is not satisfied. However, it is to be noted that in a typical sintered compact, porosity is usually along three-grain junctions of a three dimensional, polyhedral packing, which is in the form of cylindrical, not spherical, pores. It is well known that porosity in a sintered compact becomes isolated (noncontiguous) below about $6 \%$ ( 0.06 on a volume fraction basis). As the porosity in the cathode interlayer is well in excess of the minimum $(\sim 0.06)$, the porosity was indeed contiguous. The porosity in the rest of the cathode current collector layer, anode interlayer,

and the supporting anode structure was well in excess of $20 \%$, and thus was contiguous.

It is readily seen that the weight fraction of LSM, namely, $W_{L S M}$, is given by

or

$$
\begin{aligned}
W_{L S M} & =\frac{\lambda_{L S M} V_{L S M}}{\lambda_{L S M} V_{L S M}+\lambda_{Y S Z} V_{Y S Z}} \\
\frac{1}{W_{L S M}} & =1+\frac{\lambda_{Y S Z}}{\lambda_{L S M}} \frac{V_{Y S Z}}{V_{L S M}}
\end{aligned}
$$

where $\lambda$ 's are the respective densities. Thus, a plot of $1 / W_{L S M}$ vs. $V_{Y S Z} / V_{L S M}$ should be a straight line with slope $=\lambda_{Y S Z} / \lambda_{L S M}$, and intercept $=1.0$. Figure \#33 shows that a plot of $1 / W_{L S M}$ from the as-formulated cathode interlayer, vs. $V_{Y S Z} / V_{L S M}$ obtained from microstructural measurements, is indeed a straight line. The slope of the line is $\sim 1.02$. It is known that the densities of YSZ and LSM, are respectively, $\sim 5.9$ and $\sim 6.5 \mathrm{~g} / \mathrm{ml}$, the ratio of which is $\sim 0.91$, in reasonable agreement with expectations. Also note that the intercept is $\sim 0.986$, which is very close to the expected value of unity.

The effect of electrode microstructure on charge transfer at three phase boundaries in composite electrodes was theoretically analyzed by Tanner et. al. who showed that the effective charge transfer resistance, $R_{c t}^{e f f}$, of a composite electrode is given by [2]

$$
R_{c t}^{e f f} \approx \sqrt{\frac{R_{c t} \rho_{Y S Z} d}{\left(1-V_{v}\right)}}
$$

where $\rho_{Y S Z}$ is the ionic resistivity of YSZ, a constituent in the cathode, and $R_{c t}$ is the intrinsic charge transfer resistance, which depends on the electrocatalyst-electrolyte pair, here LSM and YSZ, the particle size of LSM and the number density per unit area, the latter two parameters effectively defining the three phase boundary (TPB) length, $l_{T P B}$. In terms of the charge 
transfer resistivity, $\rho_{c t}^{\prime}$, width, $\varepsilon$, and thickness, $\delta$, through which charge transfer occurs, and $l_{T P B}$, the intrinsic charge transfer resistance, $R_{c t}$, is given by

$$
R_{c t}=\frac{\rho^{\prime}{ }_{c t} \delta}{\varepsilon l_{T P B}}
$$

The parameters $\delta$ and $\varepsilon$ are on the order of a few angstroms, dimensions over which the actual charge transfer reaction occurs. Parameters, $\rho_{c t}^{\prime}, \delta$ and $\varepsilon$ are not separable from each other. Thus, one can define an intrinsic charge transfer resistivity, $\rho_{c t}$, by

$$
\rho_{c t}=\frac{\rho_{c t}^{\prime} \delta}{\varepsilon}
$$

and the intrinsic charge transfer resistance is then given by

$$
R_{c t}=\frac{\rho_{c t}}{l_{T P B}}
$$

Substitution of $R_{c t}$ in equation (42) gives

$$
R_{c t}^{e f f} \approx \sqrt{\rho_{Y S Z} \rho_{c t}} \sqrt{\frac{d}{\left(1-V_{v}\right) l_{T P B}}}
$$

The measured area specific resistance includes contributions from the electrolyte resistance, the anode interlayer, the anode support, and the cathode current collector. However, these other contributions are the same for all of the cells tested in the present study. Let us denote these other contributions by $R_{\text {other }}$ such that the area specific resistance of each cell tested is given by

$$
R_{\text {cell }}=R_{\text {other }}+R_{c t}^{e f f}=R_{\text {other }}+\sqrt{\rho_{Y S Z} \rho_{c t}} \sqrt{\frac{d}{\left(1-V_{v}\right) l_{T P B}}}
$$

Microstructural measurements and analysis allows one to determine the parameter $\sqrt{d /\left(\left(1-V_{v}\right) l_{T P B}\right)}$, while $R_{\text {cell }}$ is determined from experimentally measured voltage, $V$, vs. current density, $i$, traces. Thus, a plot of $R_{c e l l}$ vs. $\sqrt{d /\left(\left(1-V_{v}\right) l_{T P B}\right)}$ gives $R_{\text {other }}$ as the intercept, and $\sqrt{\rho_{Y S Z} \rho_{c t}}$ as the slope. Since the $\rho_{Y S Z}$ is known from independent measurements, from the slope one can determine $\rho_{c t}$, the fundamental parameter which determines the charge transfer resistivity at LSM/YSZ/air three phase boundary, exclusive of any microstructural effects. This parameter is the most fundamental one, which may be used to compare various electrocatalyst/electrolyte pairs.

Table 7 lists the measured $R_{\text {cell }}$ and the microstructural parameter $\sqrt{d /\left(\left(1-V_{v}\right) l_{T P B}\right)}$. Figure \#34 is a plot of $R_{\text {cell }}$ vs. $\sqrt{d /\left(\left(1-V_{v}\right) l_{T P B}\right)}$. The slope of the plot is $2110 \Omega \mathrm{cm}$ with a regression coefficient of $\sim 0.98$. The ionic resistivity of $\mathrm{YSZ}$ at $800^{\circ} \mathrm{C}$ is about $40 \Omega \mathrm{cm}$. Thus, the estimated value of the charge transfer resistivity, $\rho_{c t}$ is $\sim 1.11 \times 10^{5} \Omega \mathrm{cm}$. This is an interesting result in that it has been possible to estimate the fundamental parameter, which determines charge transfer characteristics at a LSM/YSZ/air three phase boundary. This suggests that a correct comparison between two electrocatalysts can only be made on the basis 
of $\rho_{c t}$, which is free from any microstructural effects. The other interesting point is that the present results clearly and quantitatively emphasize the importance of electrode microstructure, and the role of composite electrodes. It shows, for example, that through appropriate electrode microstructures, it is possible to achieve very low overall electrode polarization even if the intrinsic charge transfer characteristics, as expressed through $\rho_{c t}$, are not particularly good. The intercept in Figure \#34 should yield $R_{\text {other }}$, the expected value of which is $\sim 0.1 \Omega \mathrm{cm}^{2}$, based on prior work [10]. However, intercept in Figure \#34 is $\sim-0.11 \Omega \mathrm{cm}^{2}$, which of course cannot be true. A possible reason is the scatter in data and the fact that cathodic polarization is the dominant factor. That is, since $R_{\text {other }}$ is expected to be rather small, a negative intercept is believed to be merely due to scatter, and insufficient data. Thus, the slope appears to be reasonable, but the intercept is not. Although without any basis, one may plot $R_{\text {cell }} \mathrm{vs} .1 / l_{T P B}$, a typical procedure used in plotting data when the electrode is not a composite one (that is LSM on YSZ, rather than LSM + YSZ on YSZ), as done in Figure \#35. Even though the intercept is reasonable, the corresponding regression coefficient is only $\sim 0.84$, indicating a poorer fit. If the last data point is ignored, the fit will be considerably better, although then the intercept is not reasonable. In any event, there is no basis to ignore this point. It is thus concluded that the composite model offers a better fit to the data, although considerably more data are needed for an unequivocal assertion.

In the preceding, it was assumed that activation polarization, $\eta_{a c t}$, is linearly dependent on $i$, and can be expressed in terms of $R_{c t}^{e f f}$. At high current densities, it is expected that $\eta_{a c t}$ may be linearly related to $\ln i$ through the Tafel equation. If such is the case, the mathematical relationship between $\eta_{a c t}$ and microstructure will be different from the one implied in equation (47). Nevertheless, it is clear that the role of electrode microstructure will be equally profound, regardless of the details of relationship between $\eta_{a c t}$ and $i$.

\section{Alcohol as a Fuel:}

Figure \#36 is a scanning electron micrograph (SEM) of a cell, fractured after testing. Five distinct layers are visible in the micrograph. The anode substrate was optimized to facilitate rapid transport of large fuel molecules, such as $\mathrm{CH}_{3} \mathrm{OH}$ and $\mathrm{C}_{2} \mathrm{H}_{5} \mathrm{OH}$. Microstructures of the anode and cathode interlayers, which are electrochemically active regions for the occurrence of the anode and cathode reactions, respectively, are relatively fine as can be seen in the inset. Recent theoretical modeling by Tanner, et al. [2] emphasizes the importance of electrode microstructure on the effective charge transfer resistance, a measure of electrode electrochemical activity. The effective charge transfer resistance was shown to be proportional to the square root of a microstructural feature of an electrode, e.g. the grain size [2]. Thus, the finer the electrode microstructure, the smaller is the effective charge transfer resistance, and the higher is the effective exchange current density. The microstructures of the anode and the cathode in the present study were optimized to enhance the overall electrode reaction rate.

Figure \#37 shows performance characteristics of such a cell with hydrogen, methanol and ethanol + water (1:1 in volume) as fuels. Open circuit voltages (OCV) with $\mathrm{H}_{2}$, methanol and 
ethanol + water as fuels, were, respectively, $1.005 \mathrm{~V}, 0.978 \mathrm{~V}$ and $0.95 \mathrm{~V}$. A slightly lower OCV with $\mathrm{H}_{2}$ than the theoretical value $(\sim 1.04 \mathrm{~V})$ was probably due to some leakage of air through the seal. Lower values of OCV with methanol, and ethanol + water, as fuels, may also be due to possible non-equilibrium conditions. At $800^{\circ} \mathrm{C}$, the maximum power density was measured to be $1.7 \mathrm{~W} / \mathrm{cm}^{2}$ with hydrogen, $1.3 \mathrm{~W} / \mathrm{cm}^{2}$ with $\mathrm{CH}_{3} \mathrm{OH}$ and $0.8 \mathrm{~W} / \mathrm{cm}^{2}$ with $\mathrm{C}_{2} \mathrm{H}_{5} \mathrm{OH}+\mathrm{H}_{2} \mathrm{O}$ (1:1 in volume). The actual power densities could be between 5 and $10 \%$ lower due to differences in cathode and anode diameters. These data demonstrate that the cells made in the present work can be successfully operated on alcohols while yielding high power densities. With $\mathrm{C}_{2} \mathrm{H}_{5} \mathrm{OH}+\mathrm{H}_{2} \mathrm{O}$ as the fuel, although a fairly high power density of $0.8 \mathrm{~W} / \mathrm{cm}^{2}$ at $800^{\circ} \mathrm{C}$ was achieved, the cell performance was still much lower than with either $\mathrm{CH}_{3} \mathrm{OH}$ or $\mathrm{H}_{2}$. The possible reasons include: (1) Higher concentration polarization due to the larger molecular weight of $\mathrm{C}_{2} \mathrm{H}_{5} \mathrm{OH}$. (2) Higher activation polarization. Further optimization of electrode microstructures may be necessary to improve performance with $\mathrm{C}_{2} \mathrm{H}_{5} \mathrm{OH}$ as a fuel. To the authors' knowledge, power densities measured here with $\mathrm{CH}_{3} \mathrm{OH}$ and $\mathrm{C}_{2} \mathrm{H}_{5} \mathrm{OH}$ as fuels, are by far among the highest values reported on SOFC directly using $\mathrm{CH}_{3} \mathrm{OH}$ and $\mathrm{C}_{2} \mathrm{H}_{5} \mathrm{OH}$ as fuels, and significantly higher than polymer electrolyte based direct methanol fuel cells (DMFC).

Figure \#38 shows cell performance with $\mathrm{CH}_{3} \mathrm{OH}$ at lower temperatures. The maximum power densities measured were $0.6 \mathrm{~W} / \mathrm{cm}^{2}$ at $650^{\circ} \mathrm{C}$ and $0.2 \mathrm{~W} / \mathrm{cm}^{2}$ at $550^{\circ} \mathrm{C}$. These results show that although there is a significant decrease in cell performance at lower temperatures, power densities of practical interest can be realized at temperatures as low as $550^{\circ} \mathrm{C}$. With $\mathrm{C}_{2} \mathrm{H}_{5} \mathrm{OH}+$ $\mathrm{H}_{2} \mathrm{O}$ as a fuel, the maximum power density measured was $0.3 \mathrm{~W} / \mathrm{cm}^{2}$ at $650^{\circ} \mathrm{C}$. As discussed in what follows, lower cell performance at low temperatures is largely attributed to the decrease in the cathodic activity of LSM-YSZ electrode at low temperatures.

The performance of a fuel cell is governed by, anode and cathode polarizations as well as the cell ohmic resistance. The ohmic resistance is due to the resistances of the electrolyte and of the electrodes. The total cell ohmic resistance measured by the current interruption technique was $0.08,0.12$ and $0.3 \Omega \mathrm{cm}^{2}$ at 800,650 and $550^{\circ} \mathrm{C}$, respectively. Although it increases by greater than a factor of three from $800^{\circ} \mathrm{C}$ to $550^{\circ} \mathrm{C}$, it is still low enough to yield power densities of practical interest at temperatures as low as $550^{\circ} \mathrm{C}$.

Figures \#39 and \#40 show cathode and anode polarizations as functions of current density. Cathode polarization is due to the resistance to electrochemical reduction of $\mathrm{O}_{2}$, including charge transfer and mass transport processes. The cathode polarization (overpotential) was small, about $0.1 \mathrm{~V}$ at a current density of $3 \mathrm{~A} / \mathrm{cm}^{2}$ at $800^{\circ} \mathrm{C}$, and comparable to the anode polarization with hydrogen and methanol as fuels. However, it increases rapidly with decreasing temperature and is responsible for the observed low performance at lower temperatures. As shown in Figure \#39, the cathode overpotential reaches as high as $0.5 \mathrm{~V}$ at 2 $\mathrm{A} / \mathrm{cm}^{2}$ at $650^{\circ} \mathrm{C}$, and $0.7 \mathrm{~V}$ at only $0.75 \mathrm{~A} / \mathrm{cm}^{2}$ at $550^{\circ} \mathrm{C}$, which is much higher than the anode overpotential under similar conditions (Figure \#40). These results indicate that Ni-YSZ based anode is sufficiently active for methanol. However, LSM + YSZ is not a very good cathode material for operation at low temperatures. 
Anode polarization is principally related to the resistance to mass transport of fuel and/or to its electrochemical oxidation. The cathodic polarization and the ohmic resistance, both are expected to be independent of the fuel used. Thus, the observed differences in cell performance with different fuels are attributed to differences in anodic polarization. The results of anodic overpotential measurements with methanol as a fuel at various temperatures, as well as with hydrogen and ethanol + water as fuels at $800^{\circ} \mathrm{C}$, are shown in Figure \#40. The open symbols in Figure $\# 40$ denote anodic overpotential for methanol at 800,650 and $550^{\circ} \mathrm{C}$. As can be seen from Figure $\# 40$, the anodic polarization with $\mathrm{CH}_{3} \mathrm{OH}$ is quite small at $800^{\circ} \mathrm{C}$, and is close to that for $\mathrm{H}_{2}$ at a current density up to about $2 \mathrm{~A} / \mathrm{cm}^{2}$. At higher current densities, the anodic overpotential with $\mathrm{CH}_{3} \mathrm{OH}$ exhibits a faster increase. The relatively weak temperature dependence of the anodic polarization suggests that the principal contribution may be related to mass transport.

At $650^{\circ} \mathrm{C}$, the anodic polarization with $\mathrm{CH}_{3} \mathrm{OH}$ as a fuel is only slightly higher than at $800^{\circ} \mathrm{C}$. By contrast, it is considerably greater at $550^{\circ} \mathrm{C}$. This difference may be related to concentration polarization and the effects of anode gas composition. The possible mechanism for the electrochemical oxidation of $\mathrm{CH}_{3} \mathrm{OH}$ could be either a direct oxidation into $\mathrm{CO}_{2}+\mathrm{H}_{2} \mathrm{O}$, or first a decomposition of $\mathrm{CH}_{3} \mathrm{OH}$ into $\mathrm{CO}+\mathrm{H}_{2}$, followed by electrochemical oxidation of $\mathrm{CO}+\mathrm{H}_{2}$ into $\mathrm{CO}_{2}+\mathrm{H}_{2} \mathrm{O}$. If decomposition into $\mathrm{CO}+\mathrm{H}_{2}$ occurs prior to electrochemical oxidation, concentration polarization in the anode will be related to the transport of $\mathrm{H}_{2}$ in addition to the transport of other gas species such as $\mathrm{H}_{2} \mathrm{O}, \mathrm{CO}$ and $\mathrm{CO}_{2}$. The important binary diffusivities which govern transport are $\mathrm{D}_{\mathrm{H}_{2}-\mathrm{CO}}, \mathrm{D}_{\mathrm{H}_{2}-\mathrm{H}_{2} \mathrm{O}}$ and $\mathrm{D}_{\mathrm{H}_{2}-\mathrm{CO}_{2}}$. If, on the other hand, a direct electrochemical oxidation of $\mathrm{CH}_{3} \mathrm{OH}$ occurs, the anode gas will contain $\mathrm{CH}_{3} \mathrm{OH}, \mathrm{CO}_{2}, \mathrm{H}_{2} \mathrm{O}$, and possibly $\mathrm{CO}$; but little or no $\mathrm{H}_{2}$. In such a case, the pertinent binary diffusivities are $\mathrm{D}_{\mathrm{CH}_{3} \mathrm{OH}-\mathrm{H}_{2} \mathrm{O}}, \mathrm{D}_{\mathrm{CO}_{2}-\mathrm{H}_{2} \mathrm{O}}, \mathrm{D}_{\mathrm{CH}_{3} \mathrm{OH}-\mathrm{CO}_{2}}, \mathrm{D}_{\mathrm{CH}_{3} \mathrm{OH}-\mathrm{CO}}, \mathrm{D}_{\mathrm{CO}-\mathrm{H}_{2} \mathrm{O}}$, etc. The calculated value of the binary diffusivity of $\mathrm{H}_{2}-\mathrm{CO}$, that is $D_{\mathrm{H}_{2}-\mathrm{CO}}$ using the Chapman-Enskogg theory, is $\sim 6.4$ $\mathrm{cm}^{2} / \mathrm{s}$ at $800^{\circ} \mathrm{C}$, and that of $\mathrm{H}_{2}-\mathrm{H}_{2} \mathrm{O}, D_{\mathrm{H}_{2}-\mathrm{H}_{2} \mathrm{O}}$, is $\sim 7.7 \mathrm{~cm}^{2} / \mathrm{s}$. By contrast, the corresponding binary diffusivity of $\mathrm{CH}_{3} \mathrm{OH}-\mathrm{H}_{2} \mathrm{O}, \mathrm{D}_{\mathrm{CH}_{3} \mathrm{OH}-\mathrm{H}_{2} \mathrm{O}}$ is $\sim 1.7 \mathrm{~cm}^{2} / \mathrm{s}$., and that of $\mathrm{CH}_{3} \mathrm{OH}-\mathrm{CO}_{2}$, $D_{\mathrm{CH}_{3} \mathrm{OH}-\mathrm{CO}_{2}}$, is $\sim 1.16 \mathrm{~cm}^{2} / \mathrm{s}$. This suggests that if methanol is not converted into $\mathrm{CO}+\mathrm{H}_{2}$ prior to its electrochemical oxidation, there could be significant losses associated with concentration polarization. It is possible that at a temperature as low as $550^{\circ} \mathrm{C}$, methanol does not readily decompose into a mixture of $\mathrm{CO}+\mathrm{H}_{2}$, but at $800^{\circ} \mathrm{C}$ it does. With ethanol as a fuel, concentration polarization will similarly be high if $\mathrm{C}_{2} \mathrm{H}_{5} \mathrm{OH}+\mathrm{H}_{2} \mathrm{O}$ does not reform to form a gaseous mixture containing $\mathrm{H}_{2}$. Indeed, with ethanol as a fuel, even at $800^{\circ} \mathrm{C}$, anodic polarization was much higher than with either $\mathrm{H}_{2}$ or $\mathrm{CH}_{3} \mathrm{OH}$ as fuels, and that the power density was considerably lower than with either hydrogen or methanol as fuels. Presumably, the in-situ reformation reaction with ethanol did not readily occur at $800^{\circ} \mathrm{C}$. In order to verify the validity of this hypothesis, the following experiments were conducted.

Methanol was circulated through the anode chamber of a cell at $800^{\circ} \mathrm{C}$ without operating the cell. The exhaust was condensed to determine how much of the methanol remained un-reacted. It was observed that $\sim 25 \%$ of the methanol remained un-reacted; that is $\sim 75 \%$ was converted into $\mathrm{CO}+\mathrm{H}_{2}$. A similar experiment was conducted wherein an equi-volume mixture of $\mathrm{C}_{2} \mathrm{H}_{5} \mathrm{OH}+\mathrm{H}_{2} \mathrm{O}$ was passed through the anode compartment of the cell. Analysis of the 
condensate showed that $\sim 50 \%$ of the $\mathrm{C}_{2} \mathrm{H}_{5} \mathrm{OH}$ remained un-reacted. These results are preliminary. Nevertheless, they suggest that with ethanol as a fuel, the amount of $\mathrm{H}_{2}$ formed must have been less, and the resulting concentration polarization must have been rather high. This may explain, in part, the observed lower performance with ethanol as a fuel. These results have important implications with regard to direct electrochemical oxidation of hydrocarbon fuels. On one hand, direct electrochemical oxidation of hydrocarbon fuels is desired since it simplifies system design, as no reformer is necessary, and the introduction of water may not be required, provided carbon deposition can be suppressed. On the other hand, however, a lack of $\mathrm{H}_{2}$ in the fuel may substantially increase concentration polarization thus limiting performance.

After testing, the cells were examined visually as well as under an SEM. No noticeable carbon deposition on Ni-YSZ anode was observed with methanol as a fuel. A thermodynamic calculation shows lower tendency for carbon formation with $\mathrm{CH}_{3} \mathrm{OH}$ compared to that with $\mathrm{C}_{2} \mathrm{H}_{5} \mathrm{OH}$. Carbon deposition on the Ni-YSZ anode was observed when pure ethanol was used as a fuel. Carbon deposition, however, was successfully suppressed when the fuel used was an equi-volume solution of ethanol and water.

The present study demonstrates the feasibility of operating SOFC directly on alcohols at relatively low temperatures, while yielding fairly high power densities. Direct alcohol SOFC may significantly simplify the fuel cell system and improve the overall efficiency. The abundance and the ease of handling liquid fuels such as alcohols may lead to widespread applications of the SOFC. Also, since ethanol is a renewable fuel derived from agricultural byproducts, it is not dependent on fossil energy and may be more viable in the long run. Considerable work remains to be done to further improve the fuel cell performance with $\mathrm{C}_{2} \mathrm{H}_{5} \mathrm{OH}$ as a fuel. Improvements in cathode material and further optimization of the microstructures of both electrodes may lead to better performance at lower temperatures.

\section{LSM-LSGM Cathodes:}

A scanning electron micrograph (SEM) of a typical anode-supported cell is shown in Figure \#41. The micrograph shows the porous LSGM/LSM composite cathode (top), the dense YSZ electrolyte film, and the porous Ni/YSZ anode interlayer (bottom). The composite cathode of this particular cell contained $50 \mathrm{wt} . \% \mathrm{LSGM}$ and $50 \mathrm{wt} . \% \mathrm{LSM}$, which was fired at $1150^{\circ} \mathrm{C}$ for 2 hours.

The effect of cathode composition on cell performance was studied by varying the relative composition of the composite cathode interlayer between 30 and $70 \mathrm{wt} \%$ LSGM and 70 and 30 wt.\% LSM. For this study, the composite cathode interlayers were fired at the same temperature of $1150^{\circ} \mathrm{C}$ for two hours. The other components of the cells, including the anode, anode interlayer, electrolyte film, and cathode current collecting layer, were fabricated in batch processes under standard conditions in order to minimize differences from cell to cell. SEM analysis confirmed that the composite cathode interlayers partially sintered to form a contiguous two-phase structure while still containing a substantial amount of open porosity necessary for adequate gas flow. In addition, the composite cathode interlayers appeared firmly bonded to the dense YSZ electrolyte and no signs of delamination were observed before or after testing of the cells. The performance curves for cells with composite cathode interlayers 
of various compositions fired at $1150^{\circ} \mathrm{C}$ are shown in Figure $\# 42$. The cell testing was conducted at $800^{\circ} \mathrm{C}$. The maximum power density increased with increasing LSGM content in the composition range 30 to 50 wt.\% LSGM and then decreased for LSGM compositions greater than $50 \mathrm{wt} . \%$. The overall area specific resistance (ASR) of the cell decreased with increasing LSGM content up to $50 \mathrm{wt} . \%$ and then increased again for LSGM contents greater than $50 \mathrm{wt} . \%$. The cell with the $50 \mathrm{wt} \%$ LSGM + $50 \mathrm{wt} . \%$ LSM composite cathode interlayer exhibited the best performance with a maximum power density of $1.4 \mathrm{~W} / \mathrm{cm}^{2}$ at $2.6 \mathrm{~A} / \mathrm{cm}^{2}$ and an overall cell ASR of $0.18 \Omega \mathrm{cm}^{2}$.

The overpotentials at the anode and the cathode, as well as the ohmic overpotential (IR drop) of the cells, were measured with a reference electrode located next to the cathode. Calculations of Winkler et. al. have shown that that the measured overpotentials depend upon the relative position of the reference electrode [11]. The implied recommendation is that on anodesupported cells, one should not use a reference electrode. However, it is the experience in our laboratory that while some errors in the absolute values of overpotentials measured may well exist, reference electrode is still a valuable tool in evaluating relative differences in electrochemical performance of cells, especially when all other parameters are fixed, and only one parameter is varied. In an attempt to minimize measurement errors and variations from cell to cell, all cells from this work were made from a single anode support tape. In addition, care was taken to ensure that the thickness and the morphology of the anode interlayer, the thickness of the electrolyte layer, the morphology and the thickness of the cathode current collector layer, and the thickness of the cathode interlayer, were essentially the same for all cells. The only variability was in the composition of the cathode interlayer (and any associated morphological differences that arise due to differences in the cathode interlayer composition), or the firing temperature (and any associated morphological changes that arise due to differences in firing temperatures). In this manner, differences in the measured cathode overpotentials could be attributed to differences in the cathode interlayer.

The anode overpotential as a function of current density for cells with cathode interlayer compositions between 30 and 70 wt.\% LSGM and 70 and 30 wt.\% LSM are shown in Figure \#43. Note that the anode overpotential at $1.0 \mathrm{~A} / \mathrm{cm}^{2}$ varies between $\sim 30 \mathrm{mV}$ and $\sim 50 \mathrm{mV}$. The total ohmic overpotentials (IR drops) as a function of current density for the same cells are shown in Figure \#44. At a current density of $1.0 \mathrm{~A} / \mathrm{cm}^{2}$, the ohmic overpotential varies between $\sim 100$ and $\sim 125 \mathrm{mV}$. The corresponding area specific ohmic resistances of the cells with cathode interlayer compositions of 30/70,60/40, and 70/30 were approximately 0.125 $\Omega \mathrm{cm}^{2}$, while that for the cells with cathode interlayer compositions of 40/60 and 50/50 were lower with a value of approximately $0.1 \Omega \mathrm{cm}^{2}$. The total ohmic overpotential (IR drop) measured includes contributions from the anode, electrolyte, and cathode. The estimated ohmic resistance of a $10 \mu \mathrm{m} \mathrm{YSZ}$ electrolyte layer is $0.05 \Omega \mathrm{cm}^{2}$ at $800^{\circ} \mathrm{C}$. Thus, over half of the ohmic resistance of the cell is due to the anode and the cathode. Furthermore, since the anodes were prepared from the same tape, the higher ohmic resistances of the cells with cathode interlayer compositions of $30 / 70,60 / 40$, and $70 / 30$ as compared to the cells with cathode interlayer compositions of 40/60 and 50/50 must be due to differences in the cathode interlayer. Because of the higher electronic conductivity of LSM as compared to YSZ, it is expected that the ohmic resistances of the cathode interlayers would decrease with increasing LSM content. The lower ohmic resistances of the cells with cathode interlayers containing 50 and $60 \mathrm{wt} \%$ 
LSM as compared to those with only 30 and $40 \mathrm{wt} \%$ LSM is consistent with this notion. However, the high ohmic resistance of the cell with LSM rich 30/70 cathode interlayer indicates that other factors, such as sinterability and bonding between cathode interlayer and electrolyte, are likely factors, which determine the ohmic resistance.

The overpotentials at the cathode as a function of current density are shown in Figure \#45. As seen in the figure, the cathode interlayer composition has a profound effect on the overpotential at the cathode with the worst performing cell (70/30) exhibiting an overpotential of approximately $425 \mathrm{mV}$ at $1.0 \mathrm{~A} / \mathrm{cm}^{2}$ while the best performing cell (50/50) with an overpotential of only $60 \mathrm{mV}$ at $1.0 \mathrm{~A} / \mathrm{cm}^{2}$, which is a difference of $365 \mathrm{mV}$. Note that this difference is much greater than even the absolute values of anodic and ohmic overpotentials. As the differences in the anodic overpotentials and ohmic overpotentials were less than $25 \mathrm{mV}$, it is clear that errors due to surface mounting of a reference electrode must be small (for $<1$ $\mathrm{A} / \mathrm{cm}^{2}$ ). For this reason, it can be concluded that measurements made with respect to a reference electrode are valuable in assessing the performance of the cathode.

Since the cathode interlayers are comprised of the same materials, LSGM and LSM, the differences in performance with variation in relative amounts of LSGM and LSM are likely due to microstructural and compositional differences. Firstly, in order for composite electrodes to be effective, the two phases must be contiguous throughout the electrode. Typically a minimum of 30 vol.\% of a phase must be present to ensure contiguity, with this value being higher depending on the amount and the morphology of porosity. The theoretical densities of LSGM and LSM are approximately $6.2 \mathrm{~g} / \mathrm{cm}^{3}$ and $6.5 \mathrm{~g} / \mathrm{cm}^{3}$, respectively. Thus, approximate volume $\%$ of the two phases must be in proportion to their wt. $\%$. Therefore, for the 30/70 and $70 / 30$ cathode interlayer compositions, it is possible that one of the two phases has low contiguity in the electrode. In cases where the two phases are indeed contiguous, it has been shown that the performance of composite electrodes is dependent on porosity and three-phase boundary length (TPB). The porosity in the electrode must be adequate to allow for the transport of gases in and out of the electrode. In cases where the porosity is low and/or the current densities are high, the effects of concentration polarization can be large and may adversely affect the performance of a cell. SEM analysis, however, shows that the LSGM/LSM composite cathodes are highly porous. Although some differences in porosity may occur with differing compositions of the composite cathode interlayer, the effects of concentration polarization are small at low current densities. Thus, the large differences in cathode overpotentials at current densities below $0.5 \mathrm{~A} / \mathrm{cm}^{2}$ (Figure \#45) are likely due to changes in the three-phase boundary length (TPB) and thus dominated by activation polarization. The effects of TPB on the activation polarization of composite electrodes have been analyzed by, several groups including Kenjo et al. [12] and Tanner et al. [2]. In the model proposed by Tanner et. al., the effective charge transfer resistance $\left(R_{c t}^{e f f}\right)$ depends on the intrinsic charge transfer resistance $\left(R_{c t}\right)$ and the electrode microstructure such that

$$
R_{c t}^{e f f}=\sqrt{\frac{R_{c t} d \rho_{i}}{\left(1-V_{V}\right)}}
$$

where, $\rho_{i}$ is the ionic resistivity of the solid electrolyte (LSGM) in the cathode, $V_{V}$ is the volume percent of porosity, and $d$ is a microstructural parameter related to the particle size of solid electrolyte in the cathode. The intrinsic charge transfer resistance $\left(R_{c t}\right)$ is given as 


$$
R_{c t}=\frac{\rho_{c t}}{l_{T P B}}
$$

where $\rho_{c t}$ is the charge transfer resistivity and $l_{T P B}$ is the three phase boundary length. The ionic resistivity $\rho_{i}$, a property of solid electrolyte part of the composite cathode, and the charge transfer resistivity $\rho_{c t}$, a property of the electrocatalyst, solid electrolyte, and gas phase system, are dependent on material properties. The volume percent of porosity $V_{V}$, particle size $d$, and three-phase boundary length $l_{T P B}$, by contrast, are microstructural parameters. The effective charge transfer resistance can be rewritten as

$$
R_{c t}^{e f f}=\sqrt{\rho_{c t} \rho_{i}} \sqrt{\frac{d}{l_{T P B}\left(1-V_{V}\right)}}
$$

in order to separate and emphasize the effects of the fundamental material properties from the microstructural properties. For the LSGM/LSM composite cathodes studied, the ionic resistivity of LSGM and the intrinsic charge transfer resistivity of the LSGM/LSM system are constant and should not vary from cell to cell ${ }^{1}$. Furthermore, the different compositions of composite cathodes were prepared from the same starting LSGM and LSM powders. For a given firing temperature, the particle size of the electrolyte $d$ should not vary to a large degree, since the maximum cathode firing temperature was only $1200^{\circ} \mathrm{C}$, while the typical sintering temperature of LSGM is above $1500^{\circ} \mathrm{C}$. Thus, changes in the effective charge transfer resistance for various compositions of composite cathode should primarily be due to varying TPB length. At low current densities, the charge transfer resistance of the cathode can be estimated from the linear portions of the overpotential versus current density plots. Also, the effective exchange current density can be determined using the low current density approximation of the Butler-Volmer equation, since it is inversely proportional to the effective charge transfer resistance, $R_{c t}^{e f f}$. The area specific charge transfer resistance and the exchange current density for composite cathodes of various compositions are given in Table 8 . The area specific charge transfer resistance varies from $0.557 \Omega \mathrm{cm}^{2}$ for the cathode of $30 / 70$ composition to $0.242 \Omega \mathrm{cm}^{2}$ for the cathode of 50/50 composition. The cell with the 50/50 cathode interlayer exhibited the lowest charge transfer resistance, which is consistent with its low cathode overpotential (Figure \#45) and a high power density (Figure \#42). The anodic and the cathodic overpotentials, and the total ohmic overpotential (IR drop) for the cell with the $50 / 50$ cathode interlayer fired at $1150^{\circ} \mathrm{C}$ are shown in Figure \#46. For this cell, the anodic and cathodic overpotential contributions to the total overpotential losses are similar and lower than that due to the total ohmic resistance.

In addition to the cathode interlayer composition, the firing temperature of the cathode interlayer was varied and the resulting effects on cell performance were investigated. The cathode interlayer composition was fixed at $50 \mathrm{wt} \%$ LSGM and $50 \mathrm{wt} \%$ LSM, and fired at a temperature between 1000 and $1200^{\circ} \mathrm{C}$ for two hours. The voltage and the power density curves as a function of current density for these cells measured at $800^{\circ} \mathrm{C}$ are shown in Figure $\# 47$. The total area specific resistance decreases from $0.20 \Omega \mathrm{cm}^{2}$ to $0.16 \Omega \mathrm{cm}^{2}$ with increasing firing temperature from $1000^{\circ} \mathrm{C}$ to $1150^{\circ} \mathrm{C}$, but then increases dramatically to $0.24 \Omega \mathrm{cm}^{2}$ for a firing temperature of $1200^{\circ} \mathrm{C}$. Thus, as expected, the power density increases from

\footnotetext{
${ }^{1}$ This is strictly not true, as the ionic conductivity of LSGM is expected to be a function of the grain size.
} 
approximately $1.0 \mathrm{~W} / \mathrm{cm}^{2}$ to $1.4 \mathrm{~W} / \mathrm{cm}^{2}$ with an increasing firing temperature between 1000 to $1150^{\circ} \mathrm{C}$, and then decreases to $\sim 0.6 \mathrm{~W} / \mathrm{cm}^{2}$ for the interlayer fired at $1200^{\circ} \mathrm{C}$. The anode overpotential, as a function of current density for the cells tested at $800^{\circ} \mathrm{C}$, is shown in Figure \#48. Similar to the cells previously tested (Figure \#43), the anode overpotential at $1.0 \mathrm{~A} / \mathrm{cm}^{2}$ varies over a range of about $20 \mathrm{mV}$. The ohmic overpotentials (IR drop) of the cells as a function of current density are shown in Figure \#49. The ohmic resistances for the cells with cathode interlayers fired at 1000,1050 , and $1100^{\circ} \mathrm{C}$ are approximately the same with a value of $0.125 \Omega \mathrm{cm}^{2}$. The ohmic resistance of the cell whose cathode interlayer was fired at $1150^{\circ} \mathrm{C}$ is lower with a value of $0.1 \Omega \mathrm{cm}^{2}$, while that for the interlayer fired at $1200^{\circ} \mathrm{C}$ is higher with a value of approximately $0.175 \Omega \mathrm{cm}^{2}$. The lower area specific resistance of the sample with cathode interlayer fired at $1150^{\circ} \mathrm{C}$ may be due do to better bonding between the cathode to the electrolyte thus reducing the contact resistance at the interface. The high resistance of the cell with the cathode interlayer fired at $1200^{\circ} \mathrm{C}$ may be due to the formation of an intermediate phase at the interface between the cathode and the electrolyte. This possibility will be discussed later.

The cathode overpotentials as function of current density for the cells with 50/50 interlayers fired at temperatures between 1000 and $1200^{\circ} \mathrm{C}$ are shown in Figure \#50. The overpotential at the cathode decreases with increasing firing temperature in the range 1000 to $1150^{\circ} \mathrm{C}$, then dramatically increases for the interlayer fired at $1200^{\circ} \mathrm{C}$. At $1.0 \mathrm{~A} / \mathrm{cm}^{2}$, the cathode overpotential varies between a low of $65 \mathrm{mV}$ for the interlayer fired at $1150^{\circ} \mathrm{C}$ to a high of 250 $\mathrm{mV}$ for the interlayer fired at $1200^{\circ} \mathrm{C}$. The effective charge transfer resistances and the effective exchange current densities for cathodes with interlayers fired at various temperatures are summarized in Table 9. The effective charge transfer resistance decreases with increasing firing temperature in the range 1000 to $1150^{\circ} \mathrm{C}$, and then increases again above $1150^{\circ} \mathrm{C}$. The decrease in charge transfer resistance at the cathode with increasing firing temperature of the interlayer $\left(1000^{\circ} \mathrm{C} \leq \mathrm{T} \leq 1150^{\circ} \mathrm{C}\right)$ is likely due to more complete sintering (better particle-toparticle contact). The effective charge transfer resistance is dependent on particle size $d$, threephase boundary length $l_{T P B}$, and volume percent porosity $V_{V}$ as modeled by equation (50). At higher firing temperatures $\left(1200^{\circ} \mathrm{C}\right)$, it is possible that either a reaction between the electrocatalyst and the ionic conductor occurs wherein the intrinsic charge transfer resistivity is adversely affected, or that the microstructure is adversely affected, or both. Unless detailed microstructural analysis is conducted, it would be difficult to decipher the exact reason(s).

An examination of Figures \#45 and \#50 shows that cathodic overpotential exhibits a complex dependence on current density. Specifically, it is seen that in many cases, over some current density range, the overpotential is almost independent of current density $\left(d \eta_{\text {cathode }} / d i \approx 0\right)$. It is not known if this is a real effect, or a possible artifact of uncertainties related to the placement of reference electrodes.

In order to determine whether chemical reactions at the cathode played a role in the poor performance of the cell whose cathode was fired at $1200^{\circ} \mathrm{C}$, possible chemical interactions between LSGM and LSM and LSGM and YSZ were investigated. Chemical interactions between LSM and YSZ at elevated temperatures have been reported [13,14]. LSM and YSZ react to form the secondary phase $\mathrm{La}_{2} \mathrm{Zr}_{2} \mathrm{O}_{7}$ at temperatures above $1200^{\circ} \mathrm{C}$. In the present 
study, the phase $\mathrm{La}_{2} \mathrm{Zr}_{2} \mathrm{O}_{7}$ was not detected by XRD in milled mixtures of LSM and YSZ powder fired at temperatures between 1000 and $1200^{\circ} \mathrm{C}$ for two hours. Since the maximum cathode firing temperature was $1200^{\circ} \mathrm{C}$, it may be concluded that reaction between LSM and YSZ is not responsible for the poor performance of the cathode fired at $1200^{\circ} \mathrm{C}$. Similarly, no secondary phases were detected by XRD for milled mixtures of LSGM and LSM powder fired for two hours at a temperature as high as $1200^{\circ} \mathrm{C}$. This is in agreement with previous work by Huang et al., which reported inter-diffusion of La, Sr, Mn, and Ga between LSM and LSGM with no phase transformations [15]. Possible reactions between LSGM and YSZ were investigated by milling and firing mixtures of LSGM and YSZ powders at temperatures between 1000 and $1200^{\circ} \mathrm{C}$ for two hours. X-ray powder diffraction patterns of the powders after firing are shown in Figure $\# 51$. In the temperature range 1000 to $1200^{\circ} \mathrm{C}$, LSGM reacts with YSZ to form a secondary phase with a cubic crystal structure, which was indexed as the pyrochlore $\mathrm{La}_{2} \mathrm{Zr}_{2} \mathrm{O}_{7}$ (JCPDS 17-0450). The relative amount of the pyrochlore phase increases with increasing temperature in the range, $1000 \leq \mathrm{T} \leq 1200^{\circ} \mathrm{C}$. For the powder mixture fired at $1200^{\circ} \mathrm{C}$ for two hours, no LSGM was detectable by XRD and appears to have completely reacted with YSZ. Other than the pyrochlore, no other phases were found in any of the patterns. In order to determine if $\mathrm{Ga}$ dissolved into $\mathrm{La}_{2} \mathrm{Zr}_{2} \mathrm{O}_{7}$ or $\mathrm{YSZ}$, energy dispersive spectroscopic (EDS) analysis was performed on dense samples fabricated from LSGM and YSZ powders fired at 1000,1100 , and $1200^{\circ} \mathrm{C}$. The presence of $\mathrm{Ga}$ was detected in the pyrochlore phase but not in YSZ. This shows that LSGM reacts with YSZ to form Ga doped cubic $\mathrm{La}_{2} \mathrm{Zr}_{2} \mathrm{O}_{7}$. It was not determined whether $\mathrm{Ga}$ substitutes on $\mathrm{La}$ or $\mathrm{Zr}$ sites of the $\mathrm{La}_{2} \mathrm{Zr}_{2} \mathrm{O}_{7}$ pyrochlore phase. The six-coordinated $\mathrm{Ga}^{3+}$ ion is closer in size to the $\mathrm{Zr}^{4+}$ ion than the larger $\mathrm{La}^{3+}$ ion [16]. Thus, it is the expectation that $\mathrm{Ga}^{3+}$ ion may substitute for the $\mathrm{Zr}^{4+}$ ion resulting in an oxygen deficient pyrochlore, $\mathrm{La}_{2} \mathrm{Zr}_{2-\mathrm{x}} \mathrm{Ga}_{\mathrm{x}} \mathrm{O}_{7-\delta}$.

In all fuel cells tested, a mixture of LSGM and LSM powder was screen-printed onto an already sintered dense layer of YSZ. In order to investigate a possible reaction at this interface, LSGM powder in the form of a paste was screen-printed onto dense YSZ pellets and then fired at 1000,1100 , and $1200^{\circ} \mathrm{C}$ for two hours. After firing, the LSGM side of the pellets was analyzed with XRD and the samples were sectioned and analyzed with EDS. The presence of a pyrochlore phase was not detected with XRD indicating that the reaction was limited to the interface. EDS analysis of the cross section of the cell, whose cathode was fired at $1200^{\circ} \mathrm{C}$, revealed a thin reaction layer of approximately $4 \mu \mathrm{m}$ in thickness between the LSGM and YSZ regions. The thickness of the reaction zone for the sample fired at $1100^{\circ} \mathrm{C}$ was less than 0.5 $\mu \mathrm{m}$, while that for the $1000^{\circ} \mathrm{C}$ sample was not detectable. The formation of a thin layer of the resistive, Ga-containing $\mathrm{La}_{2} \mathrm{Zr}_{2} \mathrm{O}_{7}$ pyrochlore phase between the cathode interlayer and YSZ electrolyte, when fired at $1200^{\circ} \mathrm{C}$ for two hours, appears to increase the ohmic resistance of the cell and the cathodic overpotential and is thus detrimental to the performance of the cell.

\section{Anode Reduction-Re-Oxidation Kinetics:}

SEM micrographs of NiO-YSZ samples sintered showed that the samples were essentially fully dense, with no detectable open porosity. The grain sizes of $\mathrm{NiO}$ and $\mathrm{YSZ}$ were on the order of 1 to 2 microns. Figure \#52 shows plots of the reduced layer thickness as a function of time at various temperatures, ranging between 600 and $800^{\circ} \mathrm{C}$. It is seen that the plots are linear, indicating that the kinetics of reduction is interface-controlled. The slopes of lines in 
Figure \#52 give the phenomenological rate constant for the interface-controlled reduction, namely $k_{\text {red }}$. Typical porosity in the porous $\mathrm{Ni}+$ YSZ layer formed is $\sim 25 \%$. Prior work has shown that the estimated $D_{\text {eff }}^{r}$ is on the order of $\sim 0.1 \mathrm{~cm}^{2} / \mathrm{s}$ (at $\sim 800^{\circ} \mathrm{C}$ ). As seen in Figure \#52, the maximum reduction thickness was on the order of 800 microns for the length of time the samples were reduced. A crude estimate of the characteristic time required to equilibrate gaseous compositions in a porous body is given by

$$
\tau \sim \frac{l_{r}^{2}}{D_{e f f}^{r}}
$$

where $l_{r}=$ reduced layer thickness. For the above values, $\tau$ is estimated to be $\sim 0.1$ second, which is orders of magnitude smaller than the time required to achieve a reduced layer thickness of 800 microns, which is on the order of $3 \mathrm{~h}$ or greater than 10,000 seconds. This shows that the kinetics of reduction must be interface-controlled, as observed. The kinetics of reduction is also thermally activated with activation energy on the order of $94 \mathrm{~kJ} / \mathrm{mol}$. This observation is also reasonable, since it is well known that reaction rates are usually thermally activated.

Figure \#53 shows a plot of the square of the re-oxidized layer thickness as a function of time at $700^{\circ} \mathrm{C}$. As seen in the figure, the plot is linear, consistent with diffusion-controlled kinetics, unlike reduction kinetics, which is interface-controlled. From the slope, an estimate of the phenomenological diffusion coefficient, $D_{o x}$, can be made. For the data shown in Figure \#53, the estimated $D_{o x}$ is $\sim 1.1 \times 10^{-7} \mathrm{~cm}^{2} / \mathrm{s}$. It was observed that this was nearly the same for all temperatures between 650 and $800^{\circ} \mathrm{C}$. Such a low value of $D_{o x}$ suggests that either the reoxidized layer has no open porosity and transport of oxygen must be occurring through the solid part (for example, oxygen ions through YSZ and electrons or holes through either $\mathrm{NiO}$ and/or YSZ); or that the re-oxidized layer has open porosity and oxygen transport must be occurring through the pores. If it is the former, it is expected that oxygen transport would be thermally activated. However, experiments showed that the measured $D_{o x}$ was virtually independent of temperature. This is consistent with the occurrence of gaseous diffusion through pores. It is to be noted that for diffusion through pores, the expected temperature dependence of $D_{o x}$ is approximately $T^{0.5}$, since through the Chapman-Enskogg model, $D_{\text {eff }}^{o} \propto T^{3 / 2}$ (note that $D_{o x} \propto D_{\text {eff }}^{o} / T$ ). That is, the dependence of $D_{o x}$ on temperature is rather weak. In order to determine if indeed porosity is formed upon re-oxidation, samples were examined in SEM in the as-sintered state as well as after re-oxidation of reduced samples. Figure \#54 shows an SEM micrograph of an as- sintered sample. The light phase is NiO, the gray phase is YSZ, and black spots are pores. Note that the sample has very small amount of porosity. Figure \#55 shows an SEM micrograph a re-oxidized sample. Note that the amount of porosity is much greater in the re-oxidized sample as compared to that in the assintered sample. Table 10 lists the densities and porosities of as-sintered and re-oxidized samples. The kinetics of re-oxidation appear to be governed by diffusion of oxygen through the pores formed. 


\section{Fuel Composition Effects on Anode Polarization:}

An SEM micrograph of a polished section of the Ni-YSZ anode is shown in Figure \#56. Figures \#57, \#58 and \#59 show cell voltage vs. current density, and power density vs. current density traces with as-received $\mathrm{H}_{2}$, and $\mathrm{H}_{2}$ diluted with various concentrations of $\mathrm{He}, \mathrm{N}_{2}$ and $\mathrm{CO}_{2}$. For as-received $\mathrm{H}_{2}$ as the fuel, the open circuit potential was around $1.05 \mathrm{~V}$, the maximum power density was about $1.7 \mathrm{~W} / \mathrm{cm}^{2}$, and there was no obvious limiting current density even at the highest current density of $4.5 \mathrm{~A} / \mathrm{cm}^{2}$ at which measurements were made. When $\mathrm{H}_{2}$ was diluted with various diluents, the general trend was similar for each diluent, namely that: (1) with increasing dilution, the open circuit voltage decreased, and (2) the maximum power density as well as the maximum current density decreased. At high diluent concentrations, substantial concentration polarization was present as evidenced by the observation of a limiting current density. Since the cathode conditions were kept the same, the observed changes in performance with different diluents and their concentrations could be solely attributed to changes made in anodic conditions.

A comparison of Figures \#57 $\left(\mathrm{H}_{2}-\mathrm{He}\right)$, \#58 $\left(\mathrm{H}_{2}-\mathrm{N}_{2}\right)$, \#59 $\left(\mathrm{H}_{2}-\mathrm{CO}_{2}\right)$, and \#60 $\left(\mathrm{H}_{2}-\mathrm{H}_{2} \mathrm{O}\right)$ shows that the maximum power density achieved at the highest concentration of the diluent $(\sim 78$ $81 \%)$ was the highest for $\mathrm{H}_{2}-\mathrm{He}$ mixtures $\left(\sim 0.75 \mathrm{~W} / \mathrm{cm}^{2}\right)$ and the lowest for $\mathrm{H}_{2}-\mathrm{CO}_{2}$ mixtures $\left(\sim 0.3 \mathrm{~W} / \mathrm{cm}^{2}\right)$. Also, the corresponding short circuit current density was the highest for $\mathrm{H}_{2}-\mathrm{He}$ mixture $\left(\sim 1.55 \mathrm{~A} / \mathrm{cm}^{2}\right)$ and the lowest for $\mathrm{H}_{2}-\mathrm{CO}_{2}$ mixture $\left(\sim 0.7 \mathrm{~A} / \mathrm{cm}^{2}\right)$. The highest power density measured was $\sim 1.7 \mathrm{~W} / \mathrm{cm}^{2}$ for this cell with as-received $\mathrm{H}_{2}$ as the fuel. A comparison of $\mathrm{H}_{2}-\mathrm{He}$ and $\mathrm{H}_{2}-\mathrm{N}_{2}$ mixtures, wherein the diluent is inert, shows that the maximum power density at the highest diluent concentration is $\sim 0.75 \mathrm{~W} / \mathrm{cm}^{2}$ for $\mathrm{H}_{2}-\mathrm{He}$ and $\sim 0.5 \mathrm{~W} / \mathrm{cm}^{2}$ for $\mathrm{H}_{2^{-}}$ $\mathrm{N}_{2}$ mixtures. Also, the corresponding anode-limiting current densities were $\sim 1.5 \mathrm{~A} / \mathrm{cm}^{2}$ for $\mathrm{H}_{2-}$ He mixture and $\sim 0.85 \mathrm{~A} / \mathrm{cm}^{2}$ for $\mathrm{H}_{2}-\mathrm{N}_{2}$ mixture of similar diluent concentrations.

As seen in Figures \#61 and \#62, the open circuit voltage (OCV) exhibited a stronger dependence on the diluent concentration when the diluent was either $\mathrm{CO}_{2}$ or $\mathrm{H}_{2} \mathrm{O}$, consistent with expectations, as the diluents in these cases are not inert, and enter into chemical reactions of the following type:

In $\mathrm{H}_{2}-\mathrm{H}_{2} \mathrm{O}$ mixtures,

$$
\mathrm{H}_{2}+\frac{1}{2} \mathrm{O}_{2} \Leftrightarrow \mathrm{H}_{2} \mathrm{O}
$$

and, in $\mathrm{H}_{2}-\mathrm{CO}_{2}$ mixtures,

$$
\mathrm{H}_{2}+\mathrm{CO}_{2} \Leftrightarrow \mathrm{H}_{2} \mathrm{O}+\mathrm{CO}
$$

until the respective reaction equilibria are established.

Figure \#61 shows cell performance curves for gas mixtures containing $\mathrm{CO}$ and $\mathrm{CO}_{2}$ as the fuel. The maximum power density measured with as-received $\mathrm{CO}$ as the fuel was $\sim 0.7 \mathrm{~W} / \mathrm{cm}^{2}$, which is considerably lower than that with as-received $\mathrm{H}_{2}$ as the fuel (Figures \#57 through \#60). For the gas mixture containing $18 \% \mathrm{CO}+82 \% \mathrm{CO}_{2}$, the maximum power density was only $\sim 0.1 \mathrm{~W} / \mathrm{cm}^{2}$, and the corresponding limiting current density was only $\sim 0.2 \mathrm{~A} / \mathrm{cm}^{2}$. An examination of Figures \#57 through \#61 shows that a limiting current behavior is observed in all cases at higher diluent concentrations. The limiting current density, $i_{a s}$, for each case is 
plotted vs. the partial pressure of the fuel gas (either $\mathrm{H}_{2}$ or $\mathrm{CO}$ ) in Figure \#62. It is seen that the dependence of $i_{a s}$ on the respective partial pressure $\left(p_{\mathrm{H}_{2}}\right.$ or $p_{\mathrm{CO}}$ ) is close to linear, with $\mathrm{H}_{2}$ He fuel (or $\mathrm{H}_{2}-\mathrm{H}_{2} \mathrm{O}-\mathrm{He}$ mixtures) exhibiting the highest $i_{a s}$, and the highest slope; and the CO$\mathrm{CO}_{2}$ mixtures exhibiting the lowest $i_{a s}$, and the lowest slope.

Figure \#63 shows the performance curves with $\mathrm{H}_{2}+\mathrm{CO}$ gas mixtures as the fuel, where the composition was varied between $\sim 100 \%$ (as-received) $\mathrm{H}_{2}$ and $\sim 100 \%$ (as-received) $\mathrm{CO}$. The $\mathrm{OCV}$ is essentially independent of the relative proportions of $\mathrm{H}_{2}$ and $\mathrm{CO}$. The maximum power density varied between $\sim 1.7 \mathrm{~W} / \mathrm{cm}^{2}$ for $100 \% \mathrm{H}_{2}$, to $\sim 0.7 \mathrm{~W} / \mathrm{cm}^{2}$ for $100 \% \mathrm{CO}$. Note that the maximum power density for $\mathrm{CO}$ concentrations less than $\sim 55 \%$ ranges between $\sim 1.5$ and $\sim 1.7$ $\mathrm{W} / \mathrm{cm}^{2}$; and for $\mathrm{CO}$ concentrations between $68 \%$ and $100 \%$, the maximum power density ranges between $\sim 1.2 \mathrm{~W} / \mathrm{cm}^{2}$ and $\sim 0.7 \mathrm{~W} / \mathrm{cm}^{2}$.

Thermodynamic Calculation of Open Circuit Voltages: The thermodynamic open circuit voltage $(\mathrm{OCV})$ of a fuel cell, which is the Nernst potential, is given by

$$
E=\frac{R T}{4 F} \ln \left(\frac{p_{O_{2(\text { cathode })}}}{p_{O_{2(\text { anode })}}}\right)
$$

where $p_{O_{2(\text { cathode })}}$ is the partial pressure of oxygen at the cathode (under open circuit conditions), which is $0.21 \mathrm{~atm}$ when air is used as the oxidant; $p_{O_{2(\text { anode }}}$ is the partial pressure of oxygen in fuel at the anode (under open circuit conditions). For example, when $\mathrm{H}_{2}$ is the fuel,

$$
\mathrm{H}_{2}+\frac{1}{2} \mathrm{O}_{2} \Leftrightarrow \mathrm{H}_{2} \mathrm{O}
$$

at equilibrium, the partial pressure of oxygen at the anode, $p_{O_{2(\text { anode })}}$ is given as

$$
\ln p_{O_{2(\text { anode })}}=\frac{2 \Delta G_{3}^{o}}{R T}+2 \ln \left(\frac{p_{\mathrm{H}_{2} \mathrm{O}}}{p_{\mathrm{H}_{2}}}\right)
$$

where $\Delta G_{3}^{o}$ is the standard free energy of reaction (53). The $\Delta G_{3}^{o}$ is $-188.165 \mathrm{~kJ} / \mathrm{mol}$ at $800^{\circ} \mathrm{C}$ [17]. At various partial pressures of $\mathrm{H}_{2}$ and $\mathrm{H}_{2} \mathrm{O}, p_{O_{2(\text { anode })}}$ can be calculated from Equation (54), and the OCV can be determined using Equation (52).

Figure \#64 shows the calculated $p_{O_{2(\text { anode })}}$ (except for as-received $\mathrm{H}_{2}$, whose water content was not known), the calculated OCV and the experimentally measured OCV as a function of $p_{\mathrm{H}_{2} \mathrm{O}}$. The partial pressure of oxygen at the anode increases from $10^{-20} \mathrm{~atm}$ to $10^{-17} \mathrm{~atm}$, and the calculated OCV decreases from $1.021 \mathrm{~V}$ to $0.877 \mathrm{~V}$, when the $p_{\mathrm{H}_{2} \mathrm{O}}$ increases from 0.15 atm to $0.8 \mathrm{~atm}$. The measured OCV, in general, exhibits the same trend as the calculated one, although it is about $50 \mathrm{mV}$ lower than the calculated.

For the reaction 


$$
\mathrm{CO}+\frac{1}{2} \mathrm{O}_{2} \Leftrightarrow \mathrm{CO}_{2}
$$

the standard free energy, $\Delta G_{5}^{o}$ is $-189.65 \mathrm{~kJ} / \mathrm{mol}$ [1]. At $p_{C O}$ lower than $0.8 \mathrm{~atm}$, the disproportionation reaction,

$$
2 \mathrm{CO} \Leftrightarrow \mathrm{CO}_{2}+\mathrm{C}
$$

for which the standard free energy change is $\Delta G_{6}^{o}=17.63 \mathrm{~kJ} / \mathrm{mol}$ [17], should not occur at $800^{\circ} \mathrm{C}$ and $1 \mathrm{~atm}$ pressure, based on a thermodynamic calculation. For values of $p_{C O}$ less than $0.8 \mathrm{~atm}$, the partial pressures of $\mathrm{CO}$ and $\mathrm{CO}_{2}$ in the initial gas mixture were used to estimate the equilibrium partial pressure of oxygen at the anode, namely $p_{O_{2(\text { anode })}}$, using the following equation

$$
\ln p_{O_{2(\text { anode })}}=\frac{2 \Delta G_{5}^{o}}{R T}+2 \ln \left(\frac{p_{C O_{2}}}{p_{C O}}\right)
$$

For values of $p_{C O}$ greater than $0.8 \mathrm{~atm}$, first the partial pressures of $\mathrm{CO}$ and $\mathrm{CO}_{2}$ according to the disproportionation reaction (56) were estimated. Then, $p_{O_{2(\text { anode })}}$ was estimated using the corresponding values of the partial pressures of $\mathrm{CO}$ and $\mathrm{CO}_{2}$ and Equation (57). Finally, the $\mathrm{OCV}$ was calculated as a function of the partial pressure of $\mathrm{CO}_{2}$ in the initial mixture, $p_{\mathrm{CO}_{2}}^{o}$. The calculated $p_{O_{2(\text { anode })}}$, the calculated $\mathrm{OCV}$, and the measured $\mathrm{OCV}$, are plotted as a function of $p_{\mathrm{CO}_{2}}^{o}$ in Figure $\# 65$. The trends in the measured OCV and the calculated OCV are similar, although the measured OCV is between 50 and $75 \mathrm{mV}$ lower than the theoretical values.

For calculating $p_{O_{2(\text { anode })}}$ and $\mathrm{OCV}$ for $\mathrm{H}_{2}+\mathrm{CO}_{2}$ gas mixtures as the fuel, the reverse gas shift reaction, namely,

$$
\mathrm{H}_{2}+\mathrm{CO}_{2} \Leftrightarrow \mathrm{H}_{2} \mathrm{O}+\mathrm{CO}
$$

for which the standard free energy is $\Delta G_{8}^{o}=0.385 \mathrm{~kJ} / \mathrm{mol}$. at $800^{\circ} \mathrm{C}$, was considered. The corresponding equilibrium $p_{\mathrm{CO}}, \quad p_{\mathrm{CO}_{2}}, \quad p_{\mathrm{H}_{2}}$ and $p_{\mathrm{H}_{2} \mathrm{O}}$ were calculated. Then, the corresponding $p_{\mathrm{O}_{2(\text { anode })}}$ was calculated using either the $\mathrm{H}_{2}-\mathrm{H}_{2} \mathrm{O}$ equilibrium, or the $\mathrm{CO}^{-} \mathrm{CO}_{2}$ equilibrium. Using the calculated $p_{O_{2(\text { anode })}}$, the $\mathrm{OCV}$ was estimated by equation (52). The calculated $p_{O_{2(\text { anode })}}$, the calculated OCV and the measured OCV are plotted as a function of the partial pressure of $\mathrm{CO}_{2}$ in the initial gas mixture, $p_{\mathrm{CO}_{2}}^{o}$, in Figure \#66. As seen in the figure, the calculated and the measured OCV are in good agreement, especially for higher values of $p_{\mathrm{CO}_{2}}^{o}$.

The above thermodynamic calculations and comparison with experimental results show, in general, reasonable agreement between the calculated and experimental OCV values, insofar as the trends are concerned. However, the experimental values of the OCV are typically about 50 $\mathrm{mV}$ lower, and in some cases as much as $100 \mathrm{mV}$ lower. There are a couple of possibilities for 
this discrepancy. (1) There may have been a few pinholes in the YSZ film. (2) The sealing may not have been perfect. A lower OCV thus would imply a higher $\mathrm{H}_{2} \mathrm{O}$ or $\mathrm{CO}_{2}$ pressure, and a correspondingly higher partial pressure of oxygen at the anode, $p_{O_{2(\text { anode })}}$. Leakage is also the possible reason that $\mathrm{OCV}$ in $\mathrm{H}_{2}-\mathrm{He}$ and $\mathrm{H}_{2}-\mathrm{N}_{2}$ mixtures is dependent upon the relative proportions of $\mathrm{H}_{2}$ and inert gas. If there had been no leakage, ideally, it would be expected that the OCV would be essentially independent of the concentration of inert diluent, $\mathrm{He}$ or $\mathrm{N}_{2}$. In principle, using the measured $\mathrm{OCV}$, this $p_{\mathrm{O}_{2(\text { anode })}}$ can be calculated, and thus the relative amount of water (or $\mathrm{CO}_{2}$ ) present in the fuel can be estimated. However, as the general trend in measured OCV is consistent with calculations (and expectations) and significant uncertainties may exist in such calculations, no corrections for leakage were made, and the data reported are as measured.

Gas Transport in Porous Anodes: Gas transport through porous electrodes and correlation with electrochemical performance for binary gases, $\mathrm{H}_{2}-\mathrm{H}_{2} \mathrm{O}$ in the anode, and $\mathrm{O}_{2}-\mathrm{N}_{2}$ in the cathode, has been addressed in detail. There are two main fluxes contributing to mass transport in a porous electrode: (1) A diffusive flux and, (2) a viscous flux. In general, the viscous flow, which is driven by a pressure gradient, is negligible compared to the diffusive flow in porous electrodes. Therefore, gas transport in porous electrodes is mainly due to diffusion, which includes free molecular or Knudsen flow, and a continuum flow.

The general diffusion process for a multi-component gas system is described by StefanMaxwell equation [18]

$$
\frac{N_{i}}{D_{K, i}}+\sum_{\substack{j=1 \\ j \neq i}} \frac{X_{j} N_{i}-X_{i} N_{j}}{D_{i j}}=-\frac{p}{R T} \frac{d X_{i}}{d x}
$$

where $N_{i}$ and $N_{j}$ are molar fluxes of components $i$ and $j$ (\# mols $/ \mathrm{cm}^{2} \mathrm{sec}$ ), respectively, $D_{K i}$ and $D_{i j}$ are the Knudsen diffusion coefficient for component $i$ and the binary diffusion coefficient for components $i$ and $j$, respectively, $X_{i}$ and $X_{j}$ are the mole fractions of components $i$ and $j$, respectively, $p$ is the total pressure, $R$ is the gas constant, $T$ is the absolute temperature, and $x$ is the coordinate along the diffusion direction. Knudsen diffusion is due to molecule to wall collision, which predominates over molecule-to-molecule collision when the pore size is smaller than the mean free path [20]. The Knudsen diffusion coefficient can be computed according to the kinetic theory of gases, using the following formula [18]

$$
D_{K, i}=\frac{2}{3}\left(\frac{8 R T}{\pi M_{i}}\right)^{\frac{1}{2}} \bar{r}
$$

where $\bar{r}$ is the mean pore radius, and $M_{i}$ is the molecular weight of the diffusing gas. Binary diffusion coefficient, $D_{i j}$, is generally experimentally measured or calculated using the Chapman-Enskog equation [6], if it is not available experimentally. According to the Chapman-Enskog model, the binary diffusion coefficient in $\mathrm{cm}^{2} / \mathrm{sec}$ is given by [6] 


$$
D_{i j}=\frac{1.86 \times 10^{-3} T^{\frac{3}{2}}\left(\frac{1}{M_{i}}+\frac{1}{M_{j}}\right)^{\frac{1}{2}}}{p \Omega \sigma_{i j}^{2}}
$$

where $\Omega$ is the collision integral (dimensionless), $\sigma_{i j}$ is the average collision diameter (in angstroms), $M_{i}$ and $M_{j}$ are respectively molecular weights of component $i$ and $j$, and $p$ is the total pressure (in atmospheres). Using $\Omega$ and $\sigma_{i j}$ data from Cussler ${ }^{16}$, the calculated $D_{i j}$ for various gaseous species and at several temperatures are listed in Table 11, along with some experimental values from the literature for comparison $[17,19,20]$. Slight difference, usually less than $10 \%$, is often observed between the calculated values and the experimental values over a range of temperatures between room temperature and $473 \mathrm{~K}$. Little data are available at higher temperatures. Hence, $D_{i j}$ at $800^{\circ} \mathrm{C}$ were estimated using the Chapman-Enskog model.

In the present experiments, the mean pore radius of the Ni-YSZ electrode was estimated from SEM micrographs (Figure 54) to be $\sim 0.5 \mu \mathrm{m}$. The calculated Knudsen diffusion coefficients at $800^{\circ} \mathrm{C}$ for $\mathrm{H}_{2}$ and $\mathrm{CO}$ through the Ni-YSZ porous electrode are respectively $11.3 \mathrm{~cm}^{2} / \mathrm{s}$ and 3 $\mathrm{cm}^{2} / \mathrm{s}$. These values are comparable to the respective binary diffusion coefficients of $\mathrm{H}_{2}-\mathrm{He}$, which is $13.3 \mathrm{~cm}^{2} / \mathrm{s}$, and $\mathrm{CO}-\mathrm{CO}_{2}$, which is $1.41 \mathrm{~cm}^{2} / \mathrm{s}$ at the same temperature (Table 11). This indicates that Knudsen diffusion is an important process in the present porous anodes with $0.5 \mu \mathrm{m}$ mean pore radius, and should be taken into account.

For a ternary system such as $\mathrm{H}_{2}-\mathrm{He}-\mathrm{H}_{2} \mathrm{O}$, the $\mathrm{H}_{2}$ molar flux from Equation (59) is given by

$$
\frac{N_{\mathrm{H}_{2}}}{D_{K, \mathrm{H}_{2}}}+\frac{X_{\mathrm{He}} \mathrm{N}_{\mathrm{H}_{2}}-X_{\mathrm{H}_{2}} N_{\mathrm{He}}}{D_{\mathrm{H}_{2}, \mathrm{He}}}+\frac{X_{\mathrm{H}_{2} \mathrm{O}} N_{\mathrm{H}_{2}}-X_{\mathrm{H}_{2}} N_{\mathrm{H}_{2} \mathrm{O}}}{D_{\mathrm{H}_{2}, \mathrm{H}_{2} \mathrm{O}}}=-\frac{p}{R T} \frac{d X_{\mathrm{H}_{2}}}{d x}
$$

Under steady state conditions, $N_{\mathrm{H}_{2} \mathrm{O}}=-N_{\mathrm{H}_{2}}$ and $N_{\mathrm{He}}=0$. Thus,

$$
N_{H_{2}}\left(\frac{1}{D_{K, H_{2}}}+\frac{X_{H e}}{D_{H_{2}, H e}}+\frac{1-X_{H e}}{D_{H_{2}, H_{2} \mathrm{O}}}\right)=-\frac{p}{R T} \frac{d X_{H_{2}}}{d x}
$$

From Equation (63), $\mathrm{H}_{2}$ flux can be written in a similar form as Fick's equation by

$$
N_{H_{2}}=-\frac{p D_{H_{2}}}{R T} \frac{d X_{H_{2}}}{d x}
$$

where $D_{\mathrm{H}_{2}}$ is defined as the $\mathrm{H}_{2}$ diffusion coefficient in the $\mathrm{H}_{2}-\mathrm{H}_{2} \mathrm{O}-\mathrm{He}$ ternary system, and is given by

$$
D_{\mathrm{H}_{2}}=\left(\frac{1}{D_{\mathrm{K}, \mathrm{H}_{2}}}+\frac{X_{\mathrm{He}}}{D_{\mathrm{H}_{2}, \mathrm{He}}}+\frac{1-X_{\mathrm{He}}}{D_{\mathrm{H}_{2}, \mathrm{H}_{2} \mathrm{O}}}\right)^{-1}
$$

When $X_{H e}=0$, i.e. for $\mathrm{H}_{2}-\mathrm{H}_{2} \mathrm{O}$ binary system, the $\mathrm{H}_{2}$ diffusion coefficient becomes

$$
D_{\mathrm{H}_{2}}=\left(\frac{1}{D_{K, \mathrm{H}_{2}}}+\frac{1}{D_{\mathrm{H}_{2}, \mathrm{H}_{2} \mathrm{O}}}\right)^{-1}
$$


Similarly, for the $\mathrm{CO}-\mathrm{CO}_{2}$ binary system, the $\mathrm{CO}$ diffusion coefficient is given by

$$
D_{\mathrm{CO}}=\left(\frac{1}{D_{\mathrm{K}, \mathrm{CO}}}+\frac{1}{D_{\mathrm{CO}, \mathrm{CO}_{2}}}\right)^{-1}
$$

where $D_{K, C O}$ and $D_{\mathrm{CO}_{2} \mathrm{CO}_{2}}$ are respectively the Knudsen diffusion coefficient of $\mathrm{CO}$ and the binary diffusion coefficient of $\mathrm{CO}-\mathrm{CO}_{2}$.

The preceding equations for diffusion coefficients are for transport in a multi-component gas system and do not account for the volume fraction of porosity, and the tortuous nature of path through porous bodies. When the transport occurs through a porous body, the interaction of gaseous species with the porous matrix must be included. The simplest approach for taking this into account is to modify the diffusion coefficients by the volume fraction porosity, $V_{v}$, and the tortuous nature of the actual transport, characterized by the so-called tortuosity factor, $\tau$ [6]. The resulting diffusion coefficients or diffusivities are termed effective diffusion coefficients or effective diffusivities. For $\mathrm{H}_{2}$ and $\mathrm{CO}$, the corresponding effective diffusivities are given by [6]

$$
D_{H_{2}, e f f}=\frac{V_{v}}{\tau} D_{H_{2}}
$$

and

$$
D_{C O, e f f}=\frac{V_{v}}{\tau} D_{C O}
$$

where $D_{H_{2}}$ and $D_{C O}$ are given respectively by equations (65 or 66) and (67).

As shown on the right side of Equation (15), for a ternary system, $D_{H_{2}}$ is not only a function of diffusion coefficients, $D_{K, H_{2}}, D_{H_{2}, H e}$ and $D_{\mathrm{H}_{2}, \mathrm{H}_{2} \mathrm{O}}$, but is also a function of the mole fraction of the diluent gas, $X_{\mathrm{He}}$. If $X_{\mathrm{He}}$ varies from position to position along the diffusion direction, $D_{H_{2}}$ will be a function of position. The variation of $X_{H e}$ as a function of the position, $x$, can be determined by solving Equation (59) for the He flux, $N_{H e}$, given by

$$
\frac{N_{\mathrm{He}}}{D_{\mathrm{K}, \mathrm{He}}}+\frac{X_{\mathrm{H}_{2}} N_{\mathrm{He}}-X_{\mathrm{He}} N_{\mathrm{H}_{2}}}{D_{\mathrm{He}, \mathrm{H}_{2}}}+\frac{X_{\mathrm{H}_{2} \mathrm{O}} N_{\mathrm{He}}-X_{\mathrm{He}} N_{\mathrm{H}_{2} \mathrm{O}}}{D_{\mathrm{He}, \mathrm{H}_{2} \mathrm{O}}}=-\frac{p}{R T} \frac{d X_{\mathrm{He}}}{d x}
$$

Since the net flow of $\mathrm{He}, N_{\mathrm{He}}$, is zero and $N_{\mathrm{H}_{2}}=-\mathrm{N}_{\mathrm{H}_{2} \mathrm{O}}$ in steady state, Equation (70) becomes

$$
N_{\mathrm{H}_{2}}\left(\frac{1}{D_{\mathrm{He}, \mathrm{H}_{2} \mathrm{O}}}-\frac{1}{D_{\mathrm{He}, \mathrm{H}_{2}}}\right) X_{\mathrm{He}}=-\frac{p}{R T} \frac{d X_{H e}}{d x}
$$

Integration of Equation (71) gives

$$
X_{\mathrm{He}}^{l_{a}}=X_{\mathrm{He}}^{o} \exp \left[\frac{R T N_{\mathrm{H}_{2}} l_{a}}{p}\left(\frac{1}{D_{\mathrm{He}, \mathrm{H}_{2}}}-\frac{1}{D_{\mathrm{He}, \mathrm{H}_{2} \mathrm{O}}}\right)\right]
$$


where $l_{a}$ is the anode thickness, $X_{H e}^{o}$ is the mole fraction of He at $x=0$, and $X_{H e}^{l_{a}}$ is the mole fraction of He at $x=l_{a}$. The case of interest is that of a porous anode. Thus, the diffusivities must be those corrected for porosity and tortuosity factor. Thus, the applicable equation is actually

$$
X_{H e}^{l_{a}}=X_{H e}^{o} \exp \left[\frac{R T N_{H_{2}} l_{a}}{p}\left(\frac{1}{D_{H e, H_{2}, e f f}}-\frac{1}{D_{H e, H_{2} O, e f f}}\right)\right]
$$

Equations (72) and (73) show that, $X_{H e}$, varies exponentially as a function of position. For the case of transport through space, in the absence of a porous body, the calculated variation of $X_{H e}$ along the electrode is very small. Using the estimated diffusion coefficients from the Chapman-Enskog model, $D_{H_{e} H_{2}}=13.29 \mathrm{~cm}^{2} / \mathrm{s}$ and $D_{H e, H_{2} O}=4.07 \mathrm{~cm}^{2} / \mathrm{s}$, the $X_{H e}$ at the electrode /electrolyte interface $\left(l_{a}=0.1 \mathrm{~cm}\right)$ is about $0.8 \%$ lower than the bulk molar value of $\mathrm{He}, X_{H e}^{o}$, at a current density of $1 \mathrm{~A} / \mathrm{cm}^{2}$, i.e. for a molar flux of $5.18 \times 10^{-6} \mathrm{~mol} / \mathrm{cm}^{2} \mathrm{~s}$. Even at a current density close to the anode limiting current density, $3 \mathrm{~A} / \mathrm{cm}^{2}, X_{H e}$ is only $3 \%$ lower than $X_{H e}^{o}$. Such, however, will not be the case for a porous body. For transport through porous anodes, equation (73) must be used. The corresponding variation in $X_{H e}$ is $\sim 10 \%$ at a current density of $1 \mathrm{~A} / \mathrm{cm}^{2}$ and $\sim 20 \%$ at a current density of $3 \mathrm{~A} / \mathrm{cm}^{2}$. Though this variation is not insignificant, for simplicity, we will neglect this aspect, and assume that the diffusion coefficient of $\mathrm{H}_{2}$ is independent of position.

If the electrode microstructure is not a function of position, i.e. $V_{v}$ and $\tau$ are constant, integration of Equation (64), using effective diffusivities, gives a simple equation for $\mathrm{H}_{2}$ flux in a ternary system, similar to that for a binary system, namely

$$
N_{\mathrm{H}_{2}}=-\frac{p D_{\mathrm{H}_{2}, \text { eff }}}{R T l_{a}}\left(X_{\mathrm{H}_{2}}-X_{\mathrm{H}_{2}}^{\prime}\right)
$$

where $X_{\mathrm{H}_{2}}^{\prime}$ and $X_{\mathrm{H}_{2}}$ are the mole fractions of $\mathrm{H}_{2}$ over the anode surface $(x=0)$ and at the anode/electrolyte interface $\left(x=l_{a}\right.$ ), and $D_{H_{2}, \text { eff }}$ is the effective ternary diffusion coefficient as defined by Equations (65) and (68). Replacing mole fractions with partial pressures, Equation (74) becomes

$$
N_{H_{2}}=-\frac{D_{H_{2}, e f f}}{R T l_{a}}\left(p_{H_{2}}-p_{H_{2}}^{\prime}\right)
$$

where, $p_{\mathrm{H}_{2}}^{\prime}$ and $p_{\mathrm{H}_{2}}$ are respectively the partial pressure of $\mathrm{H}_{2}$ over the anode surface $(x=0)$ and the partial pressure of $\mathrm{H}_{2}$ at the anode/electrolyte interface $\left(x=l_{a}\right)$. Assuming gases are well-mixed above the anode, similar to the situation in a continuously stirred tank reactor $(\mathrm{CSTR}), p_{\mathrm{H}_{2}}^{\prime}$ is given by

$$
p_{H_{2}}^{\prime}=p_{H_{2}}^{o}-\frac{N_{H_{2}} A}{m_{T}} p
$$


where $p_{\mathrm{H}_{2}}^{o}$ is the initial (incoming fuel) partial pressure of $\mathrm{H}_{2}, A$ is the electrode area (1.1 $\left.\mathrm{cm}^{2}\right), m_{T}$ is the total molar flow rate of fuel and diluent, and $p$ is the total pressure. Substituting for $p_{H_{2}}^{\prime}$ from equation (76), into equation (75) gives

$$
N_{H_{2}}=-\frac{D_{H_{2}, e f f}}{R T l_{a}}\left(p_{H_{2}}-p_{H_{2}}^{o}+\frac{N_{H_{2}} A}{m_{T}} p\right)
$$

Rearranging equation (77), $\mathrm{H}_{2}$ molar flux is given by,

$$
N_{H_{2}}=-\frac{\frac{D_{H_{2}, \text { eff }}\left(p_{H_{2}}-p_{H_{2}}^{o}\right)}{R T l_{a}}}{1+\frac{D_{H_{2}, e f f}}{R T l_{a}} \frac{A p}{m_{T}}}
$$

A maximum in $\mathrm{H}_{2}$ flux occurs when $p_{\mathrm{H}_{2}}$ at the interface approaches zero. This maximum flux is given by

$$
N_{H_{2}, \text { max }}=\frac{\frac{D_{H_{2}, \text { eff }} p_{H_{2}}^{o}}{R T l_{a}}}{1+\frac{D_{H_{2}, \text { eff }}}{R T l_{a}} \frac{A p}{m_{T}}}
$$

The net current density passing through the cell is related to the net hydrogen flux arriving at the anode/electrolyte interface, and is given by

$$
i=2 F N_{H_{2}}=-\frac{\frac{2 F D_{H_{2}, e f f}\left(p_{H_{2}}-p_{H_{2}}^{o}\right)}{R T l_{a}}}{1+\frac{D_{H_{2}, e f f}}{R T l_{a}} \frac{A p}{m_{T}}}
$$

For the maximum possible hydrogen flux given by Equation (79), there will be a corresponding maximum in current density, which is, the anode limiting current density given by

$$
i_{a s}=\frac{\frac{2 F D_{H_{2}, \text { eff }} p_{H_{2}}^{o}}{R T l_{a}}}{1+\frac{D_{H_{2}, \text { eff }}}{R T l_{a}} \frac{A p}{m_{T}}}
$$

In all experiments, when the mole percent of the diluent was more than $40 \%$, a limiting current density was observed. From the experimentally measured anode limiting current density, one can estimate the effective diffusion coefficients for $\mathrm{H}_{2}$ for several diluents and at various concentrations by rearranging Equation (81) as follows

$$
D_{H_{2}, e f f}=\frac{i_{a s}}{\frac{2 F p_{H_{2}}^{o}}{R T l_{a}}-\frac{i_{a s}}{R T l_{a}} \frac{A p}{m_{T}}}
$$


Also, for $\mathrm{CO}-\mathrm{CO}_{2}$ mixtures, Equation (82) can be used with $p_{\mathrm{H}_{2}}^{o}$ replaced by $p_{C O}^{o}$, and $D_{H_{2}, \text { eff }}$ replaced by $D_{C O, e f f}$. Table 12 lists the calculated diffusion coefficients from Equations (65) through (67), and the estimated effective $\mathrm{H}_{2}$ (and $\mathrm{CO}$ ) diffusion coefficients from Equation (82) and the experimentally measured $i_{a s}$ values from the voltage-current density polarization curves.

From Table 12, it is seen that the $\mathrm{H}_{2}$ diffusion coefficient, $D_{H_{2}}$, for $\mathrm{H}_{2}-\mathrm{H}_{2} \mathrm{O}$ is about five times larger than that for $\mathrm{CO}-\mathrm{CO}_{2}, D_{C O}$. For $\mathrm{H}_{2}-\mathrm{H}_{2} \mathrm{O}$, the effective diffusion coefficient, estimated using equation (82), ranges from 0.470 to $0.506 \mathrm{~cm}^{2} / \mathrm{s}$, almost independent of gas composition, consistent with Equation (66). For CO- $\mathrm{CO}_{2}$ mixtures, it varies from 0.063 to $0.090 \mathrm{~cm} / \mathrm{s}$ over the range of $p_{C O}$ investigated. This suggests that mass transport of $\mathrm{H}_{2}$ in $\mathrm{H}_{2}-\mathrm{H}_{2} \mathrm{O}$ mixtures should be about five to six times faster than that of $\mathrm{CO}$ in $\mathrm{CO}-\mathrm{CO}_{2}$ mixtures. If $\mathrm{CO}$ is used as a fuel, the cell performance is expected to be lower than with $\mathrm{H}_{2}$ as a fuel due to slow diffusion rate, regardless of other effects, such as the intrinsically low electrochemical activity of CO.

Prior work has shown that anodic concentration polarization for $\mathrm{H}_{2}-\mathrm{H}_{2} \mathrm{O}$ gas mixtures is given by $[4]$

$$
\eta_{\text {conc }}=-\frac{R T}{2 F} \ln \left(1-\frac{i}{i_{\text {as }}}\right)+\frac{R T}{2 F} \ln \left(1+\frac{p_{\mathrm{H}_{2}}^{o} i}{p_{\mathrm{H}_{2} \mathrm{O}}^{o} i_{a s}}\right)
$$

It is readily seen that the corresponding equation for $\mathrm{CO}-\mathrm{CO}_{2}$ gas mixtures as a fuel is given by

$$
\eta_{\text {conc }}=-\frac{R T}{2 F} \ln \left(1-\frac{i}{i_{\text {as }}}\right)+\frac{R T}{2 F} \ln \left(1+\frac{p_{C O}^{o} i}{p_{C O_{2}}^{o} i_{a s}}\right)
$$

Using equations (83) and (84) ${ }^{b}, \eta_{\text {conc }}$ was calculated as a function of current density for a $\mathrm{H}_{2-}$ $\mathrm{H}_{2} \mathrm{O}$ mixture of composition $34 \% \mathrm{H}_{2}-66 \% \mathrm{H}_{2} \mathrm{O}$, and for a $\mathrm{CO}-\mathrm{CO}_{2}$ mixture of composition $32 \% \mathrm{CO}-68 \% \mathrm{CO}_{2}$, for which the corresponding anode limiting current densities were, respectively, $\sim 2 \mathrm{~A} / \mathrm{cm}^{2}$ and $\sim 0.5 \mathrm{~A} / \mathrm{cm}^{2}$. The calculated concentration polarization is compared with the measured total polarization (by subtracting the ohmic contribution) in Figure \#67. It is readily seen that anodic concentration polarization is much greater in $\mathrm{CO}-\mathrm{CO}_{2}$ mixtures as compared to $\mathrm{H}_{2}-\mathrm{H}_{2} \mathrm{O}$ mixtures. The difference between the measured total (excluding the ohmic) and the calculated anodic concentration polarization is attributed to anodic and cathodic activation polarizations, and cathodic concentration polarization. The cathodic polarization (activation + concentration) is the same for the two curves. For the test with $\mathrm{H}_{2}-\mathrm{H}_{2} \mathrm{O}$ as the fuel, at $0.25 \mathrm{~A} / \mathrm{cm}^{2}$, the difference between the measured and the calculated polarization (equation (83)) is $\sim 0.017 \mathrm{~V}$, which includes: (a) cathodic concentration polarization, (b) cathodic activation polarization, and (c) anodic activation polarization. At the same current

\footnotetext{
${ }^{2}$ Since the partial pressure of $\mathrm{H}_{2}$ or $\mathrm{CO}$ at the anode/fuel interface is a function of the current density (using equation 76), one must strictly use $p_{\mathrm{H}_{2}}^{\prime}$ instead of $p_{\mathrm{H}_{2}}^{o}$ ( or $p_{C O}^{\prime}$ instead of $p_{C O}^{o}$ ) in estimating the concentration polarization, and attribute the remainder of the terms to polarization associated with the depletion of fuel. Here, the two terms are combined into a single equation describing concentration polarization, namely equation 33 for $\mathrm{H}_{2}$ as a fuel (or equation 84 for $\mathrm{CO}$ as a fuel).
} 
density, the difference between the measured and calculated polarization (equation (84)) is $\sim 0.19 \mathrm{~V}$ for $\mathrm{CO}-\mathrm{CO}_{2}$ as the fuel. This again includes: (a) cathodic concentration polarization, (b) cathodic activation polarization, and (c) anodic activation polarization. However, the cathodic polarizations, for (a) and (b) are identical for the two tests. Clearly, greater polarization with the $\mathrm{CO}-\mathrm{CO}_{2}$ mixture, beyond what can be attributed to anodic concentration polarization, is attributed to anodic activation polarization. That is, anodic activation polarization with $\mathrm{CO}-\mathrm{CO}_{2}$ gaseous mixture of the chosen composition at $0.25 \mathrm{~A} / \mathrm{cm}^{2}$ is $\sim 0.151$ $\mathrm{V}$ higher than that with $\mathrm{H}_{2}-\mathrm{H}_{2} \mathrm{O}$ gaseous mixture. This also suggests that $\mathrm{Ni}+\mathrm{YSZ}$ is not a very good anode for $\mathrm{CO}$ as the fuel. Indeed, it has been reported in the literature that the electrochemical reaction rate of $\mathrm{CO}$ is slower than that of $\mathrm{H}_{2}$ by at least a factor of two [21]. Comparison of performance curves for $\mathrm{H}_{2}-\mathrm{H}_{2} \mathrm{O}$ mixtures with $\mathrm{CO}-\mathrm{CO}_{2}$ mixtures from Figures 5 and 6 shows that the lower performance with $\mathrm{CO}-\mathrm{CO}_{2}$ mixtures cannot be attributed entirely to concentration polarization. Thus, although $\mathrm{CO}$ does not poison SOFC anodes unlike proton exchange membrane (PEM) fuel cells, its low electrochemical activity, at least with nickelbased anodes, and high concentration polarization, suggests that it is not an ideal fuel for $\mathrm{SOFC}$, if a high power density is a requirement.

The estimated $\mathrm{D}_{\mathrm{H}_{2}}$ using the Chapman-Enskog model, and the analysis of multi-component transport, as a function of diluent type and concentration, is given in Table 12. The

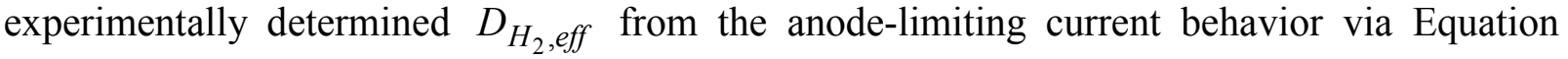
(82), which includes the effects of porosity and tortuosity, are also given in Table 12. Note that for $\mathrm{He}$ as a diluent, the estimated $D_{\mathrm{H}_{2}}$ is higher than with $\mathrm{N}_{2}$ as the diluent. Table 12 also shows that estimated $D_{H_{2}, \text { eff }}$ is also similarly higher for $\mathrm{He}$ as a diluent compared to $\mathrm{N}_{2}$ as a diluent. Similar trends are observed for $\mathrm{CO}_{2}$ as a diluent. Finally, for $\mathrm{CO}-\mathrm{CO}_{2}$ mixtures, the estimated $D_{C O}$ is much lower, and so is the $D_{C O \text {,eff }}$. In the case of either $\mathrm{N}_{2}$ or $\mathrm{CO}_{2}$ as a diluent, it is also seen that the trends in $D_{H_{2}}$ and $D_{H_{2}, e f f}$ as a function of composition are similar. That is, the results indicate that, except for $\mathrm{He}, \mathrm{H}_{2}$ diluted with either $\mathrm{N}_{2}$ or $\mathrm{CO}_{2}$ not only lowers the partial pressure of $\mathrm{H}_{2}$ but also reduces the effective $\mathrm{H}_{2}$ diffusion coefficient. Thus, the diluent can lower cell performance in two ways; reduced $p_{\mathrm{H}_{2}}$ and reduced transport kinetics. From the experimental results (Figure \#58), at $32 \% \mathrm{~N}_{2}$ dilution, the maximum power density was reduced by more than $30 \%$. It was even worse for $\mathrm{CO}_{2}$ dilution with almost $40 \%$ reduction of the maximum power density (Figure \#59) at the same diluent concentration. This suggests when either partial oxidation or auto-thermal reforming is used for processing fuel, nitrogen introduced into fuel will lead to a lowering of diffusive transport, in addition to fuel dilution. The present work also shows that if in a reforming stage most of the $\mathrm{CO}$ is converted to $\mathrm{CO}_{2}$ via a gas shift reaction, in addition to fuel dilution, there will also be an adverse effect on diffusive transport.

Using $D_{\mathrm{H}_{2}}, D_{\mathrm{H}_{2}, \text { eff }}, D_{\mathrm{CO}}$, and $D_{\mathrm{CO} \text {,eff }}$ and the measured porosity of $54 \%$ for the Ni-YSZ anode, the tortuosity factor of the anode, $\tau$, was calculated from equations (68) and (69). All of the tortuosity factors fall between 5.0 to 7.0 from $\mathrm{H}_{2}-\mathrm{H}_{2} \mathrm{O}$ and $\mathrm{CO}-\mathrm{CO}_{2}$ binary system measurements (with the exception of one value which is over 8.0) and from $\mathrm{H}_{2}-\mathrm{H}_{2} \mathrm{O}$ with $\mathrm{He}$, $\mathrm{N}_{2}$ and $\mathrm{CO}_{2}$ dilution (with the exception of one value which is 9). The observation that 
tortuosity factor is on the order of $\sim 5$ to $\sim 7$ justifies the use of effective diffusivities. At the same time, the observation that the estimated tortuosity factor does exhibit some variability suggests that it may include effects in addition to purely geometric factors (such as, possibly adsorption and surface diffusion). A value of 5 measured by a different method for a Ni-YSZ anode has been reported in the literature [22]. This suggests that the possible effects of adsorption/desorption and surface diffusion must be small in anodes of the present study.

Cell Performance with $\mathrm{H}_{2}+\mathrm{CO}$ Mixture as the Fuel: The cell performance with as-received $\mathrm{CO}$ as fuel was poor because of slow diffusion and slow electrochemical reaction rate, as discussed earlier. However, the cell performance on $\mathrm{H}_{2}+\mathrm{CO}$, even when $\mathrm{CO}$ concentration was as high as $55 \%$, was very high, close to that with as-received $\mathrm{H}_{2}$ (Figure \#63), and quite high with $\mathrm{CO}$ content as high as $80 \%$. The diffusion coefficient of $\mathrm{H}_{2}$ in $\mathrm{H}_{2}-\mathrm{H}_{2} \mathrm{O}-\mathrm{CO}$ ternary mixtures (ignoring the effects of $\mathrm{CO}_{2}$ ) may be given by

$$
D_{\mathrm{H}_{2}}=\left(\frac{1}{D_{K, \mathrm{H}_{2}}}+\frac{X_{\mathrm{CO}}}{D_{\mathrm{H}_{2}, \mathrm{CO}}}+\frac{1-X_{\mathrm{CO}}}{D_{\mathrm{H}_{2}, \mathrm{H}_{2} \mathrm{O}}}\right)^{-1}
$$

The calculated $D_{H_{2}}$ ranges between 4.17 and $4.31 \mathrm{~cm}^{2} / \mathrm{s}$ for $\mathrm{CO}$ mole fraction between 0.8 and 0.5 , which is similar to that for $\mathrm{H}_{2}-\mathrm{H}_{2} \mathrm{O}-\mathrm{N}_{2}$. However, the observed performance with $\mathrm{H}_{2}-\mathrm{CO}$ is much superior to that with $\mathrm{H}_{2}-\mathrm{H}_{2} \mathrm{O}-\mathrm{N}_{2}$ mixtures as the fuel. This, of course, is consistent with expectations, since a shift reaction is expected in $\mathrm{H}_{2}-\mathrm{CO}$ gas mixtures during cell operation. At $800^{\circ} \mathrm{C}$, the standard Gibbs free energy for the gas shift reaction

$$
\mathrm{CO}+\mathrm{H}_{2} \mathrm{O} \Leftrightarrow \mathrm{CO}_{2}+\mathrm{H}_{2}
$$

is only $-0.368 \mathrm{~kJ} / \mathrm{mol}$ [17]. However, the reaction rate constant is very high as reported in the literature and thus it may be assumed that the shift reaction at the anode/electrolyte interface is at equilibrium [22]. Thus, for a fuel gas composition containing greater than $50 \% \mathrm{H}_{2}$ (and balance $\mathrm{CO}$ ), it can be argued that $\mathrm{H}_{2} \mathrm{O}$ produced by the electrochemical oxidation of $\mathrm{H}_{2}$ is more than sufficient to react with $\mathrm{CO}$ present to form $\mathrm{H}_{2}$ and $\mathrm{CO}_{2}$. In such a case, there should be little difference in performance when compared to pure $\mathrm{H}_{2}$ as fuel (with the exception of a small difference related to differences in concentration polarization). Indeed, it is seen that there is very little difference in performance with fuels ranging in composition from $\sim 100 \% \mathrm{H}_{2}$ and $\sim 45 \% \mathrm{H}_{2}+\sim 55 \% \mathrm{CO}$, as seen in Figure \#63. For compositions of fuel containing substantially greater than $50 \% \mathrm{CO}$, the $\mathrm{H}_{2} \mathrm{O}$ produced by the electrochemical oxidation of $\mathrm{H}_{2}$ will not be sufficient to shift most of $\mathrm{CO}$ to $\mathrm{CO}_{2}$. The remaining $\mathrm{CO}$ will have to be oxidized electrochemically to $\mathrm{CO}_{2}$, for which polarization is observed to be much greater (Figure \#61). Indeed, Figure \#63 shows that the performance is much worse with fuels containing $\sim 68 \% \mathrm{CO}$ $+\sim 32 \% \mathrm{H}_{2}$ and $\sim 80 \% \mathrm{CO}+\sim 20 \% \mathrm{H}_{2}$.

\section{CONCLUSIONS}

Nanosize YSZ powder was prepared by a novel approach, in which yttria-doped $\mathrm{BaZrO}_{3}$ or yttria-doped $\mathrm{Na}_{2} \mathrm{ZrO}_{3}$ precursors were first synthesized by a solid-state reaction. Then, the unwanted species, $\mathrm{BaO}$ or $\mathrm{Na}_{2} \mathrm{O}$, was leached away by washing the precursors in a dilute $\mathrm{HNO}_{3}$ solution or in water. This led to the formation of very fine, nanosize yttria-stabilized zirconia (YSZ). The particle size of the as-synthesized YSZ powders was a few nanometers and increased to tens of nanometers after thermal treatment at a temperature as high as $1000^{\circ} \mathrm{C}$. 
The effect of asymmetric testing geometry was examined, both theoretically and experimentally, in this work. The present work developed simple analytical relationships, which elucidate the role of different cathode and anode areas, the so-called asymmetric electrodes, on the measured performance of anode-supported solid oxide fuel cells. The analytical relations show that there should be negligible effect of anode electronic resistance and the possible enhanced electrolyte region on the measured cell performance when testing cells with a different cathode area compared to anode area, wherein the cathode area is smaller than the anode area. The analysis shows that the principal source of the difference lies in differences in anodic concentration polarizations. Specifically, a cell with a smaller cathode, in relation to the anode, will exhibit a lower anodic concentration polarization by virtue of the larger area of the anode through which fuel gas transport occurs. This will effectively lead to a higher value of power density in a cell with a smaller cathode. The degree to which the power density will be overestimated will depend upon transport properties of the anode, the thickness of the anode, and the relative size of the cathode. For a cell with a relatively thin anode, for example $500 \mu \mathrm{m}$ or less, there would be virtually no detectable difference in the measured power density due to the so-called asymmetry of the cathode, as long as $r_{c} \gg l_{a}$. That is, as long as the anode is sufficiently thin, there should be virtually no effect of the cathode asymmetry on the measured cell performance. Indeed, experimental results in our laboratory and those of other researchers are in accord with this expectation. The results of experimental work of the present study are in general good agreement with the analysis presented here. Measurements demonstrated that cells with a smaller cathode exhibited a somewhat smaller overall anodic overpotential, while the ohmic and cathodic overpotentials were independent of the cathode area.

The effect of electrode microstructure on polarization was examined. The present work shows that electrode microstructure has a profound effect on polarization, and thus on cell performance. Anode-supported single cells were made with varying amounts of LSM and YSZ in cathode interlayers. Cell performance was strongly dependent on the cathode interlayer composition. Cathode interlayer microstructure was quantitatively analyzed by quantitative stereology, which was used to estimate volume fraction porosity, $V_{v}$, aggregate grain size of YSZ, $d$, and three phase boundary (TPB) line length, $l_{T P B}$, in the cathode interlayer. The previously developed theoretical model affords the definition of an effective charge transfer resistance, $R_{c t}^{\text {eff }}$, a measure of electrode activation polarization, which depends linearly on the microstructural parameter, $\sqrt{d /\left(\left(1-V_{v}\right) l_{T P B}\right)}$. From a plot of $R_{c e l l}$ vs. $\sqrt{d /\left(\left(1-V_{v}\right) l_{T P B}\right)}$, the fundamental charge transfer parameter, $\rho_{c t}$, which defines the nature of charge transfer at $\mathrm{LSM} / \mathrm{YSZ} /$ air TPB, was determined to be $\sim 1.0 \times 10^{5} \Omega \mathrm{cm}$ at $800^{\circ} \mathrm{C}$. A realistic comparison between various electrocatalyst/electrolyte pairs would require the measurement of $\rho_{c t}$.

Anode-supported solid oxide fuel cells were fabricated with a thin film YSZ electrolyte and a composite cathode, consisting of a mixture of $\mathrm{La}_{0.9} \mathrm{Sr}_{0.1} \mathrm{Ga}_{0.8} \mathrm{Mg}_{0.2} \mathrm{O}_{(3-\lambda)}$ (LSGM) and $\mathrm{La}_{0.8} \mathrm{Sr}_{0.2} \mathrm{MnO}_{(3-\delta)}$ (LSM). The relative compositions and firing temperatures of the composite cathode interlayers were varied and the resulting effects on cell performance were investigated. Variations in the composition of the cathode interlayer had a profound effect on the overpotential at the cathode and the performance of the cells. In the composition range 30 to 70 
wt.\% LSGM and 70 to $30 \mathrm{wt} . \%$ LSM, the cathodic overpotential varied between $65 \mathrm{mV}$ and $400 \mathrm{mV}$ at $1.0 \mathrm{~A} / \mathrm{cm}^{2}$ at $800^{\circ} \mathrm{C}$ and exhibited a minimum for the $50 / 50$ composition. The large change in cathodic performance with composition is reflected in the maximum power densities of the cells, which varied between 0.4 and $1.4 \mathrm{~W} / \mathrm{cm}^{2}$. In addition to compositional changes, the cathode interlayer firing temperature was varied between 1000 and $1200^{\circ} \mathrm{C}$ while the composition was fixed at $50 \mathrm{wt} \%$ LSGM $+50 \mathrm{wt} \%$ LSM. The overpotentials at the cathode decreased with increasing firing temperature in the range $1000 \leq \mathrm{T} \leq 1150^{\circ} \mathrm{C}$, and then increased again for the interlayer fired at $1200^{\circ} \mathrm{C}$. The effects of cathode interlayer firing temperature on cell performance are dramatic, with maximum power densities ranging between 0.6 and $1.4 \mathrm{~W} / \mathrm{cm}^{2}$ for firing temperatures of $1000 \leq \mathrm{T} \leq 1200^{\circ} \mathrm{C}$. The dramatic decrease in performance between the cell with the cathode interlayer fired at $1150^{\circ} \mathrm{C}$ and the one fired at $1200^{\circ} \mathrm{C}$ is attributed to a phase reaction between LSGM and YSZ. Chemical analysis and powder X-ray diffraction revealed that LSGM reacts with YSZ above $1000^{\circ} \mathrm{C}$ to form the pyrochlore phase $\mathrm{La}_{2} \mathrm{Zr}_{2} \mathrm{O}_{7}$. The formation of this resistive pyrochlore phase at the interface between the LSGM/LSM composite cathode and the YSZ electrolyte may limit the firing time and temperature of the cathode interlayer. The cathode interlayer was optimized with a composition of $50 \mathrm{wt} \%$ LSGM and $50 \mathrm{wt} \%$ LSM and a firing temperature of $1150^{\circ} \mathrm{C}$, resulting in a cell exhibiting an area specific resistance of $0.18 \Omega \mathrm{cm}^{2}$ and a maximum power density of $1.4 \mathrm{~W} / \mathrm{cm}^{2}$ at $800^{\circ} \mathrm{C}$.

The effects of temperature on the reduction of NiO-YSZ based two-phase composites, and reoxidation kinetics of porous Ni-YSZ anodes were investigated. In the temperature range of $600-800^{\circ} \mathrm{C}$ for thickness up to $1 \mathrm{~mm}$, the reduction kinetics was interface-controlled and was thermally activated with an activation energy of $\sim 94 \mathrm{~kJ} / \mathrm{mol}$. By contrast, the re-oxidation kinetics was diffusion-controlled with an apparent diffusion coefficient on the order of $\sim 10^{-7}$ $\mathrm{cm}^{2} / \mathrm{s}$, which was essentially independent of temperature over the range investigated. An examination of the re-oxidized layers showed that some porosity was created during the process. The re-oxidation process is believed to be governed by the occurrence of gaseous diffusion though the pores formed during the reduction/reoxidation process.

Anode-supported solid oxide fuel cells exhibit substantial effect of an inert gas diluent in the fuel on concentration polarization, consistent with expectations based on multi-component gas diffusion in porous bodies. Specifically, anodic concentration polarization is lower with an inert gas diluent of a low molecular weight (such as He), than an inert gas diluent of a higher molecular weight (such as $\mathrm{N}_{2}$ ). For a sufficiently high concentration of the diluent, the voltage vs. current density traces exhibits anode limiting current density behavior, characterizing a rapid drop of voltage at a critical current density. This current density was used to estimate the corresponding effective diffusivities. Electrochemical performance with $\mathrm{CO}+\mathrm{CO}_{2}$ gas mixtures is much worse than fuel gas mixtures containing $\mathrm{H}_{2}$. This is rationalized in part on higher anodic concentration polarization, and slower electrochemical oxidation of $\mathrm{CO}$. The results show that $\mathrm{Ni}+\mathrm{YSZ}$ is an excellent anode for hydrogen gas $\left(\mathrm{H}_{2}\right)$-containing fuel, but not for $\mathrm{CO}$. Studies on cell performance with $\mathrm{CO}+\mathrm{H}_{2}$ gas mixtures as fuel show that water gas shift reaction plays a major role. Effectively, as long as the $\mathrm{H}_{2}$ content is greater than $\sim 50 \%$, high performance is maintained by producing additional $\mathrm{H}_{2}$ through the shift reaction. As a result, the cell performance with essentially pure $\mathrm{H}_{2}$ is about the same as that with a $\mathrm{H}_{2}+\mathrm{CO}$ gaseous mixture as fuel, as long as the $\mathrm{CO}$ concentration is not too high. 


\section{REFERENCES}

1) I. Barin, 'Thermochemical Data of Pure Substances', $3^{\text {rd }}$. ed. Weinheim,New York, (1995).

2) C. W. Tanner, K-Z. Fung, and A. V. Virkar, J. Electrochem. Soc., 144 [1] 21-30 (1997).

3) Handbook of Physics and Chemistry, $58^{\text {th }}$ edition, CRC Press, Inc. Cleveland (1978).

4) J-W. Kim, A. V. Virkar, K-Z. Fung, K. Mehta, and S. C. Singhal, J. Electrochem Soc., 146 [1] 69-78 (1999).

5) A. V. Virkar, J. Chen, C. W. Tanner, and J-W. Kim, Solid State Ionics, 131 189-198 (2000).

6) E. L. Cussler, 'Diffusion: Mass Transfer in Fluid Systems' Cambridge University Press, Cambridge (1995).

7) E. A. Mason and A. P. Malinauskas, 'Gas Transport in Porous Media: The Dusty Gas Model', Elsevier, Amsterdam (1983).

8) E. E. Underwood, 'Quantitative Stererology', Addison-Wesley Publication, New York, (1970).

9) Y. Jiang, and A. V. Virkar, and F. Zhao, J. Electrochem. Soc., 148 (10), A1091-A1099 (2001).

10) A. V. Virkar, J. Chen, C. W. Tanner, and J-W. Kim, Solid State Ionics, 131 189-198 (2000).

11) J. Winkler, P. V. Hendriksen, N. Bonanos, and M. Mogensen, J. Electrochem. Soc., 145, 1184 (1998).

12) T. Kenjo, S. Osawa, and K. Fujikawa, J. Electrochem. Soc., 138, 349 (1991).

13) M. Feng and J. B. Goodenough, Eur. J. Solid State Inorg. Chem., 31, 663 (1994).

14) T. Ishihara, H. Matruda, and Y. Takita, J. Am. Chem. Soc., 116, 3801 (1994).

15) K. Huang, M. Feng, J. B. Goodenough, and M. Schmerling, J. Electrochem. Soc., 143, 2630 (1996).

16) R. D. Shannon, Acta Crystallographica, A32, 751 (1976).

17) D. R. Lide and H. V. Kehiaian, 'CRC Handbook of Thermophysical and Thermochemical Data', CRC Press Inc., Boca Raton, Florida (1994).

18) R. R. Remick and C. J. Geankoplis, Chemical Engineering Science, 29, 1447-1455 (1974).

19) S. Weissman and E. A. Mason, J. of Chem. Phys., 37(6), 1289-1300 (1962).

20) N. B. Vargaftik, 'Handbook of Physical Properties of Liquids and Gases', 2 ${ }^{\text {nd }}$ ed., Hemisphere Publ. Corp. (1976).

21) H. Yakabe, M. Hishinuma, M. Uratani, and Y. Matsuzaki, I. Yasuda, J. Power Sources, 86, 423-431(2000).

22) W. Lehnert, J. Meusinger, and F. Thom, J. Power Source, 87, 57-63 (2000). 


\section{TABLES}

Table 1: Chemical analysis of the leaching solution (dilute $\mathrm{HNO}_{3}$ ) after boiling $\mathrm{Y}^{-\mathrm{BaZrO}_{3}}$ in it.

\begin{tabular}{|l|l|l|l|l|}
\hline Powder & Solution & $\begin{array}{l}\text { Barium } \\
(\mathrm{mol} / \mathrm{l})\end{array}$ & $\begin{array}{l}\text { Yttrium } \\
(\mathrm{mol} / \mathrm{l})\end{array}$ & $\begin{array}{l}\text { Zirconium } \\
(\mathrm{mol} / \mathrm{l})\end{array}$ \\
\hline $\mathrm{Y}: \mathrm{BaZrO}_{3}$ & $0.3 \mathrm{M} \mathrm{HNO}_{3}$ & 0.104 & $7.11 \times 10^{-4}$ & $<2.0 \times 10^{-5}$ \\
\hline $\mathrm{Y}: \mathrm{BaZrO}_{3}$ & $0.07 \mathrm{M} \mathrm{HNO}_{3}$ & 0.062 & $3.0 \times 10^{-5}$ & $<2.0 \times 10^{-5}$ \\
\hline
\end{tabular}

Table 2: Chemical analysis of the leaching solution (water) after boiling $\mathrm{Y}-\mathrm{Na}_{2} \mathrm{ZrO}_{3}$ in it.

\begin{tabular}{|c|c|c|c|}
\hline Powder & $\begin{array}{c}\text { Sodium } \\
(\mathrm{mol} / \mathrm{l})\end{array}$ & $\begin{array}{c}\text { Yttrium } \\
(\mathrm{mol} / \mathrm{l})\end{array}$ & $\begin{array}{c}\text { Zirconium } \\
(\mathrm{mol} / \mathrm{l})\end{array}$ \\
\hline $\mathrm{Y}: \mathrm{Na}_{2} \mathrm{ZrO}_{3}$ & 0.713 & $<5 \times 10^{-5}$ & $<5 \times 10^{-5}$ \\
\hline
\end{tabular}

Table 3: Chemical analysis of the synthesized YSZ nanosize powders

\begin{tabular}{|l|l|l|l|l|}
\hline Sample & $\mathrm{Zr}^{4+}$ & $\mathrm{Y}^{3+}$ & $\mathrm{Ba}^{2+}$ & $\mathrm{Na}^{+}$ \\
\hline $\begin{array}{l}\text { YSZ made using } \\
\text { Y-Na }\end{array} \mathrm{ZrO}_{3}$ & 0.095 wt.\% & 0.017 wt.\% & ----- & $7 \mathrm{ppm}$ \\
\hline $\begin{array}{l}\text { YSZ made using } \\
\text { Y-BaZrO }\end{array}$ & 0.21 wt.\% & 0.01 wt.\% & $12 \mathrm{ppm}$ & ------- \\
\hline
\end{tabular}

Table 4: Particle size (nm) of as-synthesized nanosize YSZ powder and after heating in air at various temperatures.

\begin{tabular}{|c|c|c|c|}
\hline $\begin{array}{l}\text { Thermal treatment } \\
\text { conditions }\end{array}$ & $\begin{array}{l}\text { YSZ from } \\
\mathrm{Y}-\mathrm{BaZrO}_{3} \\
d \text { in } \mathrm{nm}\end{array}$ & $\begin{array}{l}\text { Thermal treatment } \\
\text { conditions }\end{array}$ & 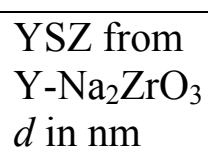 \\
\hline as washed & 2.4 & As-washed & 2.4 \\
\hline $350^{\circ} \mathrm{C} / 1.5 \mathrm{~h}$ & 8.0 & $300^{\circ} \mathrm{C} / 1.5 \mathrm{~h}$ & 4.8 \\
\hline $450^{\circ} \mathrm{C} / 1.5 \mathrm{~h}$ & 10 & $350^{\circ} \mathrm{C} / 1.5 \mathrm{~h}$ & 17 \\
\hline $650^{\circ} \mathrm{C} / 1.5 \mathrm{~h}$ & 23 & $650^{\circ} \mathrm{C} / 1.5 \mathrm{~h}$ & 18 \\
\hline $1000^{\circ} \mathrm{C} / 5 \mathrm{~h}$ & 37 & $1000^{\circ} \mathrm{C} / 5 \mathrm{~h}$ & 31 \\
\hline
\end{tabular}

Table 5: Surface areas of as-calcined precursors, as-synthesized nanosize YSZ, and after hetaing the nanosize YSZ to $1000^{\circ} \mathrm{C}$ for $5 \mathrm{hrs}$.

\begin{tabular}{|l|c|c|l|l|}
\hline Sample & $\mathrm{Y}^{-\mathrm{BaZrO}_{3}}$ & $\mathrm{Y}-\mathrm{Na}_{2} \mathrm{ZrO}_{3}$ & $\begin{array}{l}\text { As-synthesized } \\
\text { Nanosize } \mathrm{YSZ} \\
\text { from Y- } \\
\mathrm{Na}_{2} \mathrm{ZrO}_{3} \\
\text { precursor }\end{array}$ & $\begin{array}{l}\text { Nanosize } \\
\text { after 5 hrs. } \\
\text { at } 1000^{\circ} \mathrm{C}\end{array}$ \\
\hline Surface Area $\left(\mathrm{m}^{2} / \mathrm{g}\right)$ & 3.5 & 2.7 & 66.6 & 13.6 \\
\hline
\end{tabular}


Table 6: Measured Microstructural Parameters by Quantitative Stereology

\begin{tabular}{|l|l|l|l|l|l|}
\hline \hline $\begin{array}{l}\text { Cathode } \\
\text { Interlayer Composition }\end{array}$ & $V_{v}$ & $V_{L S M}$ & $V_{Y S Z}$ & $d=3 V_{Y S Z} / P_{L}(\mathrm{~cm})$ & $\begin{array}{l}l_{T P B}=P_{A} / P_{L} \\
\left(\mathrm{~cm}^{-1}\right)\end{array}$ \\
\hline 25wt.\%LSM, 75wt.\%YSZ & $\sim 0.185$ & $\sim 0.206$ & $\sim 0.609$ & $\sim 2.13 \times 10^{-4}$ & $\sim 1782$ \\
\hline 35wt.\%LSM, 65wt.\% YSZ & $\sim 0.185$ & $\sim 0.287$ & $\sim 0.528$ & $\sim 1.57 \times 10^{-4}$ & $\sim 5173$ \\
\hline 40wt.\%LSM, 60wt.\% YSZ & $\sim 0.192$ & $\sim 0.323$ & $\sim 0.485$ & $\sim 1.41 \times 10^{-4}$ & $\sim 6547$ \\
\hline 50wt.\%LSM, 50wt.\% YSZ & $\sim 0.194$ & $\sim 0.406$ & $\sim 0.4$ & $\sim 9.3 \times 10^{-5}$ & $\sim 3115$ \\
\hline 60wt.\%LSM, 40wt.\% YSZ & $\sim 0.144$ & $\sim 0.514$ & $\sim 0.342$ & $\sim 6.54 \times 10^{-5}$ & $\sim 1945$ \\
\hline
\end{tabular}

Table 7: Estimated Microstructural Parameter using Data from Table I and Measured Area Specific Resistance.

\begin{tabular}{|l|l|l|}
\hline $\begin{array}{l}\text { Cathode Interlayer } \\
\text { Composition }\end{array}$ & $\begin{array}{l}\text { Microstructural Parameter } \\
\sqrt{d /\left(\left(1-V_{v}\right) l_{T P B}\right)} \\
(\mathrm{cm})\end{array}$ & $\begin{array}{l}R_{\text {cell }} \\
\left(\Omega \mathrm{cm}^{2}\right)\end{array}$ \\
\hline 25 wt.\% LSM, 75 wt.\% YSZ & $3.8296 \times 10^{-4}$ & 0.694 \\
\hline 35 wt.\% LSM, 65 wt.\% YSZ & $1.9297 \times 10^{-4}$ & 0.243 \\
\hline 40 wt.\% LSM, 60 wt.\% YSZ & $1.6326 \times 10^{-4}$ & 0.229 \\
\hline 50 wt.\% LSM, 50 wt.\% YSZ & $1.9246 \times 10^{-4}$ & 0.288 \\
\hline 60 wt.\% LSM, 40 wt.\% YSZ & $1.9819 \times 10^{-4}$ & 0.371 \\
\hline
\end{tabular}


Table 8: Charge transfer resistance and exchange current density for composite cathodes with various compositions fired at $1150^{\circ} \mathrm{C}$.

\begin{tabular}{|l|c|c|c|c|c|}
\hline $\begin{array}{l}\text { Cathode } \\
\text { Composition }\end{array}$ & $\begin{array}{l}30 \% \text { LSGM } \\
70 \% \text { LSM }\end{array}$ & $\begin{array}{l}40 \% \text { LSGM } \\
60 \% \text { LSM }\end{array}$ & $\begin{array}{l}50 \% \text { LSGM } \\
50 \% \text { LSM }\end{array}$ & $\begin{array}{l}60 \% \text { LSGM } \\
40 \% \text { LSM }\end{array}$ & $\begin{array}{c}70 \% \text { LSGM } \\
30 \% \text { LSM }\end{array}$ \\
\hline $\begin{array}{l}\text { Charge } \\
\text { transfer } \\
\text { resistance } \\
\left(\Omega \mathrm{cm}^{2}\right)\end{array}$ & 0.557 & 0.277 & 0.242 & 0.431 & 0.417 \\
\hline $\begin{array}{l}\mathrm{i}_{\mathrm{o}} \text { exchange } \\
\text { current } \\
\text { density } \\
\left(\mathrm{mA} / \mathrm{cm}^{2}\right)\end{array}$ & 41.5 & 83.4 & 95.4 & 53.6 & 55.4 \\
\hline
\end{tabular}

Table 9: Charge transfer resistance and exchange current density for the $50 \mathrm{wt} . \%$ $\mathrm{LSGM} / 50 \mathrm{wt} \% \mathrm{LSM}$ composite cathode fired at various temperatures.

\begin{tabular}{|l|c|c|c|c|c|}
\hline $\begin{array}{l}\text { Cathode } \\
\text { Firing } \\
\text { Temperature }\end{array}$ & $1000^{\circ} \mathrm{C}$ & $1050^{\circ} \mathrm{C}$ & $1100^{\circ} \mathrm{C}$ & $1150^{\circ} \mathrm{C}$ & $1200^{\circ} \mathrm{C}$ \\
\hline $\begin{array}{l}\text { Charge } \\
\text { transfer } \\
\text { resistance } \\
\left(\Omega \mathrm{cm}^{2}\right)\end{array}$ & 0.348 & 0.323 & 0.282 & 0.242 & 0.405 \\
\hline $\begin{array}{l}\mathrm{i}_{\mathrm{o}} \text { exchange } \\
\text { current } \\
\text { density } \\
\left(\mathrm{mA} / \mathrm{cm}^{2}\right)\end{array}$ & 66.4 & 71.5 & 81.9 & 95.4 & 57.0 \\
\hline
\end{tabular}


Table 10: Density and porosities of as-sintered, reduced, and re-oxidized samples.

\begin{tabular}{|l|l|l|}
\hline Porosity & $\begin{array}{l}\text { Reduced and re-oxidized } \\
\text { At } 800^{\circ} \mathrm{C}\end{array}$ & $\begin{array}{l}\text { Reduced and re-oxidized } \\
\text { At } 700^{\circ} \mathrm{C}\end{array}$ \\
\hline $\begin{array}{l}\text { As-sintered density } \\
\text { (\% theoretical) }\end{array}$ & $99.5 \%$ & $99.5 \%$ \\
\hline $\begin{array}{l}\text { Porosity of reduced } \\
\text { Samples (\%) (by water } \\
\text { immersion) }\end{array}$ & $25.8 \%$ & $26 \%$ \\
\hline $\begin{array}{l}\text { Porosity after } \\
\text { Re-oxidation (by SEM) }\end{array}$ & $9.9 \%$ & $8.7 \%$ \\
\hline
\end{tabular}


Table 11: Calculated binary diffusion coefficients from the Chapman-Enskog equation and comparison with some experimental data from the literature.

\begin{tabular}{|l|l|l|l|l|l|l|}
\hline $\begin{array}{l}D_{i j} \\
\mathrm{~cm}^{2} / \mathrm{s}\end{array}$ & $\mathrm{H}_{2}-\mathrm{He}$ & $\mathrm{H}_{2}-\mathrm{N}_{2}$ & $\mathrm{H}_{2}-\mathrm{CO}_{2}$ & $\mathrm{H}_{2}-\mathrm{H}_{2} \mathrm{O}$ & $\mathrm{H}_{2}-\mathrm{CO}$ & $\mathrm{CO}-\mathrm{CO}_{2}$ \\
\hline & 1.535 & 0.722 & 0.604 & 0.738 & 0.726 & 0.149 \\
$293 \mathrm{~K}$ & $\begin{array}{l}1.53^{\mathrm{a}} \\
1.49^{\mathrm{c}}\end{array}$ & $\begin{array}{l}0.728^{\mathrm{a}} \\
0.772^{\mathrm{c}}\end{array}$ & $0.651^{\mathrm{b}}$ & $0.834^{\mathrm{b}}$ & $\begin{array}{l}0.735^{\mathrm{a}} \\
0.772^{\mathrm{c}}\end{array}$ & $0.162^{\mathrm{c}}$ \\
\hline & 3.417 & 1.626 & 1.395 & 1.819 & 1.642 & 0.349 \\
$473 \mathrm{~K}$ & $3.45^{\mathrm{a}}$ & $1.631^{\mathrm{a}}$ & $1.513^{\mathrm{b}}$ & $1.996^{\mathrm{b}}$ & $1.651^{\mathrm{a}}$ & $0.384^{\mathrm{c}}$ \\
& $3.39^{\mathrm{c}}$ & $1.743^{\mathrm{c}}$ & $1.473^{\mathrm{c}}$ & & $1.743^{\mathrm{c}}$ & \\
\hline & 13.29 & 6.303 & 5.56 & 7.704 & 6.373 & 1.408 \\
\hline \multirow{2}{*}{$1073 \mathrm{~K}$} & & & & & & \\
\hline
\end{tabular}

a. From reference [19].

b. From reference [20].

c. From reference [17]. 
Table 12: Partial Pressure of Dilute Gas, Anode Limiting Current Density, $\mathrm{H}_{2}$ and CO Diffusion Coefficient, Porosity and Tortuosity

H $\mathbf{H}_{2}-\mathbf{H}_{2} \mathbf{O}$ Binary System
\begin{tabular}{|l|l|l|l|l|l|}
\hline$p_{H_{2}}$ & $i_{a s}\left(\mathrm{~A} / \mathrm{cm}^{2}\right)$ & $\begin{array}{l}D_{H_{2}}, \mathrm{~cm}^{2} / \mathrm{s} \\
\text { (cal.) }\end{array}$ & $\begin{array}{l}D_{H_{2}, \text { eff }}, \mathrm{cm}^{2} / \mathrm{s} \\
\text { (exp.) }\end{array}$ & $\begin{array}{l}\text { Porosity, \% } \\
\text { (exp.) }\end{array}$ & Tortuosity \\
\hline 0.2 & 1.3 & 4.58 & 0.506 & 54 & 4.89 \\
\hline 0.34 & 2.1 & 4.58 & 0.470 & 54 & 5.26 \\
\hline 0.5 & 3.25 & 4.58 & 0.506 & 54 & 4.89 \\
\hline
\end{tabular}

\section{$\mathrm{CO}-\mathrm{CO}_{2}$ Binary System}

\begin{tabular}{|l|l|l|l|l|l|}
\hline$p_{C O}$ & $i_{a s}\left(\mathrm{~A} / \mathrm{cm}^{2}\right)$ & $\begin{array}{l}D_{C O}, \mathrm{~cm}^{2} / \mathrm{s} \\
(\mathrm{cal} .)\end{array}$ & $\begin{array}{l}D_{C O, e f f}, \mathrm{~cm}^{2} / \mathrm{s} \\
(\text { exp.) }\end{array}$ & $\begin{array}{l}\text { Porosity, } \% \\
(\text { exp. })\end{array}$ & Tortuosity \\
\hline 0.18 & 0.21 & 0.958 & 0.063 & 54 & 8.27 \\
\hline 0.23 & 0.31 & 0.958 & 0.073 & 54 & 7.08 \\
\hline 0.32 & 0.49 & 0.958 & 0.084 & 54 & 6.17 \\
\hline 0.44 & 0.73 & 0.958 & 0.091 & 54 & 5.65 \\
\hline
\end{tabular}

\section{$\mathrm{H}_{\mathbf{2}}-\mathrm{He}-\mathrm{H}_{\mathbf{2}} \mathrm{O}$ Ternary System}

\begin{tabular}{|l|l|l|l|l|l|}
\hline$p_{\text {He }}$ & $i_{\text {as }}\left(\mathrm{A} / \mathrm{cm}^{2}\right)$ & $\begin{array}{l}D_{\mathrm{H}_{2}}, \mathrm{~cm}^{2} / \mathrm{s} \\
(\mathrm{cal} .)\end{array}$ & $\begin{array}{l}D_{\mathrm{H}_{2}, \text { eff }}, \mathrm{cm}^{2} / \mathrm{s} \\
(\text { exp. })\end{array}$ & $\begin{array}{l}\text { Porosity, \% } \\
(\text { exp.) }\end{array}$ & Tortuosity \\
\hline 0.78 & 1.5 & 5.677 & 0.545 & 54 & 5.62 \\
\hline 0.65 & 2.4 & 5.458 & 0.550 & 54 & 5.35 \\
\hline 0.53 & 3.25 & 5.269 & 0.558 & 54 & 5.10 \\
\hline 0.42 & 4 & 5.108 & 0.556 & 54 & 4.96 \\
\hline
\end{tabular}

\section{$\mathbf{H}_{\mathbf{2}}-\mathbf{N}_{\mathbf{2}}-\mathrm{H}_{\mathbf{2}} \mathrm{O}$ Ternary System}

\begin{tabular}{|l|l|l|l|l|l|}
\hline$p_{N_{2}}$ & $i_{a s}\left(\mathrm{~A} / \mathrm{cm}^{2}\right)$ & $\begin{array}{l}D_{H_{2}}, \mathrm{~cm}^{2} / \mathrm{s} \\
(\mathrm{cal})\end{array}$ & $\begin{array}{l}D_{H_{2}, \text { eff }}, \mathrm{cm}^{2} / \mathrm{s} \\
\text { (exp.) }\end{array}$ & $\begin{array}{l}\text { Porosity, \% } \\
\text { (exp.) }\end{array}$ & Tortuosity \\
\hline 0.8 & 0.89 & 4.135 & 0.295 & 54 & 7.56 \\
\hline 0.67 & 1.56 & 4.2 & 0.320 & 54 & 7.09 \\
\hline 0.57 & 2.3 & 4.252 & 0.379 & 54 & 6.05 \\
\hline 0.5 & 2.65 & 4.289 & 0.375 & 54 & 6.18 \\
\hline
\end{tabular}

\section{$\mathrm{H}_{2}-\mathrm{CO}_{2}-\mathrm{H}_{\mathbf{2}} \mathrm{O}$ Ternary System}

\begin{tabular}{|l|l|l|l|l|l|}
\hline$p_{\mathrm{CO}_{2}}$ & $i_{a s}\left(\mathrm{~A} / \mathrm{cm}^{2}\right)$ & $\begin{array}{l}D_{\mathrm{H}_{2}}, \mathrm{~cm}^{2} / \mathrm{s} \\
\text { (cal.) }\end{array}$ & $\begin{array}{l}D_{\mathrm{H}_{2}, \text { eff }}, \mathrm{cm}^{2} / \mathrm{s} \\
(\text { exp.) }\end{array}$ & $\begin{array}{l}\text { Porosity, \% } \\
\text { (exp.) }\end{array}$ & Tortuosity \\
\hline 0.81 & 0.7 & 3.858 & 0.230 & 54 & 9.00 \\
\hline 0.68 & 1.43 & 3.957 & 0.296 & 54 & 7.20 \\
\hline 0.6 & 1.88 & 4.021 & 0.317 & 54 & 6.84 \\
\hline 0.5 & 2.4 & 4.103 & 0.327 & 54 & 6.77 \\
\hline
\end{tabular}




\section{FIGURES}

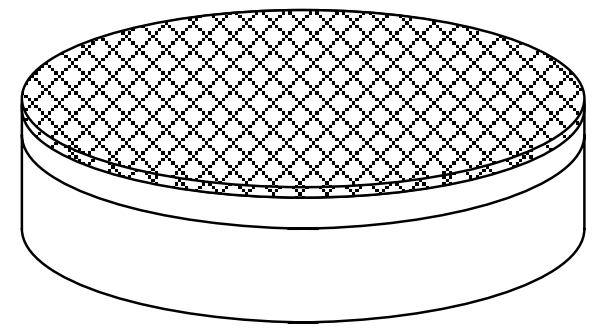

Figure \#1(a)

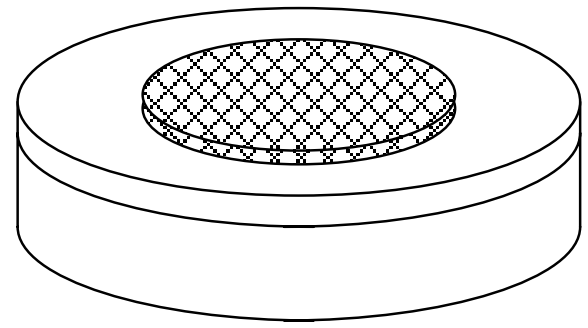

Figure \#1(b)

Figure \#1(a): A schematic showing the preferred geometry of an anode-supported cell.

Figure \#1(b): A schematic showing the geometry often used in the actual testing, and the subject of the present study. 


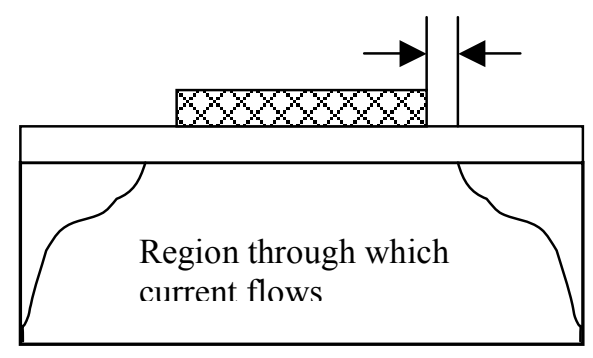

Figure \#2: A schematic showing a possible extension of the active region of the electrolyte.

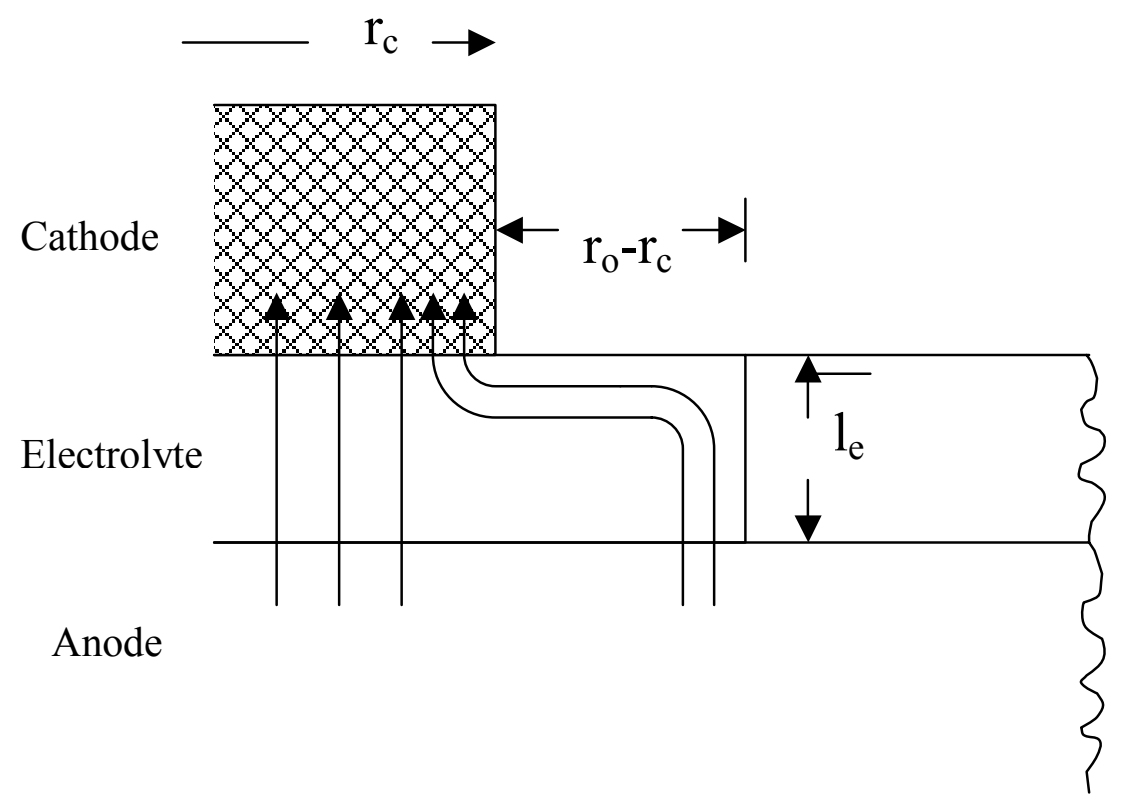

Figure \#3: A schematic showing the exploded view of the extended region from Figure \#2, used for the analysis. 


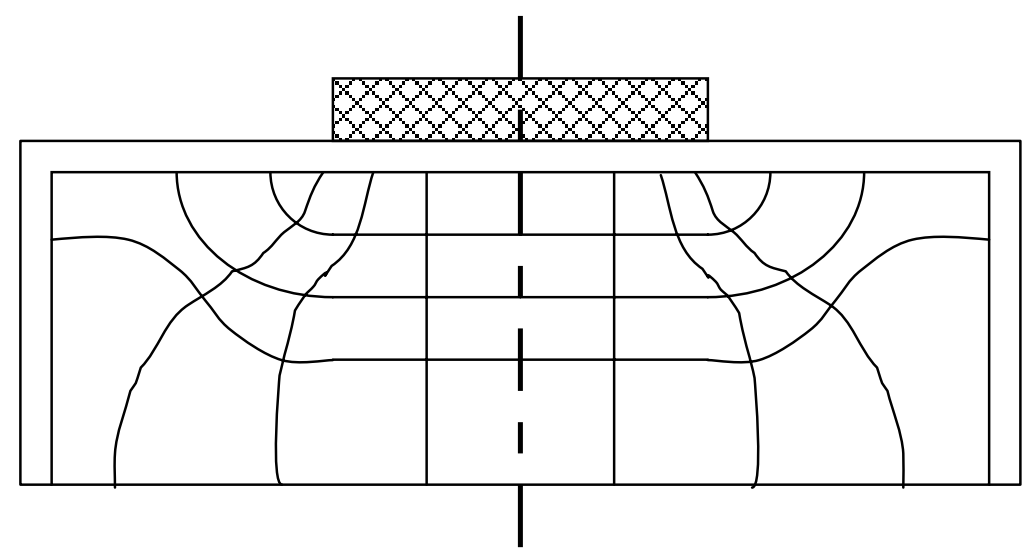

Figure \#4(a): A schematic showing the equipotential lines and the flux lines.

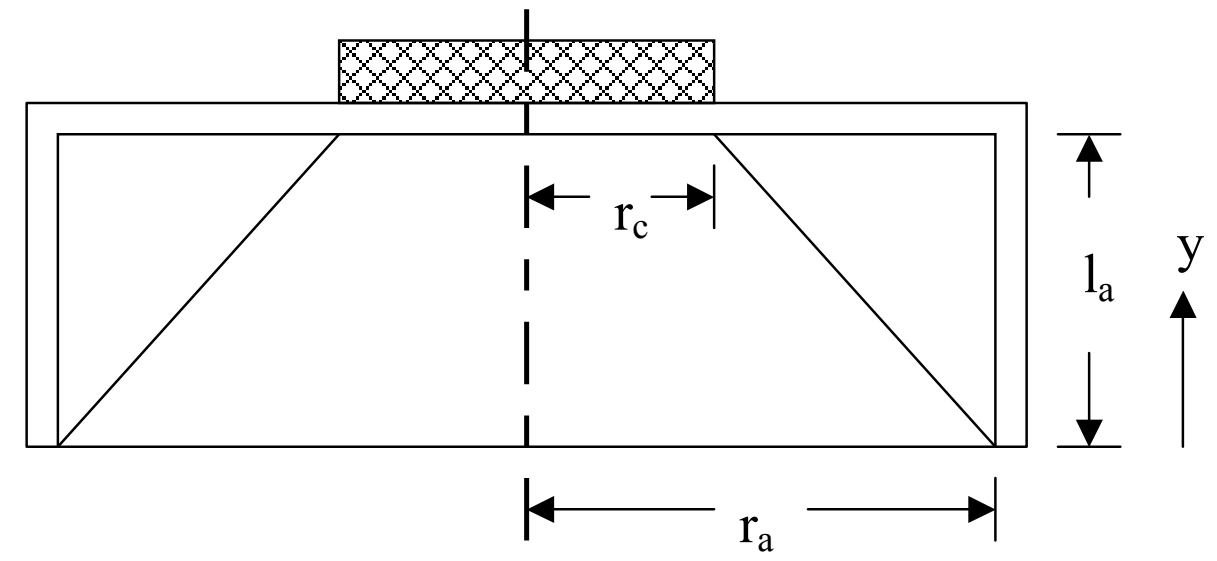

Figure \#4(b): A schematic showing the active region of the anode used in the calculations.

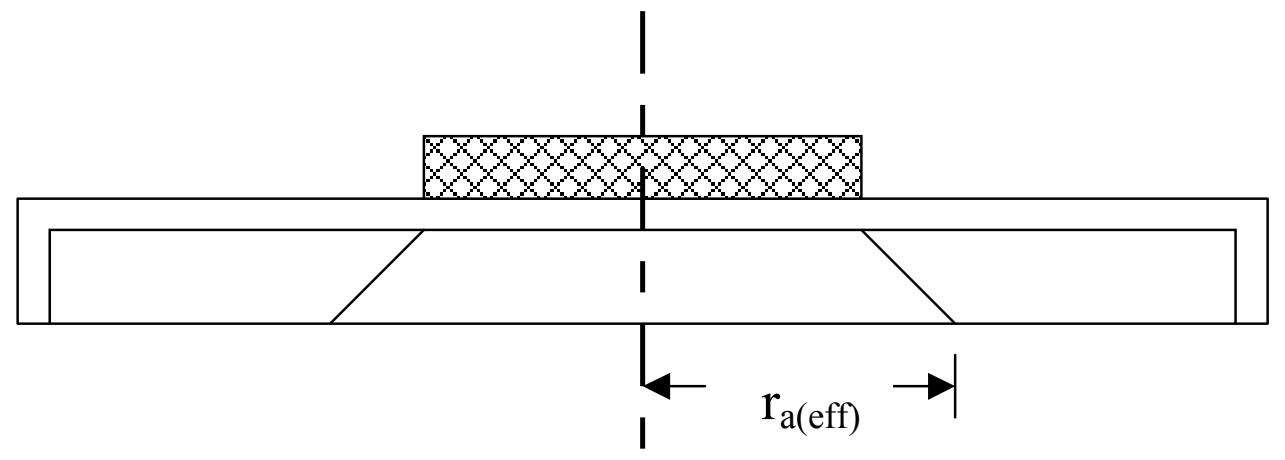

Figure \#4(c): A schematic showing the active region of the anode when the cathode radius is much larger than the anode thickness. 


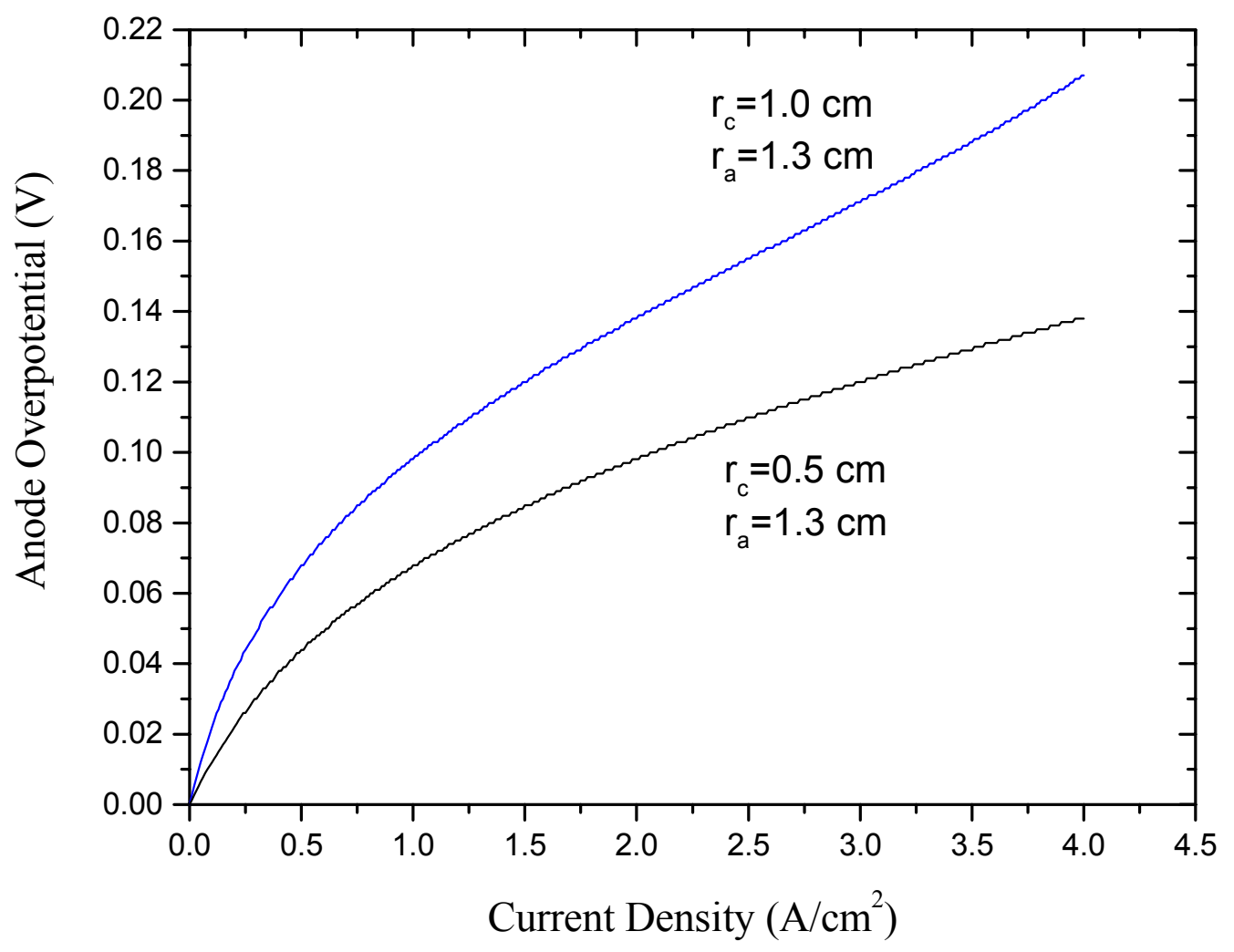

Figure \#5(a): Calculated anodic concentration polarization as a function of current density for two different cathode radii using equation (16) for the anode-limiting short circuit current density, $i_{a s}$. 


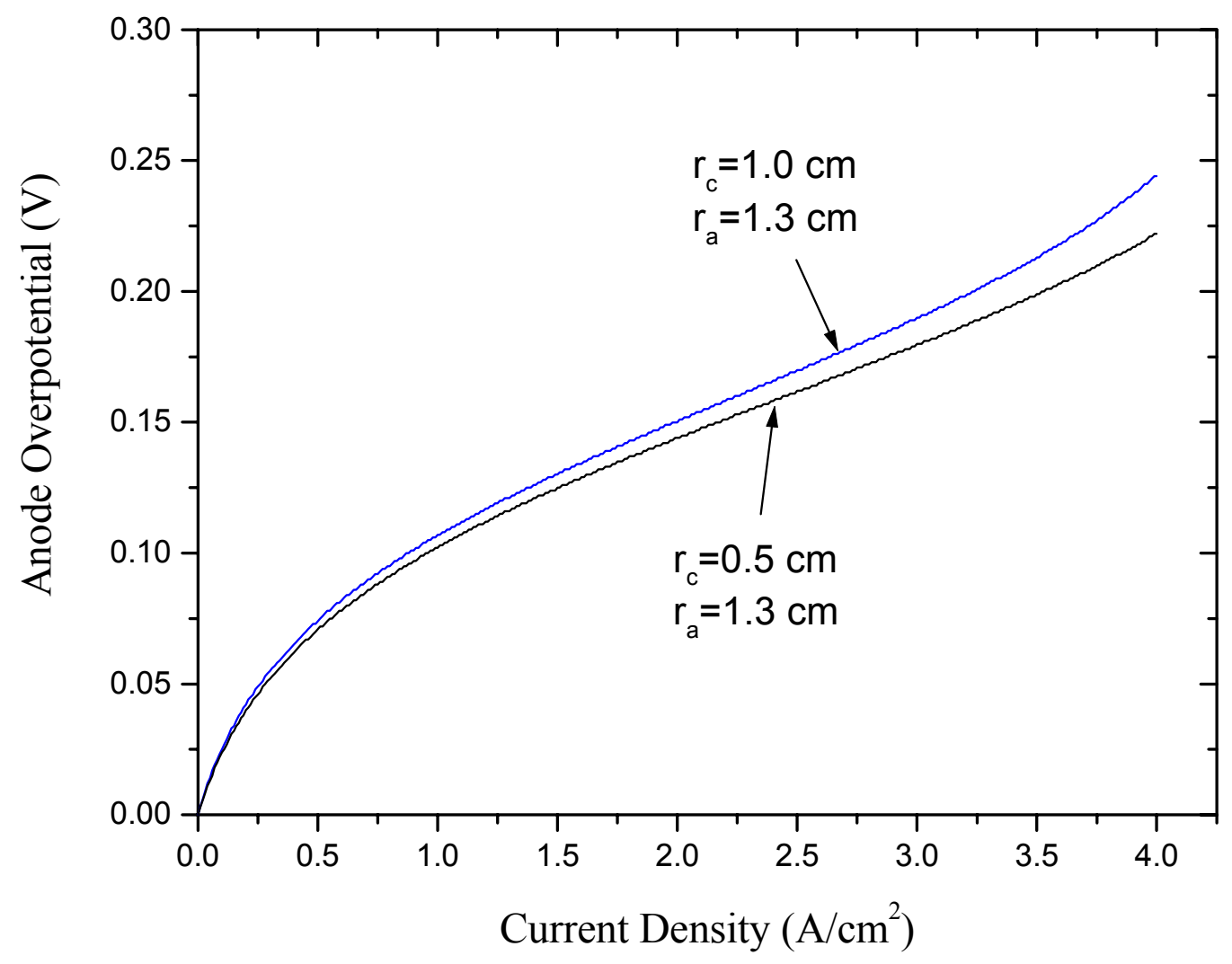

Figure \#5(b): Calculated anodic concentration polarization as a function of current density for two different cathode radii using equation (17) for the anode-limiting short circuit current density, $i_{a s}$. 


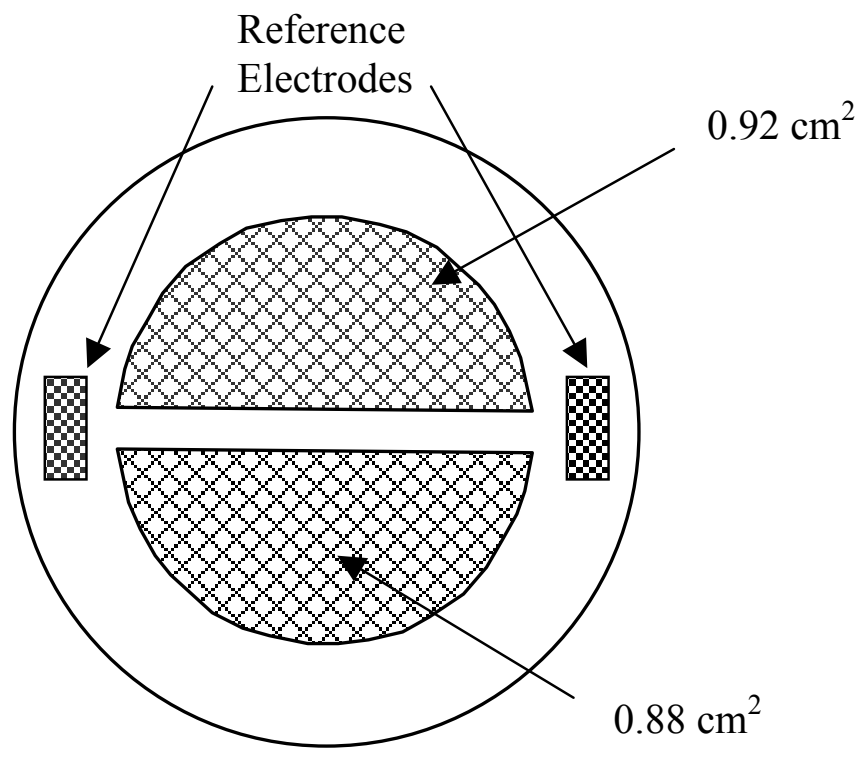

Figure \#6: A schematic of a cell with two, semicircular cathodes. 


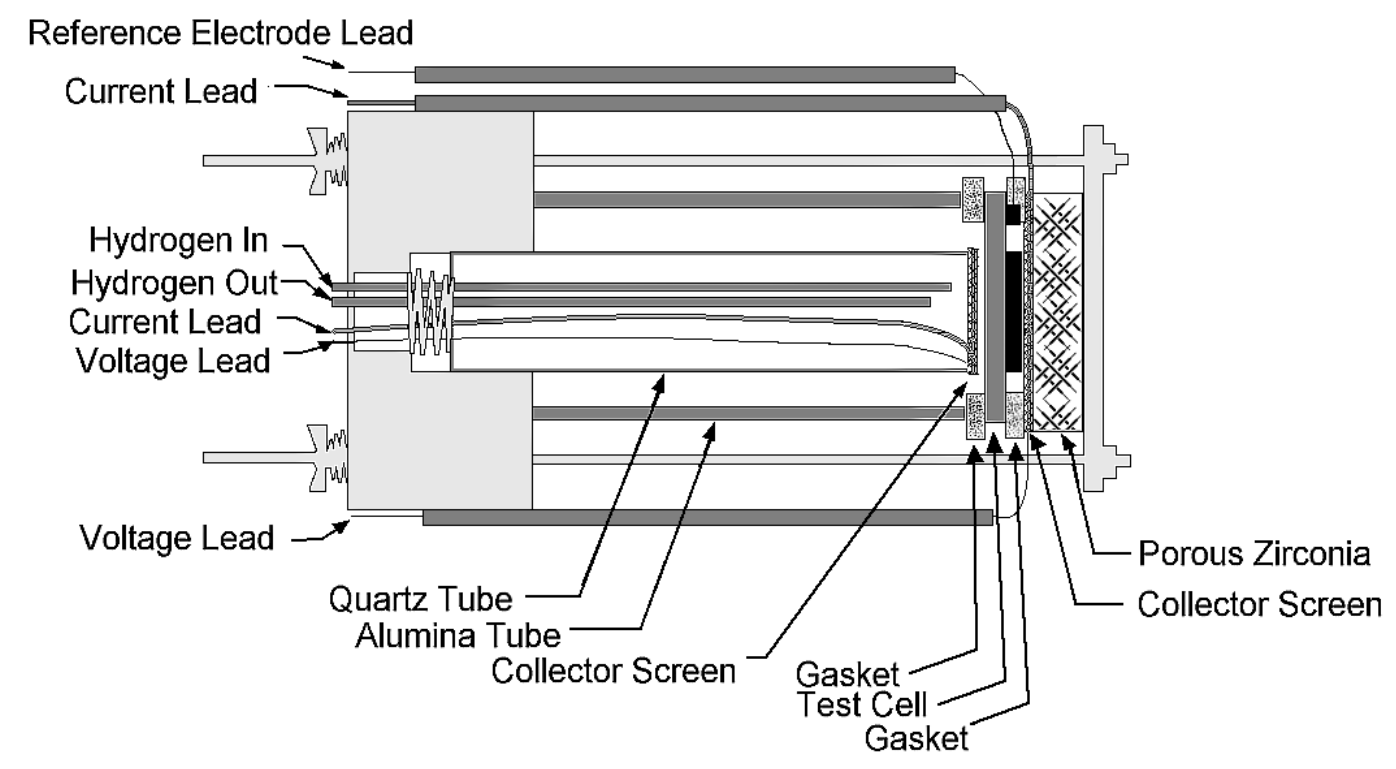

Figure \#7: A schematic of the test fixture for testing of single cells. 


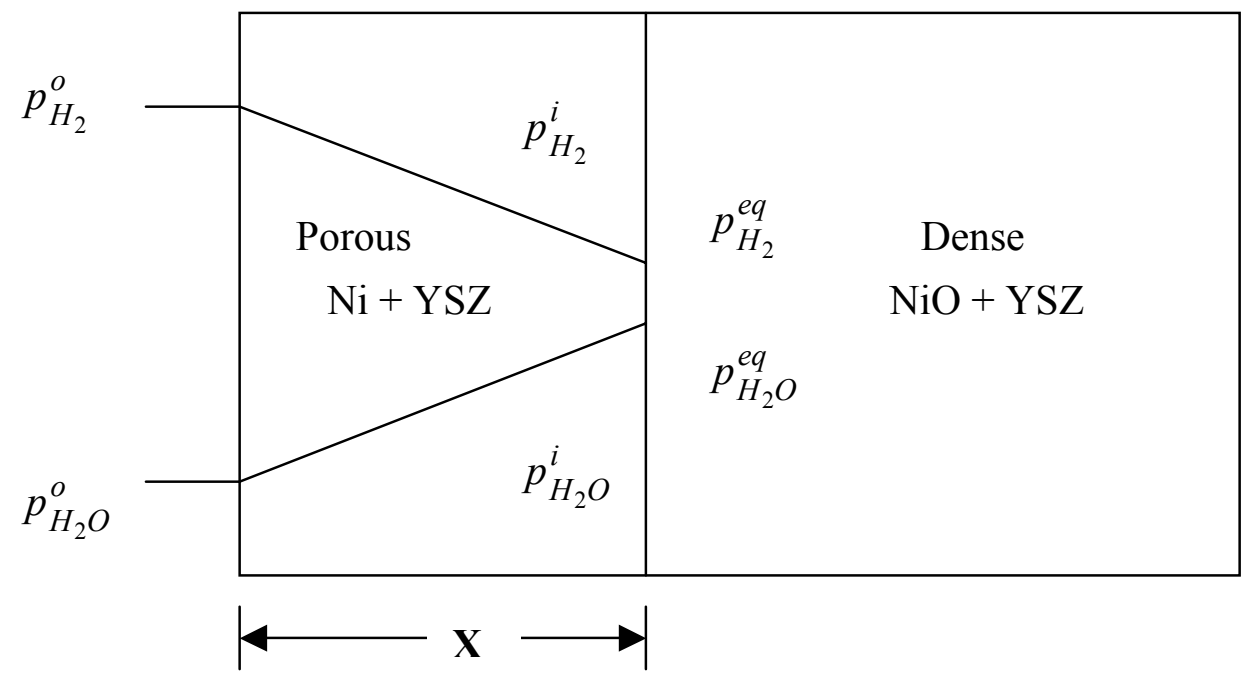

Figure \#8: A schematic of the reduction process. $X$ denotes the reduced layer thickness. $p_{H_{2}}^{o}$, $p_{\mathrm{H}_{2}}^{i}$, and $p_{\mathrm{H}_{2}}^{e q}$ are respectively hydrogen partial pressures in the atmosphere, at the reduced/pristine interface, and that corresponding to $\mathrm{Ni} / \mathrm{NiO}$ equilibrium. Similarly, $p_{\mathrm{H}_{2} \mathrm{O}}^{o}$, $p_{\mathrm{H}_{2} \mathrm{O}}^{i}$, and $p_{\mathrm{H}_{2} \mathrm{O}}^{e q}$ are the corresponding $\mathrm{H}_{2} \mathrm{O}$ partial pressures. 


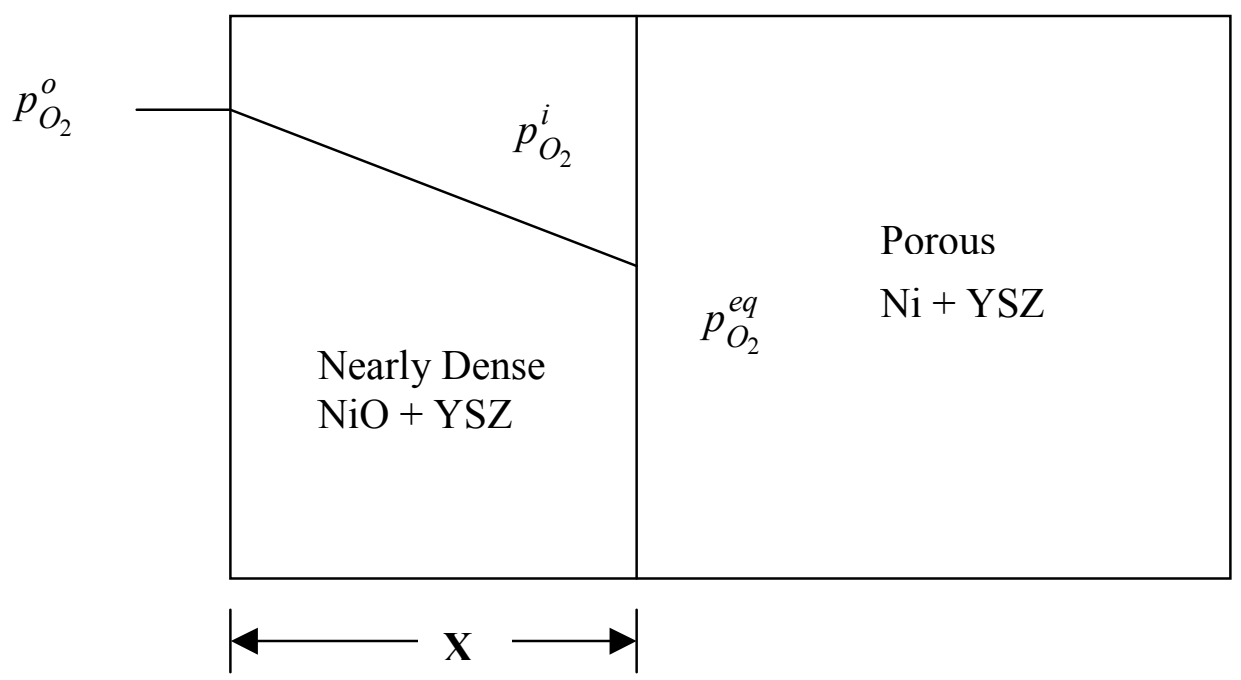

Figure \#9: A schematic of the re-oxidation process. $X$ denotes the re-oxidized layer thickness. $p_{\mathrm{O}_{2}}^{o}, p_{\mathrm{O}_{2}}^{i}$, and $p_{\mathrm{O}_{2}}^{e q}$ are respectively the partial pressures of oxygen in the atmosphere, at the re-oxidized/reduced interface, and that corresponding to $\mathrm{Ni} / \mathrm{NiO}$ equilibrium. 


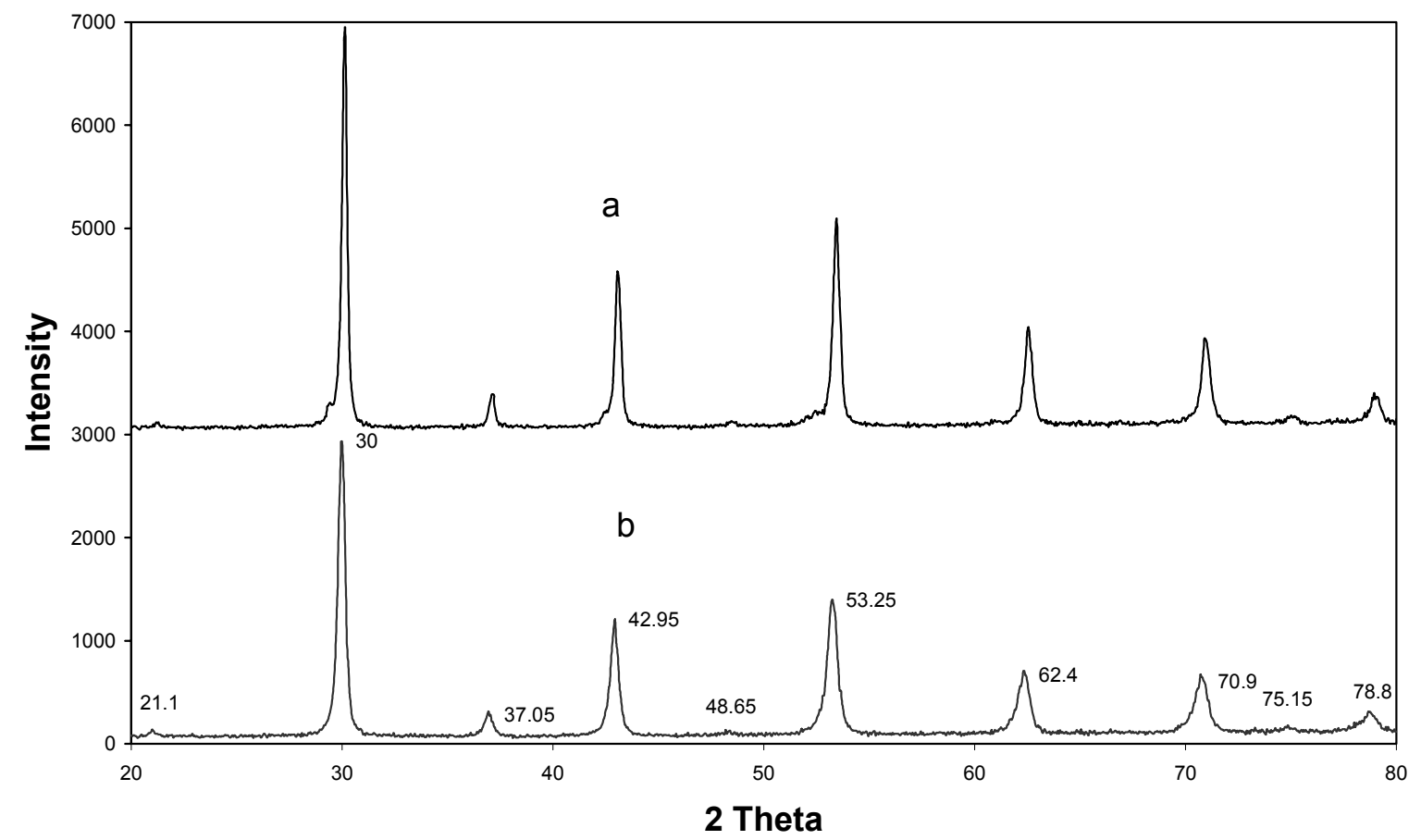

Figure \#10: (a) An XRD pattern of yttria-doped $\mathrm{BaZrO}_{3}$ powder synthesized by calcining a mixture of $\mathrm{BaCO}_{3}, \mathrm{ZrO}_{2}$ and $\mathrm{Y}_{2} \mathrm{O}_{3}$ at $1250^{\circ} \mathrm{C}$ for $2 \mathrm{~h}$. (b) An XRD pattern of yttriadoped $\mathrm{BaZrO}_{3}$ powder synthesized by calcining a mixture of $\mathrm{BaCO}_{3}$ and $\mathrm{YSZ}$ at $1250^{\circ} \mathrm{C}$ for $2 \mathrm{~h}$. 


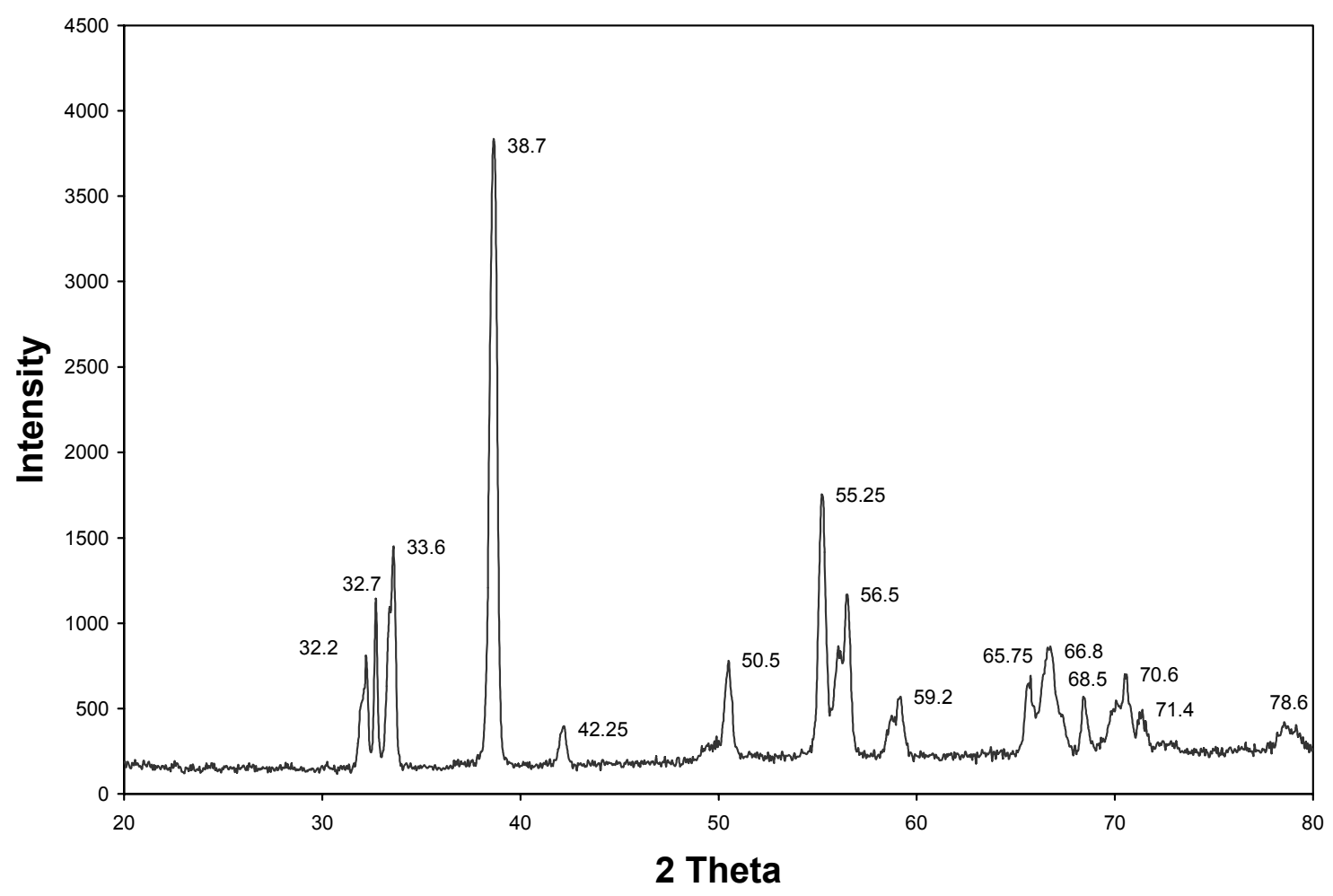

Figure \#11: An XRD pattern of yttria-doped $\mathrm{Na}_{2} \mathrm{ZrO}_{3}$ powder synthesized by calcining a mixture of $\mathrm{Na}_{2} \mathrm{CO}_{3}$ and $\mathrm{YSZ}$ at $1250^{\circ} \mathrm{C}$ for $2 \mathrm{~h}$. 


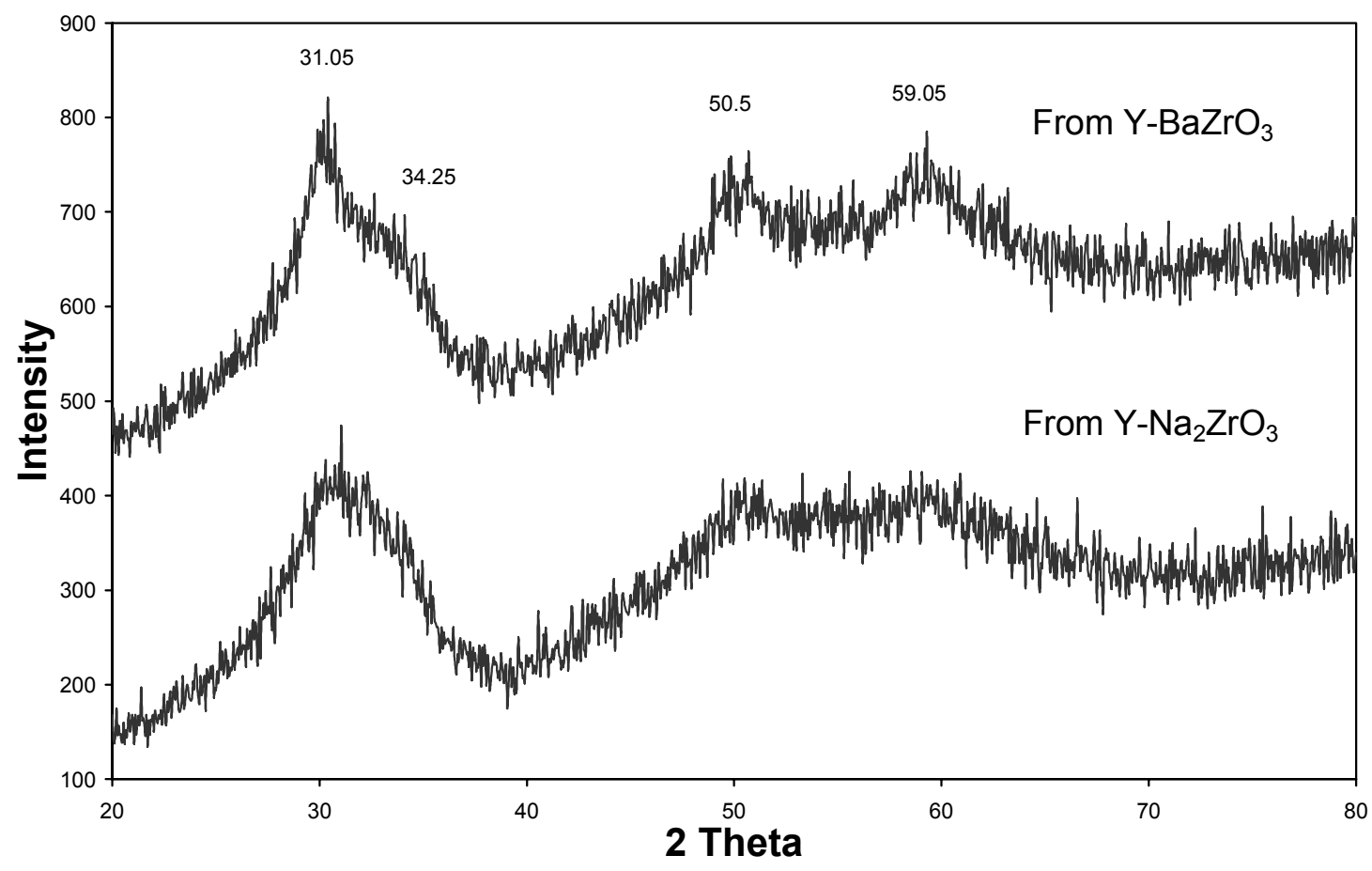




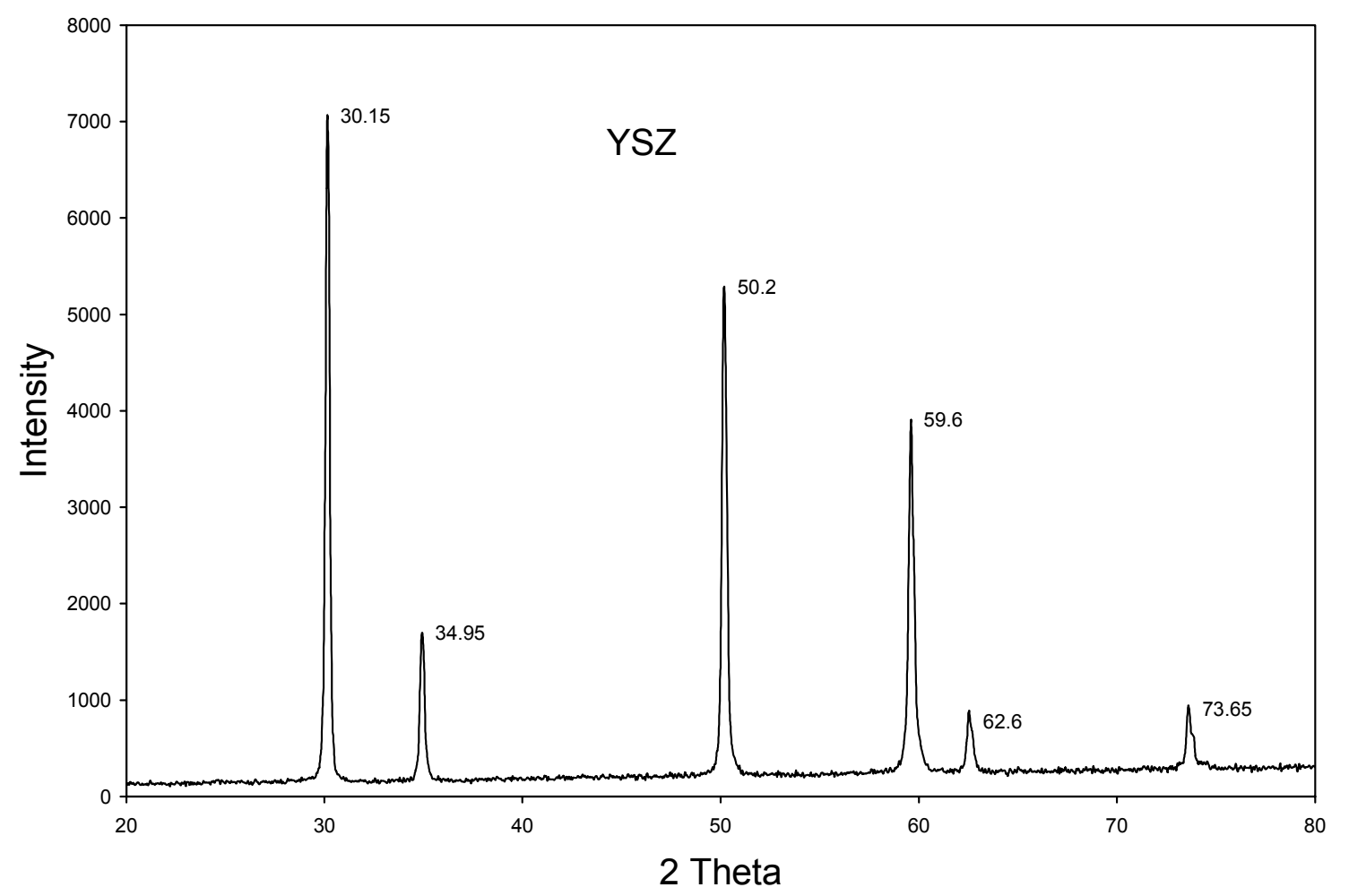

Figure \#12: (a) XRD patterns of the residue after boiling $\mathrm{Y}-\mathrm{BaZrO}_{3}$ in dilute $\mathrm{HNO}_{3}$ (after leaching $\mathrm{Ba}$ ), and washing in water, and of the residue after boiling $\mathrm{Y}-\mathrm{Na}_{2} \mathrm{ZrO}_{3}$ in de-ionized water (after leaching $\mathrm{Na}$ ), and washing in water. (b) An XRD pattern of a commercial YSZ powder. 


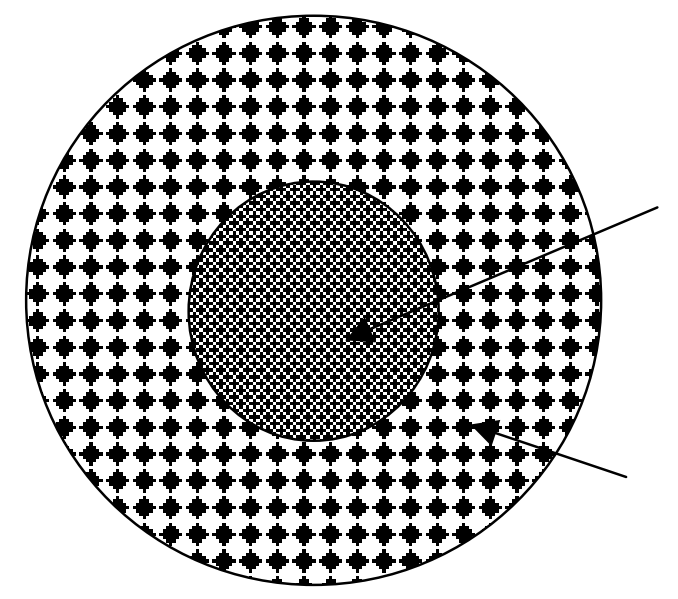

Original, Dense

$\mathrm{Y}-\mathrm{BaZrO}_{3}$

\author{
Porous, $\mathrm{Y}-\mathrm{ZrO}_{2}(\mathrm{YSZ})$ \\ after reaction with \\ $\mathrm{HNO}_{3}$. \\ $\mathrm{Ba}\left(\mathrm{NO}_{3}\right)_{2}$ is leached \\ out.
}

Figure \#13: A schematic showing a particle of $\mathrm{Y}-\mathrm{BaZrO}_{3}$ reacting with $\mathrm{HNO}_{3}$. The porous outer layer is of YSZ. The dense inner region is of the original $\mathrm{Y}-\mathrm{BaZrO}_{3}$. The reaction involves the following steps. (i) Transport of $\mathrm{HNO}_{3}$ through the porous YSZ layer to the porous $\mathrm{YSZ} /$ dense $\mathrm{Y}-\mathrm{BaZrO}{ }_{3}$ interface. (ii) Reaction between $\mathrm{Y}-\mathrm{BaZrO}_{3}$ and $\mathrm{HNO}_{3}$ to form soluble $\mathrm{Ba}\left(\mathrm{NO}_{3}\right)_{2}$ and insoluble, porous YSZ. (iii) Transport of $\mathrm{Ba}\left(\mathrm{NO}_{3}\right)_{2}$ through the porous YSZ layer into the acid bath. 


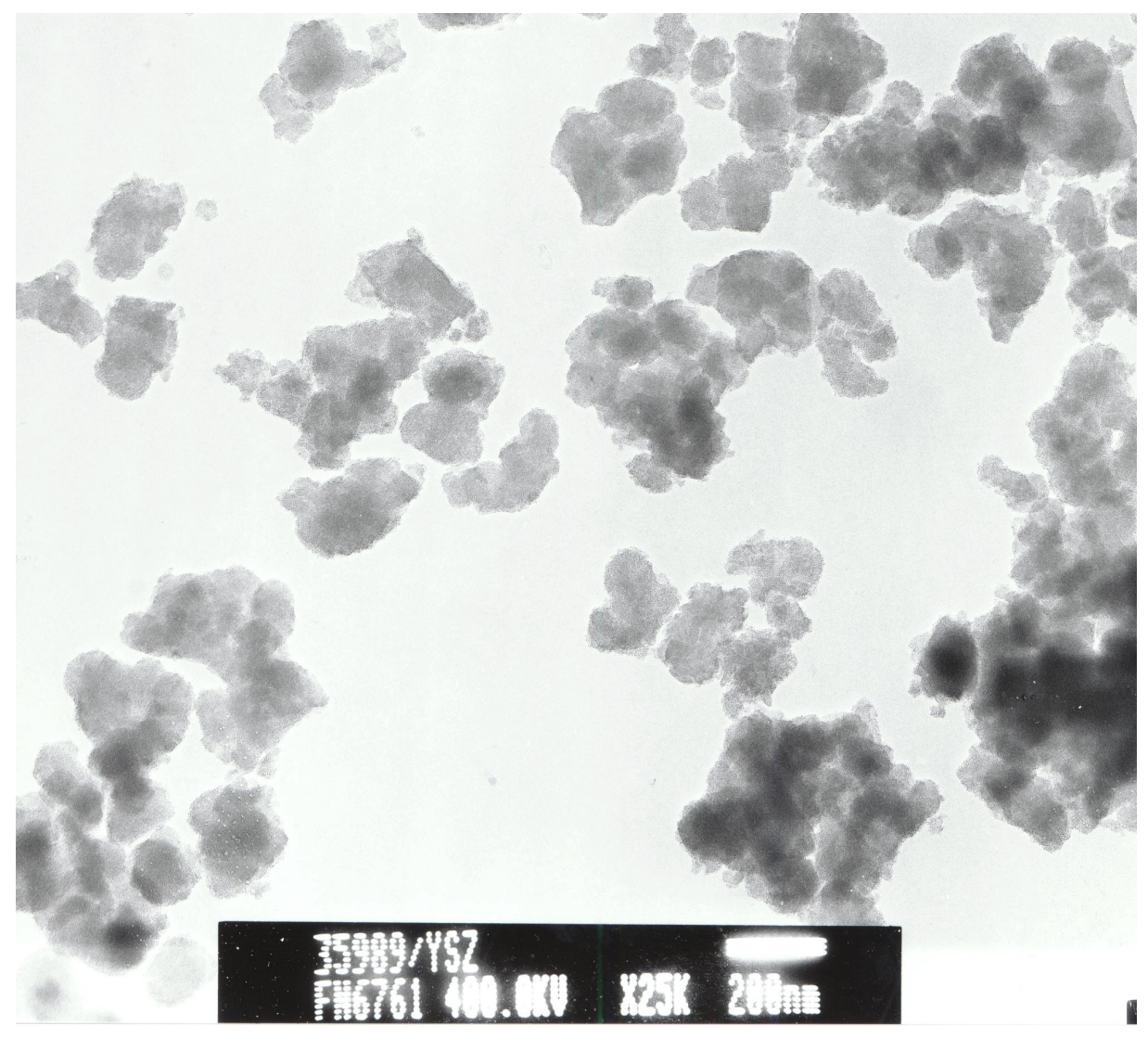

Figure \#14(a): A bright field TEM image of nanosize YSZ, synthesized using $\mathrm{Y}-\mathrm{BaZrO}_{3}$, at $25,000 \mathrm{X}$ showing agglomerates of $\sim 50$ to $200 \mathrm{~nm}$ in size. 


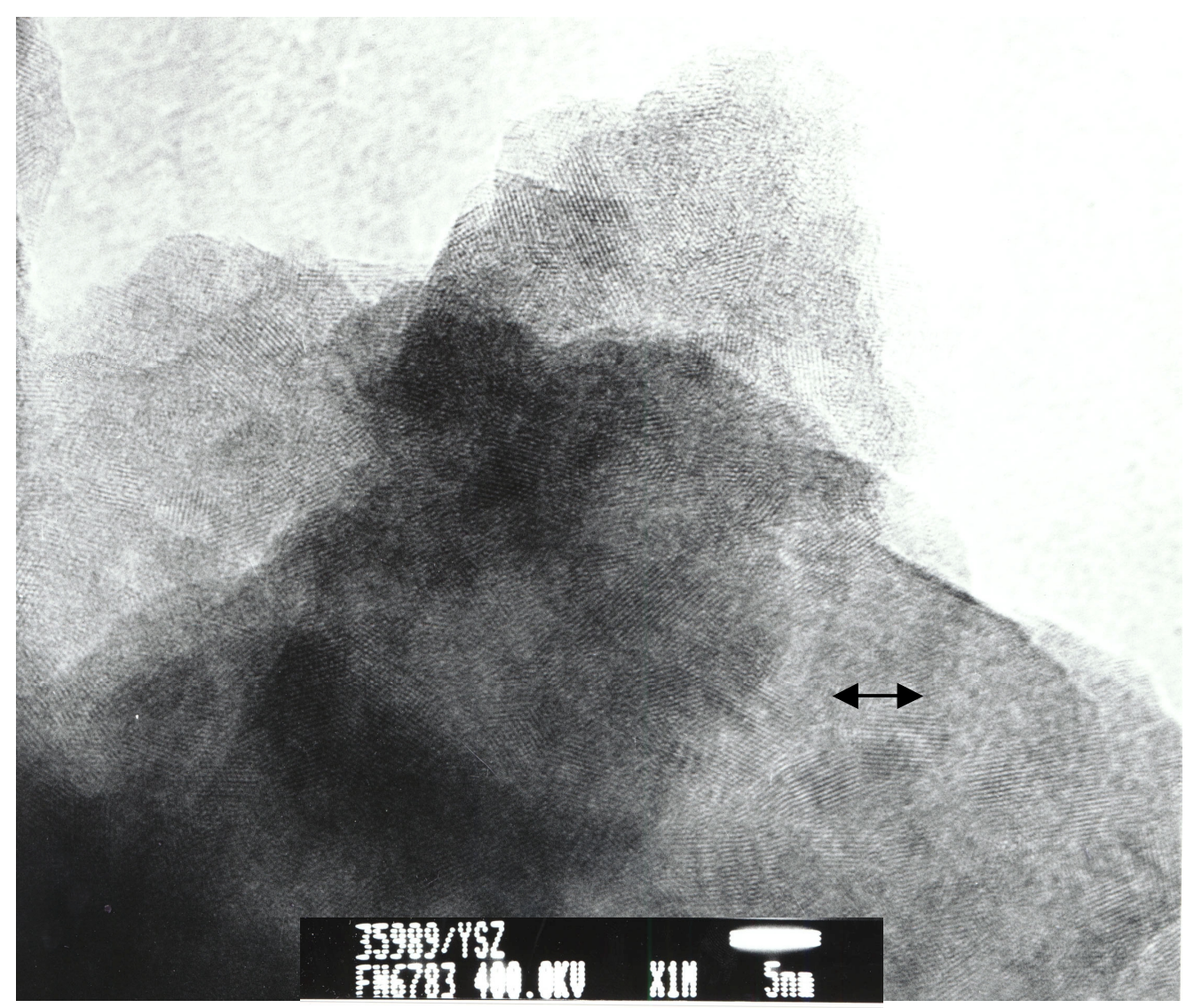

Figure \#14(b): A bright field TEM image of the same sample at 1,000,000 X, showing lattice fringes consistent with the formation of crystalline YSZ. The individual crystallite size is about $5 \mathrm{~nm}$. 


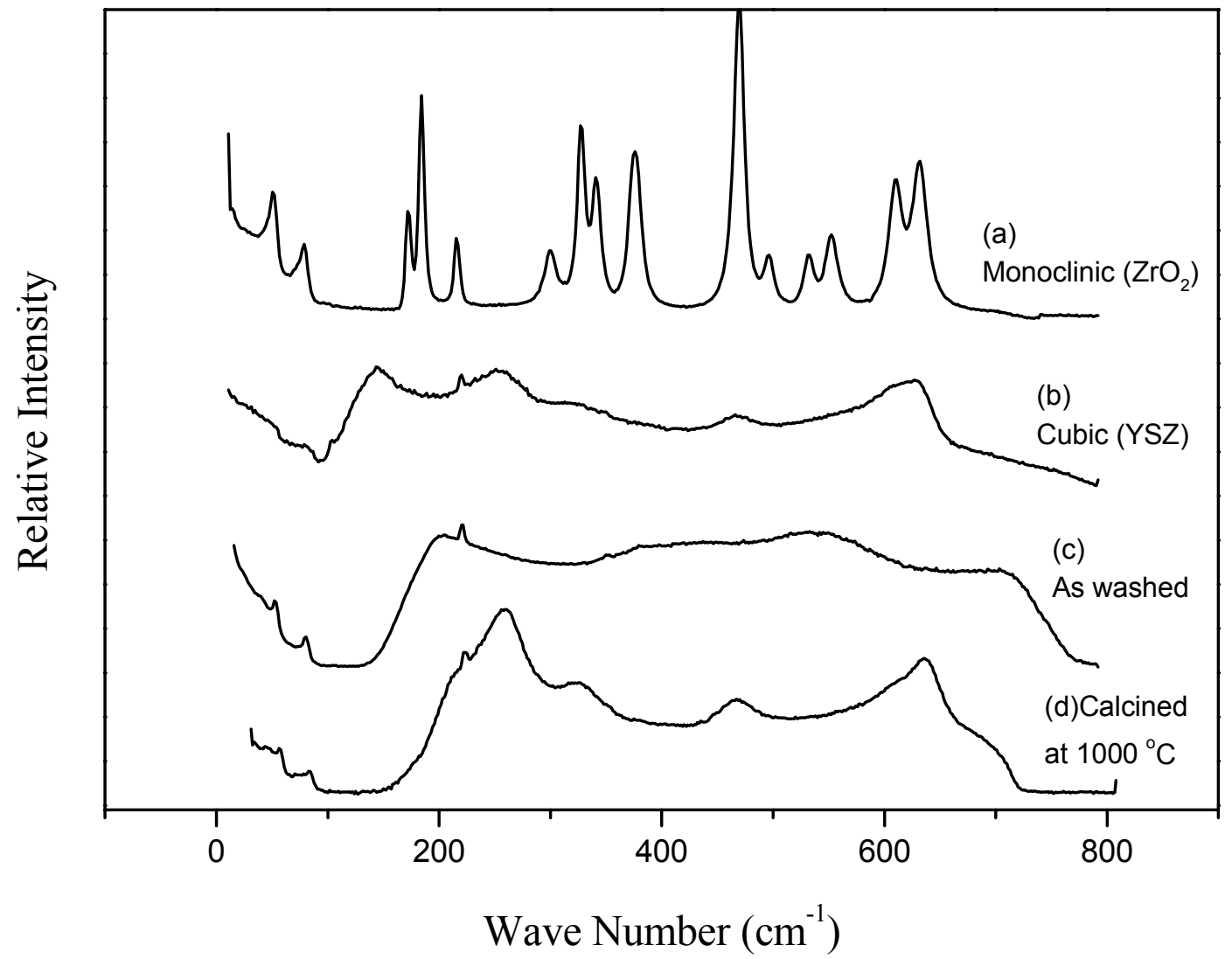

Figure \#15: Raman spectra of (a) Cubic YSZ, (b) Monoclinic $\mathrm{ZrO}_{2}$, (c) As-washed YSZ powder (synthesized using $\mathrm{Y}-\mathrm{BaZrO}_{3}$ ), (d) The same sample as in (c) after $5 \mathrm{~h}$ at $1000^{\circ} \mathrm{C}$. 


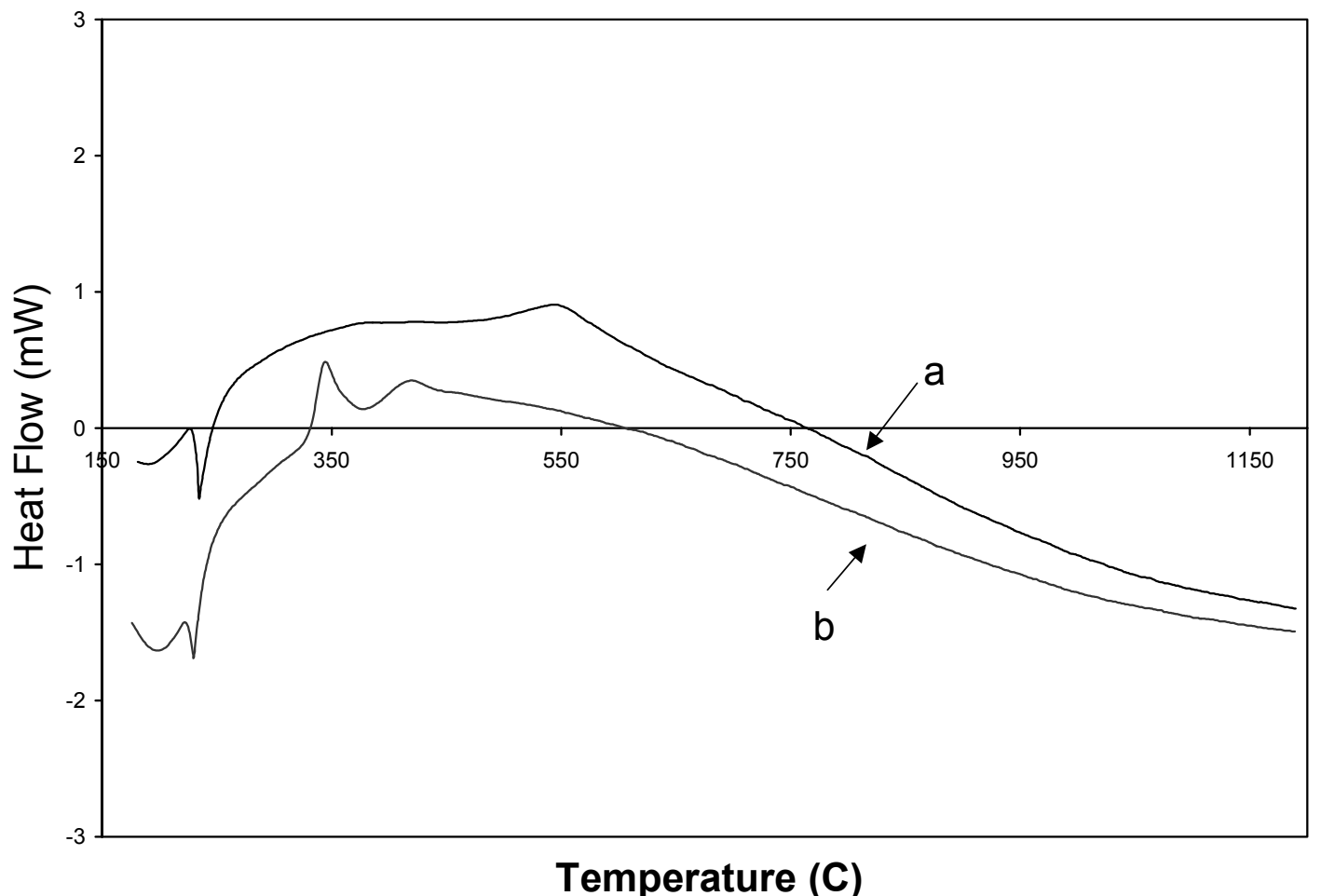

Figure \#16: DTA traces obtained at $10^{\circ} \mathrm{C} / \mathrm{min}$. in air, of nanosize $\mathrm{YSZ}$ powders synthesized from (a) $\mathrm{Y}-\mathrm{BaZrO}_{3}$ and (b) $\mathrm{Y}-\mathrm{Na}_{2} \mathrm{ZrO}_{3}$ powders. 


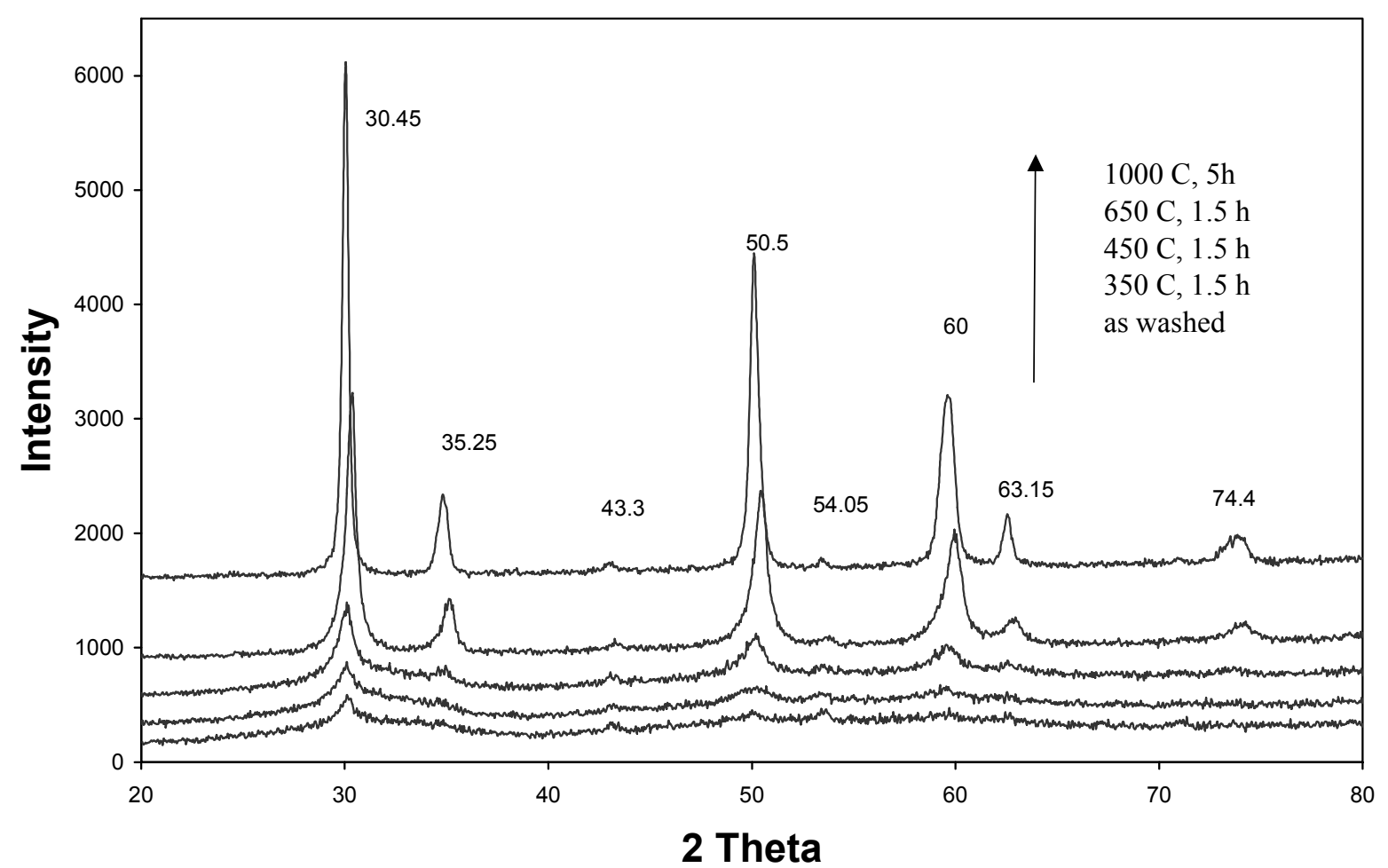

Figure \#17: XRD patterns of nanosize YSZ powders obtained from $\mathrm{Y}-\mathrm{BaZrO}_{3}$ subjected to subsequent thermal treatments at various temperatures. 


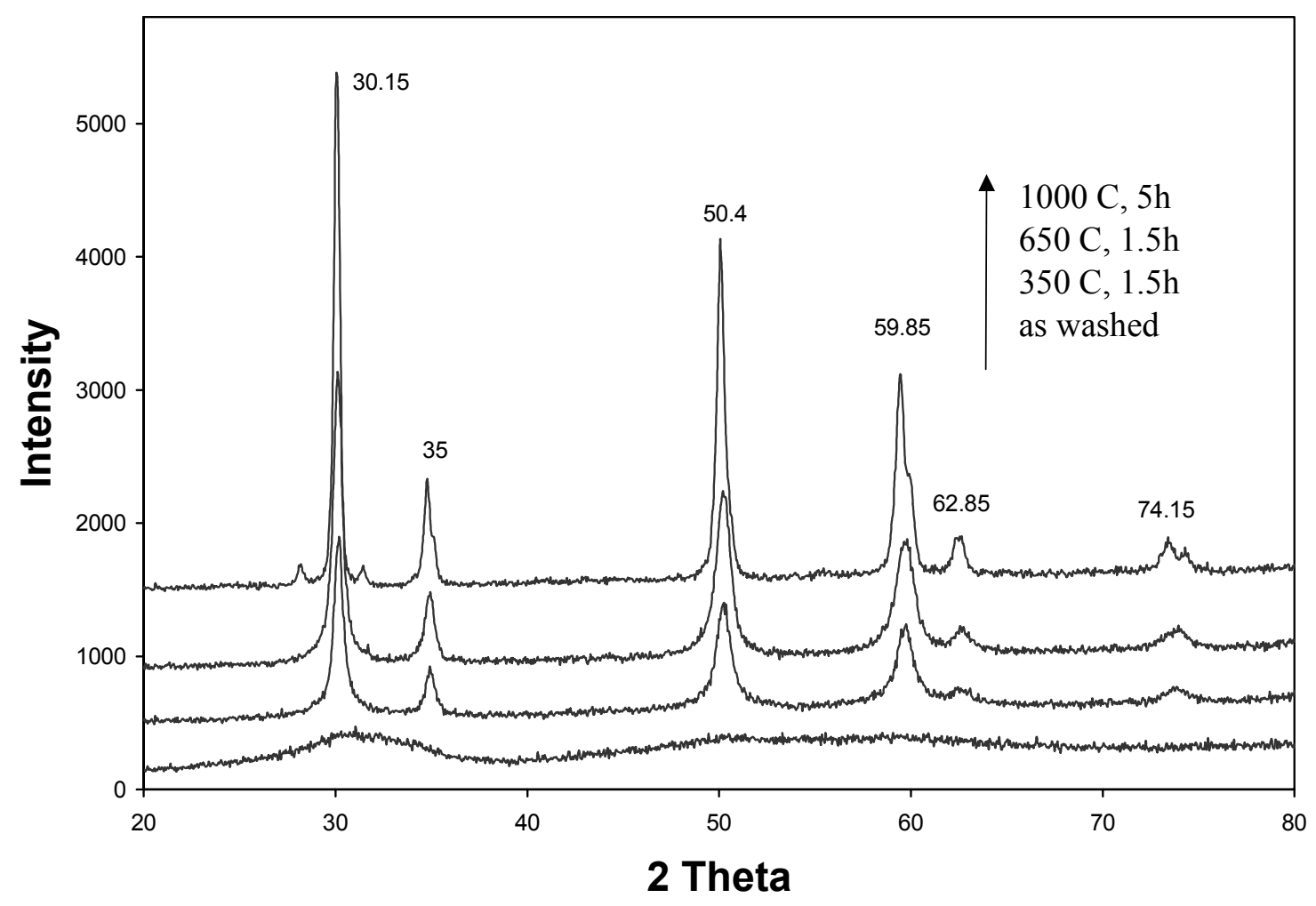

Figure \#18: XRD patterns of nanosize YSZ powders obtained from $\mathrm{Y}-\mathrm{Na}_{2} \mathrm{ZrO}_{3}$ subjected to subsequent thermal treatments at various temperatures. 


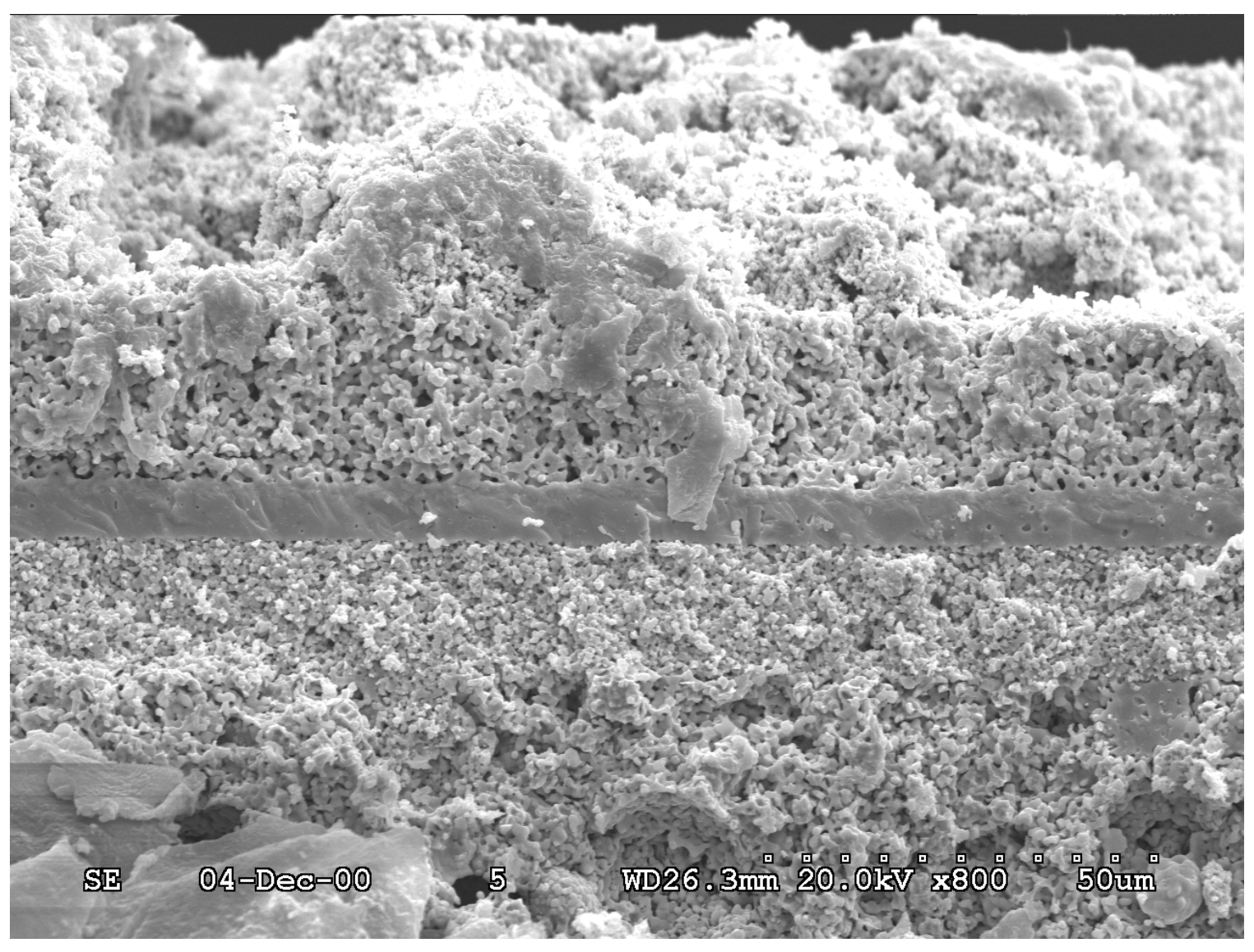

Figure \#19(a) 


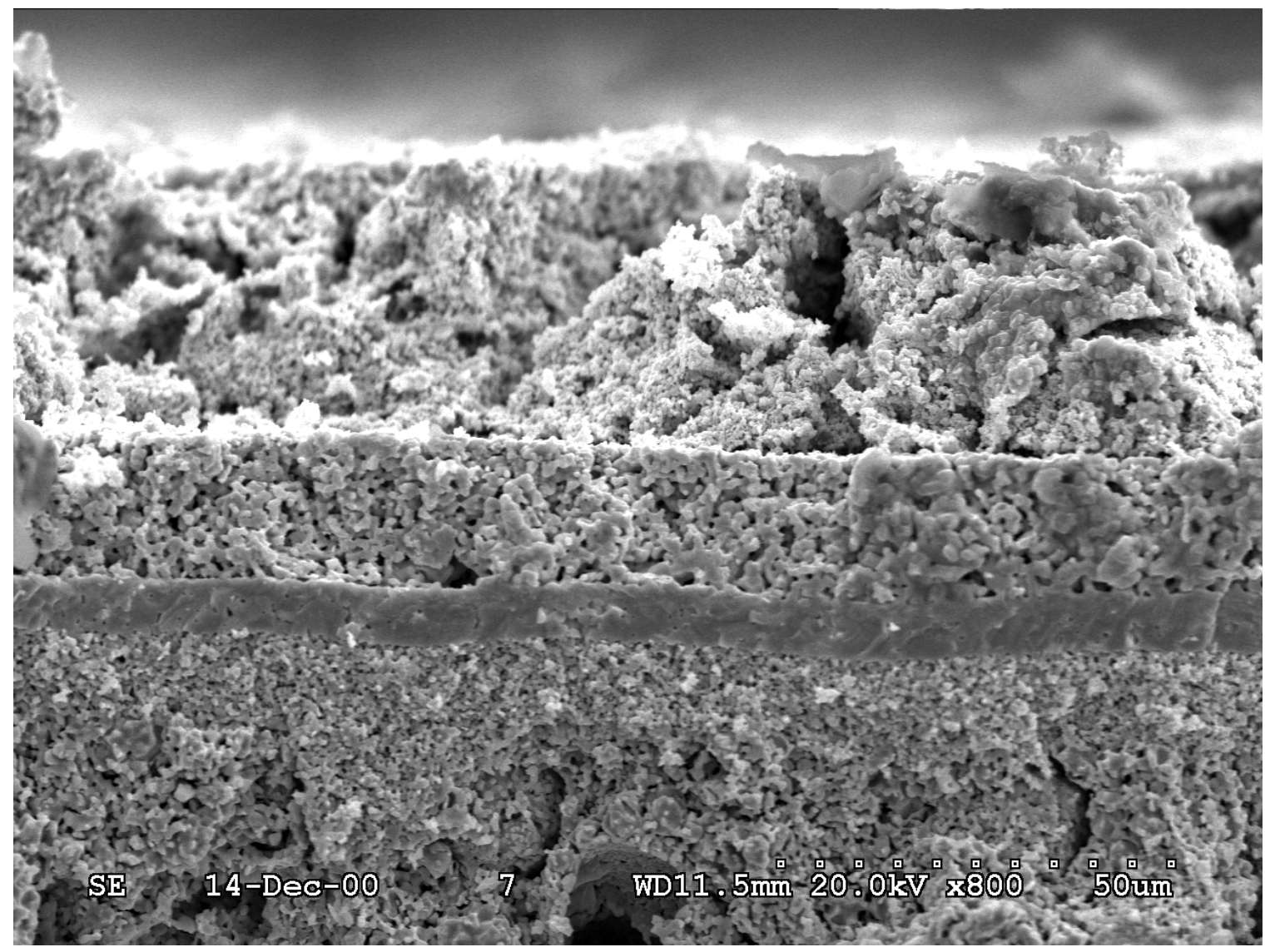

Figure \#19(b)

Figure \#19: Scanning electron micrographs of fractured cells showing the electrolyte, the cathode and anode interlayers, and parts of the cathode current collector and the anode support: (a) Cell with cathode area $\sim 1.1 \mathrm{~cm}^{2}$, (b) Cell with cathode area $\sim 2.0 \mathrm{~cm}^{2}$. 


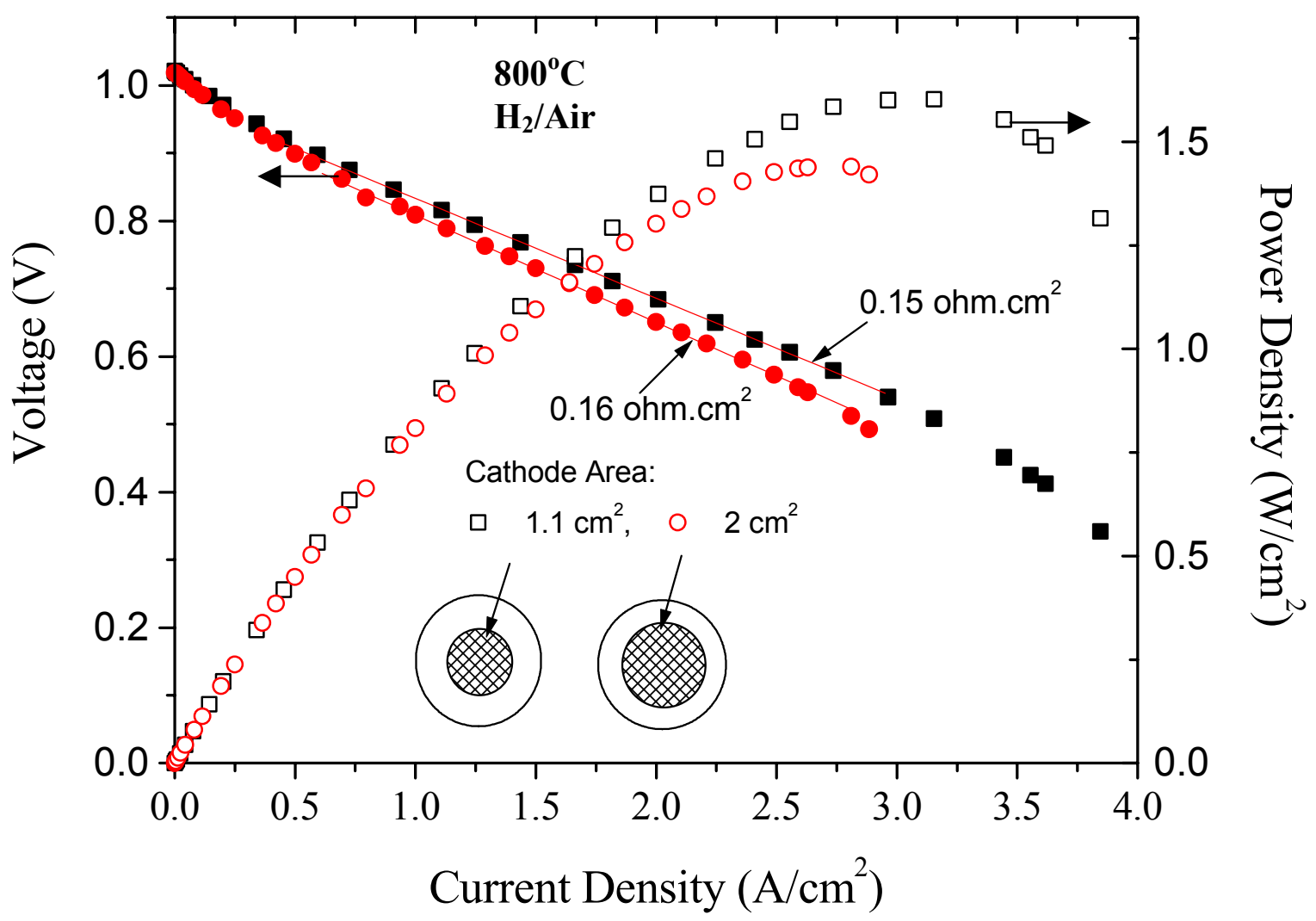

Figure \#20: Voltage and power density vs. current density for two cells tested at $800^{\circ} \mathrm{C}$ with hydrogen as fuel and air as oxidant with different cathode areas; $\sim 1.1 \mathrm{~cm}^{2}$ and $\sim 2 \mathrm{~cm}^{2}$. 


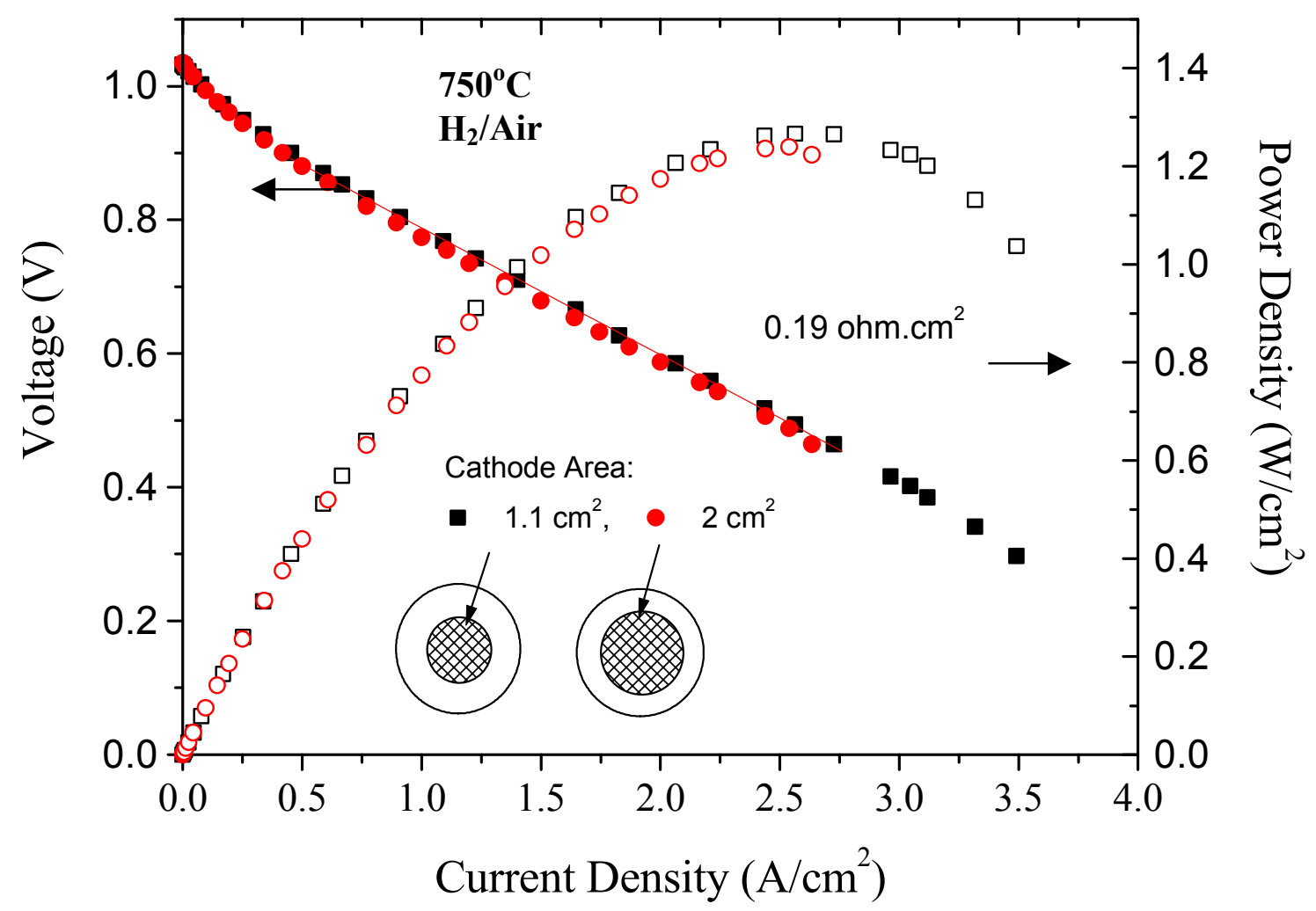

Figure \#21: Voltage and power density vs. current density for the same two cells as in Figure $\# 20$ at $750^{\circ} \mathrm{C}$ with hydrogen as fuel and air as oxidant. 


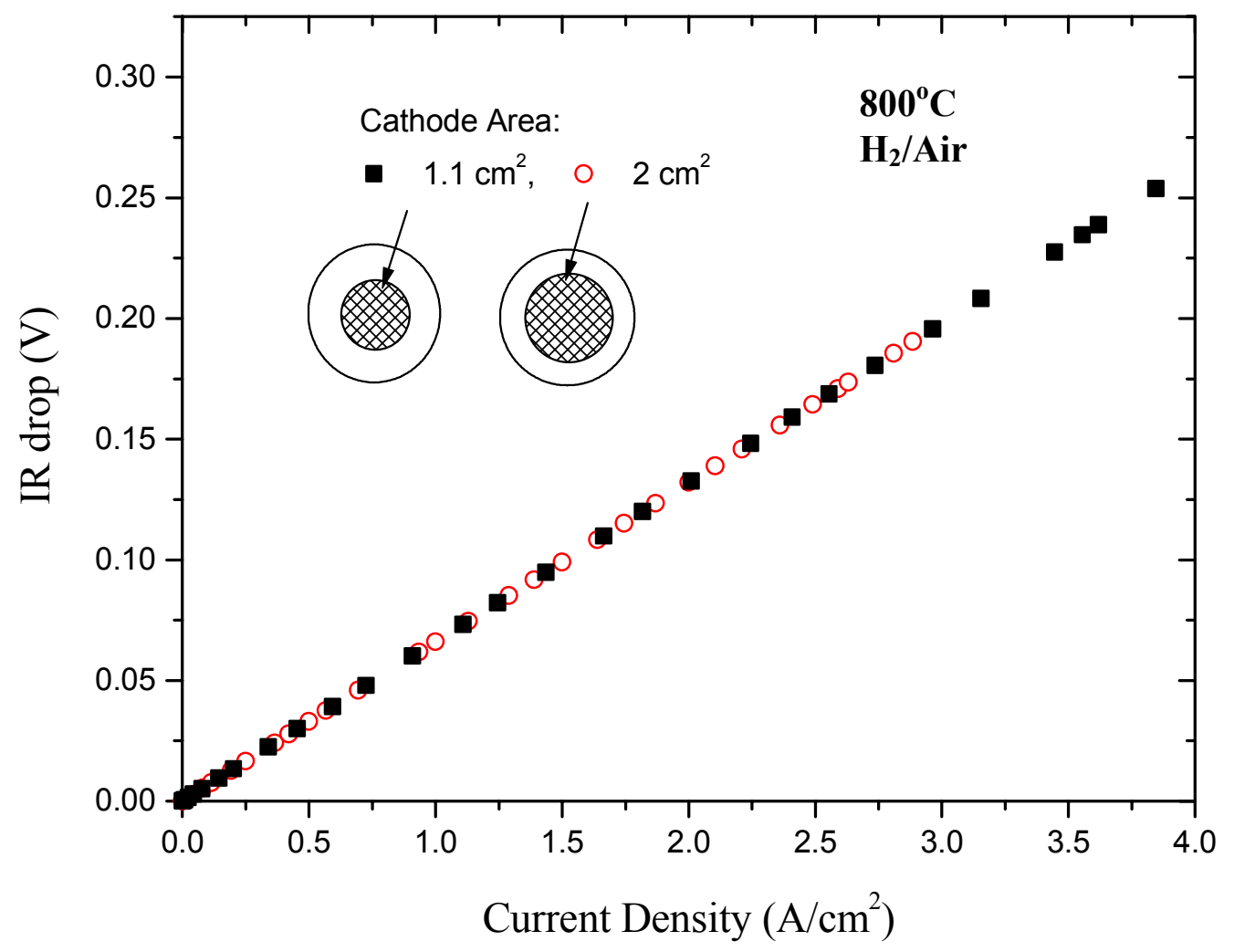

Figure \#22: Ohmic contribution (IR drop) vs. current density at $800^{\circ} \mathrm{C}$ obtained by current interruption on the two cells, corresponding to Figure \#20. 


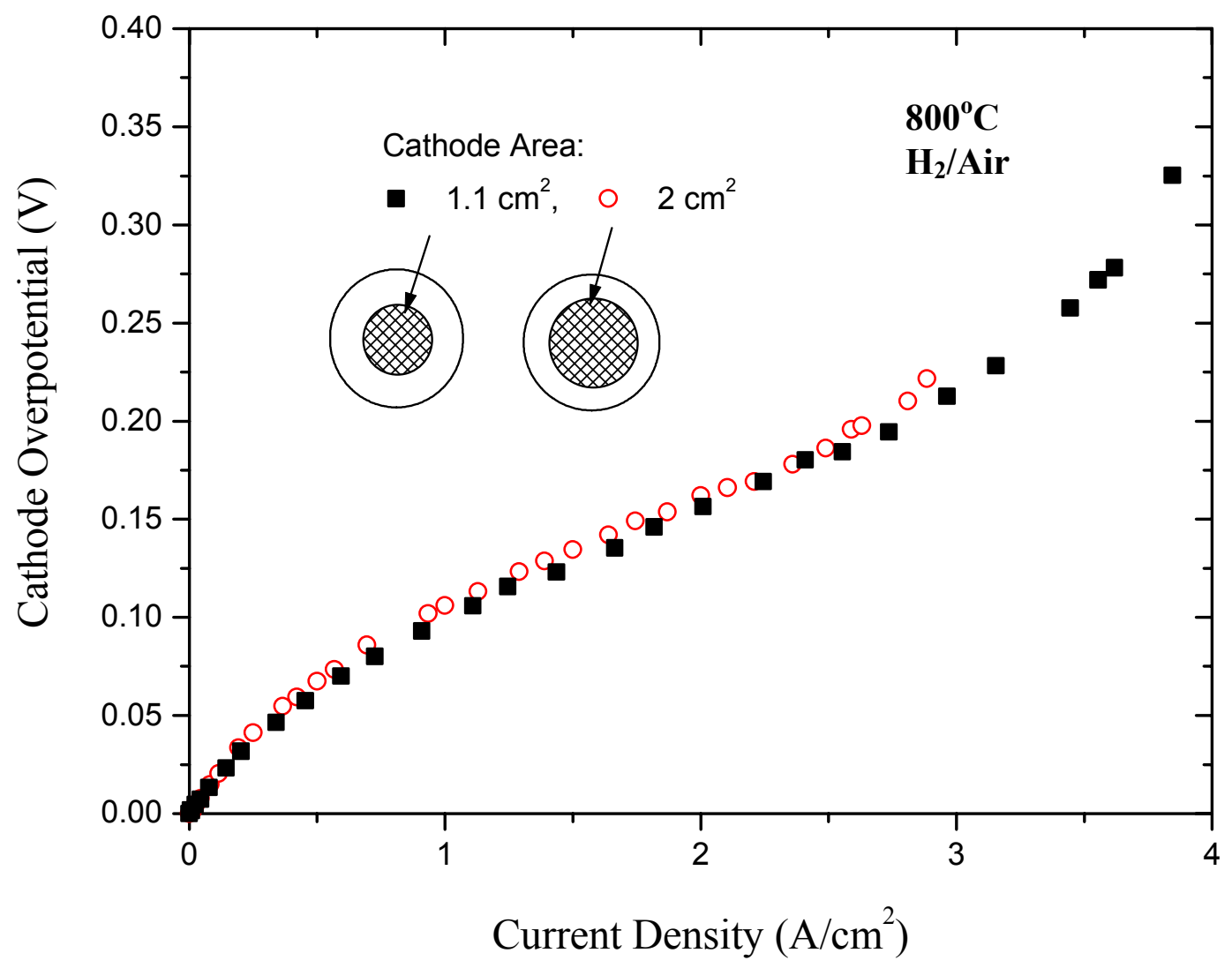

Figure \#23: Cathodic overpotential vs. current density measured at $800^{\circ} \mathrm{C}$ on the two cells, corresponding to Figure \#20. 


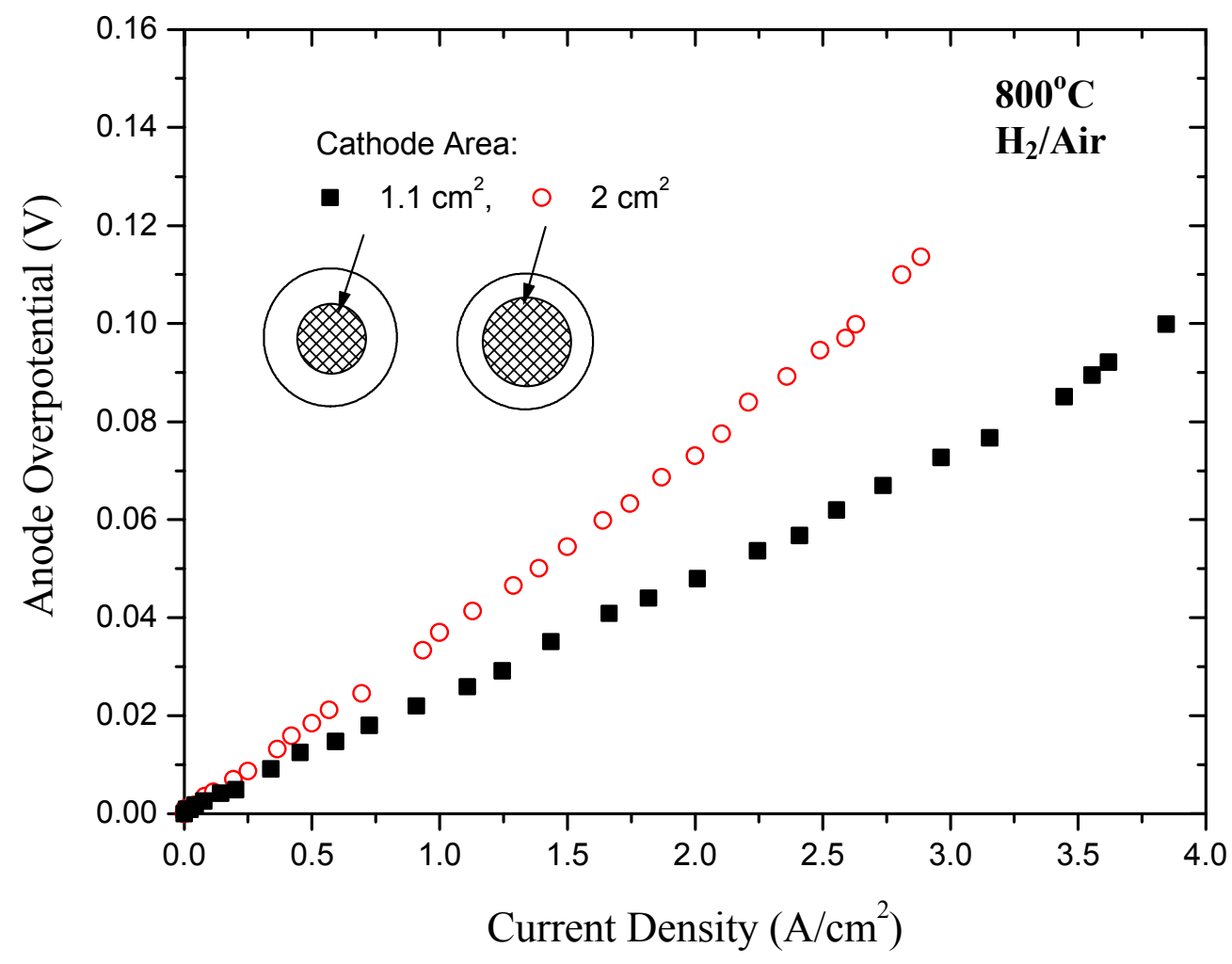

Figure \#24: Anodic overpotential vs. current density measured at $800^{\circ} \mathrm{C}$ on the two cells, corresponding to Figure \#20. 


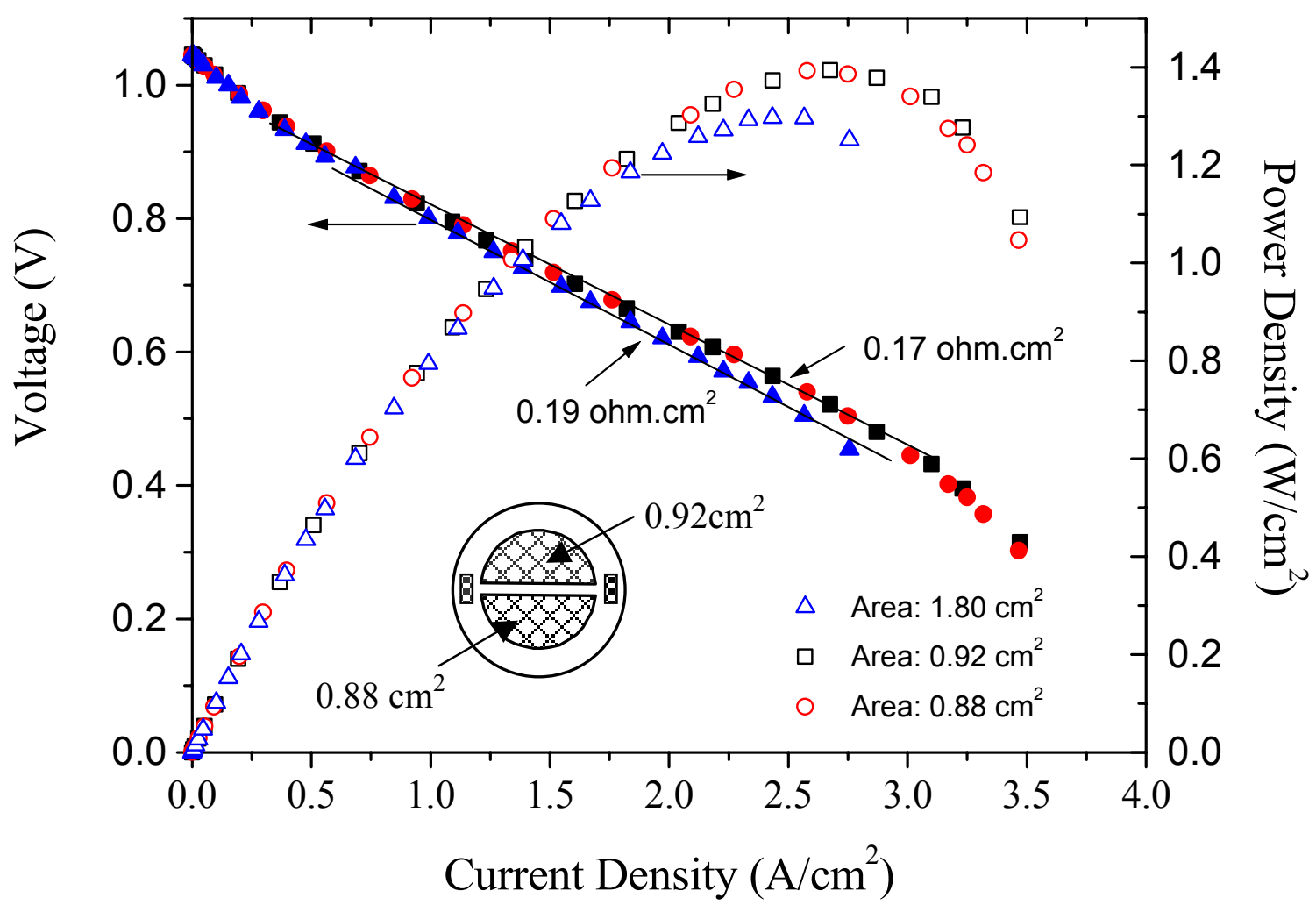

Figure \#25: Voltage and power density vs. current density for the cell with semicircular cathodes, measured at $800^{\circ} \mathrm{C}$ with hydrogen as fuel and air as oxidant. The figure shows data for the two cathodes individually, as well as after shorting the cathodes with a thick silver wire. 


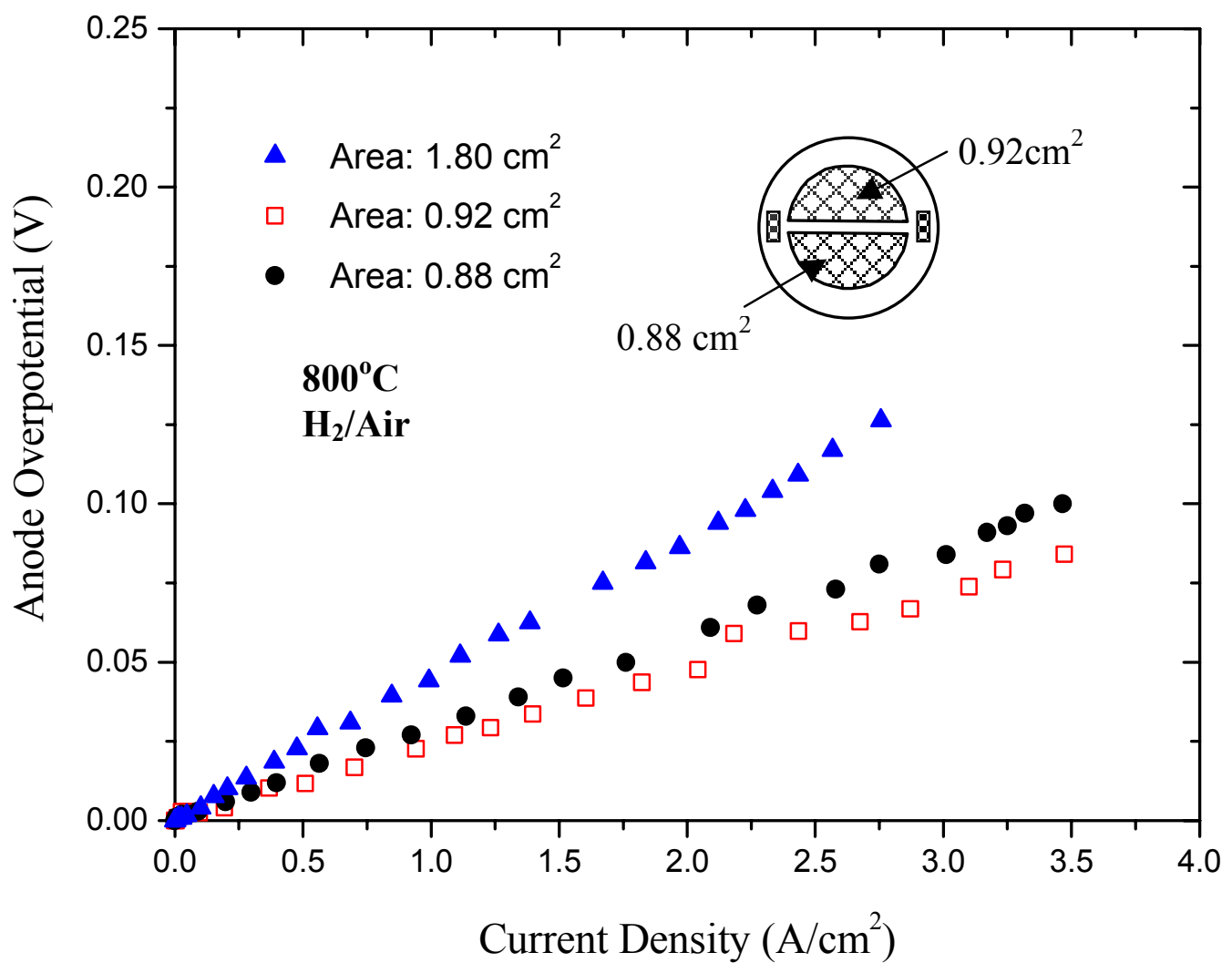

Figure \#26: Anodic overpotential vs. current density measured for the cell with semicircular cathodes, corresponding to Figure \#25. 


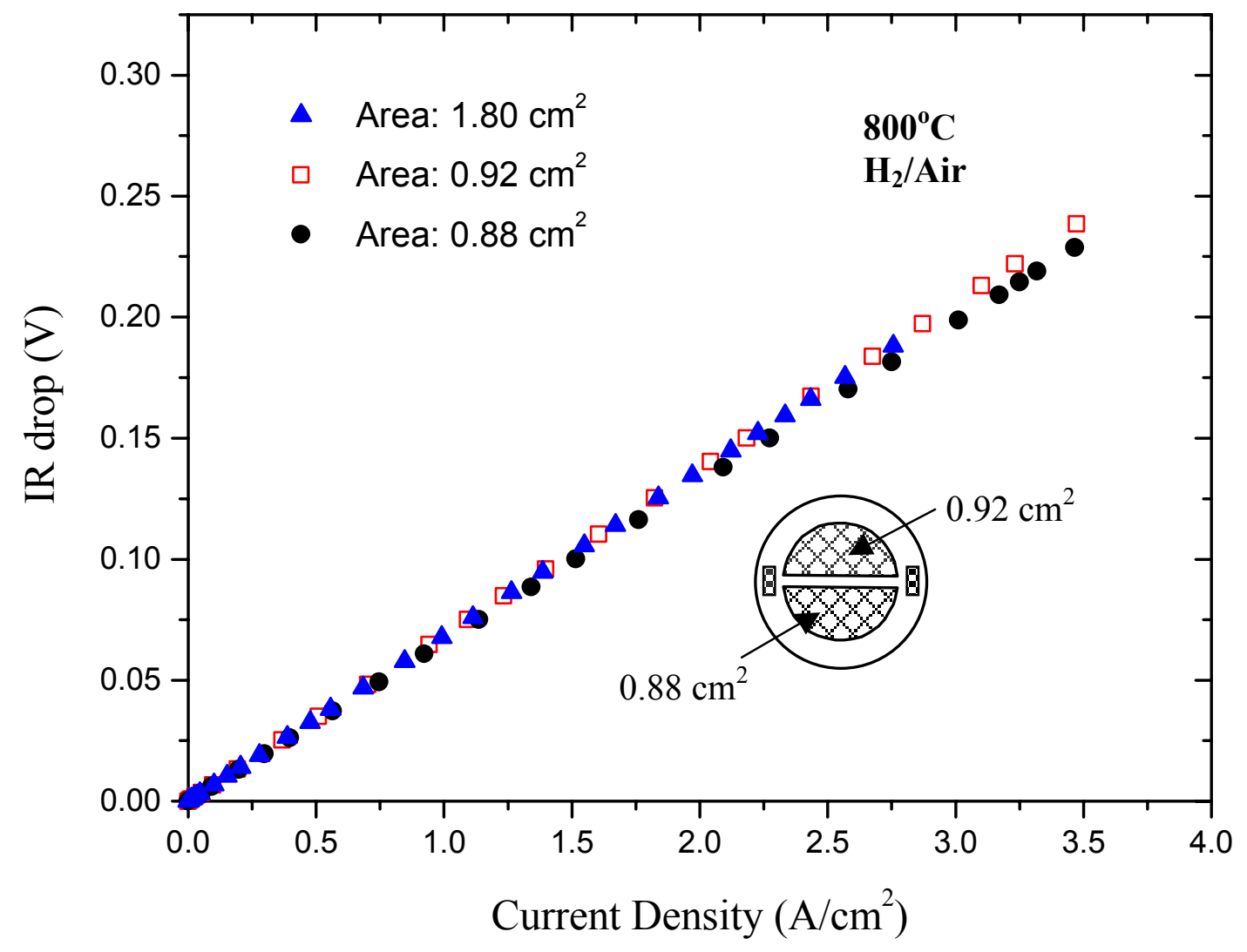

Figure \#27: Ohmic contribution (IR drop) vs. current density measured for the cell with semicircular cathodes, corresponding to Figure \#25. 


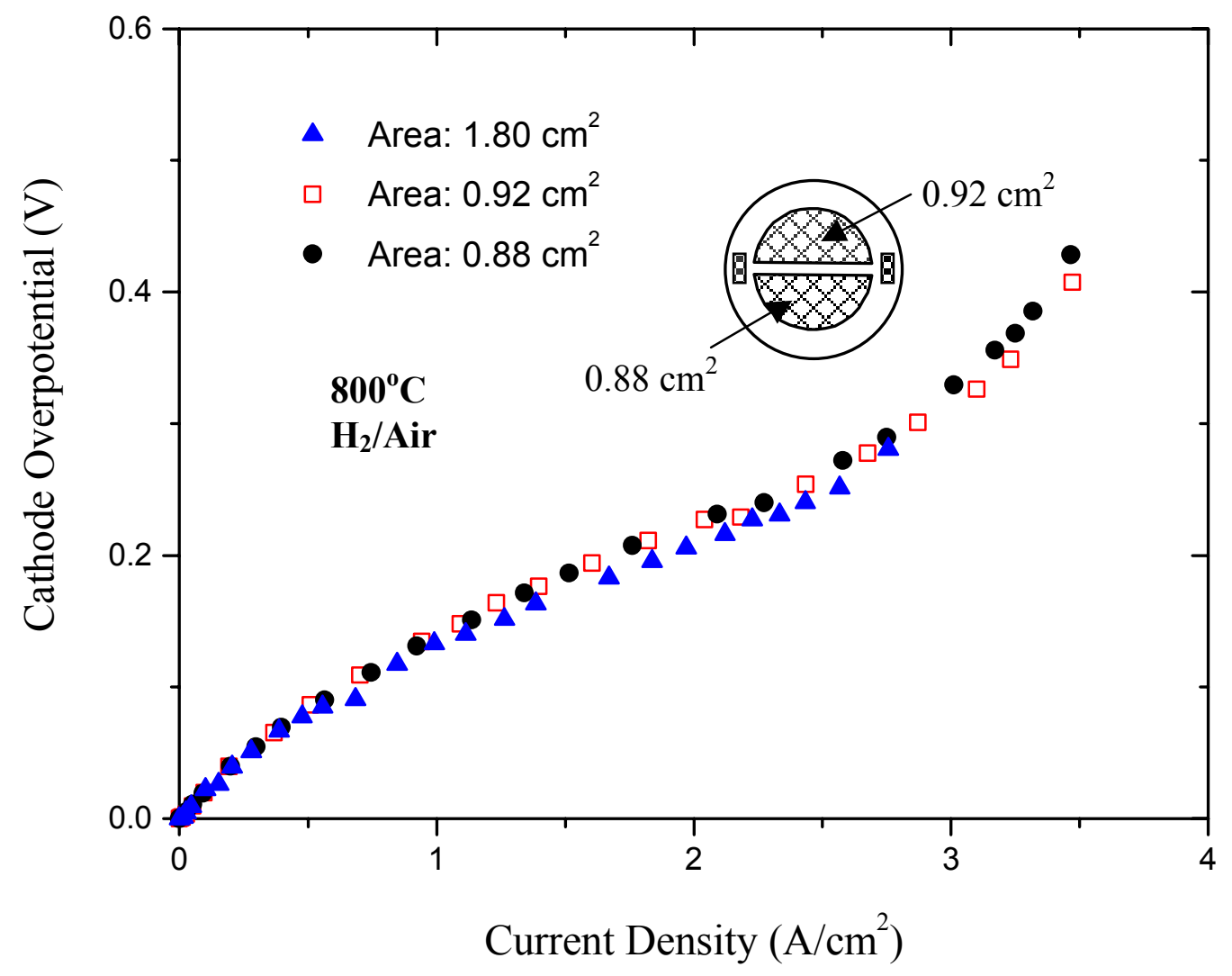

Figure \#28: Cathodic overpotential vs. current density measured for the cell with semicircular cathodes, corresponding to Figure \#25. 


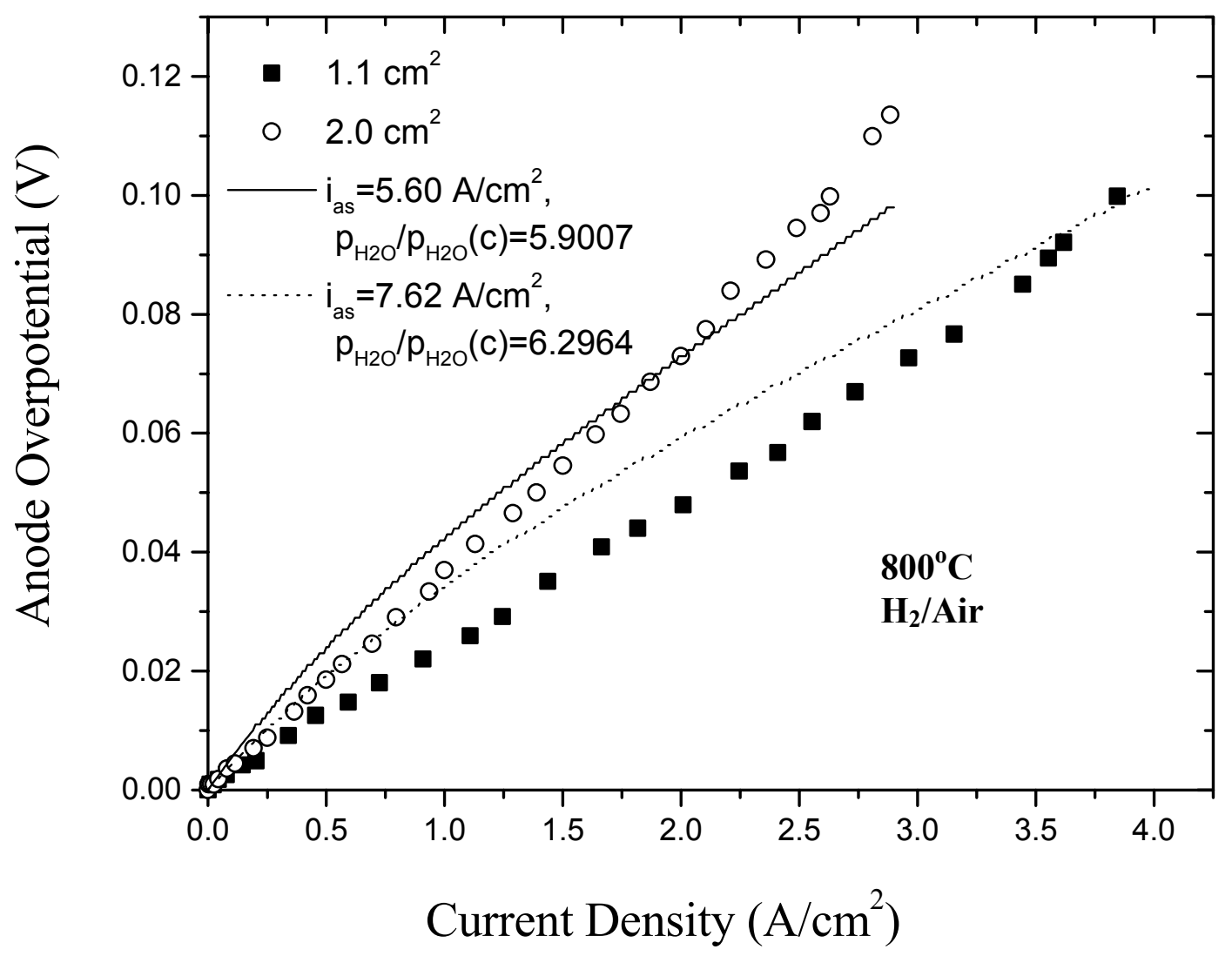

Figure \#29: Experimentally measured anodic overpotentials (the same as Figure \#24) along with fits to equation (18). The $i_{a s}$ for the best fit to the experimental data for the cell with cathode area $\sim 2.0 \mathrm{~cm}^{2}$ was made by matching at $i=2 \mathrm{~A} / \mathrm{cm}^{2}$. Using this value of $i_{a s}$, the $i_{a s}$ for the cell with cathode area of $\sim 1.1 \mathrm{~cm}^{2}$ was estimated using equations (16 or 17). The dotted curve for the cell with $\sim 1.1 \mathrm{~cm}^{2}$ of cathode area, was calculated using equation (18). 


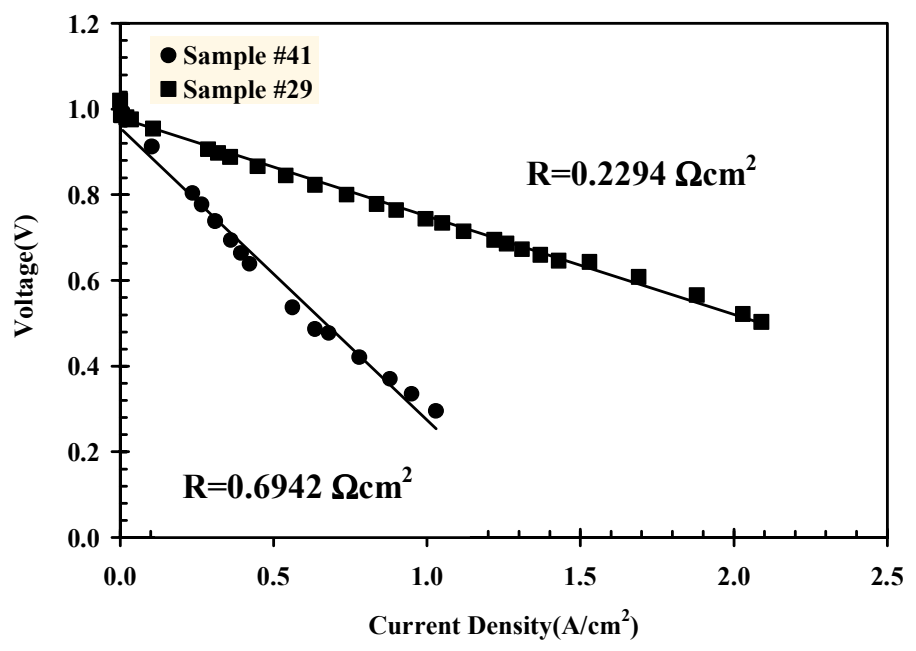

Figure \#30: Voltage vs. current density traces at $800^{\circ} \mathrm{C}$ for two cells with different cathode interlayers.

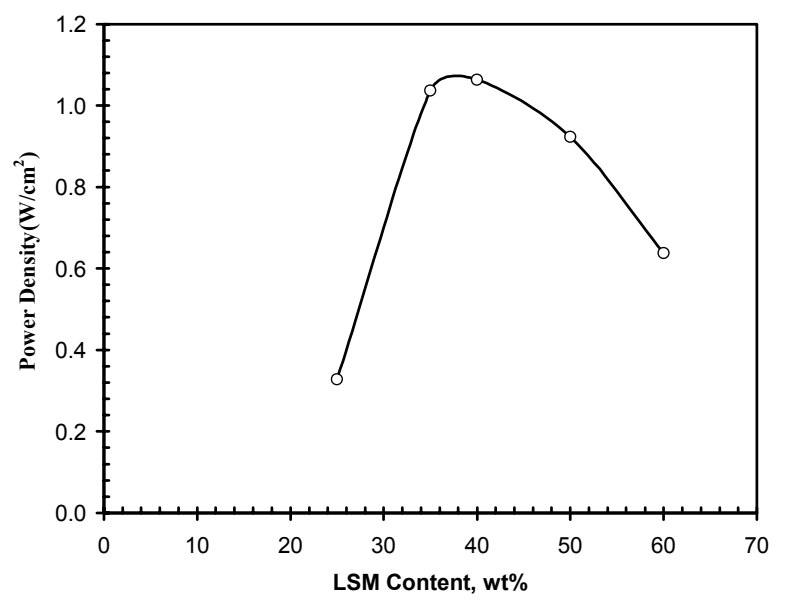

Figure \#31: A plot of maximum power density vs. the LSM content in the cathode interlayers. 


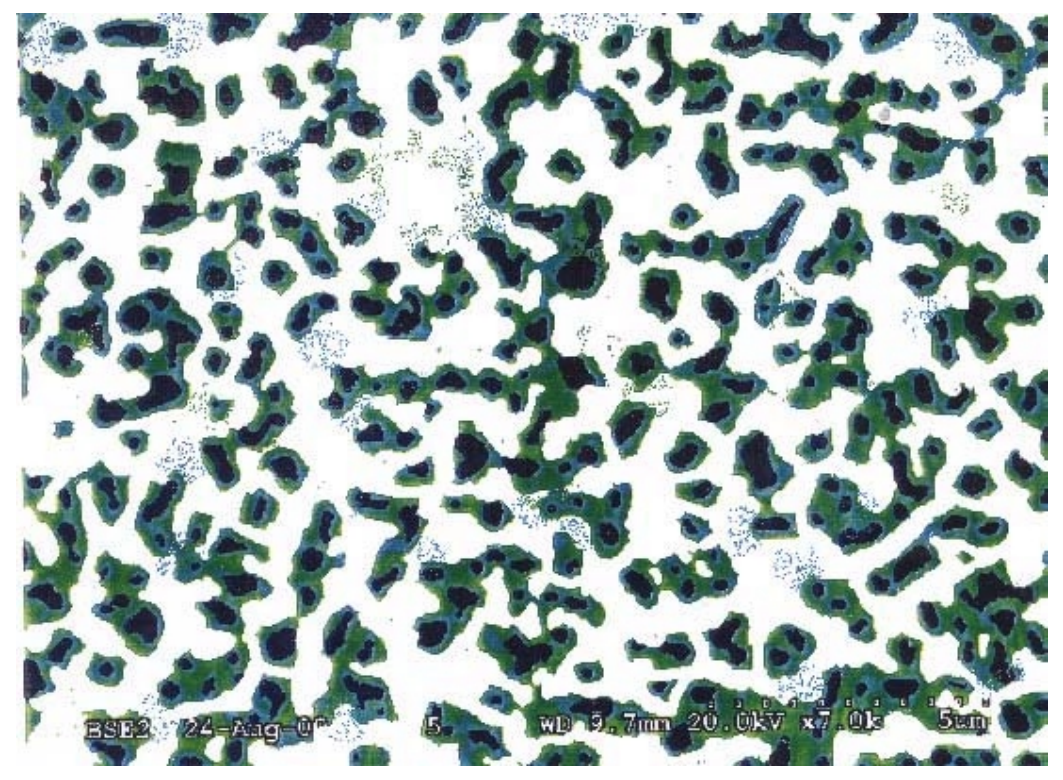

Figure \#32: An electron probe micrograph of the cathode interlayer from one of the cells.

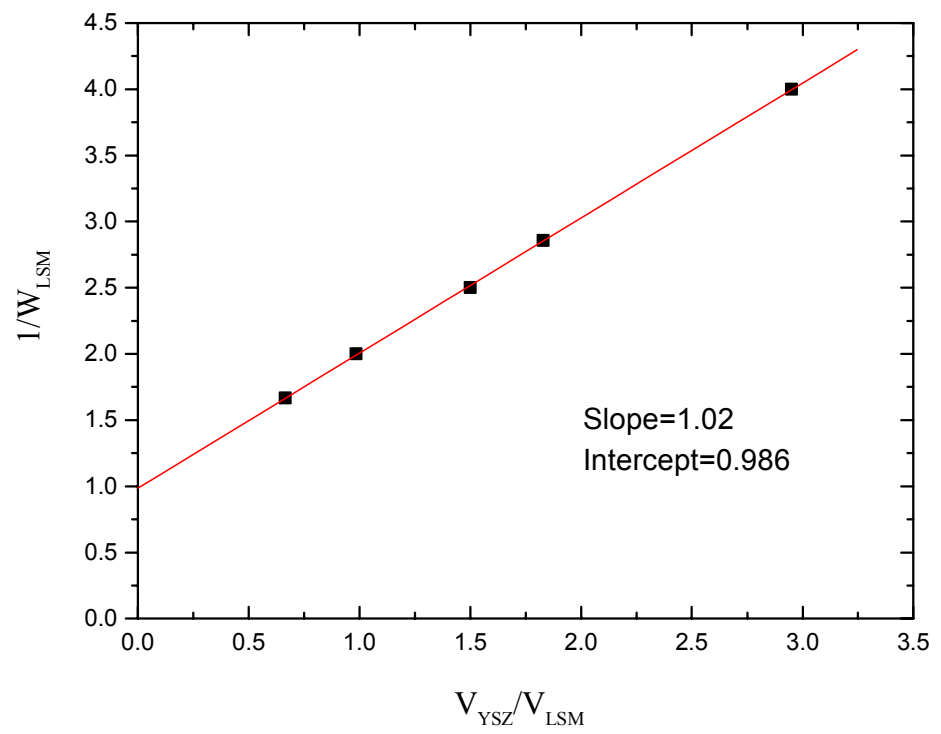

Figure \#33: A plot of $1 / W_{L S M}$ vs. $V_{Y S Z} / V_{L S M}$. 


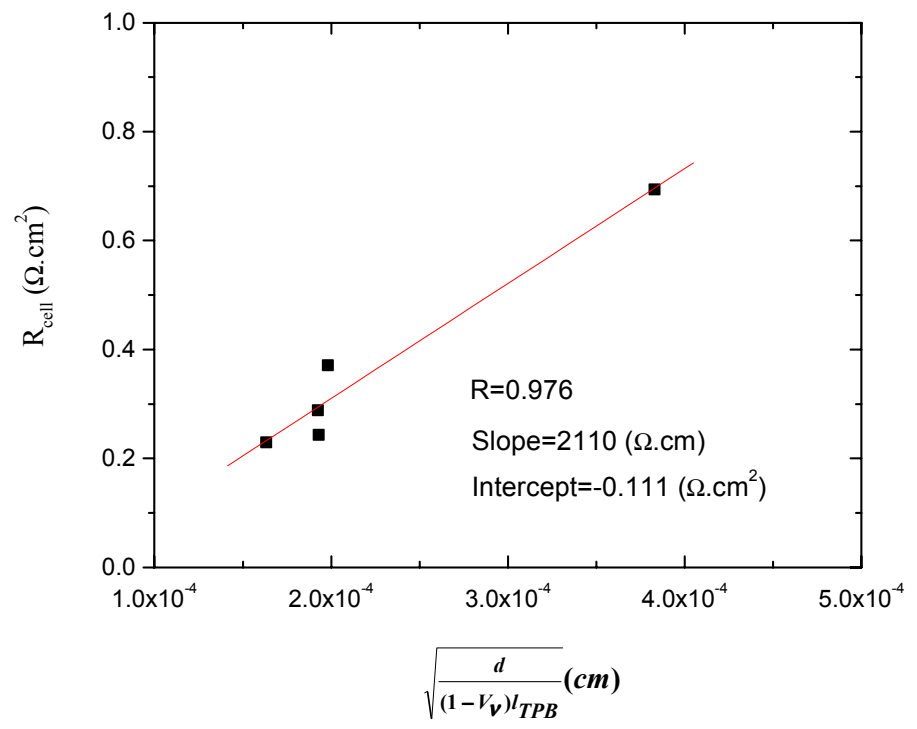

Figure \#34: A plot of the experimentally measured $R_{\text {cell }}$ vs. $\sqrt{d /\left(\left(1-V_{v}\right) l_{T P B}\right)}$.

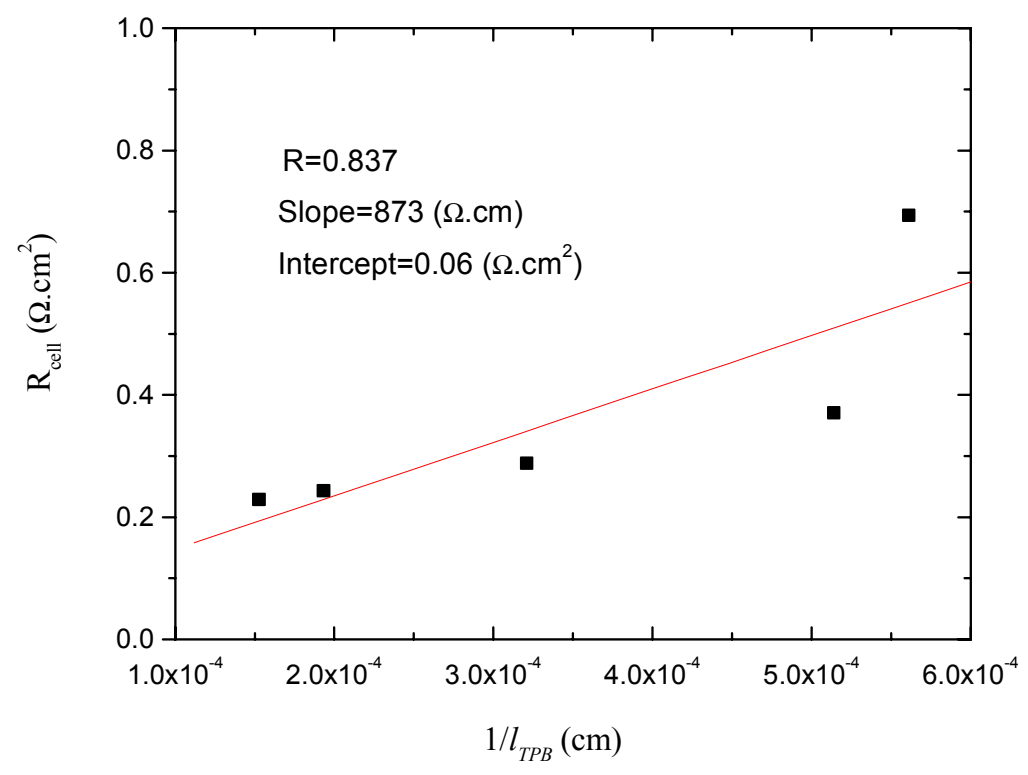

Figure \#35: A plot of the experimentally measured $R_{\text {cell }}$ vs. $1 / l_{T P B}$. 


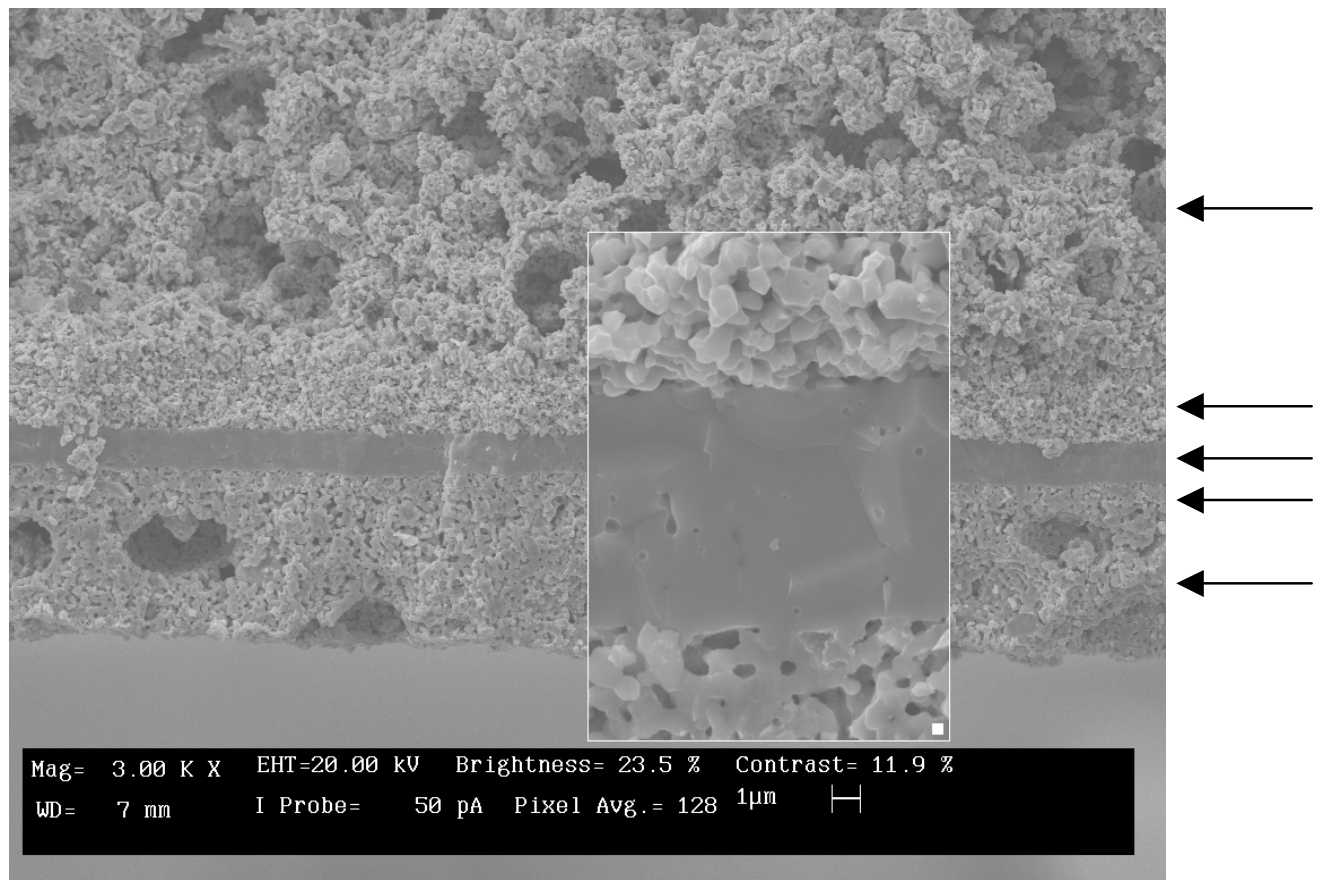

Figure \#36: An SEM micrograph of a fractured cell showing five layers: (a) The top layer is the Ni-YSZ anode support of $\sim 1 \mathrm{~mm}$ thickness. (b) The adjacent layer, sandwiched between the dense YSZ electrolyte layer and the Ni-YSZ anode support, is the anode interlayer of $\sim 20 \mu \mathrm{m}$ thickness. (c) Dense YSZ layer of $\sim 10 \mu \mathrm{m}$ in thickness. (d) Cathode interlayer of $\sim 20 \mu \mathrm{m}$ thickness adjacent to the YSZ electrolyte layer. (e) Cathode layer of $\sim 80 \mu \mathrm{m}$ thickness. The bar $(3 \mu \mathrm{m})$ is for the inset. 


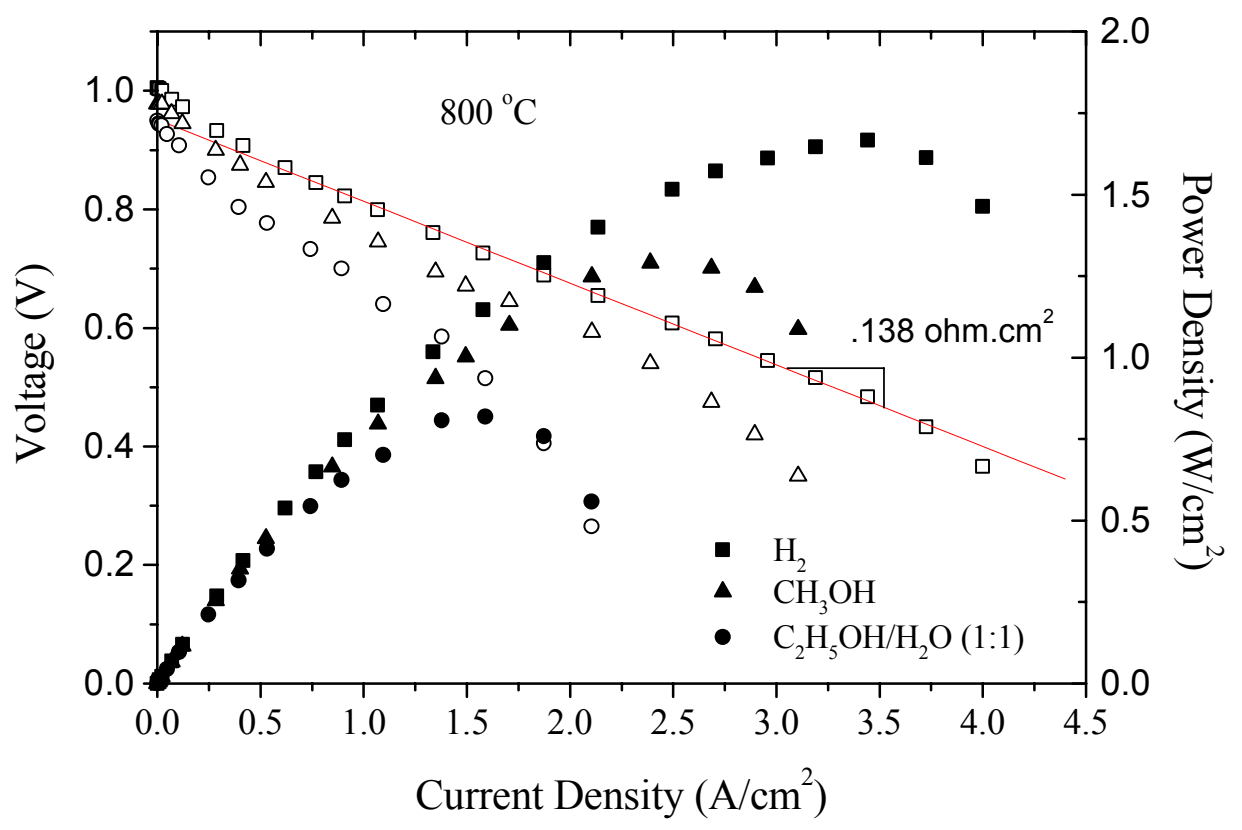

Figure \#37: Cell performance at $800^{\circ} \mathrm{C}$ with methanol, ethanol and hydrogen as fuels. Flow rate for hydrogen was $100 \mathrm{ml} / \mathrm{min}$. Methanol used was undiluted. Ethanol used was an equivolume solution of ethanol and water. The flow rates for liquid fuels were $0.2 \mathrm{ml} / \mathrm{min}$ for both. 


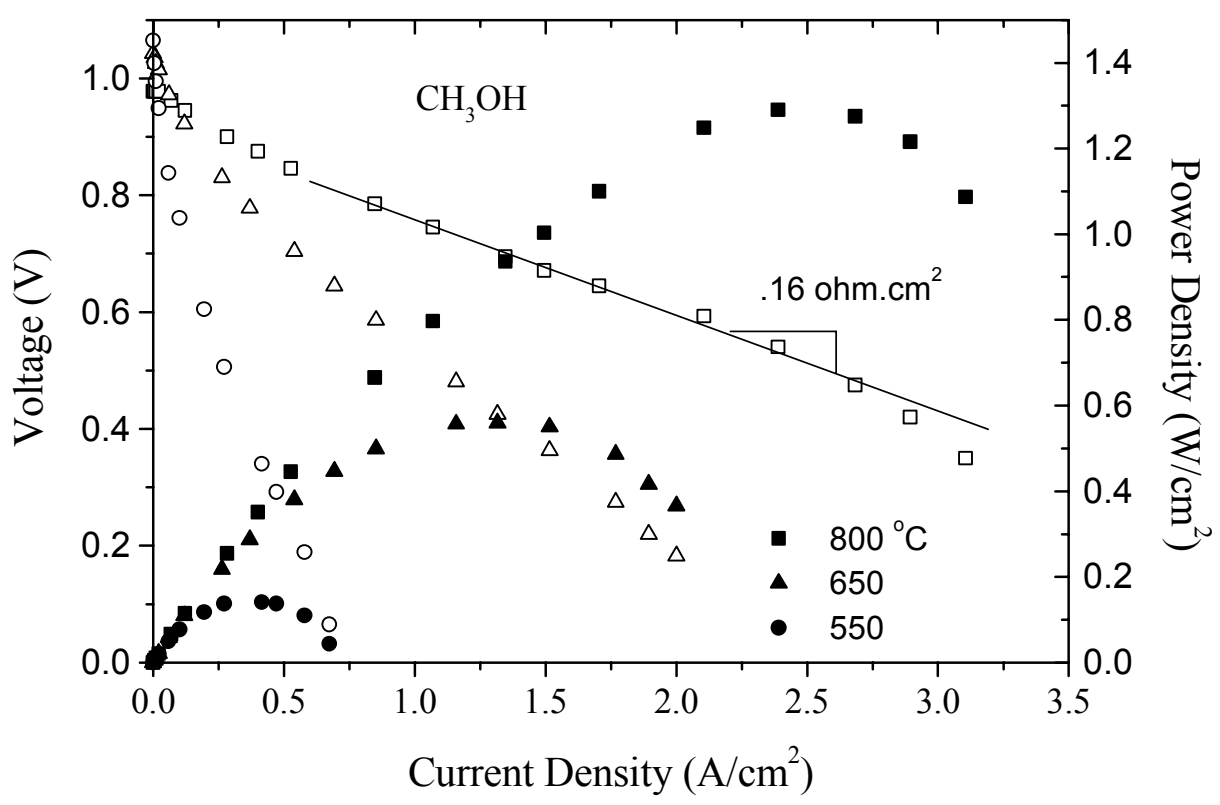

Figure \#38: Cell performance with methanol as a fuel at various temperatures. The flow rate was $0.2 \mathrm{ml} / \mathrm{min}$. 


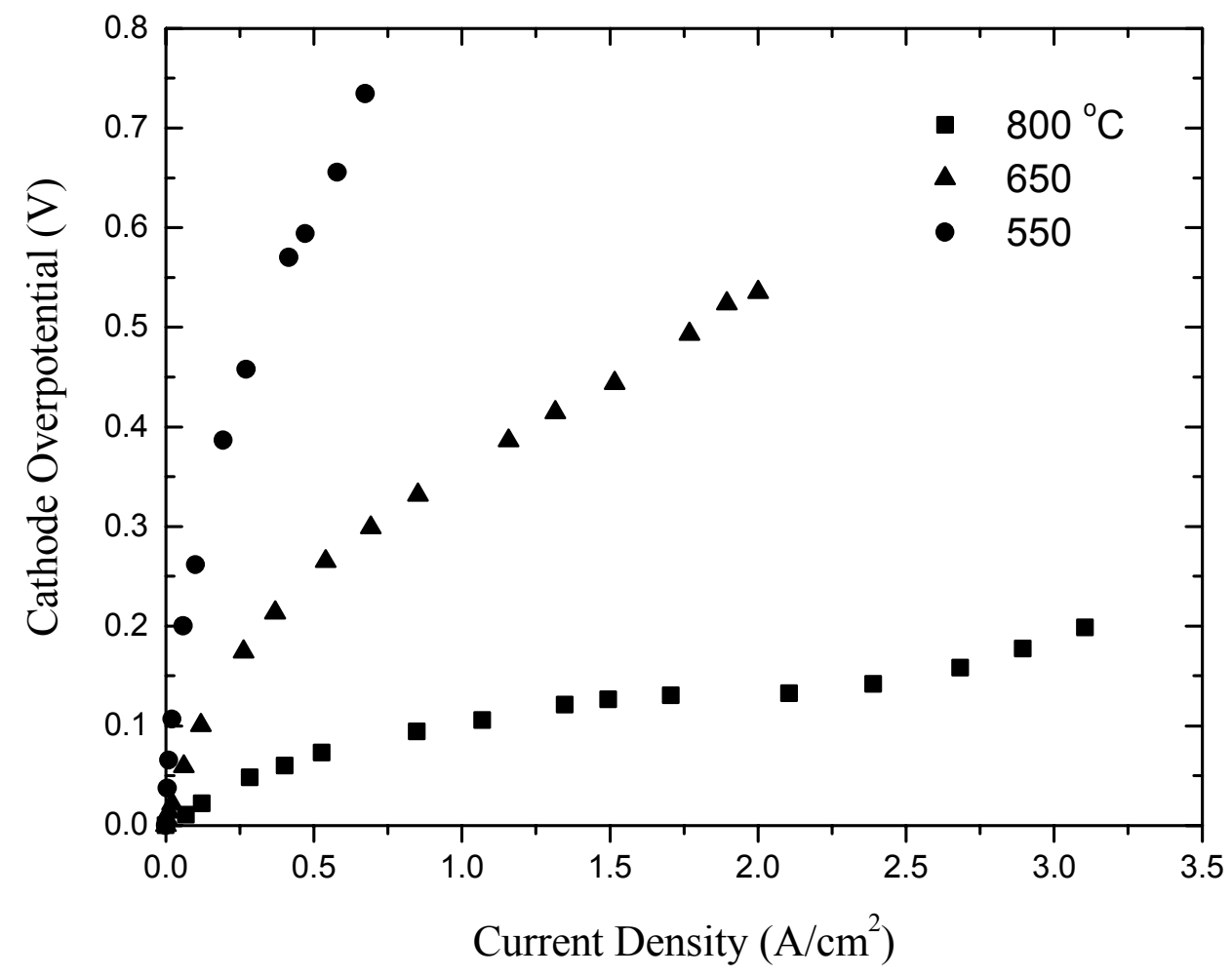

Figure \#39: Cathode overpotentials vs. current density at $800^{\circ} \mathrm{C}, 650^{\circ} \mathrm{C}$ and $550^{\circ} \mathrm{C}$ for an air flow rate of $600 \mathrm{ml} / \mathrm{min}$. 


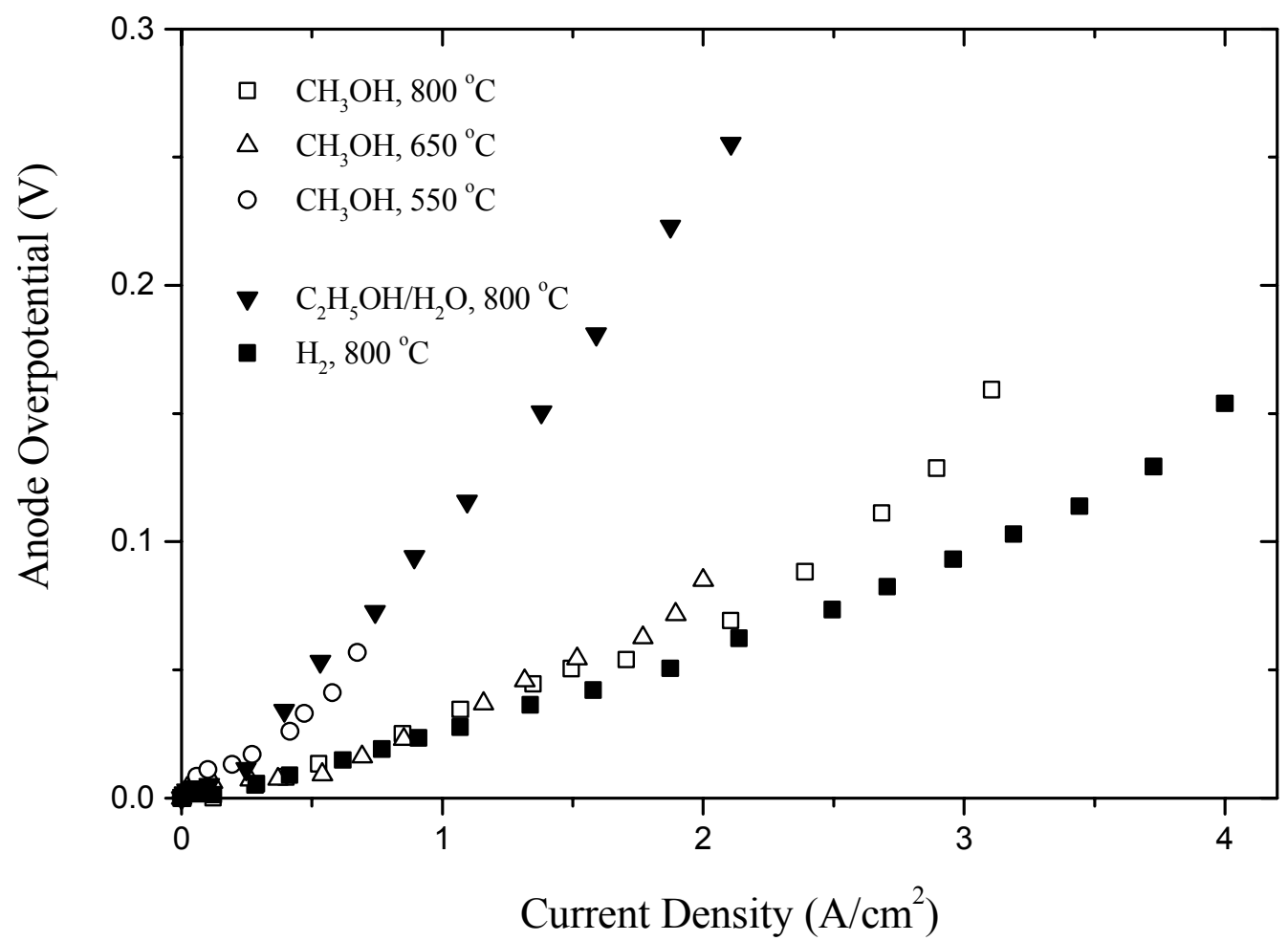

Figure \#40: Anode overpotentials vs. current density. Overpotentials were measured at $800^{\circ} \mathrm{C}$, $650^{\circ} \mathrm{C}$ and $550^{\circ} \mathrm{C}$ for methanol (open symbols) and for hydrogen and ethanol + water (solid symbols) as fuels at $800^{\circ} \mathrm{C}$. The liquid flow rate was $0.2 \mathrm{ml} / \mathrm{min}$. Hydrogen flow rate was 100 $\mathrm{ml} / \mathrm{min}$. 


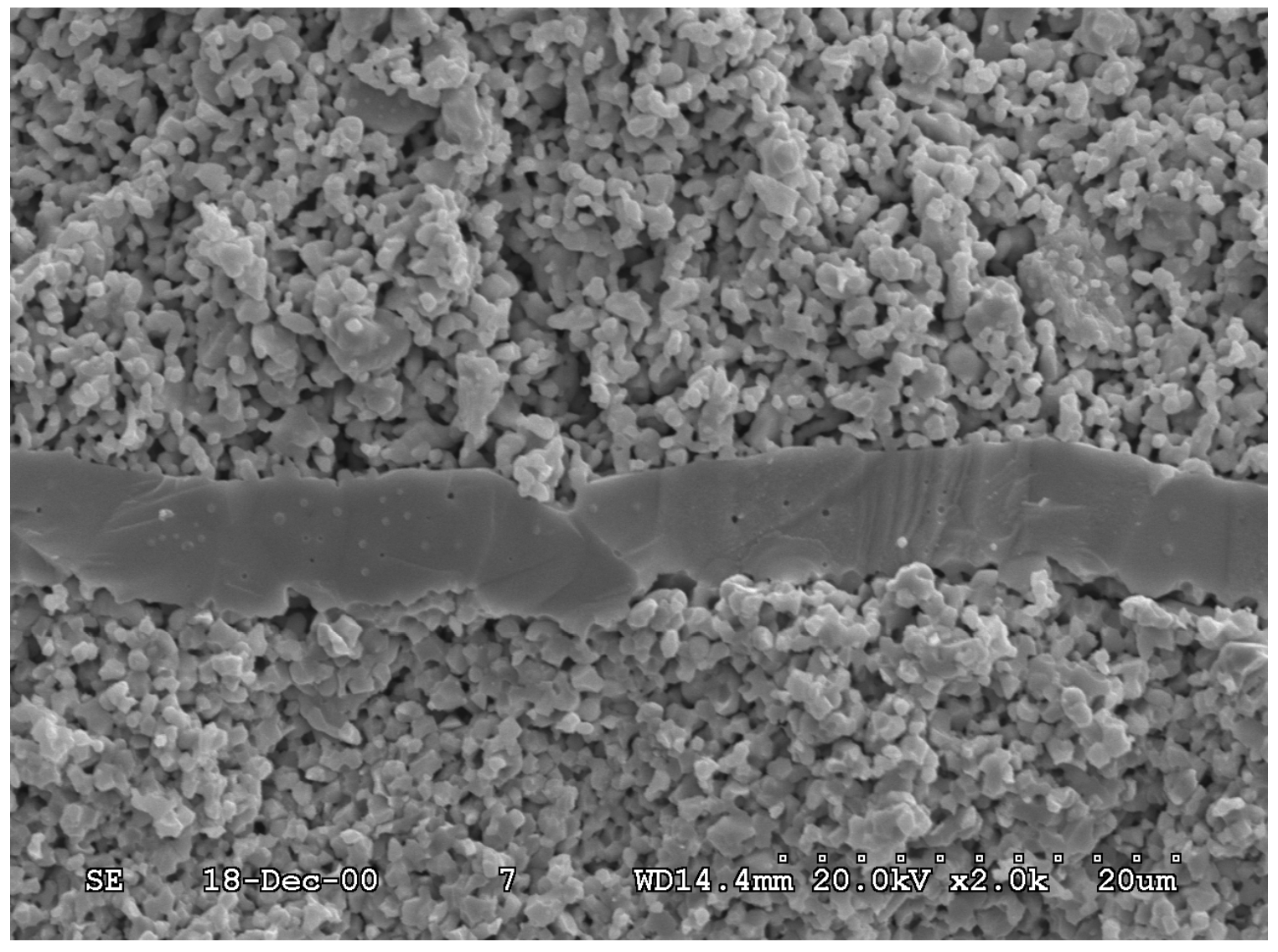

Figure \#41: A scanning electron micrograph of a fractured single cell. 


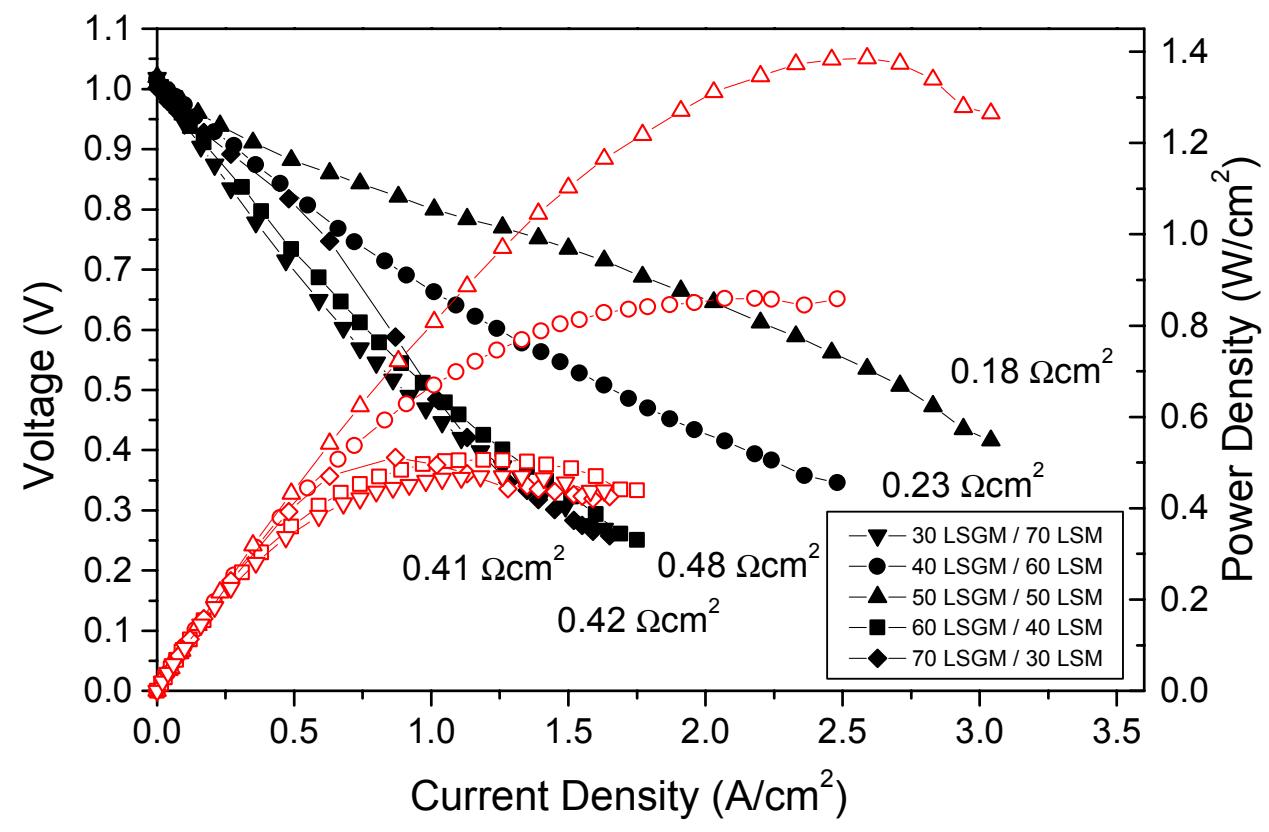

Figure \#42: Voltage and power density as a function of current density for cells with varying cathode interlayer compositions. The cells were tested at $800^{\circ} \mathrm{C}$ with air and humidified hydrogen. 


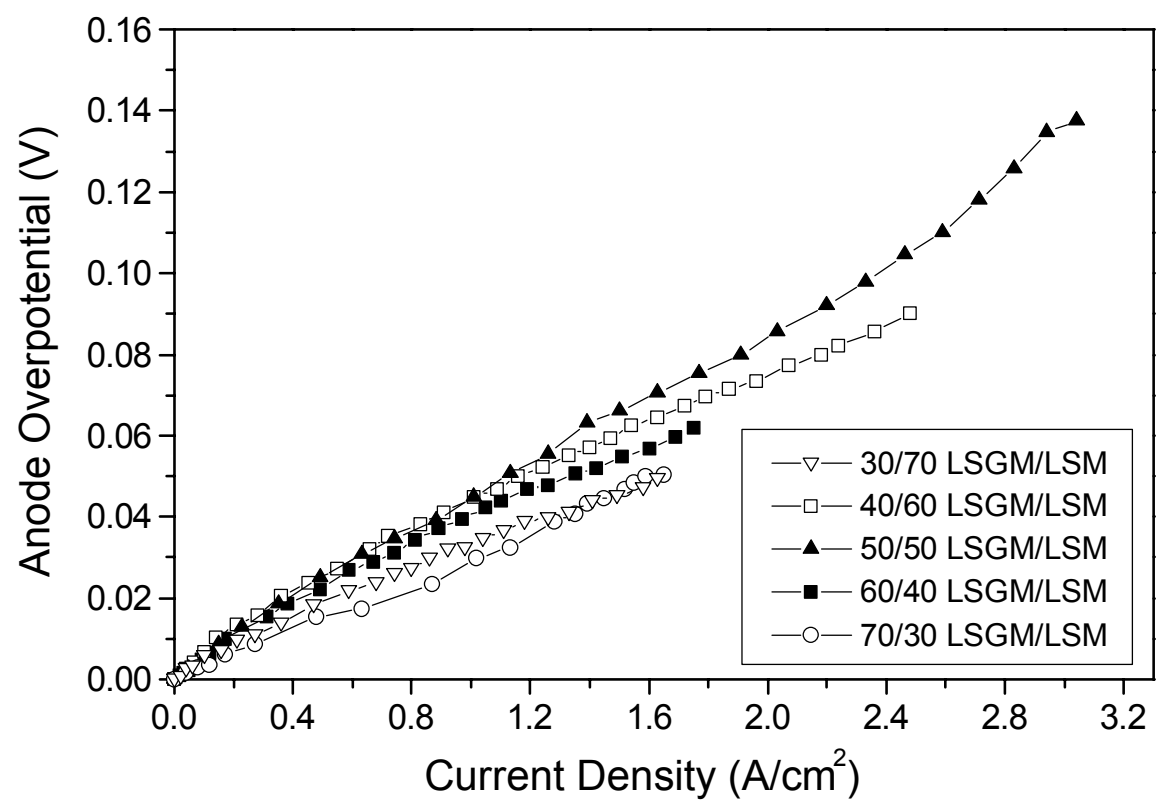

Figure \#43: Anode overpotential as a function of current density for cells with varying cathode interlayer compositions. The cells were tested at $800^{\circ} \mathrm{C}$ with air and humidified hydrogen. 


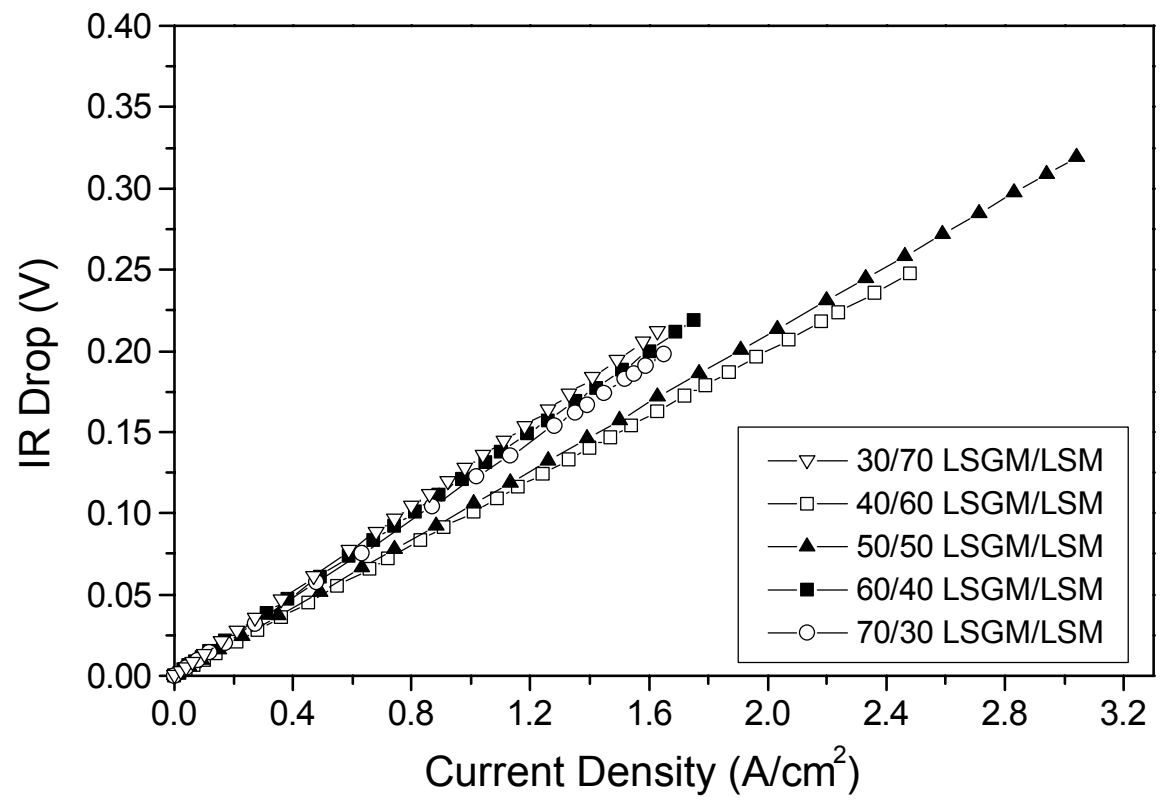

Figure \#44: Ohmic overpotential (IR drop) as a function of current density for cells with varying cathode interlayer compositions. The cells were tested at $800^{\circ} \mathrm{C}$ with air and humidified hydrogen. 


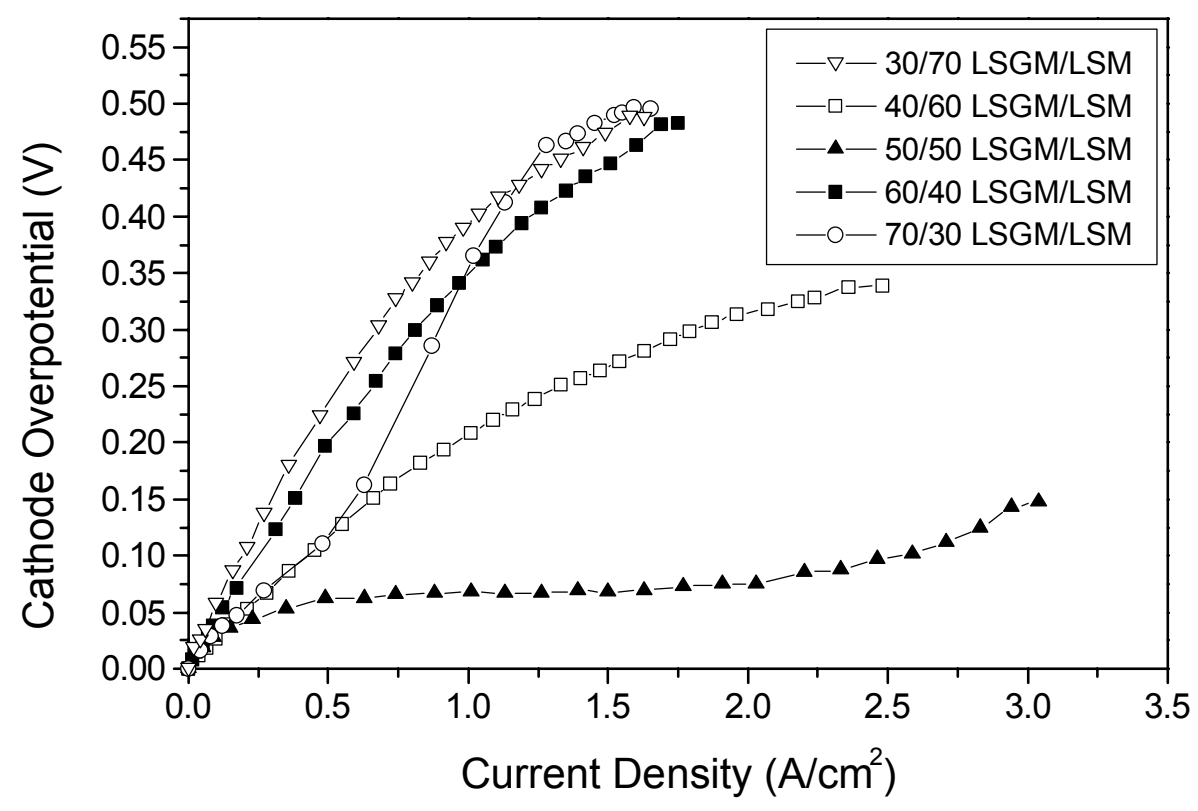

Figure \#45: Cathode overpotential as a function of current density for cells with varying cathode interlayer compositions. The cells were tested at $800^{\circ} \mathrm{C}$ with air and humidified hydrogen. 


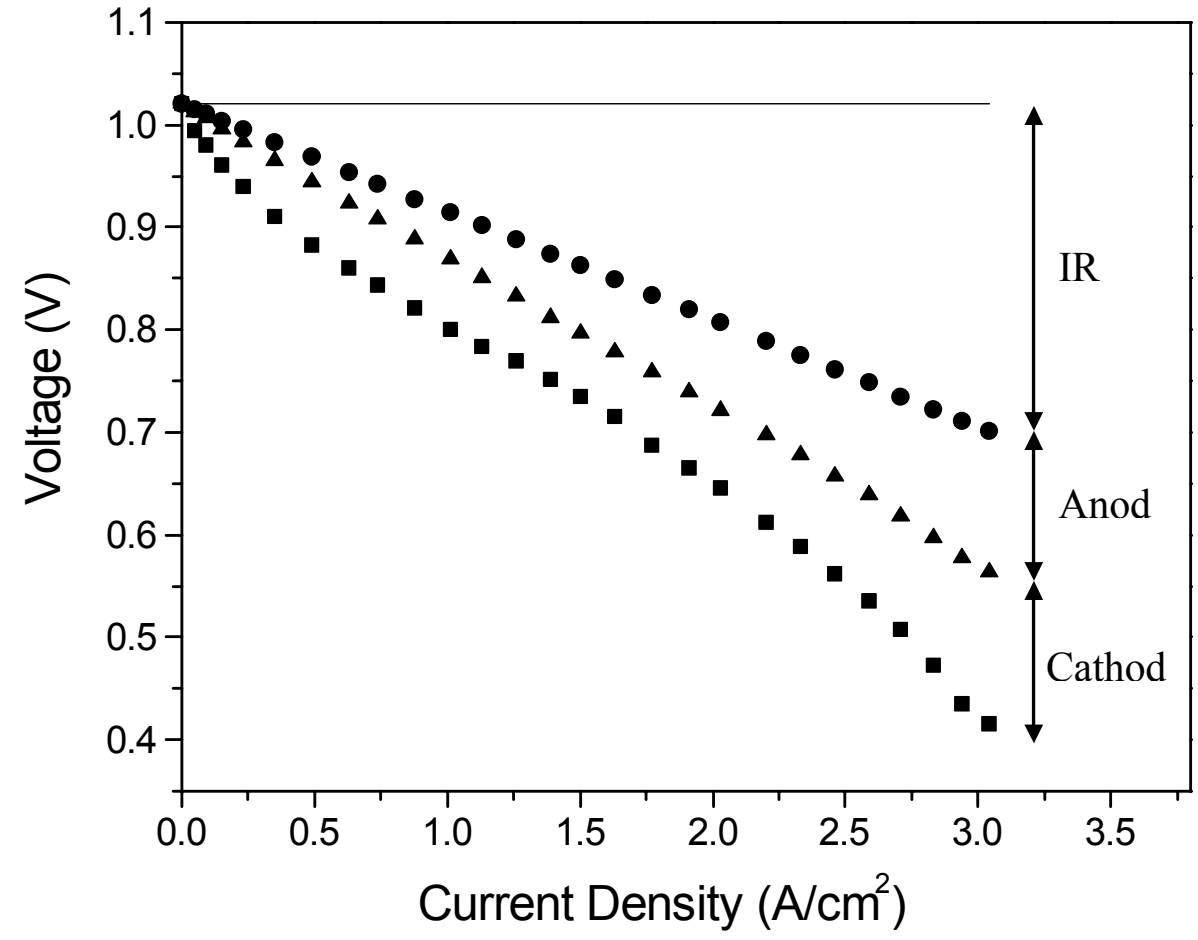

Figure \#46: Anodic, cathodic, and ohmic overpotentials at $800^{\circ} \mathrm{C}$ for the cell with the 50 wt.\% LSGM and $50 \mathrm{wt} . \%$ LSM composite cathode fired at $1150^{\circ} \mathrm{C}$. 


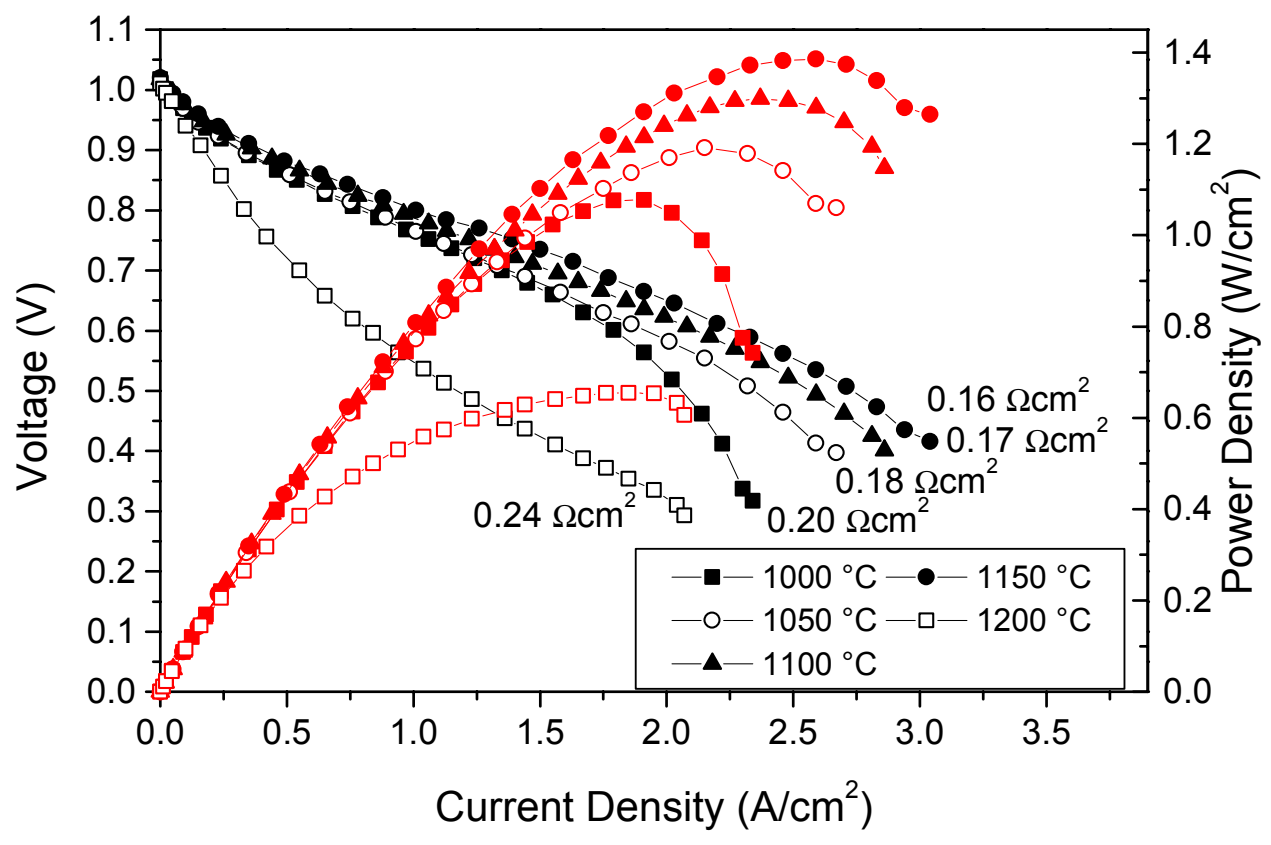

Figure \#47: The effect of cathode interlayer firing temperature on performance at $800^{\circ} \mathrm{C}$ as shown with voltage and power density as a function of current density. The cathode interlayer consisted of $50 \mathrm{wt} . \%$ LSGM and $50 \mathrm{wt} . \%$ LSM. 


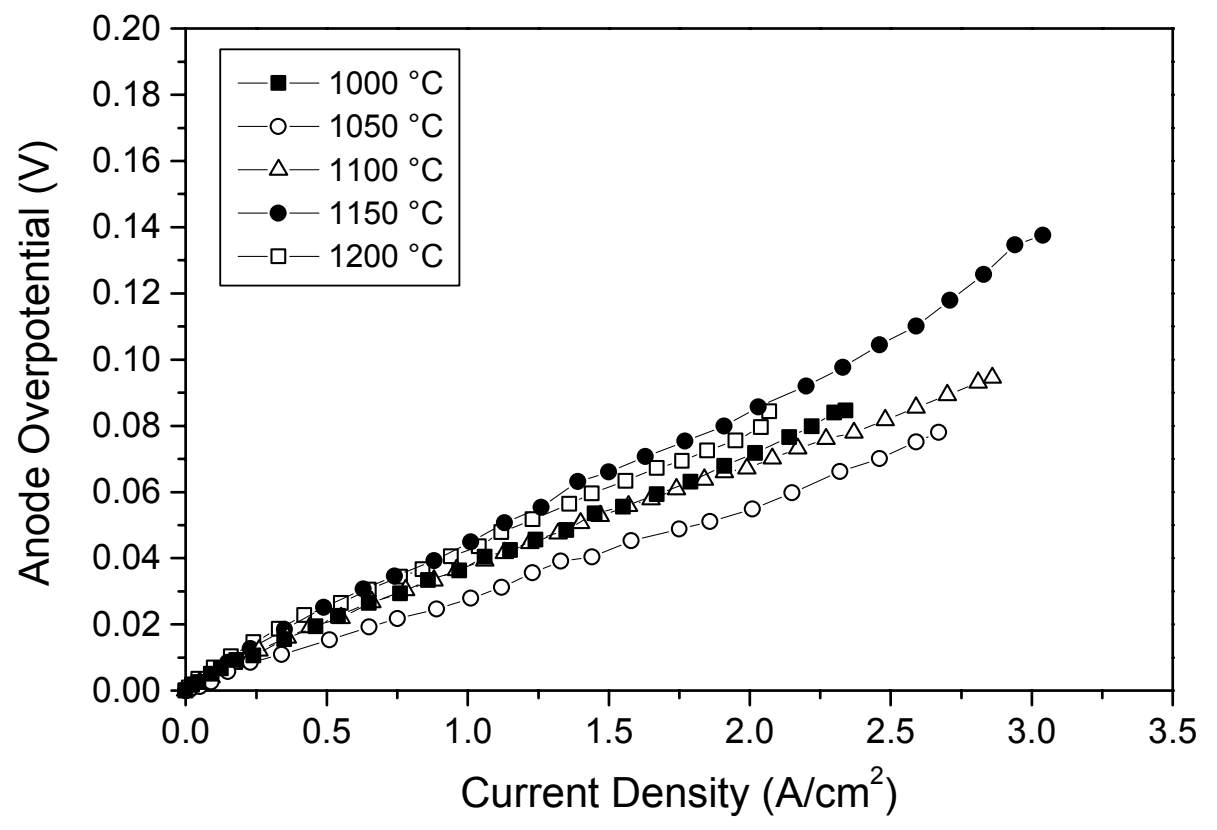

Figure \#48: Anode overpotential as a function of current density at $800^{\circ} \mathrm{C}$ for cells with a $50 \mathrm{wt} . \%$ LSGM and $50 \mathrm{wt} . \%$ LSM composite cathode fired at various temperatures. 


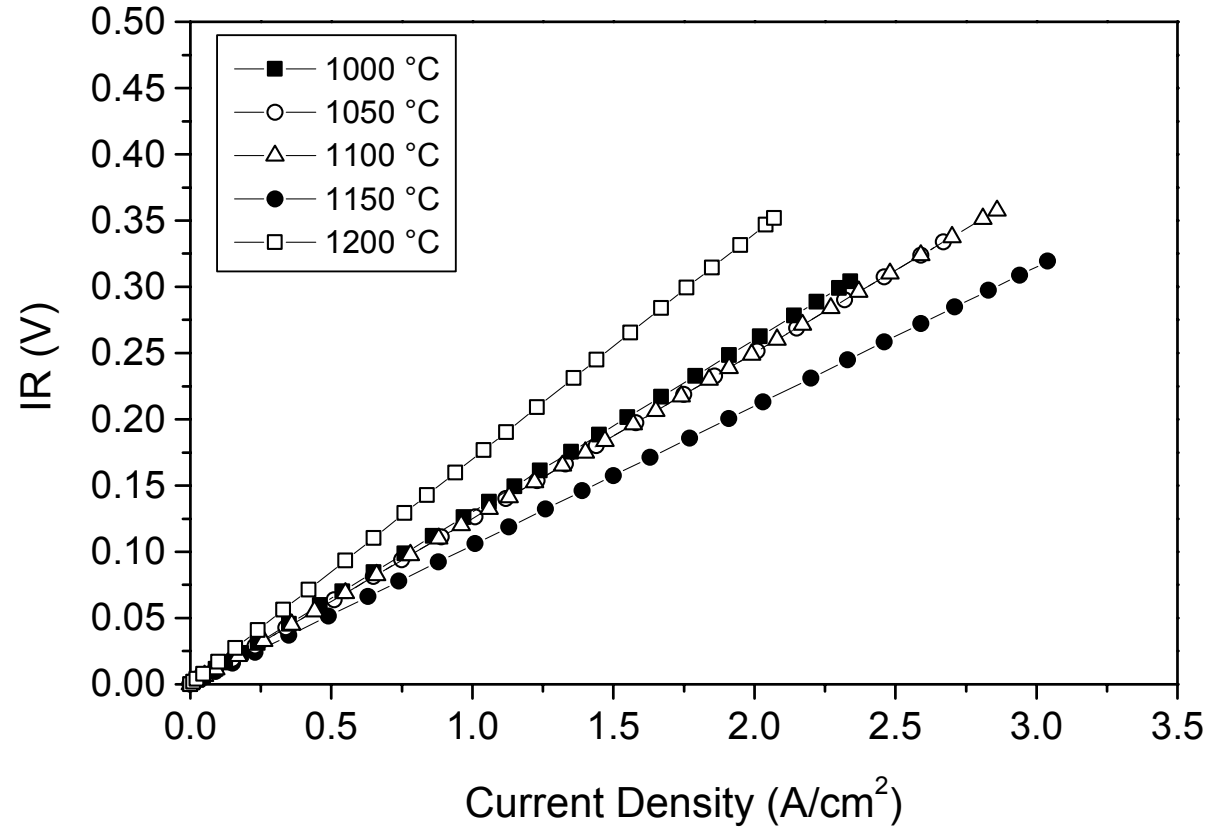

Figure \#49: Ohmic overpotential (IR drop) as a function of current density for cells with 50 wt.\% LSGM and 50 wt.\% LSM composite cathodes fired at various temperatures. 


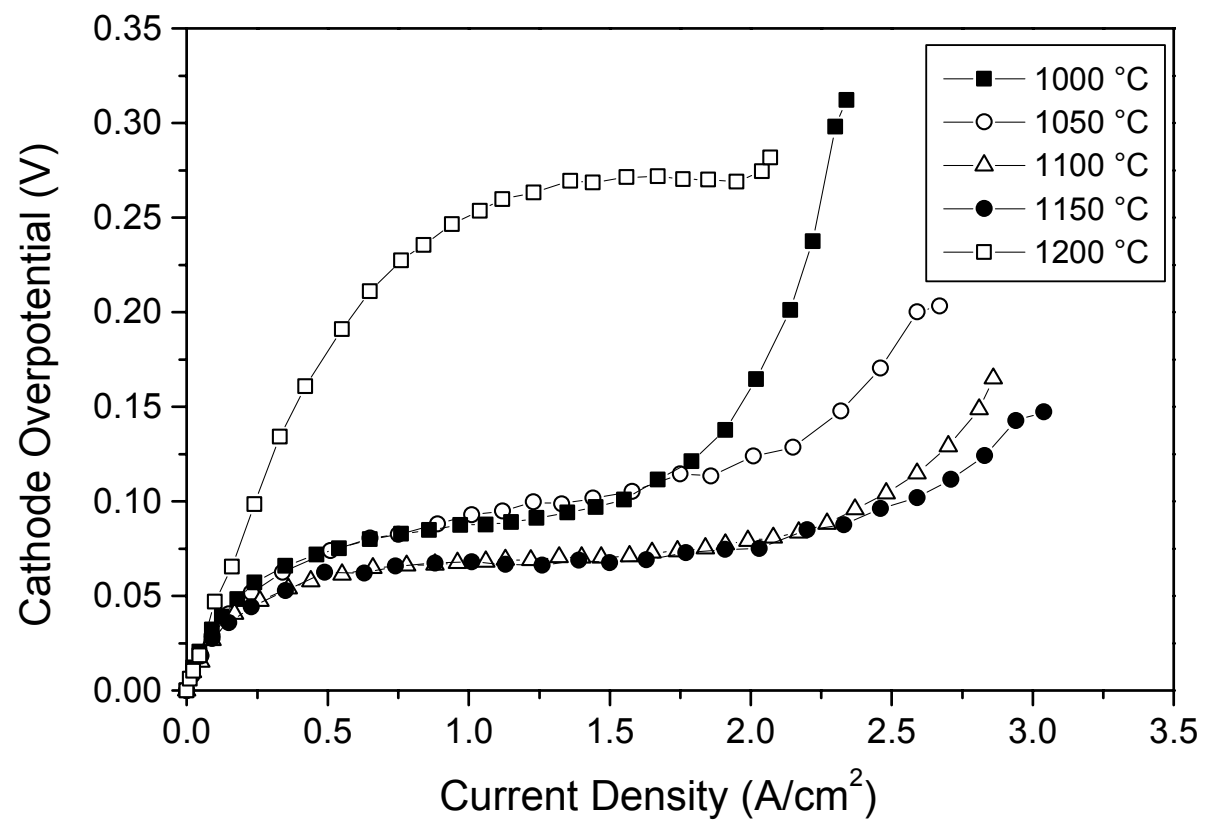

Figure \#50: Cathode overpotential as a function of current density for cells with $50 \mathrm{wt} . \%$ LSGM and $50 \mathrm{wt} . \%$ LSM composite cathodes fired at various temperatures. 


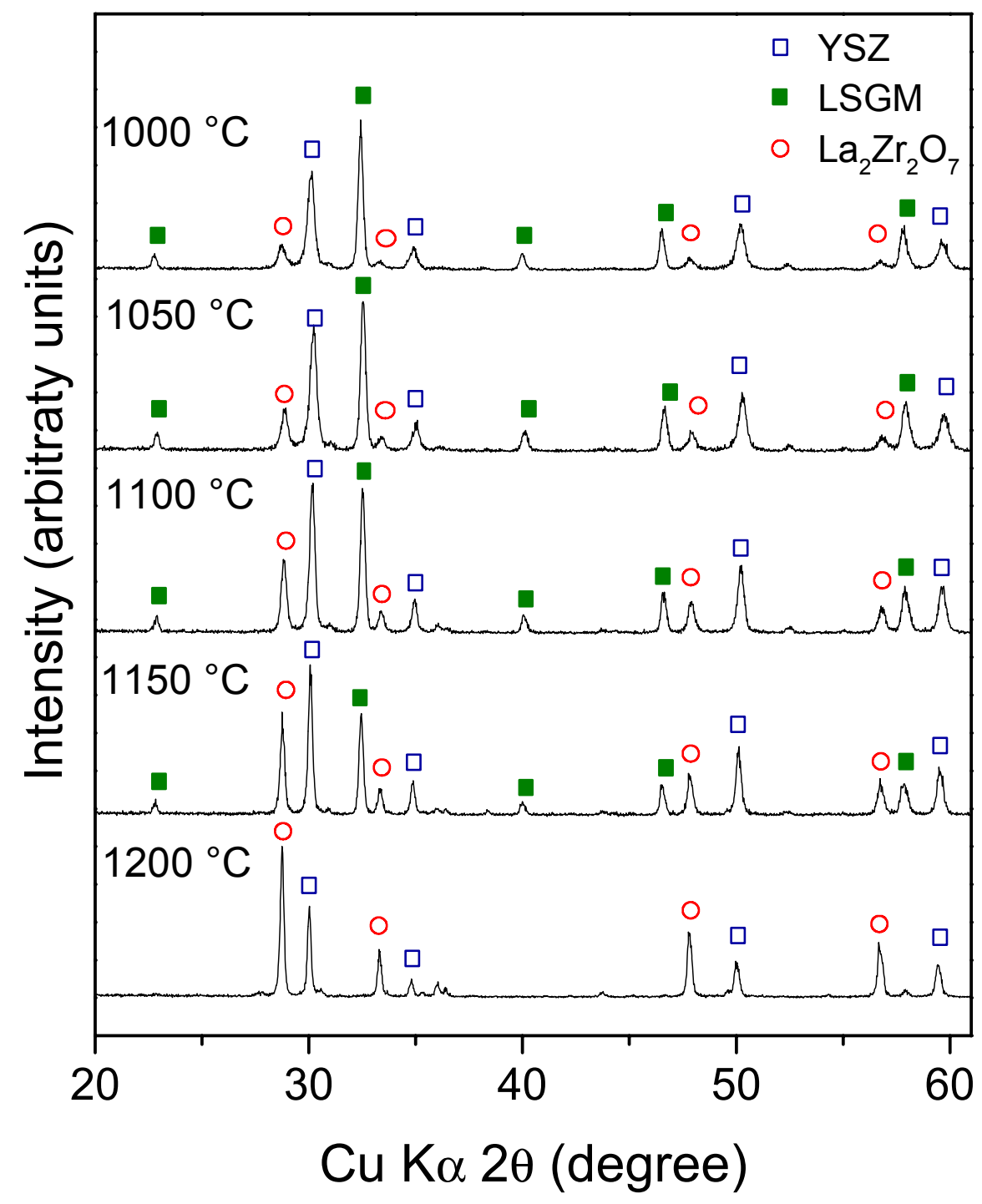

Figure \#51: Powder X-ray diffraction patterns for LSGM and YSZ powders mixed and fired at temperatures between 1000 and $1200^{\circ} \mathrm{C}$ for two hours. 


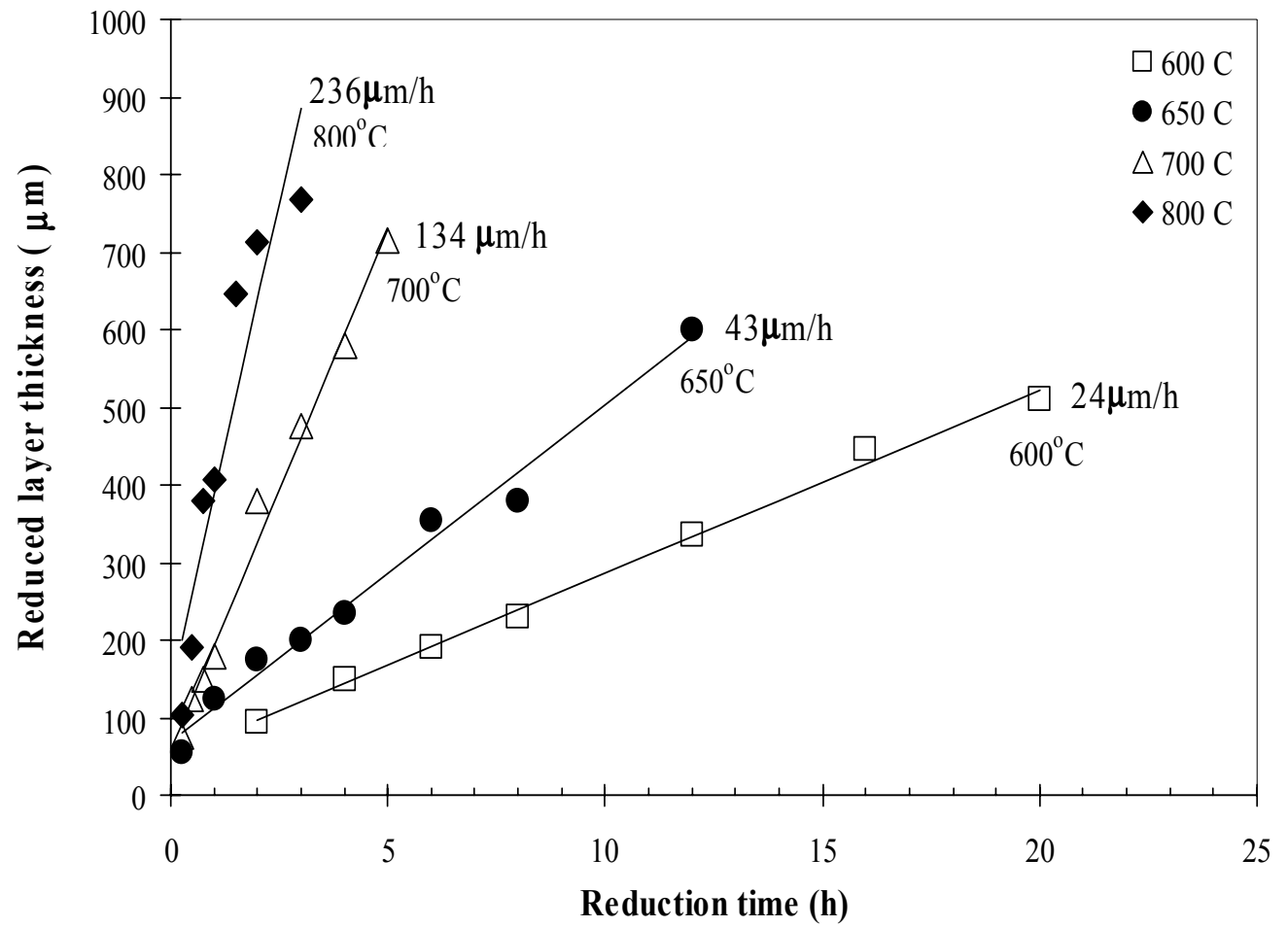

Figure \#52: Plots of the experimentally measured reduced layer thickness as a function of reduction time at various temperatures. 


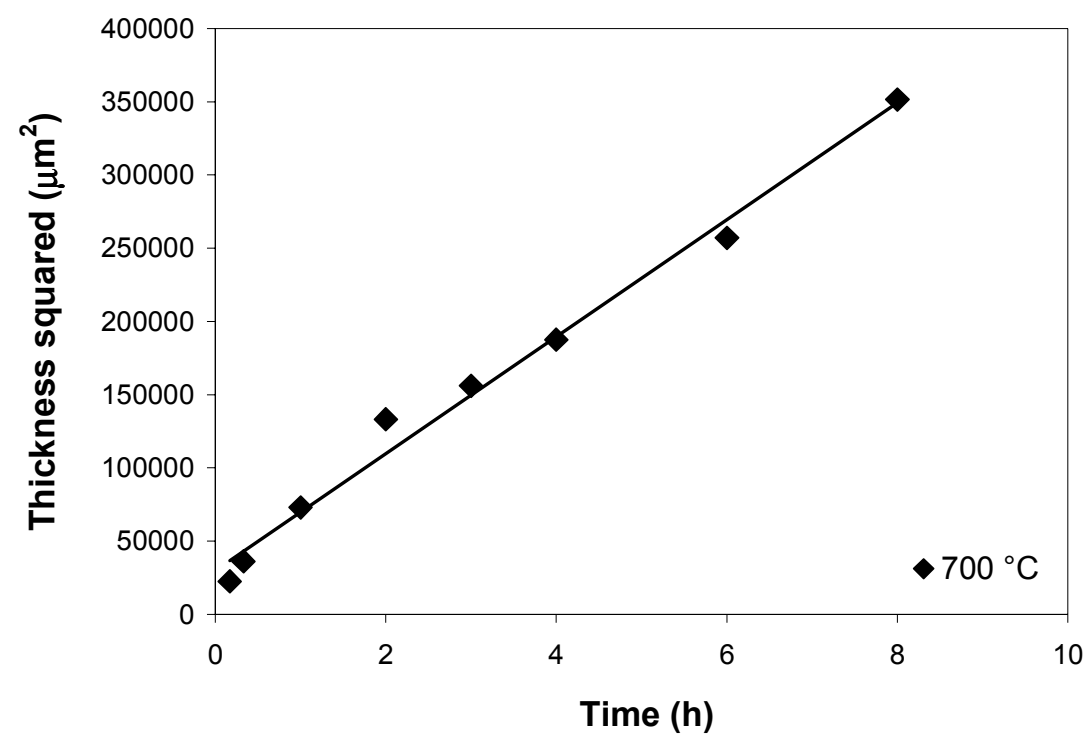

Figure \#53: Experimentally measured plot of the square of the re-oxidized layer thickness vs. time at $700^{\circ} \mathrm{C}$. A straight-line behavior of the re-oxidized layer thickness vs. time suggests that the kinetics of re-oxidation is diffusion controlled. 


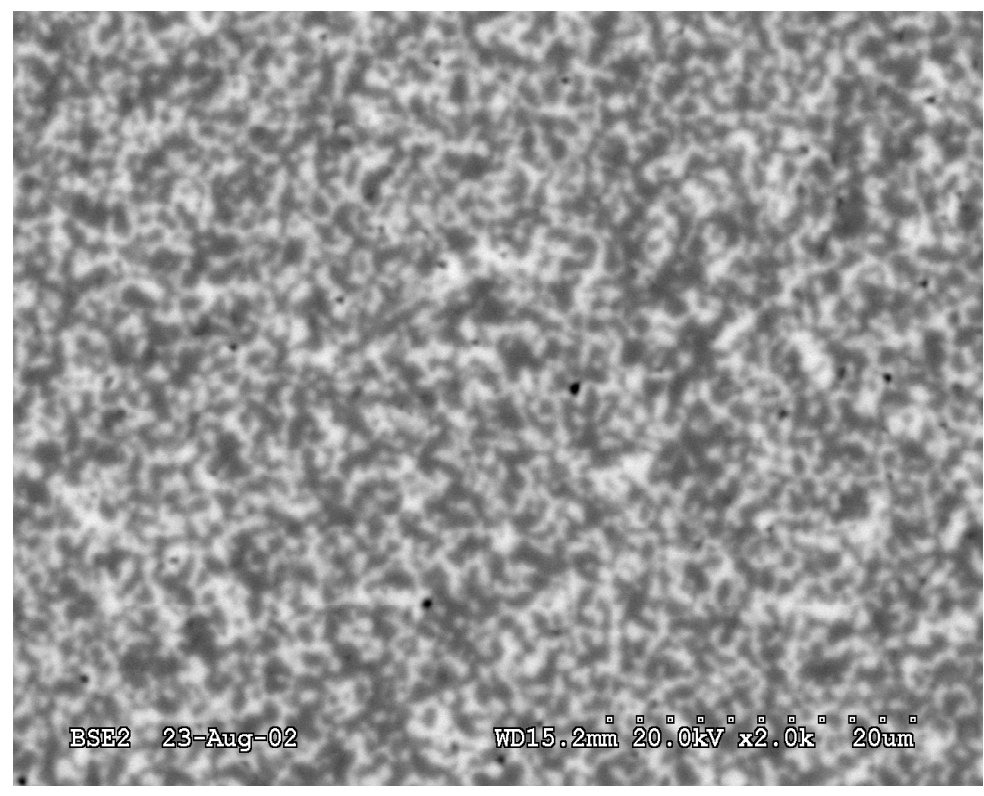

Figure \#54: An SEM micrograph of an as-sintered sample. Light regions are NiO, dark gray regions are YSZ, and black are pores. Note that the amount of porosity is very small in the as-sintered samples. That is, the original, as-sintered sample was essentially, fully dense.

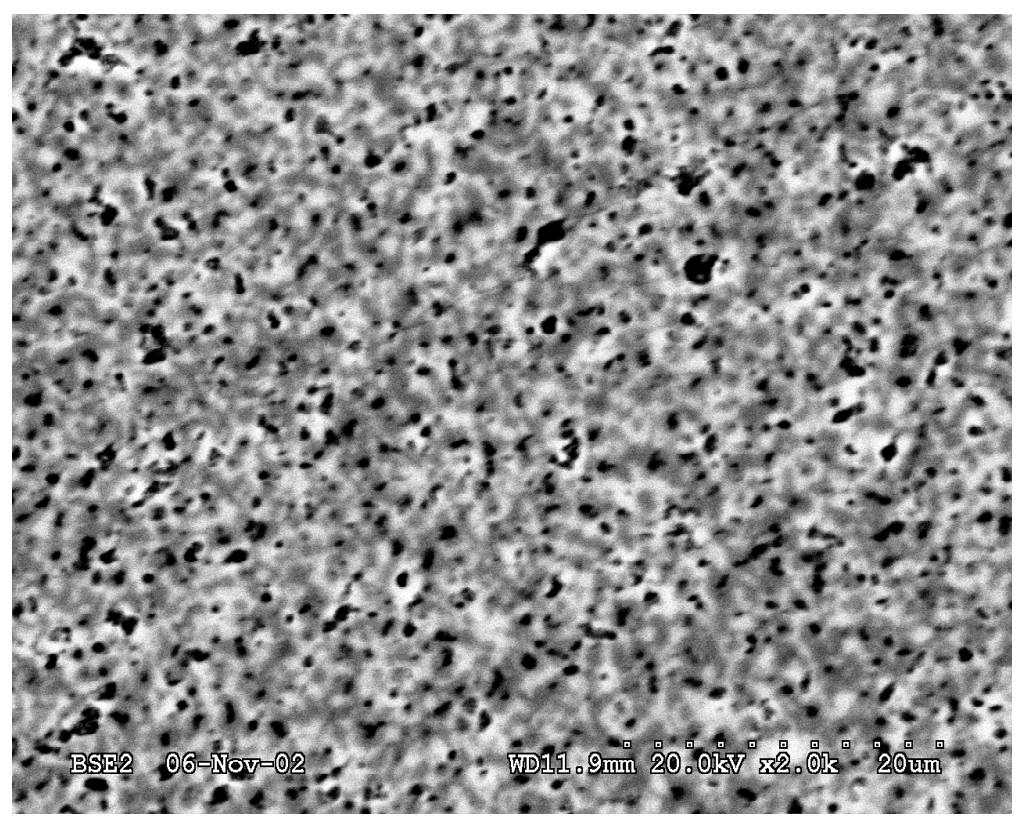

Figure \#55: An SEM micrograph of a sample that was reduced, and then re-oxidized. Note that a considerable amount of porosity was created during the reduction/reoxidation process. 


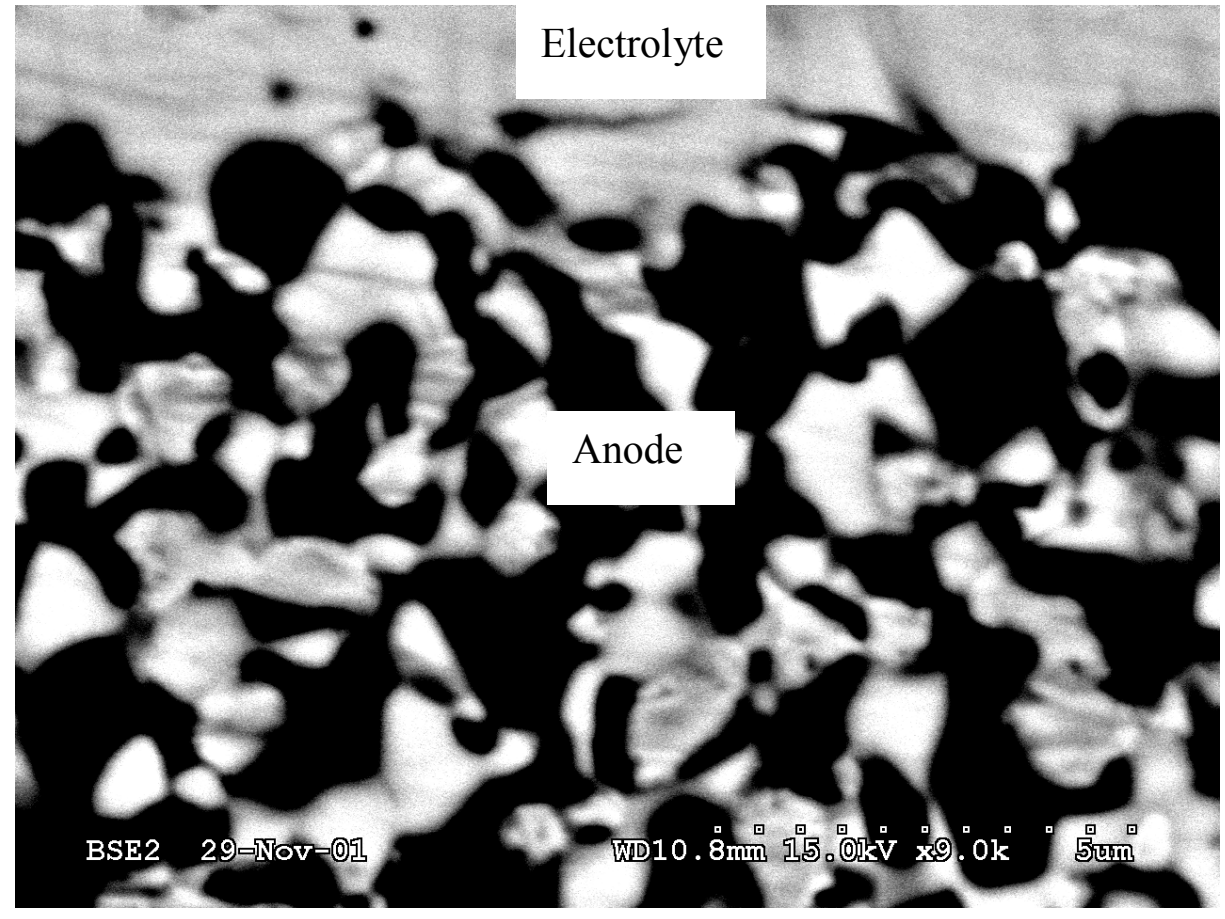

Figure \#56: An SEM micrograph of a polished section of the Ni + YSZ anode (after impregnating with an epoxy). 


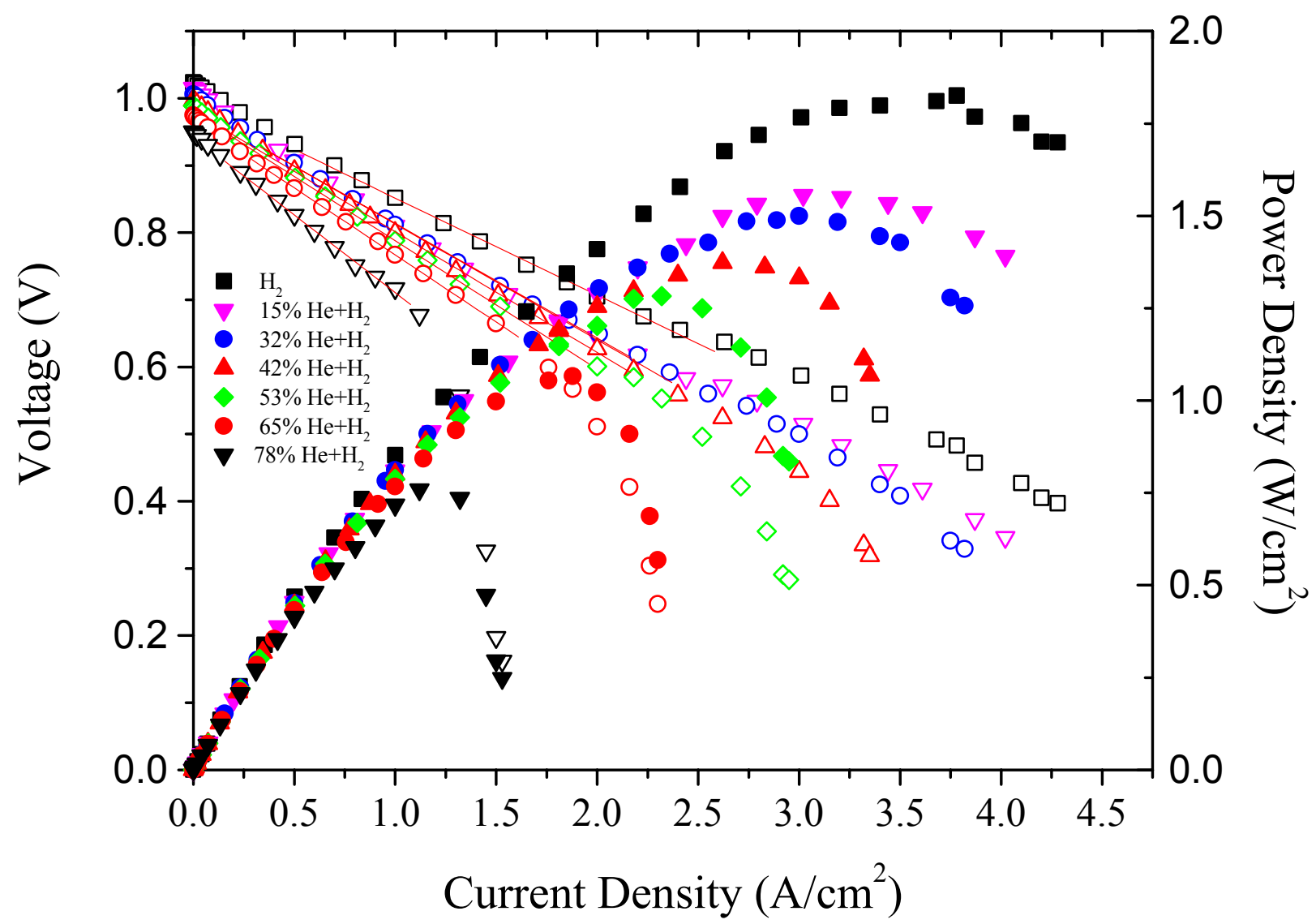

Figure \#57: Voltage and power density vs. current density at $800^{\circ} \mathrm{C}$ with as-received $\mathrm{H}_{2}$ and $\mathrm{H}_{2}$ diluted with $\mathrm{He}$ as fuel. 


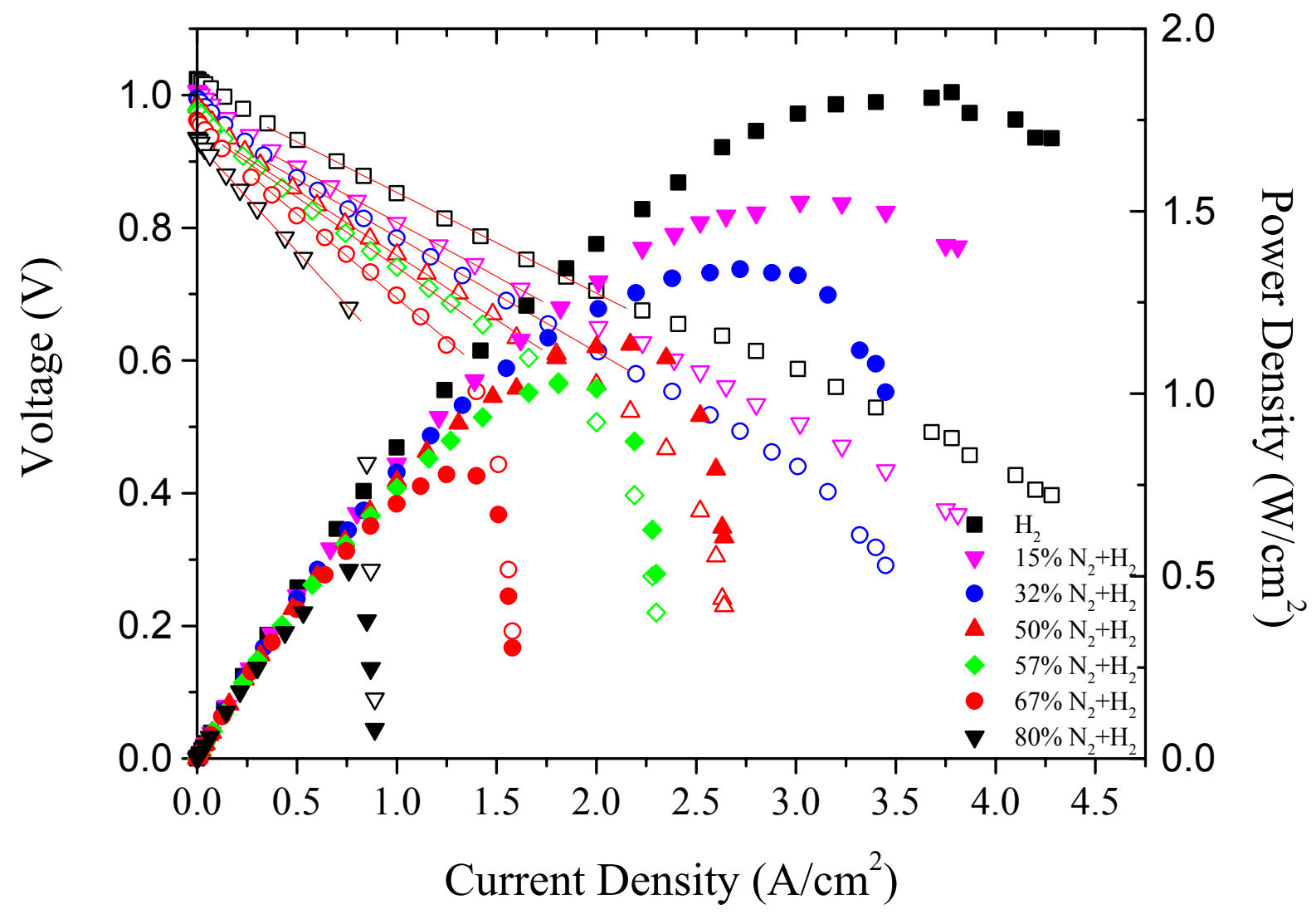

Figure \#58: Voltage and power density vs. current density at $800^{\circ} \mathrm{C}$ at with as-received $\mathrm{H}_{2}$ and $\mathrm{H}_{2}$ diluted with $\mathrm{N}_{2}$ as fuel. 


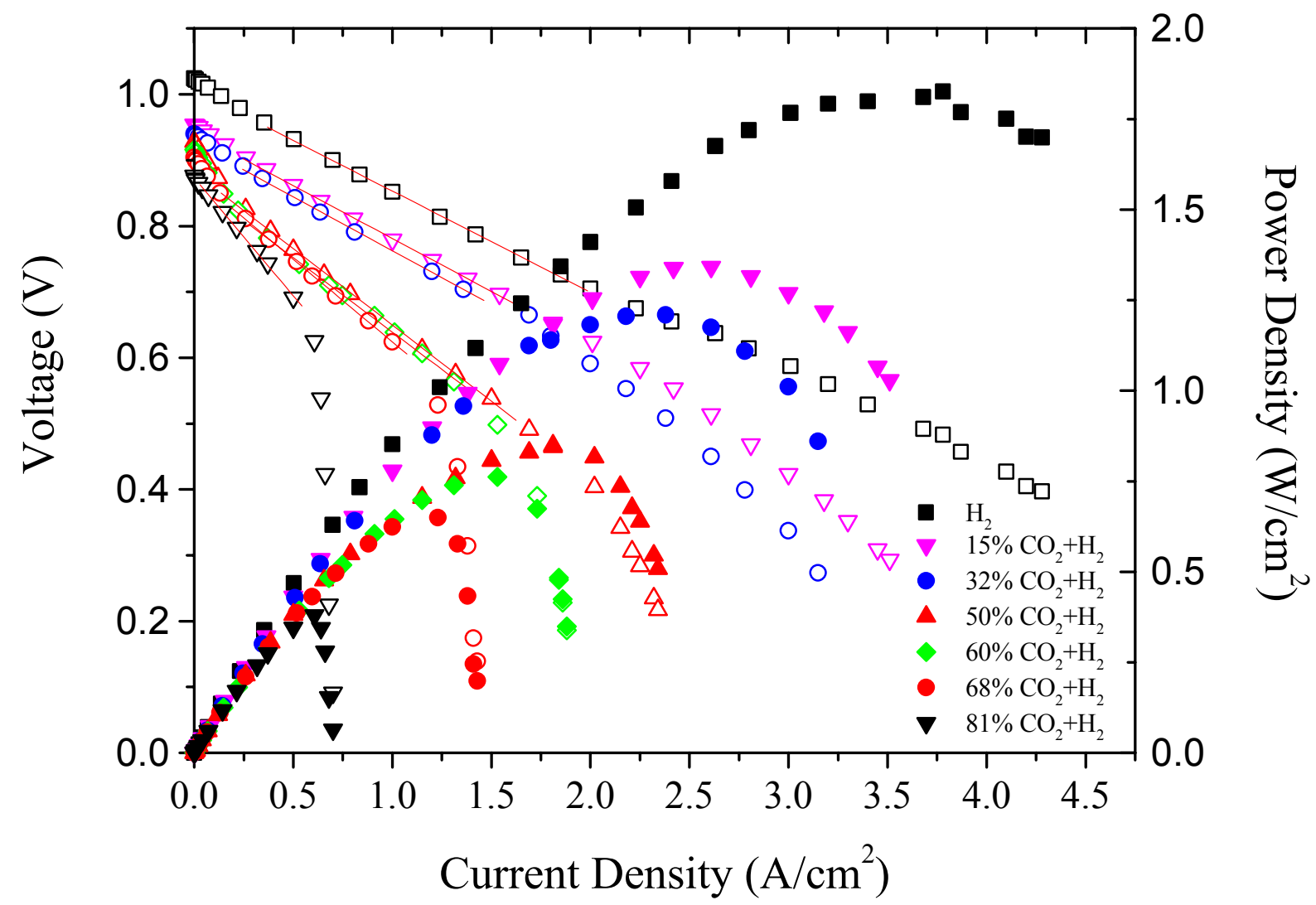

Figure \#59: Voltage and power density vs. current density at $800^{\circ} \mathrm{C}$ with as-received $\mathrm{H}_{2}$ and $\mathrm{H}_{2}$ diluted with $\mathrm{CO}_{2}$ as fuel. 


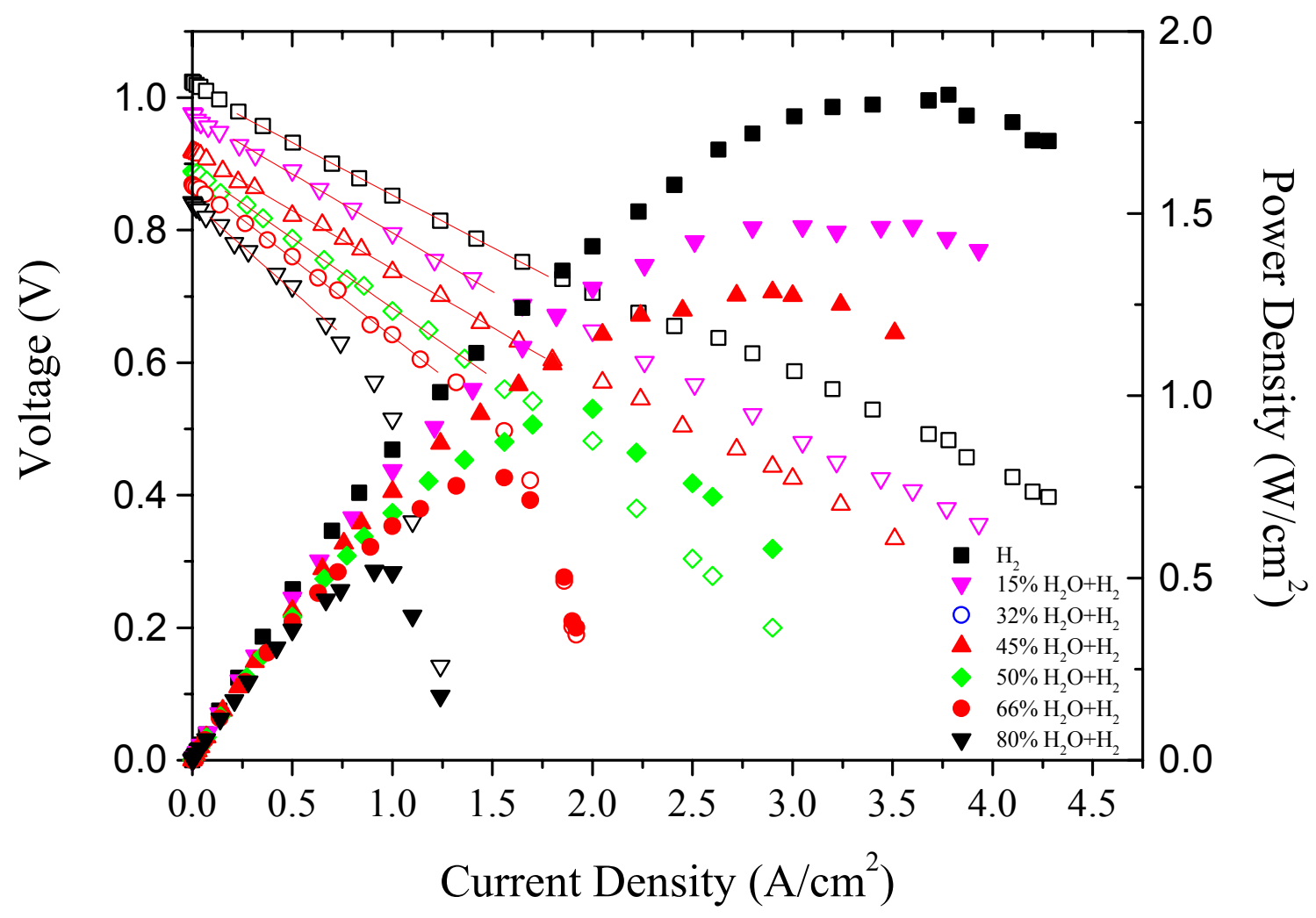

Figure \#60: Voltage and power density vs. current density at $800^{\circ} \mathrm{C}$ for $\mathrm{H}_{2}-\mathrm{H}_{2} \mathrm{O}$ binary system with various concentrations of $\mathrm{H}_{2} \mathrm{O}$. 


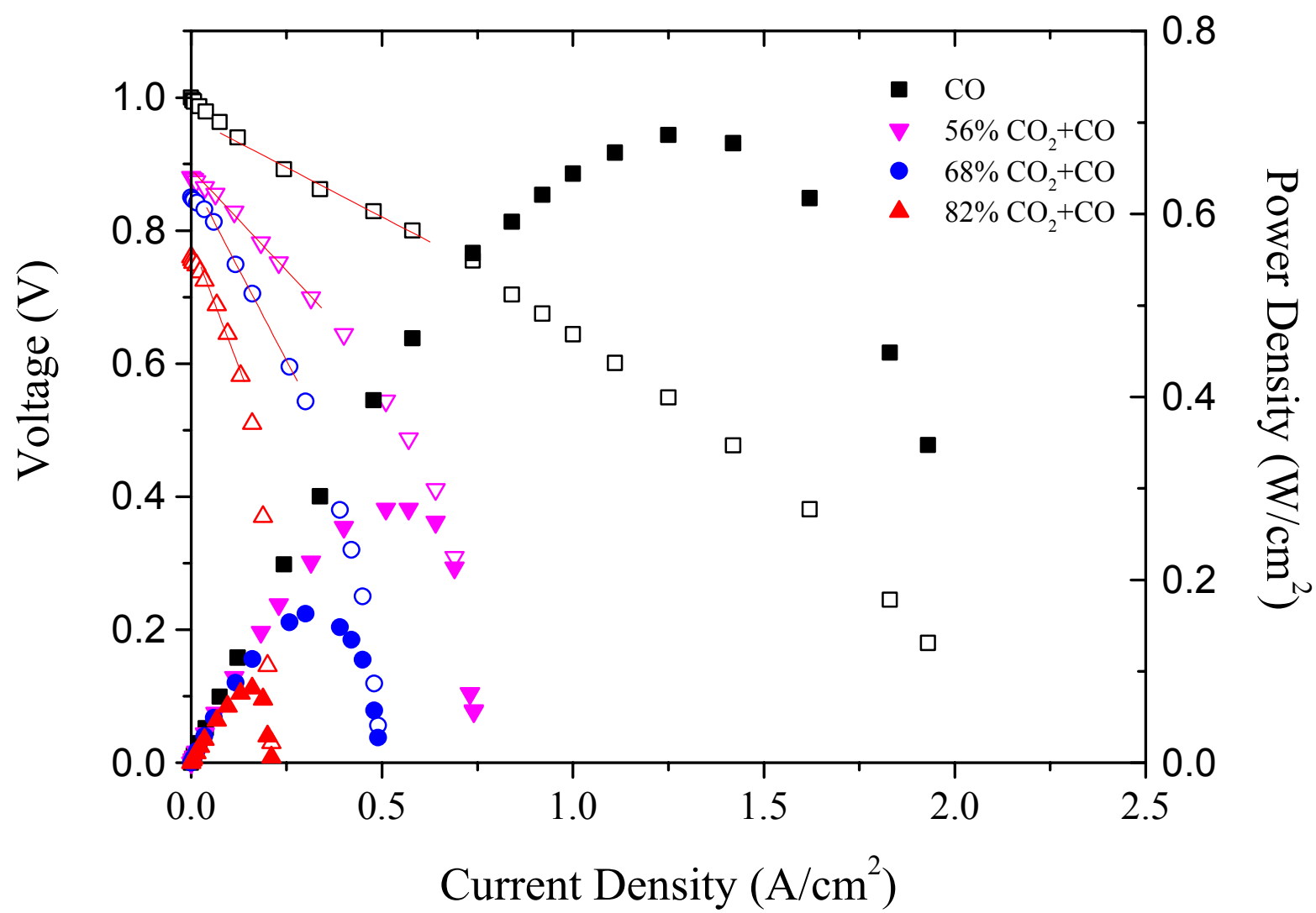

Figure \#61: Voltage and power density vs. current density at $800^{\circ} \mathrm{C}$ for $\mathrm{CO}-\mathrm{CO}_{2}$ binary system with various concentrations of $\mathrm{CO}_{2}$. 


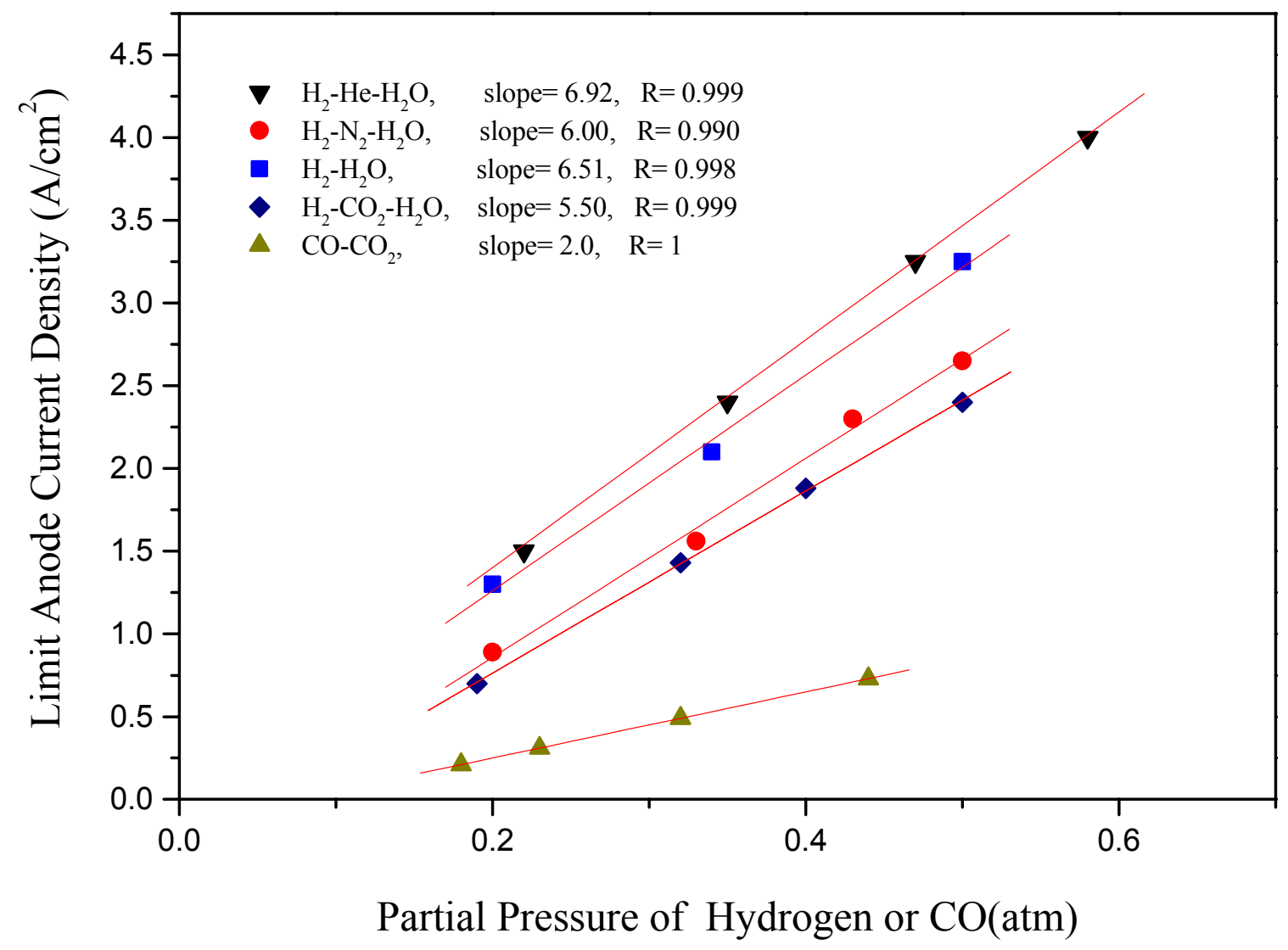

Figure \#62: Anode limiting current density vs. partial pressure of $\mathrm{H}_{2}$ or $\mathrm{CO}$ at $800^{\circ} \mathrm{C}$. 


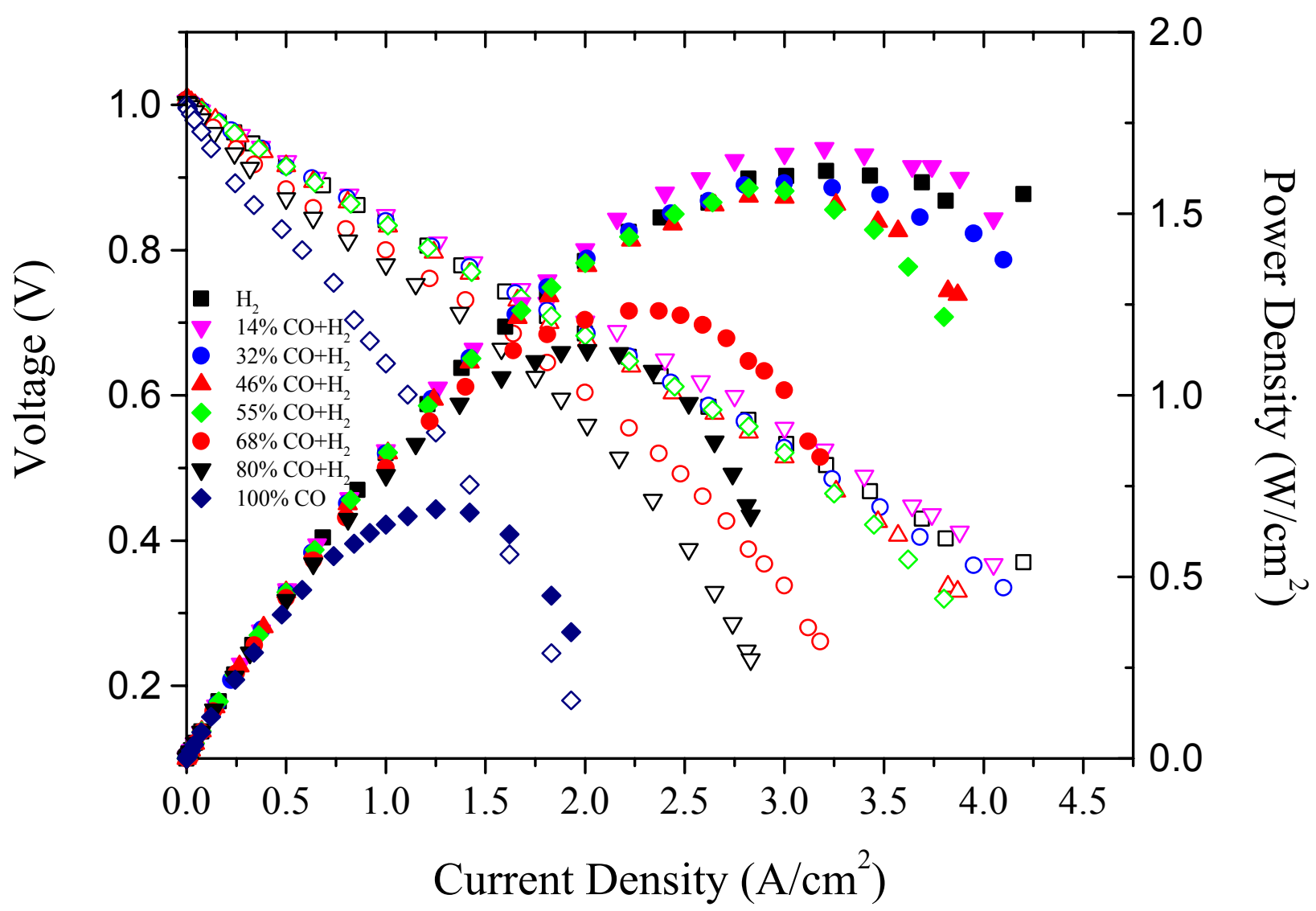

Figure \#63: Voltage and power density vs. current density at $800^{\circ} \mathrm{C}$ for $\mathrm{H}_{2}-\mathrm{CO}$ mixtures as fuel with various concentrations of $\mathrm{CO}$. 


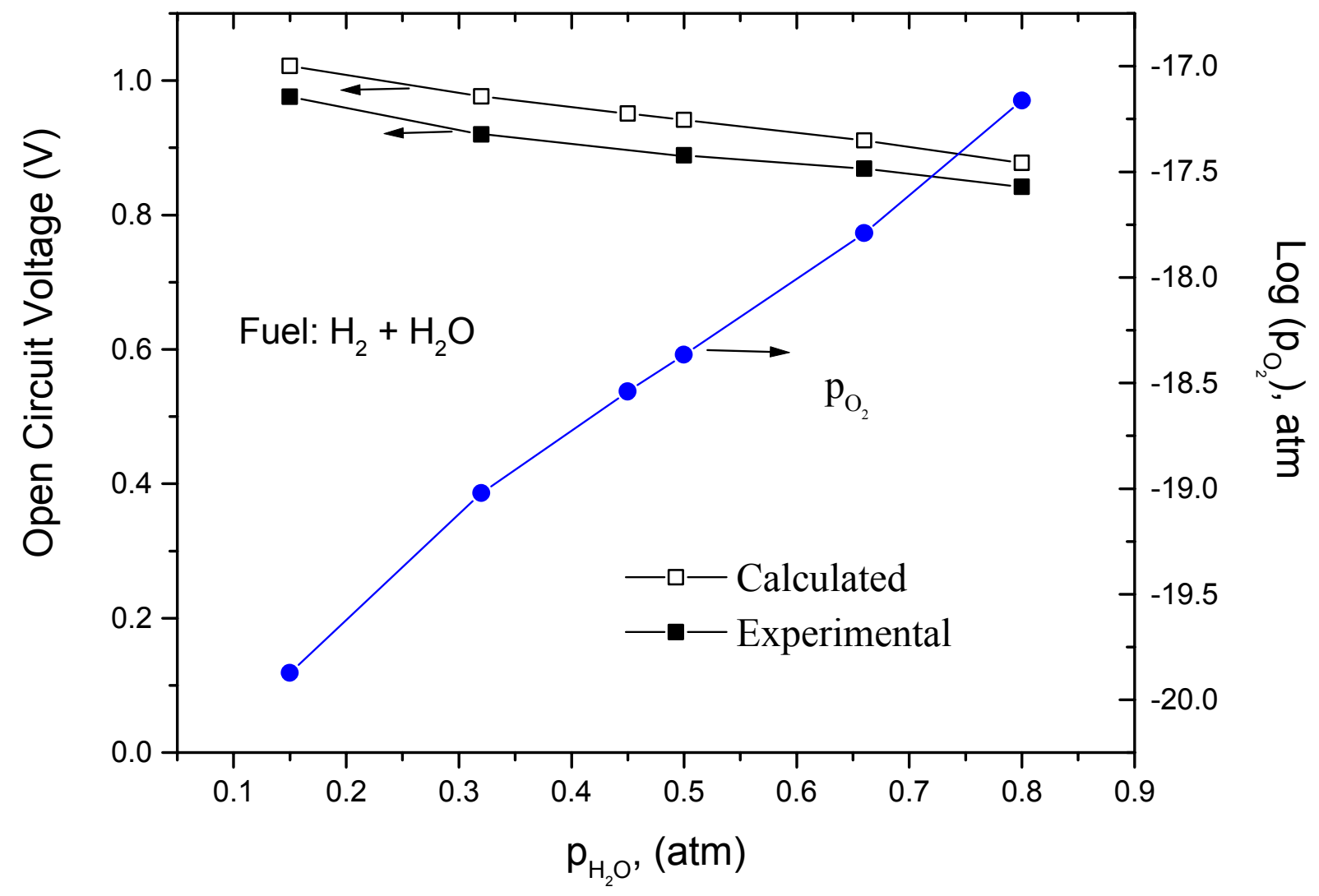

Figure \#64: Partial pressure of oxygen at the anode and open circuit voltage (OCV) as a function of $p_{\mathrm{H}_{2} \mathrm{O}}$ for $\mathrm{H}_{2}-\mathrm{H}_{2} \mathrm{O}$ at $800^{\circ} \mathrm{C}$. 


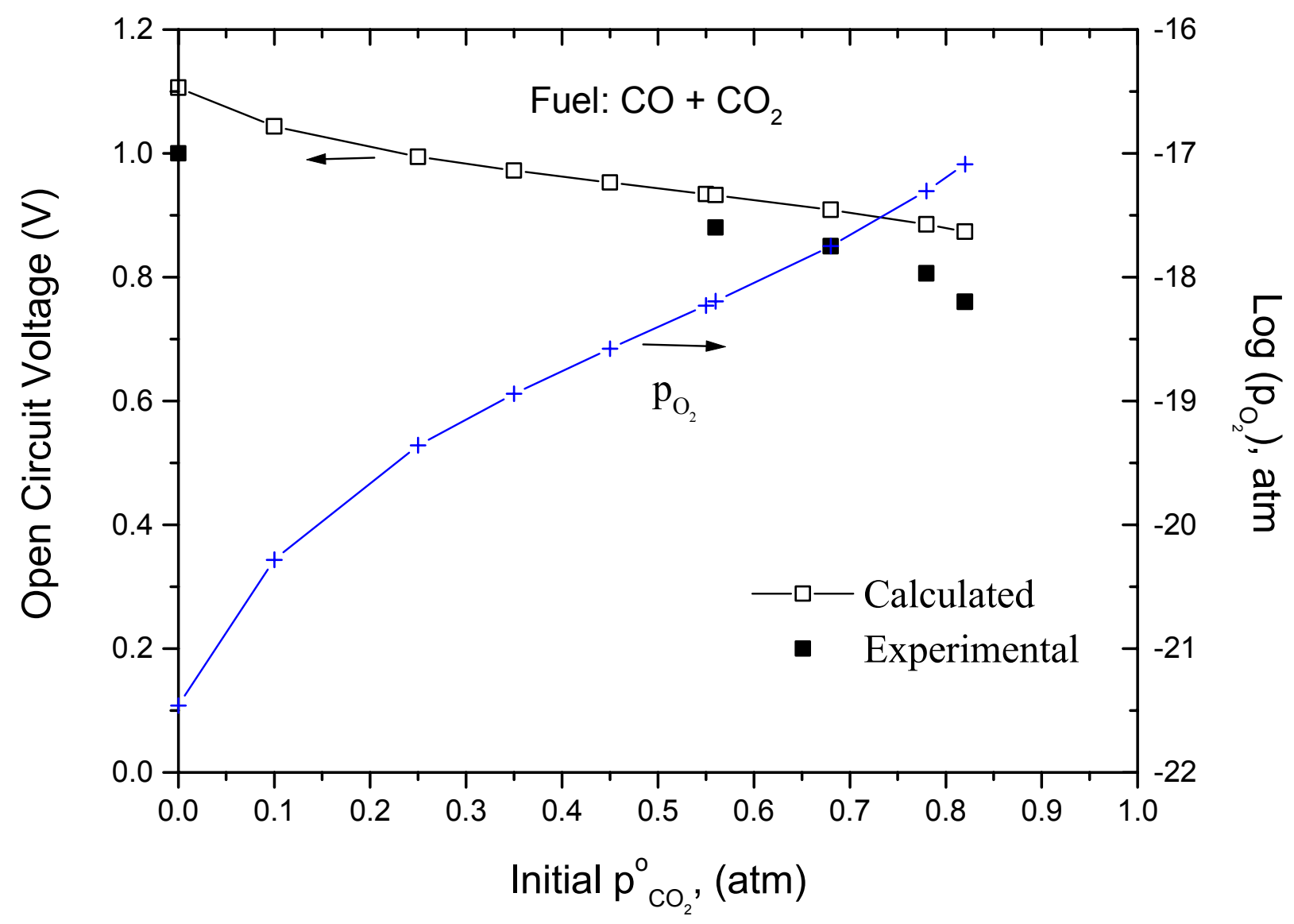

Figure \#65: Partial pressure of oxygen at the anode and open circuit voltage (OCV) as a function of $\mathrm{p}_{\mathrm{CO}_{2}}$ for $\mathrm{CO}-\mathrm{CO}_{2}$ at $800^{\circ} \mathrm{C}$. 


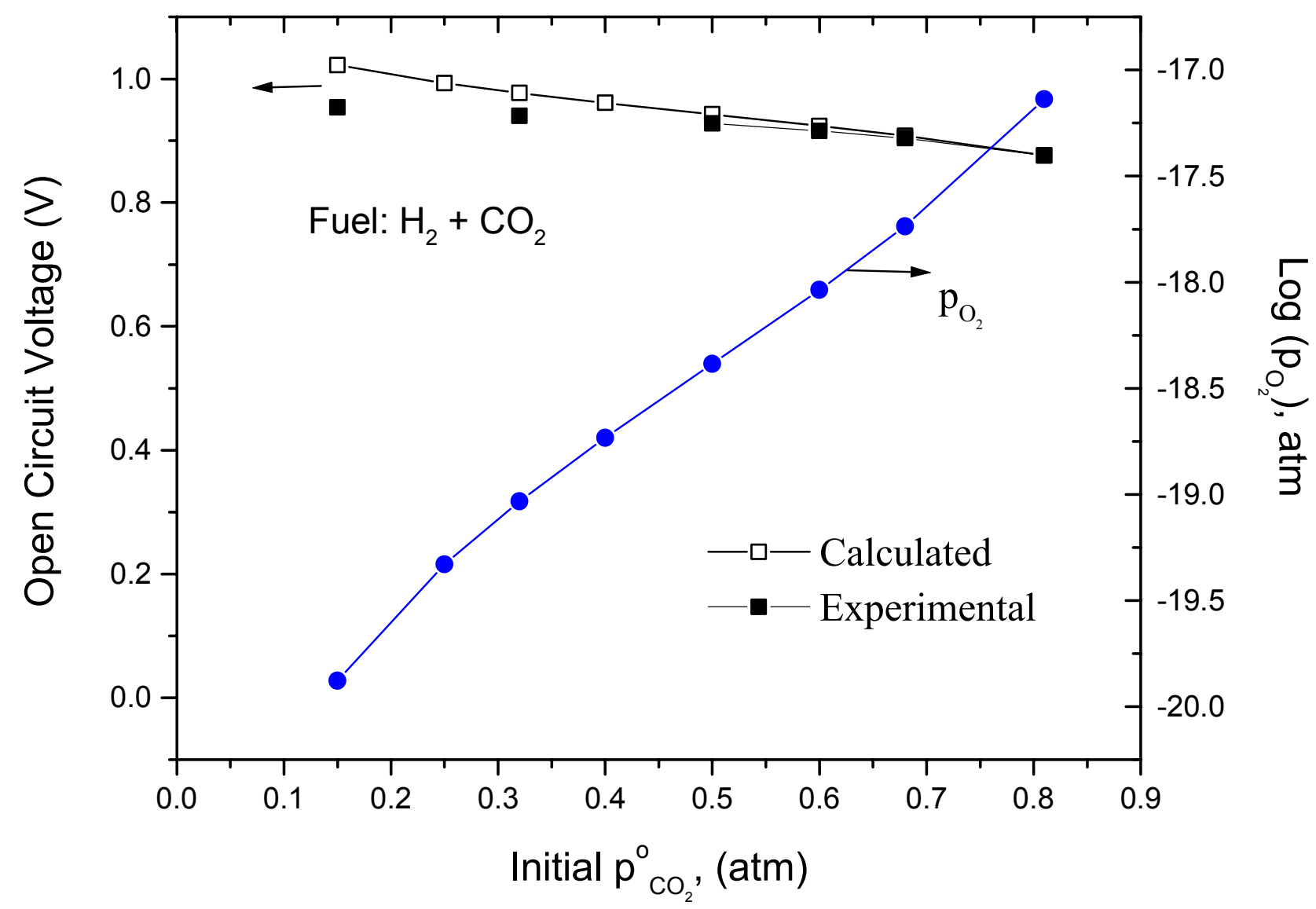

Figure \#66: Partial pressure of oxygen at the anode and open circuit voltage (OCV) as a function of $p_{\mathrm{H}_{2}}$ for $\mathrm{H}_{2}-\mathrm{CO}_{2}$ at $800^{\circ} \mathrm{C}$. 


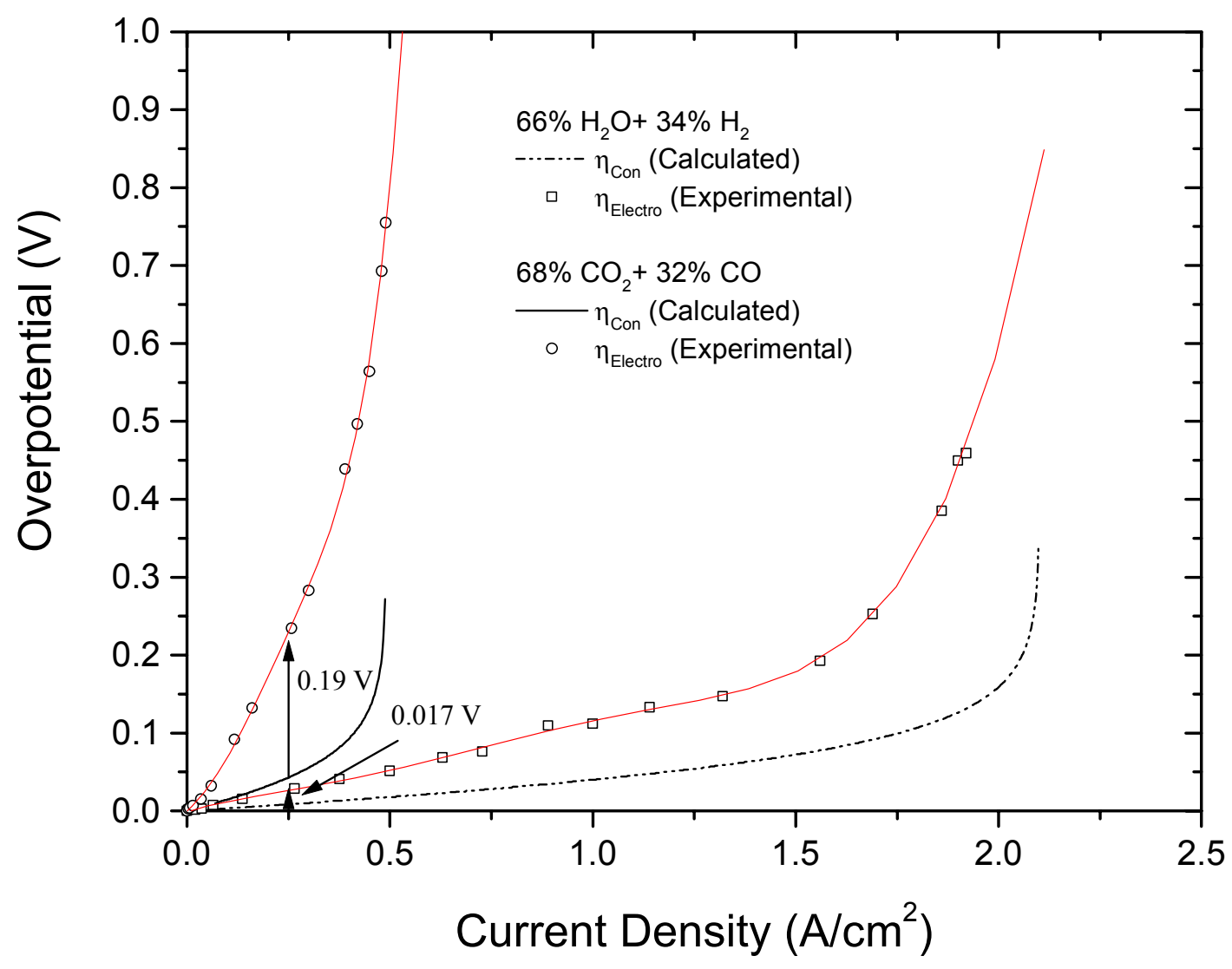

Figure \#67: Comparison of the measured total polarization (less the ohmic contribution) as a function of current density vs. calculated concentration polarization for: (a) $\sim 34 \% \mathrm{H}_{2}$ $+\sim 66 \% \mathrm{H}_{2} \mathrm{O}$, and (b) $\sim 32 \% \mathrm{CO}+\sim 68 \% \mathrm{CO}_{2}$. 


\section{LIST OF ACRONYMS AND ABBREVIATIONS}

\begin{tabular}{|c|c|}
\hline BET: & Brunauer-Emmett-Teller \\
\hline DMFC: & Direct methanol fuel cell \\
\hline DTA: & Differential thermal analysis \\
\hline EDS: & Energy dispersive spectra \\
\hline ICP: & Inductively coupled plasma \\
\hline LSC: & Sr-doped $\mathrm{LaCoO}_{3}$ \\
\hline LSGM: & Sr- and $\mathrm{Mg}$-doped $\mathrm{LaGaO}_{3}$ \\
\hline LSM: & Sr-doped $\mathrm{LaMnO}_{3}$ \\
\hline MIEC: & Mixed ionic electronic conduction \\
\hline OCV: & Open circuit voltage \\
\hline SDC: & $\mathrm{Sm}_{2} \mathrm{O}_{3}$-doped $\mathrm{CeO}_{2}$ \\
\hline SEM: & Scanning electron microscopy \\
\hline SOFC: & Solid oxide fuel cells \\
\hline TEM: & Transmission electron microscopy \\
\hline TPB: & Three-phase boundary \\
\hline XRD: & X-ray diffraction \\
\hline YSZ: & Yttria-stabilized zirconia \\
\hline
\end{tabular}

